\title{
An Analysis of Nuclear Power Plant Construction Costs
}

\author{
Energy Information Administration
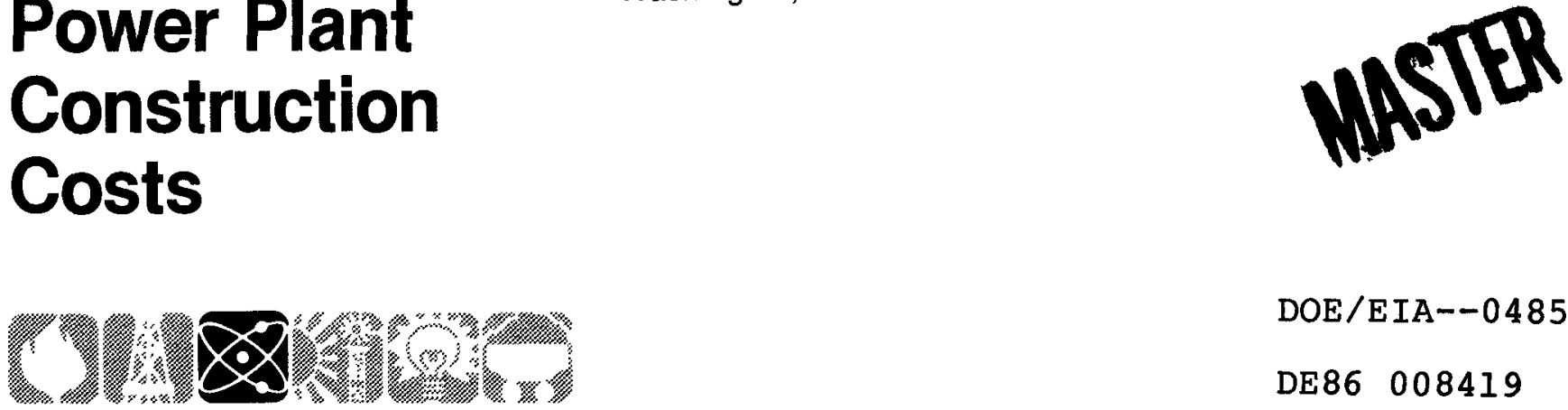

DOE/E IA- -0485

DE86 008419

\section{DISCLAIMER}

This report was prepared as an account of work sponsored by an agency of the United States Government. Neither the United States Government nor any agency thereof, nor any of their employees, makes any warranty, express or implied, or assumes any legal liability or responsibility for the accuracy, completeness, or usefulness of any information, apparatus, product, or process disclosed, or represents that its use would not infringe privately owned rights. Reference herein to any specific commercial product, process, or service by trade name, trademark, manufacturer, or otherwise does not necessarily constitute or imply its endorsement, recommendation, or favoring by the United States Government or any agency thereof. The views and opinions of authors expressed herein do not necessarily state or reflect those of the United States Government or any agency thereof.

This report was prepared by the Energy Information Administration, the independent statistical and analytical agency within the Department of Energy. The information contained herein should not be construed as advocating or necessarily reflecting any policy position of the Department of Energy or any other organization. 


\section{DISCLAIMER}

This report was prepared as an account of work sponsored by an agency of the United States Government. Neither the United States Government nor any agency Thereof, nor any of their employees, makes any warranty, express or implied, or assumes any legal liability or responsibility for the accuracy, completeness, or usefulness of any information, apparatus, product, or process disclosed, or represents that its use would not infringe privately owned rights. Reference herein to any specific commercial product, process, or service by trade name, trademark, manufacturer, or otherwise does not necessarily constitute or imply its endorsement, recommendation, or favoring by the United States Government or any agency thereof. The views and opinions of authors expressed herein do not necessarily state or reflect those of the United States Government or any agency thereof. 


\section{DISCLAIMER}

Portions of this document may be illegible in electronic image products. Images are produced from the best available original document. 


\section{Contacts}

This report was prepared by the Nuclear and Alternate Fuels Division, Office of Coal, Nuclear, Electric and Alternate Fuels, Energy Information Administration, Dr. R. Gene Clark, Director. Questions regarding nuclear power forecasting and analysis may be directed to Howard walton, Chief of the Data Analysis and Forecasting Branch (202/252-2009), or to Mark Gielecki (202/252-4442). Questions regarding the report may be addressed to the project manager, James G. Hewlett (202/252-4440). To obtain additional copies of the report, write or contact:

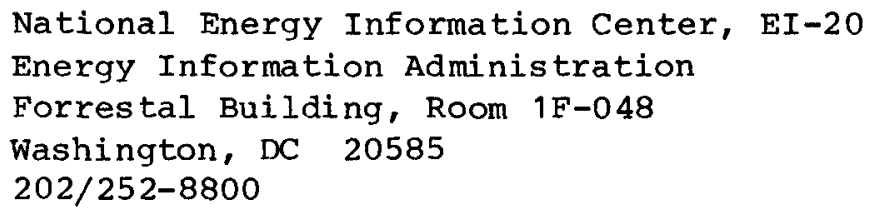




\section{Preface}

This project was conducted as part of an ongoing study of the cost of nuclear power. The work is intended to enhance the quality of the Energy Information Administration's data and analyses. This report is intended for use by the Nuclear Regulatory Commission, the nuclear industry, Congress, state public utility commissions, and the general public. The three principal contributors to the report were James G. Hewlett, Nuclear and Alternate Fuels Division; Robin A. Cantor, Oak Ridge National Laboratory; and Colleen G. Rizy, Oak Ridge National Laboratory.

As part of the Energy Information Administration's Independent Expert Review Program, a previous version of this report was reviewed by Mr. Charles Komanoff of Komanoff Energy Associates and Mr. Richard Lester, Ph.D., Department of Nuclear Engineering, Massachusetts Institute of Technology. Their comments have been incorporated into the report.

Due to the volume of data used in the analysis, much of the data is not included in the report. Interested individuals may obtain all of the data either in hard copy or computer-readable form or copies of the above-mentioned reviews upon request by contacting the Project Manager at the address below:

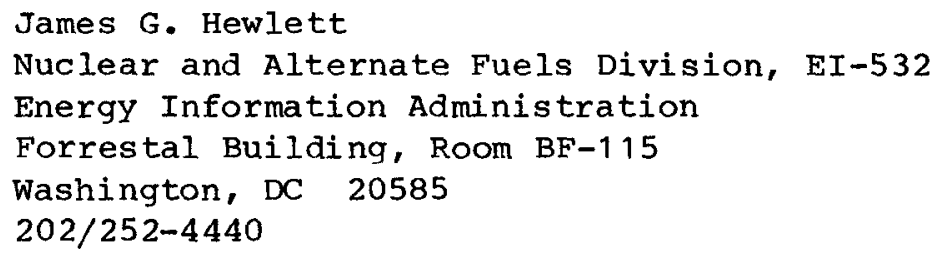




\section{Contents}

Page

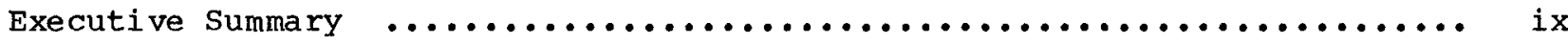

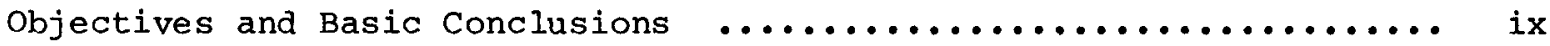

Escalation in Real "Overnight" and "Time-Related" Costs ......... x

Effects of Factors Related to Regulation and Management
on Overnight Costs

Effects of size $\ldots \ldots \ldots \ldots \ldots \ldots \ldots \ldots \ldots \ldots \ldots \ldots \ldots \ldots \ldots \ldots \ldots \ldots \ldots \ldots \ldots$ xv

Estimation of Costs and Lead-Times $\ldots \ldots \ldots \ldots \ldots \ldots \ldots \ldots \ldots \ldots \ldots \ldots \ldots$

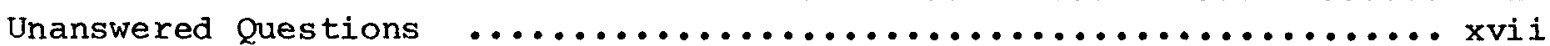

1. Introduction $\ldots \ldots \ldots \ldots \ldots \ldots \ldots \ldots \ldots \ldots \ldots \ldots \ldots \ldots \ldots \ldots \ldots \ldots \ldots \ldots \ldots$

2. Calculation and Description of the Cost and Lead-Time Data ......... 3

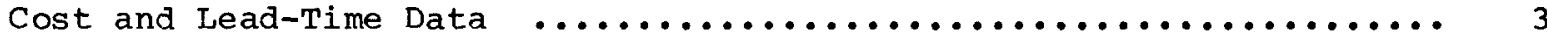

Trends in Lead-Times and $\cos t s \quad \ldots \ldots \ldots \ldots \ldots \ldots \ldots \ldots \ldots \ldots \ldots \ldots \ldots$

3. Analysis of Realized Investment Costs and Lead-Times ............ 23

Issues Affecting the Analysis of Realized Costs and Lead-Times .... 23

Analysis of Actual Construction Costs and Lead-Times ........... 25

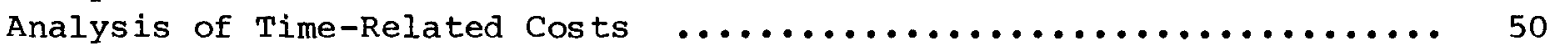

Interaction of Size, Lead-Times, and Real overnight costs ........ 50

4. Analysis of the Estimation of Costs and Lead-Times $\ldots \ldots \ldots \ldots \ldots \ldots$

Method for Statistical Analysis of the Forecast Errors

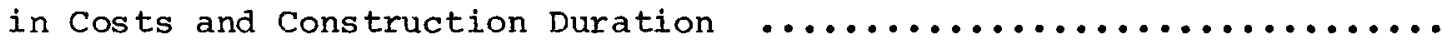

Factors Affecting the Forecast Errors for Real Overnight Costs .....

Analysis of Forecast Errors at the start of Construction ..........

Changes in the Effects of Lead-Time on Estimated Real Overnight Costs

During the Construction Period ..........................

Effects of Experience on Forecast Erxors

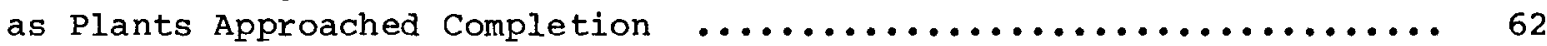

Factors Affecting the Underestimation of Time-Related Costs ...... 64

Factors Influencing the Underestimation of Construction Duration ... 68

Conclusions

5. Summary and Conclusions

Appendices

A. Methodology Used to Compute Real Overnight Costs

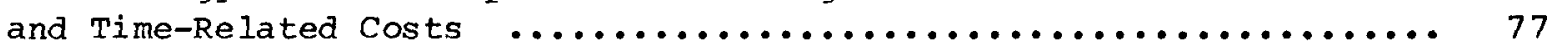

B. Review of Previous Cost and Lead-Time Analyses .............. 93

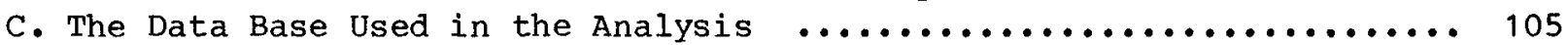

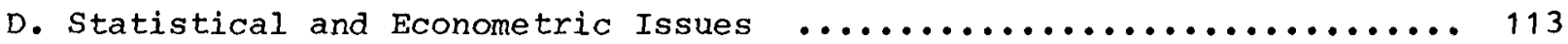




\section{Tables}

ES1. Average Estimated and Realized Overnight Costs of Nuclear Power Plants by Year of Construction Start ........... xvi

ES2. Average Estimated and Realized Lead-Times of Nuclear Power Plants by Year of Construction start .......... xvi

1. Ranking of Plants in the Sample According to Real Overnight Construction Costs, by Year of Construction start ............. 16

2. Average Estimated and Realized Overnight Costs of Nuclear Power Plants by Year of Construction start .......... 18

3. Average Estimated and Realized Lead-Times of Nuclear Power Plants by Year of Construction Start .......... 19

4. Ranking of Plants in the Sample According to Real Overnight Construction Costs and Reported Construction Costs ............. 20

5. Results of Regression Analysis of Real Overnight Construction Costs .................................. 29

6. Results of Regression Analysis of Lead-Times, Using

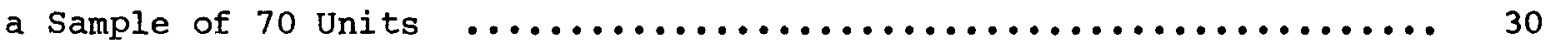

7. Results of Regression Analysis of Lead-Times, Using

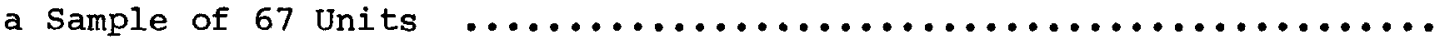

8. Results of Regression Analysis of Real Overnight Costs, Using Two Spline Variables for Unit Size .......................

9. Results of Regression Analysis of Lead-Times: Sample Divided

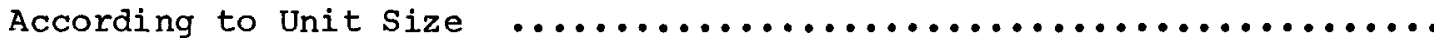

10. Results of Regression Analysis of Real Overnight Costs: Sample Divided According to Date of Commercial Operation ...............

11. Results of Regression Analysis of Lead-Times: Sample Divided

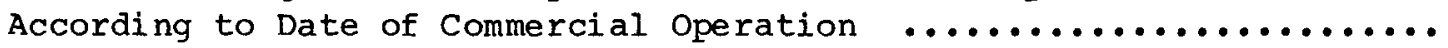

12. Results of Regression Analysis of Actual Costs: Sample Divided According to Date of Construction start $\ldots \ldots \ldots \ldots \ldots \ldots \ldots \ldots \ldots$

13. Results of Regression Analysis of Lead-Times: Time Variable Split at 1970 .....................................

14. Results of Regression Analysis of Actual Costs: Sample Divided

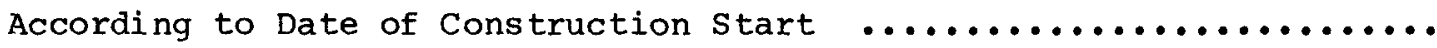

15. Results of Regression Analysis of Lead-Times: Time Variable Split at 1972 .......................................

16. Results of Regression Analysis of Time-Related Costs ............

17. Results of Regression Analysis of Estimated Real Overnight Costs ...

18. Results of "Imputed" Regression Analysis of Real Overnight Cost

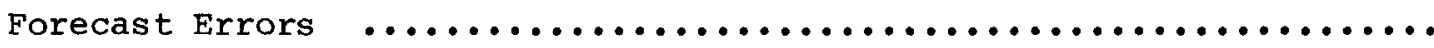

19. Differential Effects of Actual Time Spent to Date and Estimated Time to Completion on Utility Estimates of Real Overnight Costs ........

20. Results of Regression Analysis of Estimated Time-Related Costs .....

21. Imputed Results of Regression Analysis of Time-Related Cost

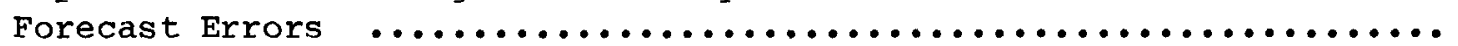

22. Results of Regression Analysis of Estimated Lead-Times .......... 


\section{Figures}

ES1. Total Costs Including Financing Charges in 1982 Dollars

Page

for Nuclear Power Plants in Operation by the End of $1986 \ldots \ldots \ldots$. . . xi

1. Actual and Estimated Total Costs in Mixed Current Dollars

for Nuclear Power Plants in Operation by the End of $1986 \ldots \ldots \ldots \ldots .11$

2. Actual and Estimated Lead-Times

of Nuclear Power Plants in Operation by the End of $1986 \ldots \ldots \ldots \ldots .12$

3. Total Costs Including Financing Charges in 1982 Dollars

for Nuclear Power Plants in Operation by the End of $1986 \ldots \ldots \ldots \ldots .14$

4. Actual and Estimated Real Overnight Costs

of Nuclear Power Plants in Operation by the End of $1986 \ldots \ldots \ldots \ldots$ 


\section{Executive Summary}

\section{Objectives and Basic Conclusions}

The objective of this report is to present the results of a statistical analysis of nuclear power plant construction costs and lead-times (where lead-time is defined as the duration of the construction period), using a sample of units that entered construction during the 1966-1977 period. For more than a decade, analysts have been attempting to understand the reasons for the divergence between predicted and actual construction costs and lead-times. More importantly, it is rapidly being recognized that the future of the nuclear power industry rests precariously on an improvement in the cost and lead-time situation. Thus, it is important to study the historical information on completed plants, not only to understand what has occurred but also to improve the ability to evaluate the economics of future plants. This requires an examination of the factors that have affected both the realized costs and lead-times and the expectations about these factors that have been formed during the construction process.

The major results of the analysis can be summarized as follows:

1. There has been a substantial amount of escalation in the inflation-adjusted (real) cost of construction for nuclear power plants. The real costs, including financing charges, for units that entered construction in 19661967 were about $\$ 700$ per kWe, compared with about $\$ 3,100$ per kWe for units that entered construction in 1974-1975. Overall, real construction costs increased at a rate of about 14 percent per year during that period.

2. Approximately 75 percent of the $\$ 2,400$-per-kWe increase in real costs can be attributed to increases in the quantities of land, labor, material, and equipment used to build a nuclear power plant, as measured by the real overnight costs, expressed in 1982 dollars. (The overnight costs measure the cost of building a unit instantaneously, using 1982 prices for land, labor, material, and equipment.) The remaining 25 percent of the increase can be attributed to increases in the real financing charges, escalation in the rate of increase in the real prices of land, labor, material, and equipment during the construction period, and increases in construction lead-times.

3. One of the most statistically significant variables that explains variation in the effort and material required to build a power plant, as measured by the real overnight costs, is the length of the construction period. (Other factors that were tested for statistical significance were regulation, size, and contractor and industry experience.) As discussed below, although the construction duration statistically explains a substantial portion of the variation in real overnight costs, lead-times did not directly cause these variations. This is because the construction duration acts only as a surrogate for a number of unmeasurable factors that influence costs, such as design changes, safety and environmental retrofits required by regulatory change, and labor productivity.

4. The analysis also indicates that the cost estimates reported by utilities at the start of construction did not reflect the statistical relationship derived in this analysis between actual realized lead-times and real overnight costs. That is, there was no correlation between estimated lead-time and estimated real overnight costs across utilities. 
5. When all other variables used in the analysis - including lead-time -were held constant, larger plants tended to have lower costs per unit of capacity. However, the larger plants took longer to build than the smaller ones, and thus the increased costs resulting from the additional time needed to build the larger units more than of fset the direct cost savings associated with economies of scale.

6. The management structure under which a power plant is constructed is an important determinant of real overnight costs. Utilities that acted as their own construction manager not only had lower costs but also were able to translate increased experience and learning into lower real overnight costs. This result suggests that direct utility participation in the construction process may be an important factor in controlling construction costs.

\section{Escalation in Real "Overnight" and "Time-Related" Costs}

A major undertaking in this analysis was to compute the "overnight" and "time-related" components of total construction costs. (See Chapter 2 for rankings of the units in the sample according to real overnight costs.) The overnight portion of the total costs, expressed in 1982 dollars, reflects the cost of building a plant overnight in 1982. Since all of the overnight cost figures used in the analysis were expressed in 1982 dollars, variations in these costs directly reflect variations in the quantities of land, labor, materials, and equipment used to build the plants. Thus, the overnight costs measure the amount of effort and material needed to build a nuclear power plant. The second portion of the total costs is time-related costs, which include real financing charges and real cost increases resulting from increases in the relative prices of land, labor, material, and equipment during the construction period. Obviously, time-related costs will be a function of the time needed to license and construct the unit.

The factors causing the cost escalation can be placed in either of two categories. One of these categories would include all factors that influence the time-related costs, and the second would consist of all factors affecting the overnight costs. In particular, some have argued that the increased complexity of the licensing process and other factors have caused the increase in lead-times from about 8 years to over 11 years. Such increases in lead-time have resulted in large increases in the time-related costs, which in turn have caused the escalation in real costs. On the other hand, there are many factors that influence the overnight costs, including the increased stringency of regulations affecting reactor design and construction, the overestimation of economies of scale from building large multi-unit plants, and construction management factors. It has been argued that the factors influencing the real overnight costs or quantities of land, labor, and materials used to construct nuclear power plants have caused the majority of the cost escalation.

Figure ES1 shows the total construction costs, in 1982 dollars, for 75 nuclear power plants that entered construction during the 1966-1977 period and are scheduled to enter commercial operation by the end of 1986. Figure ES1 also shows the division of the total costs into "overnight" and "time-related" costs. Figure Es1 indicates that the total cost, including financing charges, expressed in 1982 dollars, increased from about $\$ 700$ per kilowatt-electric ( $k W e$ ) for plants that entered construction in 1966-1967 to about $\$ 3,100$ per kWe for units that entered construction about 8 years later. Of the total increase of about $\$ 2,400$ per kWe, approximately $\$ 1,800$ per kWe 
Figure ES1. Total Costs Including Financing Charges In 1982 Dollars for Nuclear Power Plants in Operation by the End of 1986

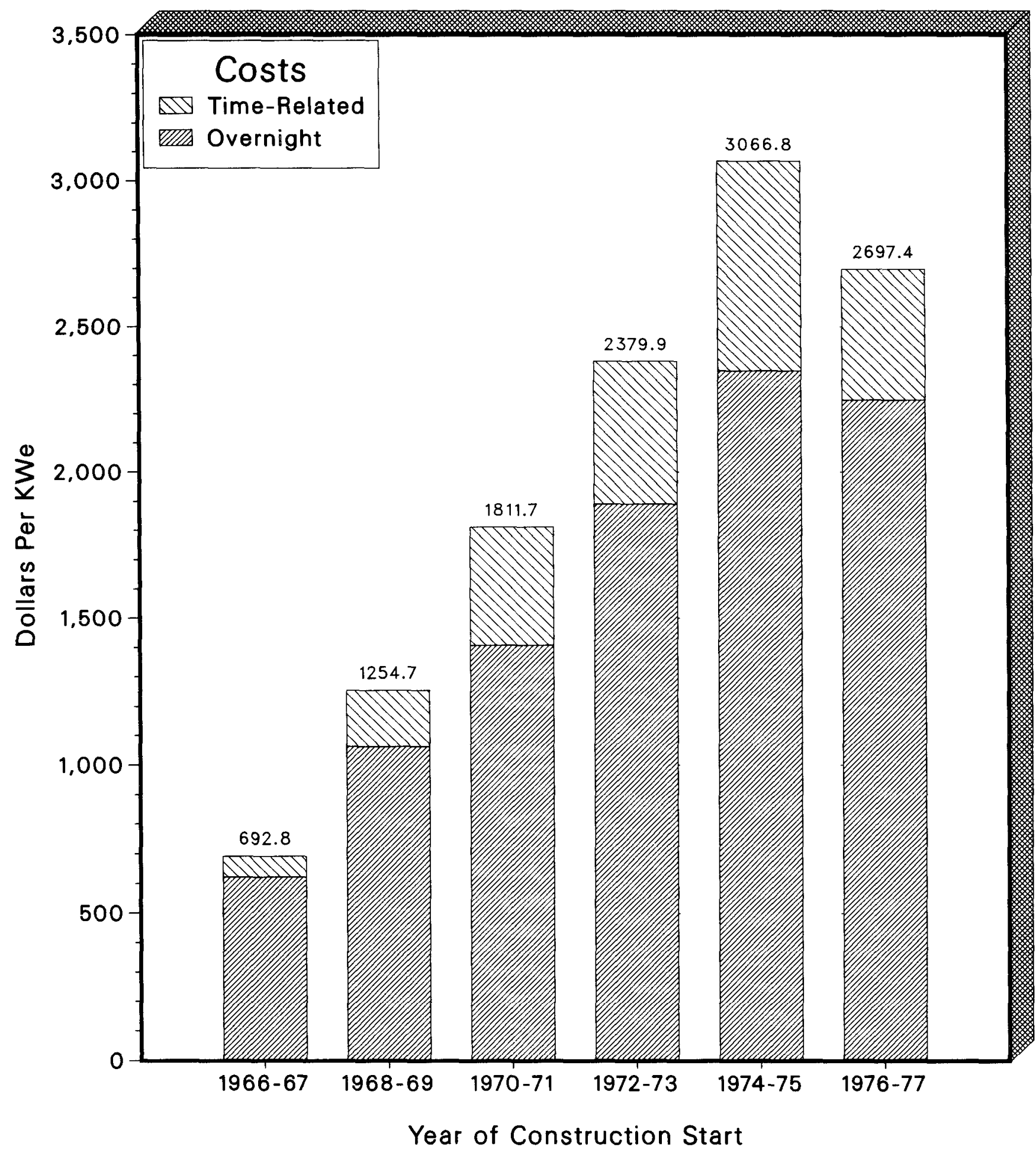

Note: When the allowance for funds used during construction was not included in the reported costs, the unit was excluded.

Source: Computations based on data from Energy Information Administration, Form ElA-254,

"Semiannual Progress Report on Status of Reactor Construction," and predecessor survey forms. 
was due to escalation in the real costs (i.e., the quantities of land, labor, materials, and equipment used for construction). The remaining $\$ 600$ of the increase was due to increases in the time-related costs (increases due to escalation in the relative prices and financing charges over the construction period). Thus, approximately 75 percent of the total escalation in costs, expressed in 1982 dollars, was due to increases in the real costs or quantities of the land, labor, materials, and equipment used in the construction projects.

One of the major findings of this study is the importance of escalation in the real overnight costs. In particular, the analysis described in this report indicates that when costs are placed in the same year's dollars, the factors causing the increases in the real costs or quantities of land, labor, materials, and equipment used to build a power plant -- not increases in costs directly due to time-related factors -- explain the majority of the cost escalation. This finding has important implications for current policy decisions. That is, attempts to control the costs of units still under construction must address managerial and regulatory factors relating to the design of the reactors and to the construction process, as well as the licensing time required to start construction and to begin commercial operation. It should be noted that one reason for the relatively small absolute increases in the time-related costs. was the fact that the real rate used to compute the financing charges on reactor construction loans was negative in five of the years between 1971 and 1981. Thus, it is possible that efforts to reduce licensing times, in periods when real interest rates are high, would substantially affect real construction costs. Indeed, one of the reasons for the large increase, in percentage terms, in the time-related costs was the high real interest rates that existed after 1981 . These high real interest rates would mainly affect the time-related costs for units that entered construction in the mid-1970's.

Also examined in the study were the rate base costs. These are the total costs in "nominal" terms and include financing charges. These costs generally correspond to the costs reported to the Government, the financial community, and the general public. The analysis suggests that increases in the time-related costs caused much of the escalation in the rate base, as opposed to real costs. Since escalation in the overnight costs also influences total financing costs, attempts to control the rate base costs of nuclear power plants must also focus on factors influencing reactor design and construction.

\section{Effects of Factors Related to Regulation and Management on Overnight Costs}

The analysis also attempted to examine the following factors: (1) the combined effect of industry learning and regulations in place at the start of construction; (2) the joint effect of changes in regulations during the construction period and managerial factors correlated with long lead-times; and (3) the effect of the management regime under which a unit is constructed.

\section{Effects of Regulations in Place at the Start of Construction and of Industry Learning}

There is no direct measure of regulatory changes or the "quantity" of regulations. Thus, another variable had to be used to approximate the effects of regulation. Two variables used in other studies -- (1) a weighted average number of regulations and (2) nuclear sector size, as measured by cumulative capacity -- were employed in the analysis. Neither of these variables was better than time as a predictor of 
real costs and lead-times. This is because any measure of the "quantity" of regulation has a high positive correlation with time. In the statistical analysis described here, the construction start date was chosen as the variable representing the amount of regulation in place at the start of construction, since regulations existing at the beginning of a nuclear construction project were deemed likely to have the greatest influence on the design of the plant.

It should be noted that the construction start date variable also captures the effects of industry experience (i.e., "learning") on lead-times and real costs. This is due to the fact that the expansion of the industry, and thus industry experience, is itself highly correlated with time. An attempt was made to capture separately the effects of regulation and industry experience, but this proved to be impossible, since both variables are highly correlated with time. Thus, to the extent that industry experience will reduce costs, the estimated effects of regulation will be understated.

The statistical analysis suggests that, with other factors held constant, the rate of increase in real overnight costs that were presumably the result of regulations in place at the start of construction and industry learning was about 9 percent per year. The analysis of lead-times, however, indicated a different pattern in the rate of growth of the construction duration resulting from regulation and industry learning. In particular, for plants entering construction before 1972, lead-times increased at about 3 percent per year. That is, holding other factors constant, the analysis indicates that, on average, plants begun in 1968 had 3 percent longer lead-times than plants begun in 1967. For plants that entered construction after 1972 and were scheduled to become operational by the end of 1986, those with later construction start dates had shorter lead-times, again with all other factors held constant. A possible explanation for this decrease in lead-times is that industry learning may have outweighed the effects of regulation.

\section{Effects of Time-Related Factors on Real Overnight Costs}

One of the most important results of the analysis is the strong correlation found between real overnight costs and lead-times. In particular, the analysis indicates that, with all other factors held constant, a 1 percent increase in the duration of the construction period was associated with a 1.2 percent increase in real overnight costs. In fact, the construction lead-time "explained" more of the variation (in a statistical sense) in real overnight costs than did any other variable included in the analysis, with the exception of the construction start date. (It should be noted that lead-time is defined as the difference between the date of commercial operation and the construction start date, i.e., the beginning of site preparation.)

Most analyses of nuclear power plant construction costs have studied the relationship between lead-time and cost increases resulting from the increased prices of inputs during the construction period and financing charges -- i.e., the time-related costs. These two factors, however, have been removed from the real costs computed here. Thus, the strong correlation between lead-time and real costs or quantities of land, labor, material, and equipment is the result of other, unquantifiable factors. Thus, in this analysis, lead-time functions as a surrogate for such factors.

A number of unmeasurable factors could have caused the strong correlation between actual lead-times and real costs. First, it is possible that attempts to accelerate the construction of a nuclear power plant will require that higher wages (and overtime costs) be offered in order to attract more workers. Thus, total costs could 
increase (decrease) as lead-times decrease (increase). Second, as lead-times increase, workers may have to be released for part of the construction period and later rehired, and because of hiring expenses, costs will increase. Third, even if workers are not released and rehired, there may be additional costs from keeping idle workers on the construction project during the interim periods when their skills are not required. Fourth, the continual stretching out of lead-times could lower the productivity of both workers and management. Indeed, a recent study has identified the morale problem of workers on plants undergoing continual delays as an underlying cause of the divergence between the U.S. and French experience with nuclear power. 1 Finally, there is an interaction between regulatory effects and increased lead-times. In an environment where regulations are changing over time, longer lead-times will result in an increased likelihood that changes associated with new or revised regulations will be required for the unit under construction. This dragging out of the project may lead to more reworking of completed work, which can add to the managerial and productivity problems already present. Given the nature of the data used in this analysis, it was not possible to ascertain the relative importance of these five factors.

Since lead-time is used as a surrogate for other unmeasurable factors, the results of the analysis should not be interpreted to indicate that reducing lead-times per se would lead to a reduction in real overnight costs. To reduce the lead-times the time-related managerial difficulties and regulatory changes associated with longer lead-times would have to be reduced and then the real overnight costs would be lower.

\section{Importance of the Management Regime}

The majority of nuclear power plants are built by external contractors. In a number of cases, however, the utility itself has acted as the construction manager. others have argued that, in such cases, the utilities are better able to monitor and control control costs. 2 The present study indeed indicates that the management regime under which a nuclear power plant is constructed is an important determinant of its real cost. First, those utilities that acted as their own construction manager built power plants with real costs approximately 35 percent lower than those incurred by utilities that used external constructors as managers. Second, when an outside contractor managed the construction of a power plant, there was no correlation between the real costs of the plant and the constructor's experience. If outside contractors did benefit from increased experience, such learning effects did not result in lower costs. There is evidence, however, that the real costs of power plants built by utilities that acted as their own construction manager fell as they gained experience, in relation to the costs of power plants built by utilities that employed outside contractors. Thus, the utilities that acted as their own construction managers not only had lower real costs but also were able to translate increased experience and learning into lower costs.

${ }^{1}$ Chaim Braun et al., "International Comparison of Power Plant Captial Costs," paper presented at the ANS/ENC International Conference (Washington, D.C., November $1984)$.

${ }^{2}$ See for example, John O. Sellin, "Managing to Reduce Nuclear Financial Risk," Public Utilities Fortnightly, October 11, 1984, pp. 26-32. 


\section{Effects of Size}

The analysis also indicates that a 25 percent increase in the size of a nuclear power plant would be associated with a 12 percent reduction in real construction cost per unit of capacity if lead-time and size were not related. The results of the study also indicate, however, that, in fact, a 25 percent increase in size is associated with an 18 percent increase in lead-time, and the 18 percent longer lead-time is related to a 22 percent increase in the real cost or quantity of land, labor, and material used to construct a nuclear power plant. Thus, the analysis indicates that the indirect effect of size on real cost, through the influence of lead-time, outweighs the direct reduction in costs per kwe of capacity that would result from the construction of large power plants if the lead-time and size were not related.

\section{Estimation of Costs and Lead-Times}

This study also addresses the issue of the estimation of costs and lead-times, and how the accuracy of the forecasts changed as plants neared completion. The analysis yields some insight into the effects of learning on cost and lead-time estimates as units approached completion. The latter is important in any evaluation of the economics of plants that have not been completed.

The utility's estimates of the real overnight costs and lead-times for all the plants in the sample when they were in various stages of construction are shown in Tables ES1 and ES2.3 The actual, or realized, costs and lead-times are also shown in these tables. As can be seen, although the utilities did increase their lead-time and cost estimates as work on the plants proceeded, they still tended to underestimate real overnight costs (i.e., quantities of land, labor, material, and equipment) and lead-times even when the plants were 90 percent complete.

A statistical analysis was undertaken in an attempt to identify the reasons for the underestimation of costs. As noted above, the strong relationship between actual lead-times and actual costs measures the effects of time-related managerial difficulties and regulatory changes on costs. If utilities perceived that plants with longer lead-times were more difficult to manage and were affected by more regulatory changes, then a positive correlation between expected lead-times and expected costs should be observed. However, the statistical analysis of the cost estimates made at the start of construction revealed that no such correlation existed. The other variables included in the analysis -- size, date of construction start, type of management regime, type of cooling mechanism, and regional location of the plant -- were not correlated with the forecast errors. 4

${ }^{3}$ As discussed in Chapter 2, the estimated real overnight costs were computed on the basis of data obtained from Form EIA-254 and predecessor survey forms. The estimated lead-times were obtained directly from the same forms.

4The forecast error is defined as the difference between actual and predicted costs. For an analysis of forecast errors in other industries, see Edward Merrow, Stephen Chapel, and Christopher Worthing, A Review of Cost Estimation in New Technologies: Implications for Energy Process plants (Rand Corporation, Santa Monica, California, July 1979), p. 38. 


\section{Table ES1. Average Estimated and Realized Overnight Costs of Nuclear Power Plants by Year of Construction Start (1982 Dollars per Kilowatt-Electric)}

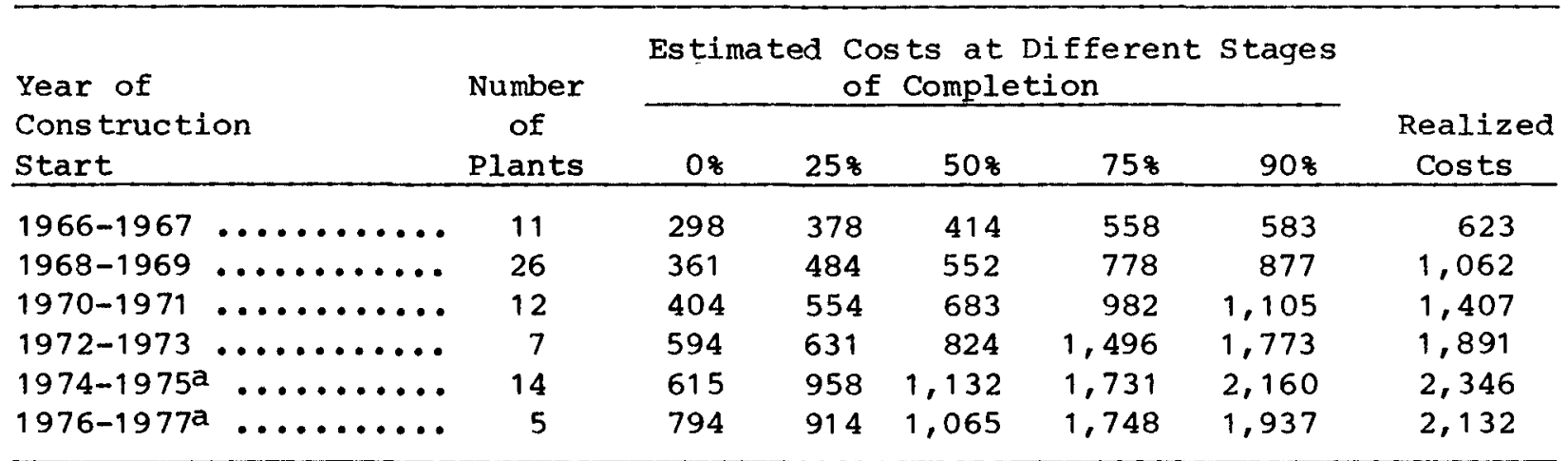

These groups include 8 plants that are only about 90 percent complete, for which the total estimated costs were assumed to equal the realized costs. These 8 plants are a sample of plants scheduled to become operational by the end of 1986. As a result, they may not be totally representative of all the plants still under construction. Plants scheduled to become operational after 1986 were excluded from this sample because they are less than 75 percent complete, and thus their estimated costs may not reflect the final realized costs.

Source: Computations based on data from Energy Information Administration, Form EIA-254, "Semiannual Progress Report on Status of Reactor Construction," and predecessor survey forms.

\section{Table ES2. Average Estimated and Realized Lead-Times of Nuclear Power Plants by Year of Construction Start (Months)}

\begin{tabular}{|c|c|c|c|c|c|c|c|}
\hline \multirow{2}{*}{\multicolumn{2}{|c|}{$\begin{array}{l}\text { Year of } \\
\text { Construction } \\
\text { Start }\end{array}$}} & \multicolumn{5}{|c|}{$\begin{array}{c}\text { Estimated Lead-Times at Different } \\
\text { Stages of Completion } \\
\end{array}$} & \multirow{2}{*}{$\begin{array}{l}\text { Realized } \\
\text { Lead-Times }\end{array}$} \\
\hline & & 08 & 258 & 508 & 758 & $90 \%$ & \\
\hline $1966-1967$. & ........ & 52 & 56 & 65 & 76 & 82 & 91 \\
\hline $1968-1969$. & ........ & 55 & 63 & 72 & 83 & 91 & 107 \\
\hline . & ......... & 59 & 77 & 92 & 97 & 110 & 132 \\
\hline $1972-1973$ & ......... & 65 & 87 & 96 & 107 & 115 & 131 \\
\hline $1974-1975^{a}$ & ........ & 68 & 93 & 105 & 117 & 123 & 132 \\
\hline $1976-1977^{a}$ & $\ldots \ldots \ldots$ & 74 & 92 & 95 & 97 & 100 & 112 \\
\hline
\end{tabular}

a sample of plants scheduled to become operational by the end of 1986 was used. These groups include 8 units are only about

90 percent complete. For those 8 units the estimated lead-time was assumed to equal the realized lead-time.

Source: Computations based on data from Energy Information Administration, Form EIA-254, "Semiannual Progress Report on Status of Reactor Construction," and predecessor survey forms. 
It must be noted that the strong correlation between actual costs and actual leadtimes was, in part, the result of events and regulatory changes that occurred after the cost estimates were prepared especially early in the construction period. Thus, at least part of the explanation for the lack of any correlation between estimated lead-time and estimated costs was the inability to foresee future events and regulatory changes.

\section{Unanswered Questions}

This analysis identifies four unanswered questions. First, it would be useful to know why, with all other factors held constant, the lead-times for the sample of units begun after 1972 and scheduled to become operational by the end of 1985 have fallen. Second, the cost increases due to managerial factors and those that were initiated by regulatory changes could not be distinguished on the basis of available data, and further work is therefore needed in order to separate the influences of these two factors. Such a task will require more detailed studies of the historical accounts of each unit's construction, specifically focusing on the causes underlying particular changes in design, reworking of completed tasks, scheduling problems, and so on. The importance of distinguishing these influences cannot be overemphasized, because the success of current and future public policies aimed at the problems of the nuclear construction process is ultimately tied to identifying the cause of the problems. Third, another issue that has not been addressed in the current literature is the postoperation capital investments made by the utilities for their nuclear units. Thus it is not clear whether there will be variations in the real overnight costs of nuclear units when the lifetime, rather than just the construction period, of each unit is the timespan for observation. Although for most units lifetime data are not available, postoperation data may provide some insight into this question. Finally, the issue of the management regime under which a power plant is constructed needs additional research. Such analysis could provide important insights into the problem of determining the most efficient institutional structure for building a nuclear power plant. 


\section{Introduction}

For more than a decade, analysts have been attempting to understand the divergence between predicted and realized costs and lead-times for commercial nuclear power plants. More importantly, it is rapidly being recognized that the future of the nuclear industry rests precariously on an improvement in the cost and lead-time situation. Studying the historical information on completed plants not only helps to make some sense of what has occurred but also improves the ability to evaluate prospective plants. This requires an examination of the factors that have affected the realized costs and construction times to build the current generation of commissioned reactors, as well as expectations formed during the construction process.

One of the principal reasons given for the current problems of the nuclear industry pertains to increasing construction costs. For example, the total costs of plants beginning construction in the early 1970's were more than 3 times greater than those for plants that entered construction in the mid-1960's; in some cases, the final total costs were also 10 times greater than initial cost estimates. These cost increases, in turn, have caused a number of serious problems. First, the increasing costs have complicated the entire planning process. Second, given the traditional methods of financing the construction of nuclear power plants, increases in costs of the nature reported above have caused serious cash flow problems for a few utilities. Third, in a number of cases, the inclusion of a high-cost plant in a utility's rate base has caused large price increases for the utility's customers. Such large price increases could cause reductions in electricity demand, which could affect utility revenues. Finally, capital costs are roughly 70 percent of the total cost of electricity generated from nuclear power, and thus a tripling of construction costs would result in an increase of more than 140 percent in the cost of electricity generated from nuclear power plants. 1 such cost increases have caused some to question the cost-effectiveness of nuclear relative to coal-fired power plants.2

There are two major approaches to analyzing the issues of cost and lead-time escalation. The first employs a case-study approach and, thus, examines the historical information on a plant-by-plant basis. This approach is useful for providing what can be enlightening details about the individual cases being studied. The other approach uses statistical methods to examine the possible relationships between selected factors from a number of cases. This approach is valuable when the objective is to investigate the influence of several variables across a number of plants and, perhaps, across time. Underlying such an analysis, of course, must be a model of the cause-and-effect relationships that theoretically supports the design of the statistical methods.

The objective of this report is to present the results of a statistical analysis of nuclear power plant construction costs. There have been at least five similar studies performed in the past, and the basic methodology and statistical techniques used in this study are similar to those used in the previous studies (reviewed in Appendix B). However, an important difference pertains to the data and the data

1 Energy Information Administration, Projected Costs of Electricity From Nuclear and Coal-Fired Power Plants, Volume 2, DOE/EIA-0356/2 (Washington, D.C., November 1982 ).

2See, for example, Richard Hellman and Caroline J.C. Hellman, The Competitive Economics of Nuclear and Coal Power (Lexington Books, Lexington, Massachusetts, 1983). 
transformations used in the present study. The previous studies used cost data published by the Energy Information Administration (EIA) in Historical Plant Cost and Annual Production Expenses ${ }^{3}$ and predecessor publications. Earlier researchers were aware that the cost data published by EIA are accounting data and, therefore, not suitable for use in cost analyses. As a result, they used a method employed by Charles Komanoff, William Mooz, and others to transform the accounting data into a form suitable for analysis.

The basic cost data used in the present study were obtained primarily from Form EIA254, "Semiannual Progress Report on Status of Reactor Construction," and its predecessor Form HQ-254. As in the previous cost studies, it was necessary to transform these accounting data into a form suitable for analysis. However, the present study also used a substantial amount of unpublished data, as well as a different methodology to transform the data. Thus, the intent of this study was to use the same general methodology and statistical techniques employed in previous studies but with a larger data base and a better method of transforming the reported (accounting) data into a form suitable for analysis.

Chapter 2 of this report discusses the data used in the study and the data-related issues mentioned above, along with some of the basic data trends. A detailed statistical analysis of construction costs and lead-times is reported in Chapter 3 , and a discussion of forecast errors is presented in Chapter 4. Chapter 5 presents the conclusions derived from the analysis, and the Appendices contain details of the computations and a review of previous studies.

${ }^{3}$ Energy Information Administration, Historical Plant Cost and Annual Production Expenses for Selected Electric Plants 1983, DOE/EIA-0455(83) (Washington, D.C., Apri1 1985). 


\section{Calculation and Description of the Cost and Lead-Time Data}

One of the major problems encountered in this study, as well as in previous studies, is that the cost data as reported are not in a form suitable for comparison and analysis (Appendices $A$ and B). This chapter, therefore, discusses some of the problems encountered and describes the method used to transform the data into analyzable form. Some basic trends are also described in this chapter.

\section{Cost and Lead-Time Data}

The basic data used in the analysis were obtained from Form EIA-254 and its predecessor, Form HQ-254. Data on total estimated construction costs, disbursed costs to date, and estimated chronological data (including the dates of construction start and commercial operation) have been submitted quarterly by utilities, beginning in the mid-1960's. Until quite recently, response to the form was not mandatory; however, in general, the response rate was high.

Because the survey form has undergone a number of changes since the mid-1960's, one of the first tasks of this study was to validate the EIA-254 data against similar data reported on Form FERC-1.1 In general, both the estimated and disbursed cost data reported on Form EIA-254 compared favorably with the analogous data reported on Form FERC-1. Thus, the cost data from Form EIA-254 were computed using the Uniform System of Accounts, 2 and therefore both the actual and estimated cost data were reported in the dollars of the year the funds were expended. More importantly, the cost data reported on both forms were the sum of the actual cash outlays and an imputed amount of financng charges called Allowance for Funds Used During Construction (AFUDC). As discussed below, the inclusion of AFUDC and the fact that the cost data were not in constant dollars presented some serious problems for this and other cost studies.

\section{Inclusion of Allowance for Funds Used During Construction}

The cost data reported on Form EIA-254 generally are the sum of the actual dollars spent on land, labor, equipment, and materials, plus the amount of accrued AFUDC. Essentially, the AFUDC is computed by multiplying the AFUDC rate (which in theory reflects the returns to the investment in question commensurate with the risks taken) by the amount of accrued construction expenditures inclusive of AFUDC at the beginning of the period, plus the cash outlays in the current period. (In this regard, the computation of AFUDC is similar to the computation of interest in a passbook savings account.) Thus, if the AFUDC is computed correctly, the financing costs included in

${ }^{1}$ For a description of Form EIA-254, see Energy Information Administration, Nuclear Power Plant Construction Activity 1984, DOE/EIA-0473(84) (Washington, D.C., July 1985), pp. 63-75. For a brief description of Form FERC-1, see Energy Information Administration, Financial Statistics of Selected Electric Utilities 1982, DOE/EIA0437(82) (Washington, D.C., February 1984).

2The Uniform System of Accounts (USA) is an accounting system developed by the Federal Energy Regulatory Commission and its predecessor agency, the Federal Power Commission. It was designed to ensure consistency in the reporting of accounting data. The total costs reported on both Form EIA-254 and Form FERC-1 generally correspond to the rate base costs. Thus, the term "reported costs" is the same as "rate base costs." 
the reported costs should measure the economic financing cost of a plant. For the purposes of this analysis, however, the inclusion of AFUDC presents certain problems, which dictate that it be removed from the reported costs.

The primary objective of this study was to ascertain the reasons for the cost increases. Obviously, the two factors influencing the amount of AFUDC are the general state of credit markets and the time needed to construct the power plant. It is possible that the real cost of the land, labor, and materials and the AFUDC would be influenced by completely different sets of factors, which in turn implies that these factors should be analyzed separately. This, of course, requires that AFUDC be separated from cash outlays.

It is also important to note that accounting variations in the methods used to compute the AFUDC can result in variations of up to 40 percent in the total "reported" or "rate base" costs (see Appendix A). Thus, the reported costs for two identical plants could conceivably vary by as much as $\$ 2$ billion simply because of differences in the methods used to compute the AFUDC. Since the use of these accounting variations is dictated in part by the relevant state regulatory commission, it is possible that the use of cost data that include AFUDC could introduce spurious correlations with any factor that varies by region.

\section{Timing of Expenditures}

The validation exercise indicated that the cost data reported on Form EIA-254 were in the dollars of the year the funds were expended, and the cumulative cost data were in a mixture of current dollars of various years. Since the reported data were in a mixture of current dollars, the cost data for plants in different generations were not comparable. Further, there were large variations in the time profiles of cash expenditures for many of the current generation of plants, and thus the cost data for plants just becoming operational could not be compared. As a result, it was necessary to transform the data into constant dollars (i.e., adjusted for inflation) before any comparisons could be made.

For example, suppose that the total reported costs for two plants are $\$ 1$ billion and that this amount has been expended over the time period from 1972 through 1982 . Further, assume that for the first plant, 10 percent of the funds were spent in 1972, 10 percent in 1973, 10 percent in 1974, and so on. Ten percent of the $\$ 1$ billion would, therefore, be in 1972 dollars, 10 percent in 1973 dollars, and so on. Next, assume that for the second plant 55 percent of the $\$ 1$ billion was spent in 1972 and 5 percent in each of the next 9 years. Even though each of these plants had the same reported costs, the second plant would be much more expensive after adjusting for inflation, since a much larger portion was spent in more expensive 1972 dollars.

\section{Other Possible Inconsistencies in the Data}

Three other possible inconsistencies in the cost data are also worthy of some discussion. The first deals with costs for multi-unit plants. The others pertain to the inclusion of certain taxes and power credits in the reported costs.

Approximately 10 to 25 percent of the expenditures of a multi-unit plant (for example, Catawba 1 and Catawba 2) are common or joint costs, the best example of such costs 
being site preparation. ${ }^{3}$ There is a strong economic incentive for a utility to allocate all of the common costs to the first unit, since it is the first one to enter the rate base. Thus, it is possible that the first unit of a multi-unit plant might appear to be more expensive simply because of the incentive to allocate all the common costs to that unit.

In all likelihood, the problem of allocating common costs has not caused serious distortions in the data. Allocation of the common costs is usually dictated by the relevant state regulatory body. Since the early 1970's, most commissions have consistently required that only 50 to 60 percent of the common costs be allocated to the first unit. Thus, since the cost data used in this analysis were computed using the Uniform System of Accounts, the common costs have been allocated to both units.

Additionally, the data used in the analysis included all costs that were capitalized. Some state commissions permit the expensing of property taxes, whereas others require that they be capitalized. Thus, the percent of total property taxes included in the cost data varies from 0 to 100 percent. Similarly, some commissions permit a credit for power generated and sold into the grid prior to commercial operation, allowing it to be capitalized and included in the construction cost data. The magnitude of these two distortions is unknown, but they tend to be mutually offsetting. Indeed, this illustrates the problems that are encountered when accounting data are used for analytical purposes.

\section{Computations of Cash Expenditures in Constant Dollars, Exclusive of AFUDC}

The inclusion of AFUDC in the reported (rate base) costs and the fact that the costs are in mixed current dollars make any comparison impossible. Thus, the AFuDC must be removed, and the resulting cash expenditures must be converted to constant dollars. The result will be a series of actual and estimated costs suitable for analysis.

All the previous studies used a generic algorithm to compute the constant-dollar cash expenditure from the reported costs published in Historical Plant Cost and Annual Production Expenses for Selected Electric Plants. Essentially, the algorithm first uses a generic "cash profile" curve to compute the incremental expenditures (including AFUDC) for each year. (A cash profile curve relates the proportion of the total expenditures in any one year to construction time.) Then, some estimate of the rate used to compute the AFUDC is employed to derive the cash outlays for the year from the yearly expenditures of AFUDC. Finally, each year's cash outlay is deflated (or inflated) to a common year and then summed to derive the cumulative cash outlays in constant dollars.

There are two problems with this approach. First, the generic "cash profile" curve used to estimate the yearly expenditures is just an approximation of the actual cash profiles, which was estimated using data from the early 1960's.4 second, these studies used an average, or embedded, debt rate, published in Financial statistics

${ }^{3}$ Based on information reported on the revised Form EIA-254.

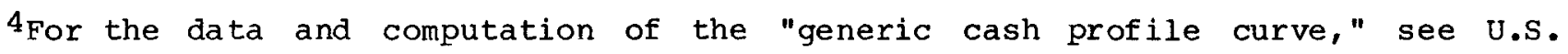
Atomic Energy Commission, Power Plant Capital Costs, Current Trends, and Sensitivity to Economic Parameters, WASH-1345 (Washington, D.C., October 1974). 
of Selected Electric Utilities, 5 as a proxy for the actual rate used to compute the AFUDC. As discussed in Appendix $A$, the use of an average debt rate caused the cash outlays to be overstated. More important, the resulting bias became smaller over time. Therefore, the effects on costs of any variable correlated with time would have been understated.

In this study, the actual yearly expenditures, including AFUDC, were first compiled from a combination of Form FERC-1 and Form EIA-254 data. Then, the actual AFUDC rates were collected from Form FERC-1 and were used to compute yearly cash outlays from the yearly cash expenditures including AFUDC. Information from Form FERC-1, supplemented by information from various state public utility commissions, was used to incorporate important accounting conventions in the computations (see Appendix A for details). Finally, each year's cash outlays were deflated (inflated) to a common year using the regional Handy-Whitman index -- a fixed-weight price index of the land, labor, and materials used to construct a nuclear power plant. Cumulative costs in constant dollars were then derived by simple summation.

The computed cash outlays (in current dollars) were validated against a number of other sources. First, figures on yearly cash outlays for a number of plants were obtained from various state regulatory commissions. Second, the Tennessee valley Authority publishes semiannually the cumulative cash outlays for almost all plants in operation and under construction. 6 similar data for plants still under construction are now reported on Form EIA-254. Comparison of the computed cash outlays with those reported in the above sources showed the computed outlays to be in general within 5 percent of the reported outlays. It therefore appears that for the cash outlays used in the present study, the figures are accurate within a reasonable margin of error.

\section{Deflation of Estimated Costs}

Total estimated costs are also reported on Form EIA-254. As was the case with the actual expenditures, the cost estimates, in general, include AFUDC and are in mixed current dollars. (For about 4 years, the instructions on Form EIA-254 asked for the cost estimates in real terms; however, a verification effort using data from Form FERC-1 indicated that the estimates were reported in mixed current dollars.) Since much of the present analysis consists of a comparison of actual and estimated costs, the Form EIA-254 data also had to be expressed in constant dollars exclusive of AFUDC.

The approach used to deflate the estimated costs was similar to those used in previous studies, as described above. First, a generic cash profile curve was used to compute the yearly estimated expenditures inclusive of AFUDC. Since a generic cash profile curve was actually used in the preparation of many of the cost estimates, using it to compute the time distribution of the estimated costs is reasonable. A series of estimated AFUDC rates and cost escalation rates was compiled from the nuclear construction cost estimates for each plant published in various Environmental

5Energy Information Administration, Financial Statistics of Selected Electric Utilities 1982, DOE/EIA-0437(82) (Washington, D.C., February 1984).

${ }^{6}$ Tennessee Valley Authority, Office of Engineering, U.S. Nuclear Plants Cost Per KW Report (Chattanooga, Tennessee, March 1985). 
Impact Statements (EIS's), which are required as part of a utility's application for a construction permit. The initial cost estimates reported on Form EIA-254 and those found in the EIS's were similar. Thus, expected AFUDC and cost escalation rates reported in the EIS's are indicative of the expected rates used to derive the estimated costs on Form EIA-254. These data were therefore used to remove the estimated AFUDC and to deflate the estimated cash expenditures.

The estimated deflated costs exclusive of AFUDC computed using the procedure just described were also compared to estimates of the deflated costs of generic nuclear units reported in engineering studies. The comparisons were favorable and indicated that these deflated cost estimates are reasonable and are the best that can be derived, given available data. The estimated deflated costs exclusive of AFUDC were also computed using two different sets of assumptions about expected AFUDC and cost escalation rates. One set of assumptions was consistent with a "rational expectations" hypothesis. The second set assumed that utilities were "myopic" or "irrational" with respect to the generation of expected AFUDC and cost escalation rates. These two sets of assumptions were then used as the basis for a sensitivity analysis. As reported in Appendix D, the results of the analysis were not sensitive to the change in assumptions about expected AFUDC and cost escalation rates. similarly, a sensitivity analysis was performed using a linear cash profile curve. Again, the results were insensitive to the assumption about the exact shape of the cash profile curve.

\section{Computation of Overnight and Time-Related Costs}

The cost in constant dollars, either actual or estimated, exclusive of AFUDC (the computation of which was just described), can be expressed in any year's dollars. In this study, two "sets" of constant dollar costs were chosen. The first was a set of costs without AFUDC expressed in mid-1982 dollars. The second was a set of costs expressed in the dollars of the year in which construction of the plant began. (The latter will be called costs in "first-year" dollars.) AFUDC was excluded from both sets of costs, and the effects of price increases during the construction period were removed. Thus, the deflated costs in either 1982 or first-year dollars can be considered to be "overnight" costs. That is, both sets of costs reflect the cost of building a plant "instantaneously," since the AFUDC and effects of inflation throughout the construction period have been removed. The overnight costs in 1982 dollars measure the cost of building a plant overnight in mid-1982, using 1982 prices of land, labor, equipment, and material. Differences in the overnight costs in 1982 dollars, therefore, represent variations in the quantities of land, labor, equipment, and material required for the project, since the effects of prices were removed. These data were used in much of the analysis described in this report.

The overnight costs in first-year dollars represent the cost of building a plant overnight in the dollars of the year construction began. Thus, the difference between the total reported (rate-base) costs and the overnight costs in first-year dollars represents the increase in costs resulting from the fact that plants cannot be constructed overnight. This difference will be called "time-related" costs. Because the "time-related" costs include both the increase in costs due to increases in the prices of the land, labor, and materials during the construction period and also AFUDC, this difference is a direct measure of the effect of time on reported construction costs.

The estimated overnight and time-related costs were computed in a similar manner. That is, the deflated estimated costs exclusive of AFUDC would represent the overnight costs. Thus, the deflated costs exclusive of AFUDC, expressed in 1982 dollars, 
represent the estimated real overnight costs in 1982 dollars. The estimated timerelated costs would equal the estimated costs in mixed current dollars, as reported on Form EIA-254, minus the deflated costs exclusive of AFUDC expressed in the dollars of the year in which construction of the plant began.

The computation of real overnight costs allows a direct comparison of the costs of labor, equipment, and materials of all units at a common point in time, after removing the time-related costs reflected in the two categories above. However, referring to these costs as "real" costs can be misleading if one takes that term to mean the real resource costs of the plant as measured by economists. Real resource costs would include an adjustment for real price changes (i.e., those that diverged from changes in the general price index) and the "real marginal cost of capital" (i.e., costs incurred from investment in this activity rather than another). Real costs of resources would be relevant if the objective of the analysis were to compare the social value of one unit with that of another. Because the objective here was more modest, the real overnight costs were selected as the relevant construction costs.

\section{Issues Dealing With the Lead-Time Data}

The lead-time variable may be defined in several different ways, which differ in their selection of an initial date and an ending date in the construction process. Some prior studies have used the length of time between the issuance of the construction permit and the initial fuel loading (see Appendix B). This is sometimes referred to as the construction lead-time. (In 1978, Mooz made a separate analysis of the time required to receive a construction permit.) 7 In the case of the construction lead-time, the implicit assumption is that construction began when the construction permit was issued and was finished at the point of the first fuel loading. This assumption may be inaccurate, especially when the period of time from fuel loading to commercial operation is significant. In these cases, one would expect additional construction activity necessitated by design changes required either by the utility or by the regulators. Moreover, prior to the mid-1970's, utilities were permitted to undertake a substantial amount of construction before the issuance of a construction permit. Indeed, in some cases 20 percent of the total manhours involved in the construction project were expended before a construction permit was issued.

Others have used the time from the day the unit was announced by the utility to the date of commercial operation as the definition of lead-time. In such cases, taking the announcement date as the initial point for the lead-time ignores the fact that at this stage, the unit or plant has not gone through any sort of rigorous review by the Nuclear Regulatory Commission (NRC). Given the possibility for substantial design changes during this review, it seems appropriate to select a point in time that is consistent with the regulatory process. For these reasons, we have defined

7William E. Mooz, Cost Analysis of Light-Water Reactor Power Plants (Rand Corporation, Santa Monica, California, June 1978). 
lead-time as the length of time (in days) between the date reported by the utility as the start of construction and the date of commercial operation. 8

\section{Sample of Plants Used in the Analysis}

The primary sample of plants used in the statistical analysis reported in Chapters 3 and 4 essentially consisted of all plants except turnkey or partial turnkey units with scheduled commercial operation dates by the end of 1985. Turnkey plants are those purchased by a utility at a firm fixed price from a contractor. Any cost overruns for such plants would, therefore, be absorbed by the contractor and would not be reflected in the costs reported by the utility. Since the reported costs for turnkey plants do not reflect the actual costs, they were excluded. Furthermore, one of the principal objectives of the study was to examine the differences between actual and estimated costs. To include plants scheduled to begin operation after 1985, the actual costs must be assumed to be equal to the estimated costs, which historically has not been the case. The total sample for the cost analysis consisted of 67 non-turnkey nuclear power plants. Three additional units were included in the lead-time analysis. 9

Because plants with commercial operation dates later than 1985 were excluded, a number of high-cost plants were not in the sample. Therefore, for a better portrayal of the trends, plants with usable cost data that are scheduled to become operational in 1986 were included in the sample used in the remainder of this chapter. For these plants, the total estimated costs, as reported by the utilities, were assumed to equal the final realized costs. Because these additional plants are only 50 to 90 percent complete, however, they were not included in the sample used for statistical analysis. To determine the extent of the possible bias, the most important regression equations were estimated from the enlarged sample. The results were similar to those obtained with the original sample, indicating that the bias was very small. The actual lead-time equation was also reestimated using data for all units except those with uncertain completion dates. The most significant results of the lead-time analysis were confirmed when this larger sample was used.

\section{Trends in Lead-Times and Costs}

There have been two different explanations proposed for the increases in the costs of constructing nuclear power plants. The first asserts that the increases were principally the result of increases in the time-related costs, with small increases, or none, in the overnight costs. Furthermore, this would imply that attempts to reduce costs should focus on reducing lead-times per se. The competing hypothesis

${ }^{8}$ See Martin B. Zimmerman, "Learning Effects and the Commercialization of New Energy Technologies: The Case of Nuclear Power," Bell Journal of Economics and Management Science (Autumn 1982), for an example of a study that used the announcement date. Also, the construction start date was validated by comparison to detailed milestone information published by the U.S. Nuclear Regulatory Commission in various issues of its Construction Status Report (NUREG-0030). In almost all cases, the construction start date reported by the utilities corresponded to the beginning of site preparation.

${ }^{9}$ Appendix $C$ gives a more detailed description of the sample. 
states that increases in the real overnight costs are important. Because AFUDC and cost increases resulting from increases in the input prices over the construction period are not included in the overnight costs, increases in real overnight costs would be the result of factors that influence the design and construction of a plant. In short, a basic issue is whether the increases in construction costs are the result of lead-times per se or of factors that influence the design and construction of nuclear power plants. The previous section of this chapter outlined the method used to estimate the real overnight and time-related costs. Some general trends in costs and lead-times will now be outlined. Chapters 3 and 4 present a statistical analysis, which will attempt to explain these trends.

\section{Trends in Overnight and Time-Related Costs}

The overnight costs in first-year dollars, the time-related costs, and the total initial estimated costs for the sample of plants used in the analysis are shown in Figure 1. The plants are grouped by the year of construction start for two reasons. First, the overnight costs for units in a particular group are in roughly the same year's dollars. Second, plants beginning at about the same time would initially face the same set of regulations and standards. The trends in the costs, when the plants are grouped in this fashion, can, in part, be attributed to regulatory changes. It should also be noted that the time-related costs are in "nominal," as opposed to real, terms.

Figure 1 indicates that there has, indeed, been a substantial increase in both overnight costs (which are partly influenced by factors affecting reactor design and construction) and time-related costs (which are influenced by the factors affecting lead-times, the escalation of prices over the construction period, and interest rates). For the average plant with construction beginning in 1966 or 1967, the timerelated costs were about $\$ 110$ dollars per kWe, or roughly 35 percent of the total reported (or rate base) costs. Plants with construction beginning 6 years later had time-related costs of about $\$ 1,300$ per $k W e$, and by 1974-75 these costs had increased to about $\$ 1,800$ per kwe, or 65 percent of the total reported costs. Over the entire period, there was an increase of about 16-fold in the time-related costs.

Much of the escalation in the time-related costs was not reflected in the initial cost estimates (Figure 1). For example, the estimated time-related costs for plants begun in 1966 to 1967 were about $\$ 35$ per kWe, increasing to over $\$ 215$ per kWe for plants that were begun 8 years later. Thus, the estimates of time-related costs have increased by about 500 percent. Utilities have clearly underestimated both the absolute time-related costs and the rate of growth of these costs over time. As discussed above, estimated time-related and overnight costs were not reported directly by the utilities and thus had to be computed.

The reasons for the escalation in time-related costs are explored in the statistical analysis in Chapters 3 and 4. As can be seen from Figure 2, when the reactors in the sample are grouped by year of construction start, there appears to be an increase in actual lead-times for the plants begun in the early 1970's relative to those started in the mid-1960's. However, there was virtually no increase in the leadtimes for plants that entered construction after 1970. Since the same sample of plants was used to calculate both costs and lead-times, the steady increase in timerelated costs appears to be more the result of the cost increases occurring over the construction period and increases in interest rates than of increases in lead-time. 
Figure 1. Actual and Estimated Total Costs In Mixed Current Dollars for Nuclear Power Plants in Operation by the End of 1986

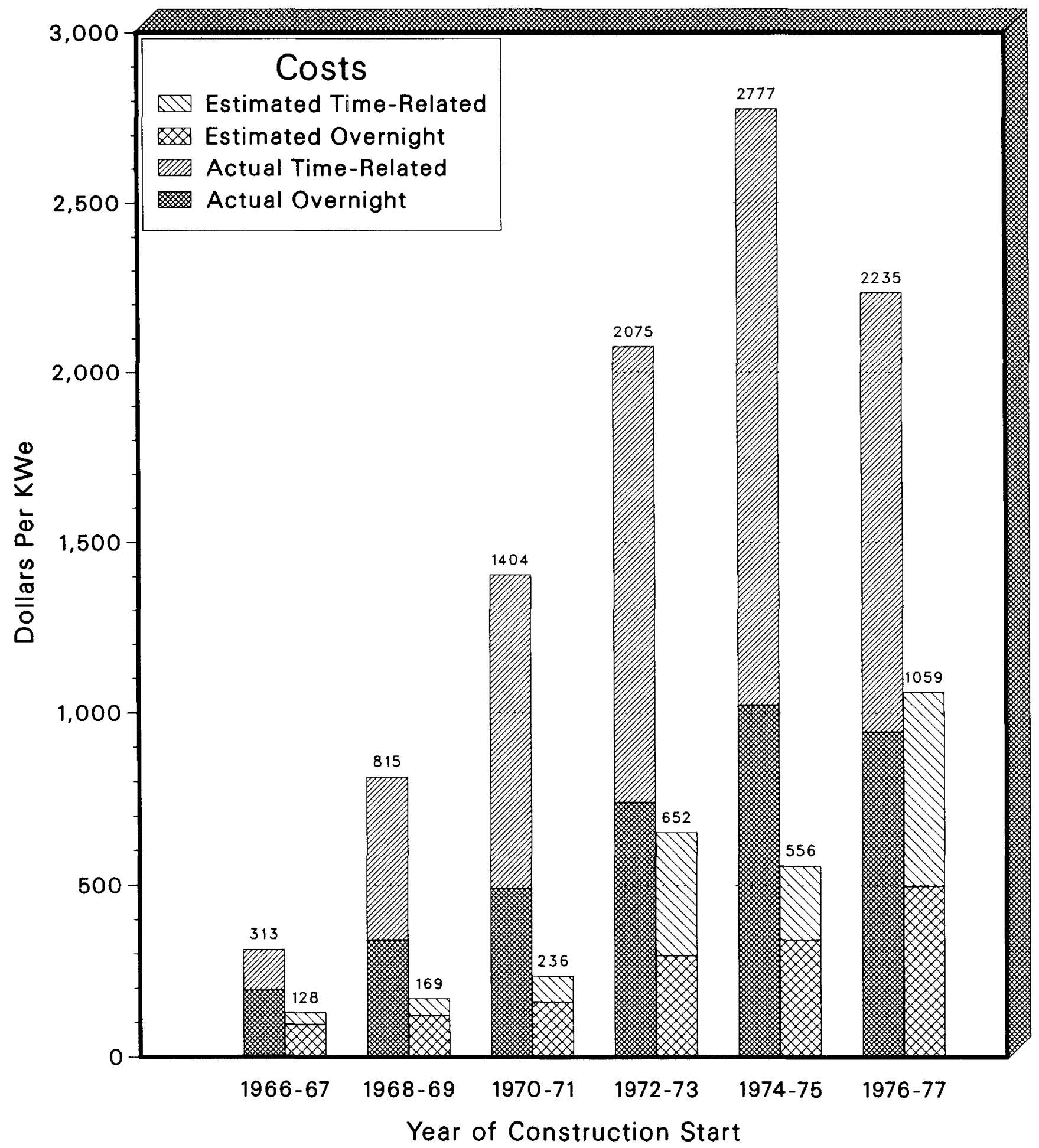

Note: Cost estimates made at construction start were used. Estimated time-related and overnight costs were computed from data reported by the utility.

Source: Computations based on data from Energy Information Administration. Form ElA-254.

"Semiannual Progress Report on Status of Reactor Construction," and predecessor survey forms. 
Figure 2. Actual and Estimated Lead-Times of Nuclear Power Plants in Operation by the End of 1986

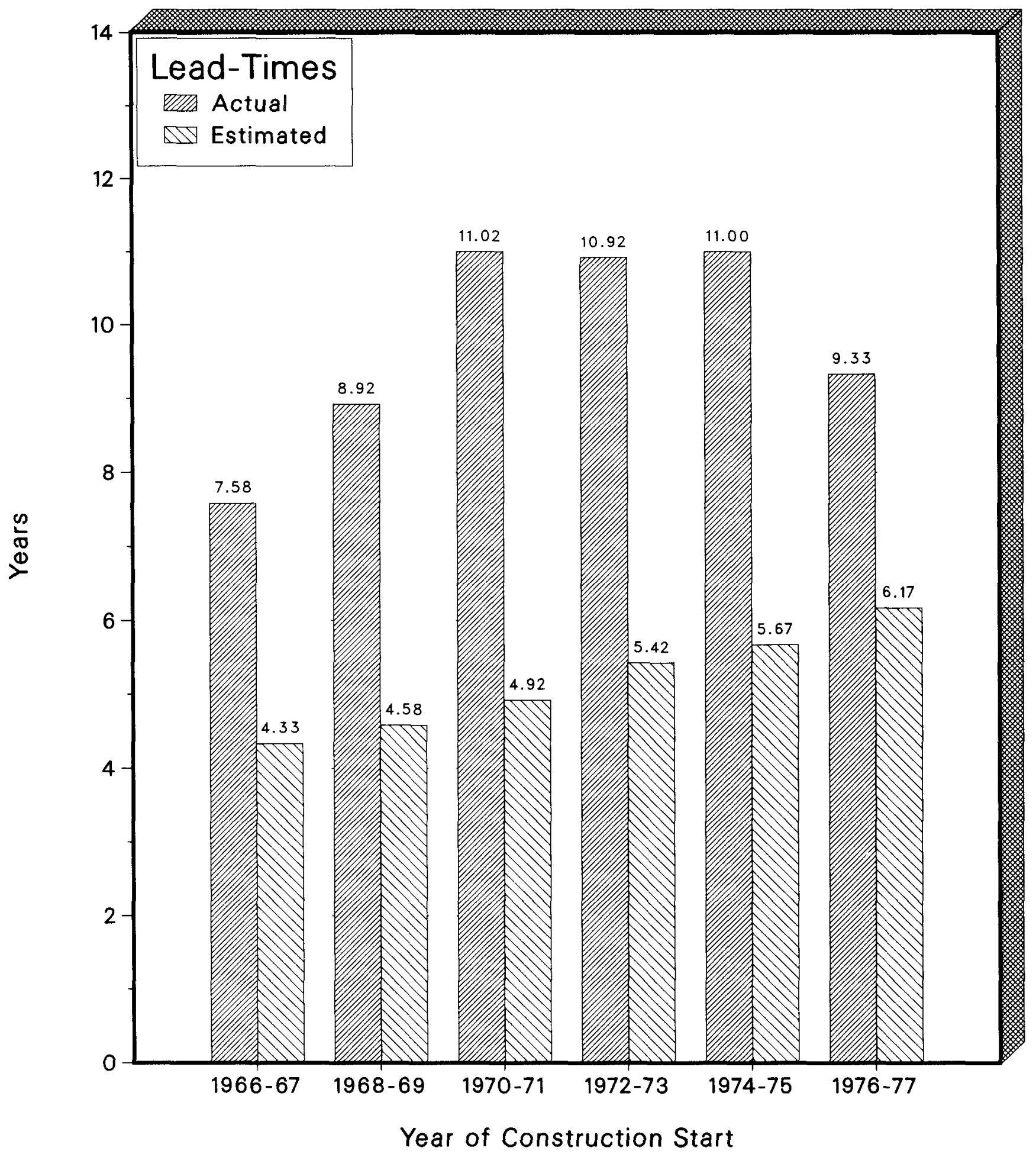

Note: Lead-time estimates made at construction start were used.

Source: Computations based on data from Energy Information Administration, Form EIA-254,

"Semiannual Progress Report on Status of Reactor Construction," and predecessor survey forms. 
Overnight costs measured in "first-year" dollars have also increased. In particular, overnight costs have increased from about $\$ 200$ per kWe for plants begun in 1966 to 1967 to about $\$ 1,000$ for those units begun 8 years later. However, all of these overnight costs are in different years' dollars. Thus, it is impossible to ascertain from these data whether the increase was due to an increase in the prices of construction materials and labor or the result of increases in "quantities." To determine this, all the costs must be placed in the same year's dollars.

The overnight and time-related costs expressed in 1982 dollars are shown in Figure 3. When compared to Figure 1, Figure 3 shows slightly different trends. In absolute terms, the bulk of the real cost increases in Figure 3 are the result of escalation in the overnight, as opposed to the time-related, costs. In particular, the reported (rate base) costs expressed in 1982 dollars have increased by about $\$ 2,400$ per kWe. Approximately $\$ 1,800$ of this $\$ 2,400$ increase was due to escalation in the real overnight costs. In contrast, the results shown in Figure 1 indicate that roughly $\$ 1,700$ of the $\$ 2,500$ per $\mathrm{kWe}$ increase in the mixed current dollar expenditures was due to escalation of time-related costs.

As discussed at the beginning of this chapter, the time-related costs are the component of the total expenditures that result from the fact that a plant is not constructed "overnight." Thus, the time-related costs should be the sum of the cost increases resulting from increases over the construction period in the prices of land, labor, and materials used to construct the plant, plus financing charges.

There are, therefore, two reasons why the importance of time-related costs is diminished when the expenditures are expressed in real terms. First, during the past 10 years, in real or relative terms, the prices of the land, labor, and materials used to build a power plant in general have increased at a rate roughly equal to the overall rate of inflation. Thus there were only small increases in the real prices of the land, labor, and materials used to construct a power plant. Second, on average, the real or inflation-adjusted AFUDC rates were also very small, which implies that the real financing costs were also small.

In short, in real, inflation-adjusted terms, escalation in overnight costs, rather than time-related costs, is the principal factor causing the cost increases. Thus, attempts to reduce costs should focus on the managerial and regulatory factors that affect plant design and construction, as well as on the factors that just affect the time required for licensing of the plants. Moreover, the trends in the rate base or reported costs indicate that the increases in the "nominal" time-related costs appear to be due more to increases in interest rates than to increases in leadtimes. Indeed, when the plants in the sample are grouped by year of construction start, there is no increase in lead-times for any of the plants begun in the 1970's, but there are large increases in the time-related costs.

The actual costs in relation to the estimated real overnight costs are shown in Figure 4. (The derivation of the estimated real overnight costs from the costs reported on Form EIA-254 was outlined above and is described in detail in Appendix A.) As can be seen from the figure, there has always been a tendency to underestimate the real overnight costs or quantities of land, labor, and materials needed to produce a nuclear power plant. The forecast errors in these costs have also tended to increase over time. The real overnight costs for plants that started construction in 1966 to 1967 were underestimated by approximately 100 percent, and the forecast error increased to 280 percent for plants that entered construction in 1974-1975. These forecast exrors were possibly the result of a lack of understanding of basic 
Figure 3. Total Costs Including Financing Charges In 1982 Dollars for Nuclear Power Plants in Operation by the End of 1986

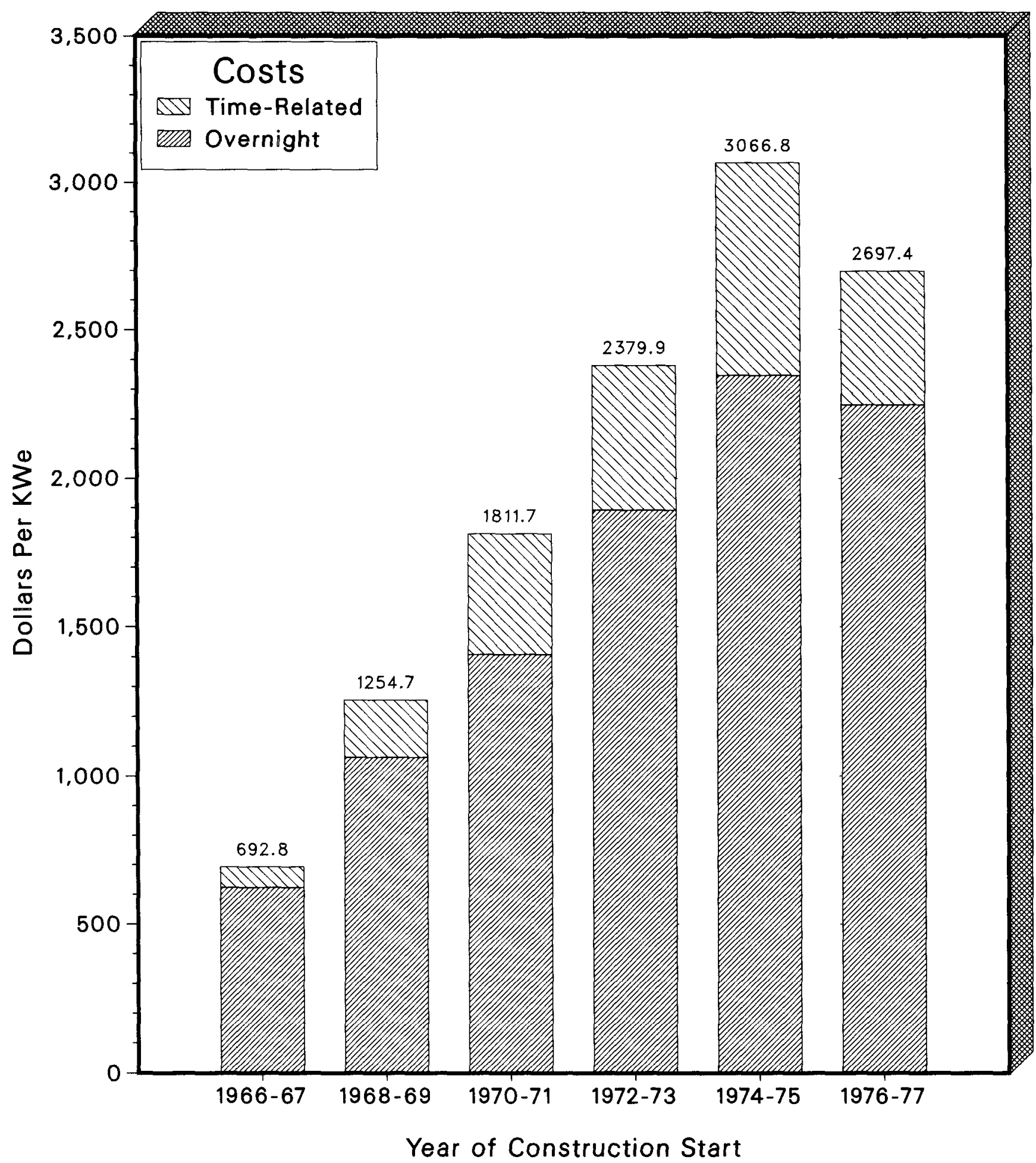

Note: When allowance for funds used during construction was not included in the reported costs, the unit was excluded.

Source: Computations based on date from Energy Information Administration, Form ElA-254

"Semiannual Progress Report on Status of Reactor Construction," and predecessor survey forms. 
Figure 4. Actual and Estimated Real Overnight Costs of Nuclear Power Plants in Operation by the End of 1986

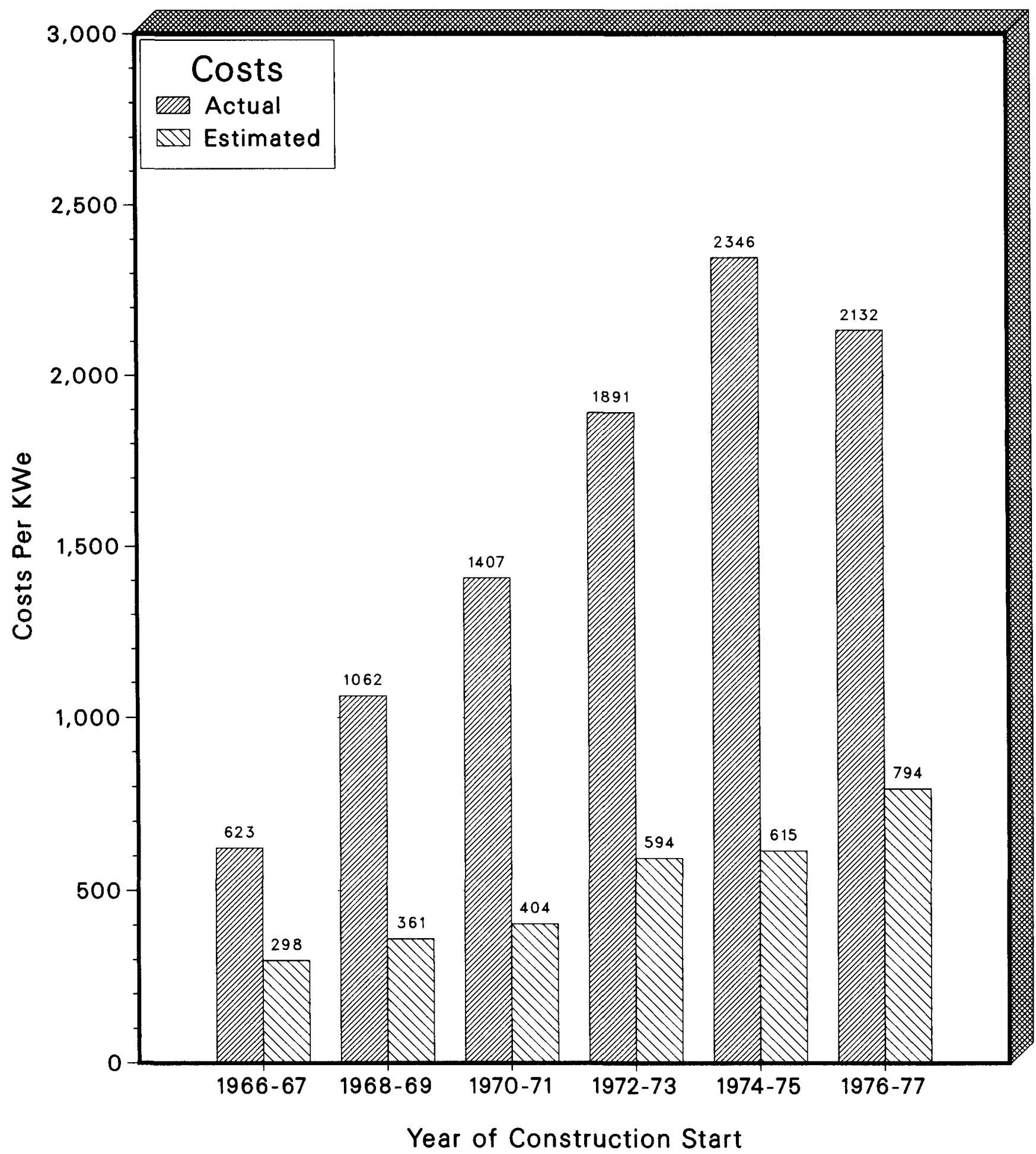

Note: Cost estimates made at construction start were used. Estimated costs were computed from data reported by the utility.

Source: Computations based on data from Energy Information Administration, Form ElA-254,

"Semiannual Progress Report on Status of Reactor Construction," and predecessor survey forms. 
engineering relationships, lack of experience, failure to predict future regulatory changes, and/or managerial considerations. An attempt to analyze the factors that contributed to the real cost overruns is reported in Chapter 4.

Finally, a list of units by year of construction start, along with the estimated and realized overnight costs, is shown in Table 1. Within each group, the plants are listed in order of increasing realized real overnight costs. The large variation in realized real overnight costs within each group should be noted. (Since each year's overnight costs are reported in 1982 dollars, comparisons among units are valid.)

Table 1. Ranking of Plants in the Sample According to Real Overnight Construction Costs, by Year of Construction Start

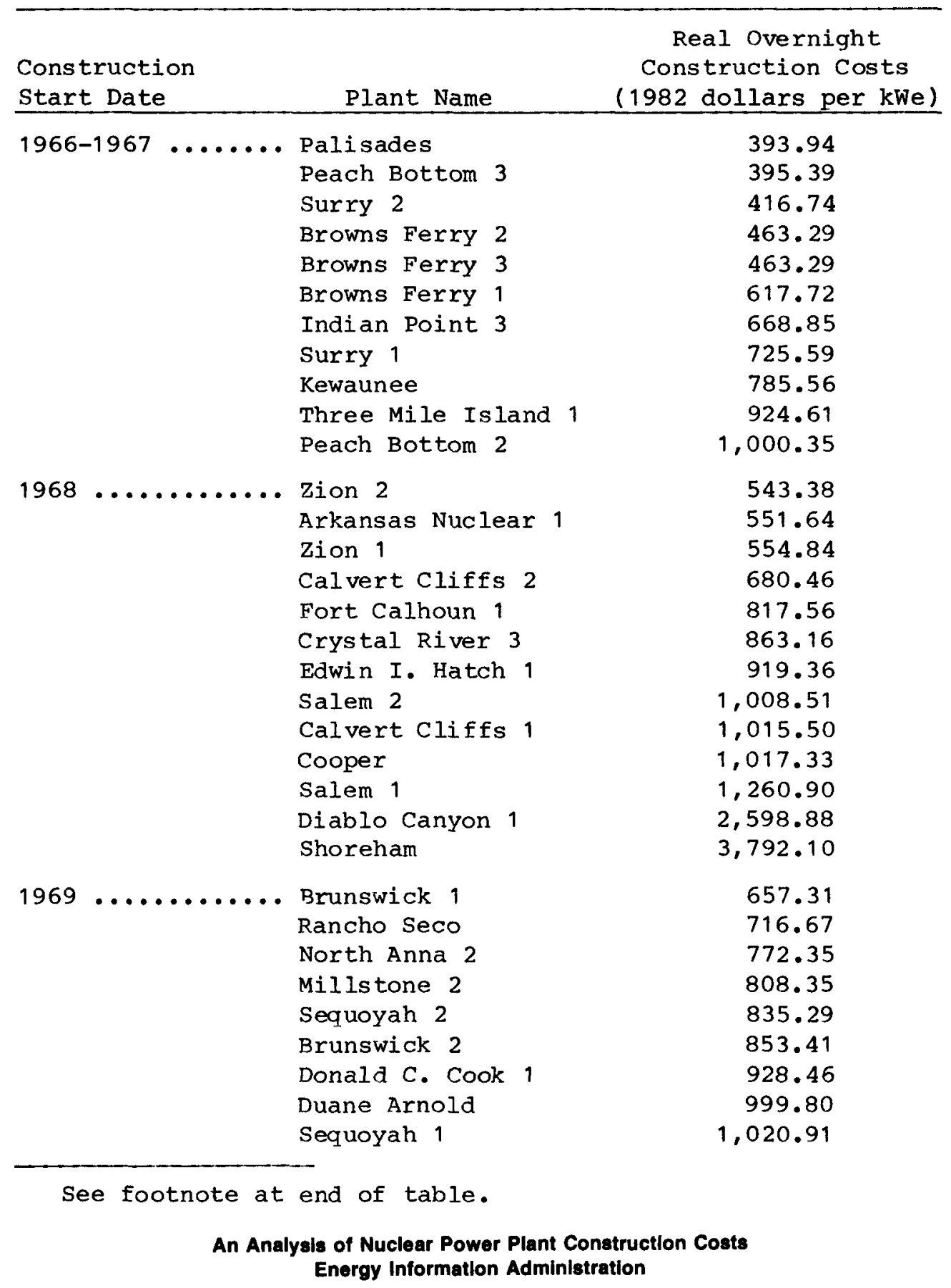


Table 1. Ranking of Plants in the Sample According to Real Overnight Construction Costs, by Year of Construction Start (Continued)

\begin{tabular}{|c|c|c|}
\hline $\begin{array}{l}\text { Construction } \\
\text { Start Date }\end{array}$ & Plant Name & $\begin{array}{c}\text { Real Overnight } \\
\text { Construction Costs } \\
\text { (1982 dollars per kWe) }\end{array}$ \\
\hline & $\begin{array}{l}\text { St. Lucie } 1 \\
\text { Beaver Valley } 1 \\
\text { Three Mile Island } 2 \\
\text { North Anna } 1\end{array}$ & $\begin{array}{l}1,023.26 \\
1,037.22 \\
1,067.15 \\
1,288.44\end{array}$ \\
\hline $1970-1971 \ldots \ldots \ldots$ & $\begin{array}{l}\text { Trojan } \\
\text { McGuire } 2 \\
\text { McGuire } 1 \\
\text { Edwin I. Hatch } 2 \\
\text { Arkansas Nuclear } 2 \\
\text { Joseph M. Farley } 2 \\
\text { Davis-Besse } 1 \\
\text { Joseph M. Farley } 1 \\
\text { Diablo Canyon } 2 \\
\text { Waterford } 3 \\
\text { Fermi } 2 \\
\text { Limerick } 1\end{array}$ & $\begin{array}{r}761.10 \\
808.08 \\
826.78 \\
884.00 \\
890.67 \\
1,112.96 \\
1,126.59 \\
1,325.60 \\
1,584.78 \\
2,132.18 \\
2,600.23 \\
2,834.16\end{array}$ \\
\hline $1972-1974 \ldots \ldots \ldots$ & $\begin{array}{l}\text { LaSalle } 2 \\
\text { LaSalle } 1 \\
\text { Catawba } 1 \\
\text { San Onofre } 3 \\
\text { Virgil Summer } 1 \\
\text { Susquehanna } 2 \\
\text { Susquehanna } 1 \\
\text { Grand Gulf } 1 \\
\text { San Onofre } 2 \\
\text { Perry } 1 \\
\text { Millstone } 3 \\
\text { WPPSS } 2 \\
\text { Shearon Harris } 1 \\
\text { Nine Mile Point } 2 \\
\text { Beaver Valley } 2\end{array}$ & $\begin{array}{l}874.39 \\
1,337.04 \\
1,360.79 \\
1,419.03 \\
1,425.31 \\
1,627.20 \\
1,898.83 \\
2,087.20 \\
2,283.48 \\
2,324.97 \\
2,598.41 \\
2,737.76 \\
3,338.68 \\
3,610.08 \\
3,697.10\end{array}$ \\
\hline 1975 and After ... & $\begin{array}{l}\text { Palo Verde } 2 \\
\text { Byron } 2 \\
\text { Byron } 1 \\
\text { St. Lucie } 2 \\
\text { Braidwood } 1 \\
\text { Wolf Creek } 1 \\
\text { Callaway } \\
\text { Palo Verde } 1 \\
\text { Hope Creek } 1 \\
\text { Clinton } 1 \\
\text { River Bend } 1\end{array}$ & $\begin{array}{l}1,355.22 \\
1,398.77 \\
1,688.94 \\
1,740.13 \\
1,826.30 \\
1,852.25 \\
2,011.69 \\
2,475.98 \\
3,237.37 \\
3,267.94 \\
3,290.52\end{array}$ \\
\hline
\end{tabular}

Source: Computations based on data from Energy

Information Administration, Form EIA-254, "Semiannual Progress Report on Status of Reactor Construction," and predecessor survey forms. 


\section{Changes in Cost and Lead-Time Estimates}

The tendency at the start of construction was to underestimate lead-times and costs. Knowing how these forecast errors changed as the plants neared completion should yield some insight into the effects of learning on the cost and lead-time estimates, and will help in judging the accuracy of cost estimates of plants that are still under construction. The latter is important in any evaluation of the economics of plants that have not been completed.

The cost and lead-time estimates for all the plants in the sample when they were in various stages of construction are shown in Tables 2 and 3 . As can be seen from these tables, while the utilities did increase their lead-time and cost estimates as work on the plants proceeded, they tended to underestimate costs and lead-times even when the plants were 90 percent complete. Given the licensing process and other regulatory factors, some errors in the lead-time estimates are to be expected, even for plants that are nearly finished. However, the 20 percent average forecast error in the real overnight costs for plants that were 90 percent complete would seem to indicate a tendency to underestimate the amount of effort and materials needed to complete units that were nearly finished.

\section{Table 2. Average Estimated and Realized Overnight Costs of Nuclear Power Plants by Year of Construction Start (1982 Dollars per Kilowatt-Electric)}

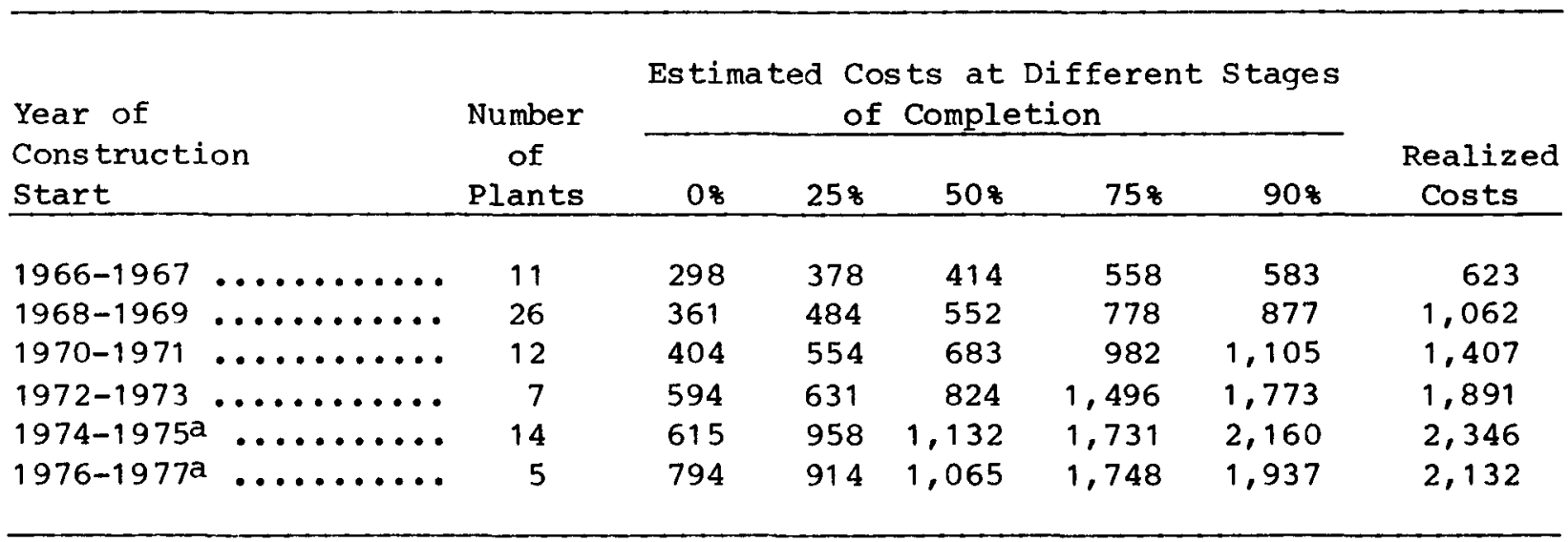

aThese groups include 8 plants that are only about 90 percent complete, for which the total estimated costs were assumed to equal the realized costs. These 8 plants are a sample of plants scheduled to become operational by the end of 1986. As a result, they may not be totally representative of all the plants still under construction. Plants scheduled to become operational after 1986 were excluded from this sample because they are less than 75 percent complete, and thus their estimated costs may not reflect the final realized costs.

Source: Computations based on data from Energy Information Administration, Form EIA-254, "Semiannual Progress Report on Status of Reactor Construction," and predecessor survey forms. 


\section{Table 3. Average Estimated and Realized Lead-Times of Nuclear Power Plants by Year of Construction Start (Months)}

\begin{tabular}{|c|c|c|c|c|c|c|}
\hline \multirow{2}{*}{$\begin{array}{l}\text { Year of } \\
\text { Construction } \\
\text { Start }\end{array}$} & \multicolumn{5}{|c|}{$\begin{array}{c}\text { Estimated Lead-Times at Different } \\
\text { Stages of Completion }\end{array}$} & \multirow{2}{*}{$\begin{array}{c}\text { Realized } \\
\text { Lead-Times }\end{array}$} \\
\hline & 08 & $25 \%$ & 508 & 758 & $90 \%$ & \\
\hline $1966-1967 \ldots \ldots \ldots$ & 52 & 56 & 65 & 76 & 82 & 91 \\
\hline 1968-1969 ........ & 55 & 63 & 72 & 83 & 91 & 107 \\
\hline $1970-1971 \ldots \ldots \ldots$ & 59 & 77 & 92 & 97 & 110 & 132 \\
\hline $1972-1973 \ldots \ldots \ldots$ & 65 & 87 & 96 & 107 & 115 & 131 \\
\hline $1974-1975^{a} \ldots \ldots \ldots$ & 68 & 93 & 105 & 117 & 123 & 132 \\
\hline 1976-1977a ....... & 74 & 92 & 95 & 97 & 100 & 112 \\
\hline
\end{tabular}

$a_{A}$ sample of plants scheduled to become operational by the end of 1986 was used. These groups include 8 units are only about 90 percent complete. For those 8 units the estimated lead-time was assumed to equal the realized lead-time.

Source: Computations based on data from Energy Information Administration, Form EIA-254, "Semiannual Progress Report on Status of Reactor Construction," and predecessor survey forms.

In short, the accuracy of the cost and lead-time forecasts is an issue in many regulatory hearings. Assuming that history tends to repeat itself, these results indicate that the estimated costs and lead-times of plants that are still under construction, even ones that are 90 percent complete, are too low. The reasons for the changes in the cost and time estimates will be explored in Chapter 4.

\section{Ranking of Plants According to Cost}

One of the objectives of this chapter is to describe the method used to transform the accounting data into a form suitable for analysis. To illustrate the possible exrors that could be caused by the use of the reported (rate base) cost data to compare the true costs of the plants, a ranking of ull the units in the enlarged sample in ascending order, based on real overnight costs, is shown in Table 4 . The first column in this table gives the name of the plant, and the second and third columns show their ranking based on real overnight costs and reported costs, respectively. The substantial differences in the rankings illustrate the possible errors that can result from comparisons using the construction costs as reported by the utilities. 
Table 4. Ranking of Plants in the Sample According to Real Overnight Construction Costs and Reported Construction Costs

\begin{tabular}{|c|c|c|c|}
\hline $\begin{array}{l}\text { Ranking } \\
\text { Based on } \\
\text { Real } \\
\text { Overnight } \\
\text { Costs } \\
\end{array}$ & $\begin{array}{l}\text { Ranking } \\
\text { Based on } \\
\text { Reported } \\
\text { Costs } \\
\end{array}$ & $\begin{array}{l}\text { Real Overnight } \\
\text { Cons truction } \\
\text { Costs } \\
\text { (1982 dollars } \\
\text { per kWe) }\end{array}$ & $\begin{array}{c}\text { Reported } \\
\text { Construction } \\
\text { Costs } \\
\text { (mixed current } \\
\text { dollars per kWe) }\end{array}$ \\
\hline Palisades ........... & 1 & 393.94 & 170.22 \\
\hline Peach Bottom $3 \ldots . .$. . & 3 & 395.39 & 206.20 \\
\hline Surry $2 \ldots \ldots \ldots \ldots$ & 2 & 416.74 & 187.37 \\
\hline Browns Ferry $2 \ldots \ldots \ldots$ & 4 & 463.29 & 244.73 \\
\hline Browns Ferry $3 \ldots \ldots \ldots$ & 5 & 463.29 & 244.73 \\
\hline zion $2 \ldots \ldots \ldots \ldots$ & 7 & 543.38 & 266.90 \\
\hline Arkansas Nuclear $1 \ldots \ldots 7$ & 8 & 551.64 & 281.05 \\
\hline Zion $1 \ldots \ldots \ldots \ldots$ & 6 & 554.84 & 254.45 \\
\hline Browns Ferry $1 \ldots \ldots \ldots 9$ & 11 & 617.72 & 326.31 \\
\hline Brunswick $1 \ldots \ldots \ldots \ldots 10$ & 16 & 657.31 & 384.80 \\
\hline Indian Point $3 \ldots \ldots .11$ & 18 & 668.85 & 396.89 \\
\hline Calvert Cliffs $2 \ldots \ldots 12$ & 13 & 680.46 & 366.86 \\
\hline Rancho Seco ......... 13 & 14 & 716.67 & 367.55 \\
\hline Surry $1 \ldots \ldots \ldots \ldots \ldots 14$ & 10 & 725.59 & 313.91 \\
\hline Trojan ........... 15 & 17 & 761.10 & 392.09 \\
\hline North Anna $2 \ldots \ldots \ldots \ldots$ & 29 & 772.35 & 596.38 \\
\hline Kewaunee ........... 17 & 15 & 785.56 & 376.11 \\
\hline McGuire $2 \ldots \ldots \ldots \ldots 18$ & 42 & 808.08 & 866.10 \\
\hline Mills tone $2 \ldots \ldots \ldots \ldots 19$ & 21 & 808.35 & 475.50 \\
\hline Fort Calhoun $1 \ldots \ldots \ldots 20$ & 12 & 817.56 & 364.69 \\
\hline McGuire $1 \ldots \ldots \ldots \ldots 21$ & 36 & 826.78 & 778.81 \\
\hline Sequoyah $2 \ldots \ldots \ldots \ldots .22$ & 30 & 835.29 & 650.42 \\
\hline Brunswick $2 \ldots \ldots \ldots \ldots 23$ & 19 & 853.41 & 461.42 \\
\hline Crystal River $3 \ldots \ldots .24$ & 24 & 863.16 & 502.00 \\
\hline LaSalle $2 \ldots \ldots \ldots \ldots .25$ & 44 & 874.39 & 954.48 \\
\hline Edwin I. Hatch $2 \ldots \ldots 26$ & 31 & 884.00 & 651.79 \\
\hline Arkansas Nuclear $2 \ldots 27$ & 34 & 890.67 & 694.08 \\
\hline Edwin I. Hatch $1 \ldots \ldots 28$ & 20 & 919.36 & 469.93 \\
\hline Three Mile Island $1 \ldots 29$ & 23 & 924.61 & 490.86 \\
\hline Donald c. Cook $1 \ldots . . .30$ & 26 & 928.46 & 508.54 \\
\hline Duane Arnold ........ 31 & 27 & 999.80 & 533.72 \\
\hline Peach Bottom $2 \ldots \ldots . .32$ & 22 & $1,000.35$ & 488.26 \\
\hline Salem $2 \ldots \ldots \ldots \ldots . . .33$ & 33 & $1,008.51$ & 686.50 \\
\hline Calvert Cliffs $1 \ldots \ldots .34$ & 25 & $1,015.50$ & 507.69 \\
\hline Cooper ............ 35 & 9 & $1,017.33$ & 298.53 \\
\hline Sequoyah $1 \ldots \ldots \ldots \ldots 36$ & 38 & $1,020.91$ & 794.96 \\
\hline St. Lucie $1 \ldots \ldots \ldots .37$ & 28 & $1,023.26$ & 557.83 \\
\hline Beaver valley $1 \ldots \ldots \ldots 38$ & 32 & $1,037.22$ & 684.74 \\
\hline Three Mile Island $2 \ldots 39$ & 37 & $1,067.15$ & 789.04 \\
\hline Joseph M. Farley $2 \ldots 40$ & 43 & $1,112.96$ & 941.95 \\
\hline
\end{tabular}

See footnote at end of table. 


\section{Table 4. Ranking of Plants in the Sample According to Real Overnight Construction Costs and Reported Construction Costs (Continued)}

\begin{tabular}{|c|c|c|c|}
\hline $\begin{array}{l}\text { Ranking } \\
\text { Based on } \\
\text { Real } \\
\text { Overnight } \\
\text { Costs } \\
\end{array}$ & $\begin{array}{l}\text { Ranking } \\
\text { Based on } \\
\text { Reported } \\
\text { Costs }\end{array}$ & $\begin{array}{l}\text { Real Overnight } \\
\text { Construction } \\
\text { Costs } \\
\text { (1982 dollars } \\
\text { per kWe) }\end{array}$ & $\begin{array}{c}\text { Reported } \\
\text { Construction } \\
\text { Costs } \\
\text { (mixed current } \\
\text { dollars per kWe) }\end{array}$ \\
\hline Davis-Besse $1 \ldots \ldots \ldots 41$ & 35 & $1,126.59$ & 701.66 \\
\hline Salem $1 \ldots \ldots \ldots \ldots \ldots \ldots 42$ & 40 & $1,260.90$ & 858.30 \\
\hline North Anna $1 \ldots \ldots \ldots .43$ & 41 & $1,288.44$ & 859.35 \\
\hline Joseph M. Farley $1 \ldots 44$ & 39 & $1,325.60$ & 827.97 \\
\hline Lasalle $1 \ldots \ldots \ldots \ldots \ldots 45$ & 46 & $1,337.04$ & $1,245.72$ \\
\hline Palo verde $2 \ldots \ldots \ldots .46$ & 45 & $1,355.22$ & $1,197.64$ \\
\hline Catawba $1 \ldots \ldots \ldots \ldots 47$ & 50 & $1,360.79$ & $1,690.83$ \\
\hline Byron $2 \ldots \ldots \ldots \ldots 48$ & 48 & $1,389.77$ & $1,585.71$ \\
\hline San Onofre $3 \ldots \ldots \ldots 49$ & 49 & $1,419.03$ & $1,590.10$ \\
\hline Virgil Summer $1 \ldots \ldots$. 50 & 47 & $1,425.31$ & $1,425.59$ \\
\hline Diablo Canyon $2 \ldots \ldots . .51$ & 52 & $1,584.78$ & $1,911.03$ \\
\hline Susquehanna $2 \ldots \ldots \ldots 52$ & 53 & $1,627.20$ & $2,056.19$ \\
\hline Byron $1 \ldots \ldots \ldots \ldots 5$ & 54 & $1,688.94$ & $2,119.64$ \\
\hline st. Lucie $2 \ldots \ldots \ldots .54$ & 51 & $1,740.13$ & $1,767.00$ \\
\hline Braidwood 1 ........ 55 & 56 & $1,826.30$ & $2,187.50$ \\
\hline Wolf Creek $1 \ldots \ldots \ldots 56$ & 60 & $1,852.25$ & $2,490.43$ \\
\hline Susquehanna $1 \ldots \ldots \ldots 57$ & 55 & $1,898.83$ & $2,149.28$ \\
\hline Callaway ........... 58 & 62 & $2,011.69$ & $2,741.07$ \\
\hline Grand Gulf 1 ....... 59 & 61 & $2,087.20$ & $2,511.96$ \\
\hline Waterford $3 \ldots \ldots \ldots 60$ & 59 & $2,132.18$ & $2,345.36$ \\
\hline San Onofre $2 \ldots \ldots \ldots 61$ & 58 & $2,283.48$ & $2,335.48$ \\
\hline Perry $1 \ldots \ldots \ldots \ldots \ldots 62$ & 66 & $2,324.97$ & $3,273.86$ \\
\hline Palo verde 1 ....... 63 & 57 & $2,475.98$ & $2,200.00$ \\
\hline Millstone $3 \ldots \ldots \ldots \ldots 64$ & 67 & $2,598.41$ & $3,308.82$ \\
\hline Diablo Canyon $1 \ldots \ldots .65$ & 64 & $2,598.88$ & $2,976.01$ \\
\hline Fermi $2 \ldots \ldots \ldots \ldots 66$ & 65 & $2,600.23$ & $3,084,17$ \\
\hline WPPSS $2 \ldots \ldots \ldots \ldots 67$ & 63 & $2,737.76$ & $2,909.09$ \\
\hline Limerick $1 \ldots \ldots \ldots \ldots 68$ & 71 & $2,834.16$ & $3,655.92$ \\
\hline Hope Creek $1 \ldots \ldots \ldots .699$ & 69 & $3,237.37$ & $3,520.15$ \\
\hline clinton $1 \ldots \ldots \ldots \ldots 70$ & 68 & $3,267.94$ & $3,370.85$ \\
\hline River Bend $1 \ldots \ldots \ldots \ldots 71$ & 70 & $3,290.52$ & $3,574.82$ \\
\hline Shearon Harris $1 \ldots \ldots 72$ & 72 & $3,338.68$ & $3,790.30$ \\
\hline Nine Mile Point $2 \ldots .73$ & 74 & $3,610.08$ & $4,640.58$ \\
\hline Beaver valley $2 \ldots \ldots \ldots 74$ & 73 & $3,697.10$ & $4,160.86$ \\
\hline Shoreham .......... 75 & 75 & $3,792.10$ & $5,159.76$ \\
\hline
\end{tabular}

Source: Computations based on data from Energy Information Administration, Form EIA-254, "Semiannual Progress Report on Status of Reactor Construction," and predecessor survey forms. 


\section{Analysis of Realized Investment Costs and Lead-Times}

This chapter discusses the empirical analysis of cost and lead-time data for the sample of plants described in the previous chapter. The next chapter examines the estimated costs and lead-times at different points in the construction period.

\section{Issues Affecting the Analysis of Realized Costs and Lead-Times}

Two major sets of issues are relevant for this kind of analysis. The first pertains to the definition and measurement of variables used in the analysis, as discussed in some detail in the previous chapter. The second set of issues is analytical in nature. To some extent, these issues arise from the level of detail that is reasonable in a statistical cost analysis. In particular, as a policy issue, it is important to know to what degree increases in either costs or lead-times are caused by externally imposed regulatory changes or internal management factors. However, management factors and unit-specific regulatory impacts are mostly unobservable, and some persuasive arguments exist as to why the influences of both are reflected in the effects of the variables available for empirical analysis. For example, in the analysis reported below, the time variable is statistically indistinguishable from any of several regulatory variables. This is due to the high correlation between the number of implemented regulations and time. Similarly, management factors may be closely related to the constructor's experience in building nuclear plants. Other variables also measure the effects of more than one factor. Size, for example, may be an indicator of both the amount of difficulty and/or the frequency of events associated with the compliance with regulatory changes that the constructor encounters, as well as any engineering economies of scale. The above problem may also occur in the analysis of lead-times. It is possible that longer lead-times give rise to, or are the result of, more incidents of changes due to the regulatory environment and decreased ability of the construction managers to coordinate, schedule, and plan efficiently.

There is much theoretical and some empirical evidence for important effects of learning both in the industry as a whole and by individual firms. Unfortunately, given any amount of construction at all, industry experience necessarily increases with time. This makes it difficult to distinguish experience from the time variable, which also reflects regulatory changes. Furthermore, evidence from detailed case studies suggests that, for the sample of plants studied, industry learning has been dampened by the specialized nature of each plant design. 1 Although all nuclear units in the sample use light-water reactor technology, plant designs may differ sufficiently to hinder the transfer of industry learning from one design to another. Lastly, as one study has noted, learning-by-doing effects may be reflected mainly in the stage at which components are manufactured. ${ }^{2}$ If this is true, then the learning

1 For a summary of research on the effects of learning on costs, see Martin B. Zimmerman, "Learning Effects and the Commercialization of New Energy Technologies: The Case of Nuclear Power," Bell Journal of Economics and Management Science (Autumn 1982). For issues relating to the discussion of industry learning and plant design, see United Engineers and Constructors, Nuclear Power Plant Cost Drivers, report prepared for the U.S. Department of Energy (July 1983).

${ }^{2}$ Paul Joskow and Nancy Rose, "The Effects of Technological Change, Experience, and Environmental Regulations on the Construction Cost of Coal-Burning Generating Units," Rand Journal of Economics (Spring 1985), pp. 1-27. 
effects should be reflected in either the input price changes or the manufacturers' profits. In either case, the effects would not be detected by the analysis because changes in input prices have been removed from the variable used to measure construction costs. Furthermore, the component manufacturers' profits are beyond the scope of this study.

A final analytical issue involves two alternative perspectives of the construction process -- the "bottoms-up" perspective and the socioeconomic perspective. 3 This issue is important because it dictates which variables will be included in the analysis and which will not. The "bottoms-up" perspective suggests that the construction process is influenced primarily by the physical parameters of the designed plant or unit. The size of the plant, the type of cooling, and whether the unit is a pressurized-water reactor or a boiling-water reactor are examples of some of these characteristics. 4 Costs and lead-times would be determined by the physical relationships implied by these variables. Regulations and learning would be included in the model to the extent that changes in their levels signal changes in the amounts of labor, materials, and equipment used to build the plant. These changes, however, would be based on an engineering estimate of the typical effect for each plant design, rather than a separate empirical analysis of learning phenomena or regulatory trends.

The socioeconomic perspective augments the "bottoms-up" approach with information on social and economic variables in order to reflect behavioral influences on the costs and lead-times. This includes information on the management of the project, the work force, the economic environment, and so on. The socioeconomic approach recognizes such influences as the incentives to the construction process embedded in the contract design, the difference in productivity due to the size or complexity of the tasks, and some notion of a learning process that reflects changes in experience and/or the uncertainties of the process. Perhaps the most significant difference between the extreme "bottoms-up" perspective and the socioeconomic perspective is the former's exclusion of influences that are not plant-specific at all but derived from the general conditions of demand and supply for new generating power in the market. For example, lead-time estimates should allow for the possibility of shortages in the supply of necessary components and/or skilled labor. These variables may be affected by the number of other nuclear plants being built at the time. As another example, it has been suggested that utilities may deliberately alter the speed of the construction process on the basis of the value of the plant to the system, i.e., the demand for the new capacity. This claim implies that utilities do not necessarily follow the construction process that would minimize the construction costs of the plant but, rather, may attempt to respond to financial and demand conditions in order to maximize the value of the plant. In the engineering process perspective, estimates of realized costs are not structured to incorporate the market conditions for the plant.

$3_{\text {A }}$ "bottoms-up" approach takes prices and quantities at a very detailed level and computes costs at that level. Total costs are derived by simple addition. This approach is used in many engineering process models.

${ }^{4}$ For a description of pressurized-water and boiling-water reactor designs, see Energy Information Administration, Projected Cost of Electricity From Nuclear and Coal-Fired Power Plants, Vol. 2, DOE/EIA-0356/2 (Washington, D.C., November 1982). 


\section{Analysis of Actual Construction Costs and Lead-Times}

Construction costs and "lead-times" were analyzed by using multiple regression analysis. 5 This statistical tool permits an examination of the variation in a dependent variable associated with a variation in an explanatory variable. The resulting coefficients and their statistics are direct measures of the effects of varying one of the explanatory variables while holding all others constant, and they provide information about the statistical variability of the estimate. For example, suppose that unit size is one of the determinants of cost and thus is to be included in the regression analysis. If the resulting regression coefficient associated with the size variable is 2 , a 1-kilowatt variation in size will be associated with a $\$ 2$ variation in costs, holding all other factors constant. The adjusted $\mathrm{R}$-squared statistic also gives an overall indication of how well the variation in the dependent variable is "explained" by the variables in the model. 6 Regression analysis can be used to demonstrate a statistical relationship between the dependent and explanatory variables, but causal assertions must be made on the basis of the conceptual model that underlies the selection of explanatory variables.

The basic model used to explain construction costs was similar to those used in prior research. (Appendix B reviews research on this issue.) Costs were expected to vary with such variables as the size of the unit, the region of the country where the unit was constructed, whether or not a natural cooling system was used, whether it was the first or only unit at a site, the construction "lead-time," the date of construction start, the experience of the constructor, and whether the utility did its own construction or used an outside contractor. Thus, the regression equation is represented by the following:

$$
\begin{aligned}
\ln (\cos t s / k W)= & \ln (\text { size })+\text { RWNW }+ \text { RS + COOL + FIRST } \\
& +\ln (\text { lead-time })+\operatorname{CONSTRT}+\text { BUILD }+\operatorname{CST} 1+\operatorname{INTER}+e,
\end{aligned}
$$

where: In (costs $/ \mathrm{kW})$ is the natural logarithm of the overnight construction costs in 1982 dollars per unit of net electrical output of the plant;

In(size) is the natural logarithm of the net electrical output of the unit;

In(lead-time) is the natural logarithm of the actual lead-time (lead-time is defined as the difference between the date of commercial operation and the start of construction);

5 In this report, lead-time is usually used as a surrogate for a number of unobservable variables. The term "lead-time" is sometimes enclosed in quotation marks to emphasize the fact that lead-times are being used as a proxy for other factors.

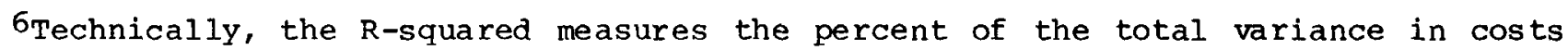
explained by the regression. An R-squared value of 1 would indicate that all of the variance in costs was explained by the regression; a value of 0 would indicate that none of the variance was explained by the regression. 
RWNW is a binary variable 7 taking on the value of 1 if the unit is located in the West or Northwest region, 0 otherwise;

RS is a binary variable taking on the value of 1 if the plant is located in the South or Southwest region, 0 otherwise;

COOL is a binary variable that is 1 when a natural cooling system is used, 0 otherwise;

FIRST is a binary variable that is 1 when the unit is a first or a single unit, 0 otherwise;

CONSTRT is the day construction started;

BUILD is a binary variable that is 1 when the utility is the constructor, 0 otherwise;

CST1 is the constructor's experience variable (denoted as the "Experience of External Contractor" variable in the tables);

INTER is the interactive term between BUILD and CST1 (denoted as the "Experience of Utility That Acts as Its Own Construction Manager" variable in the tables; and

e is an error term.

The calculation of the overnight costs in 1982 dollars was outlined in the previous chapter. Sources for the other variables and the means of all the variables are given in Appendix $C$.

As with the construction costs, the "lead-time" analysis focused on the same 67 nuclear units that entered construction between the late 1960's and the mid-1970's and were due to be completed by the end of 1985, plus 3 additional ones. (These 3 additional units were ones that were scheduled to become operstional by the end of 1985 but did not have sufficient cost data.) The basic model that was used to examine the lead-time variable was:

$$
\begin{aligned}
\ln (\text { lead-time })= & \ln (\text { size })+\text { RNEMW }+ \text { RS + COOL + FIRST } \\
& + \text { CONSTRT }+ \text { BUILD + CST } 1+\text { INTER + e }
\end{aligned}
$$

where: In(lead-time) is the natural logarithm of the lead-time variable;

In(size) is the natural logarithm of the size variable;

${ }^{7} \mathrm{~A}$ binary or dummy variable is used to capture the effects of qualitative variables, such as regional location. The coefficient associated with a binary variable represents the difference in costs associated with the qualitative factor. Thus, the coefficient associated with the South/Southwest binary variable represents the difference between the costs of plants located in those regions and the costs of plants in the North and Midwest regions, with all other factors held constant (see Appendix $D$ for more details). 
RNEMW is the binary variable for the Northeast and Midwest regions;

RS is the binary variable for the south and Southwest regions; and

all other variables are as defined in the cost equation.

The results for the 67 units that were used in the cost analysis and the 70 units that were used in the lead-time analysis are presented below. A similar analysis of lead-times was undertaken, using the same 67 units. This was followed by an analysis in which the data set was disaggregated into different groups. These groups were determined by four characteristics that were of special interest in view of recent debates about the technology. Each grouping was examined for significant differences in the effects of the explanatory variables. The four different groupings used were as follows:

- Size. Two groups were extracted from the larger sample, where size was either greater than or less than 850 megawatts-electric (MWe).

- Commercial Operation Date. Two groups were identified, with commercial operation dates before and after January 1, 1979.

- Construction Start Date. Two groups were identified, with construction start dates before and after January 1, 1970.

- Construction Start Date. Two groups were identified, with construction start dates before and after January 1, 1972.

The size grouping is of interest because of the claim that small plants are somehow different from large ones. Because all of the other studies of this problem used a sample of units that became operational before 1980, the second grouping was chosen to determine whether there were any "differences" in the sample of plants used by other analysts and those used in the present study. Finally, a major study of construction lead-times has indicated that lead-times were falling for units begun after 1972. The third and fourth groups were used to test the results of that study. 8

The chapter concludes with an analysis of the time-related costs, as described in the previous chapter. As stated previously, the time-related costs are those that result from changes in input prices during the construction period, or from financial charges associated with annual construction expenditures.

8The importance of differentiating between scale economies for plants of different size is discussed in Paul Joskow and Nancy Rose, "The Effects of Technological Change, Experience, and Environmental Regulations on the Construction Cost of CoalBurning Generating Units," Rand Journal of Economics (Spring 1985), pp. 1-27. See also Electric Power Research Institute, An Analysis of Power Plant Construction Lead Times, Volume I, EPRI-EA-2880 (Palo Alto, California, 1983), for a discussion of the importance of differentiating between units that entered construction before and after 1970 and 1972 . 


\section{Analysis of Construction Costs and Lead-Times Using the Complete Data Set}

Table 5 presents the results of the regression analysis for the 67 units in the sample for construction costs. All the equations were estimated using ordinary least squares. (Appendix D discusses the associated econometric issues.) The regression analysis explained 83 percent of the "variation" in construction costs. Table 6 presents comparable information for the "lead-time" equation, and Table 7 presents the results of the "lead-time" analysis using the 67 units that were examined in the cost analysis. The explanatory variables and their implications for costs and lead-times are discussed in more detail below.

\section{Effects of Time-Related Factors on Real Overnight Costs}

Most of the recent studies of nuclear power construction costs include some analysis of the construction leadtimes. 9 Lead-times are usually associated with the time-related costs, for obvious reasons. However, there is also a need to examine the effect of "lead-time" on overnight costs, where the influence is much more subtle.

The first question to be addressed is how the construction duration affects the overnight costs. Presumably, if it takes two workers to complete a task in one day, then one worker could complete the task in two days. This relationship implicitly assumes that the output per worker per time period is constant, so that only the number of workers per time period varies with the number of time periods allocated to the task. Thus, with a constant price per laborer, the real overnight costs should be unaffected by an increase in the time needed to complete a task when it occurs with a corresponding decrease in the number of workers per time period.

Further reflection, however, suggests that there are other considerations which might cast considerable doubt on the validity of this simple description of leadtime and labor requirements. In order to appreciate these considerations, it is useful to recognize that construction duration can be used as a surrogate for unobservable infiuences on costs that are correlated with the time required to build a plant. Thus, the construction duration measures the effects of unobservable factors on costs that occur over the construction period, similar to the way that the size variable represents engineering and financial influences that are related to variation in the design size.

In particular, there are four unobservable factors correlated with the construction duration ("lead-time") that, conceptually, might affect costs. First, the assumption of a constant price per laborer implies that the firm can hire any number of laborers in each time period. This is probably not true where construction labor is scarce, so that higher prices must be offered to attract more workers per time period. Consequently, the total cost, given a decrease in the lead-time, should also rise. This will be called the "speedup" effect. 10 The converse of this effect is that as the lead-time is lengthened, total costs fall.

${ }^{9}$ See, for example, United Engineers and Constructors, Inc., Advanced Engineering Department, Nuclear Powerplant Cost Drivers (Philadelphia, Pennsylvania, July 1983). The inclusion of lead-time as an explanatory variable raises the issue of multicollinearity, since lead-time was also a function of the other explanatory variable. As discussed in Appendix D, the collinearity between lead-time and the other explanatory variables does not cause serious problems.

$10_{\mathrm{A}}$ good example of the speedup effect is River Bend, which had a short lead-time but was also expensive. 
Table 5. Results of Regression Analysis of Real Overnight Construction Costs

\begin{tabular}{|c|c|c|}
\hline Variable & $\begin{array}{l}\text { Regression } \\
\text { Coefficient }\end{array}$ & $\begin{array}{l}\text { Standard } \\
\text { Errora }\end{array}$ \\
\hline Intercept $\ldots \ldots \ldots \ldots \ldots \ldots \ldots \ldots \ldots$ & 0.065 & 1.27 \\
\hline Log of Net Megawatts $\ldots \ldots \ldots \ldots \ldots \ldots$ & -0.569 & $0.19 *$ \\
\hline $\begin{array}{l}\text { Binary Variable for Plant Being } \\
\text { Located in South or Southwest ......... }\end{array}$ & -0.106 & $0.05 *$ \\
\hline $\begin{array}{l}\text { Binary Variable for Plant } \\
\text { Being Located in west ............. }\end{array}$ & 0.115 & 0.09 \\
\hline $\begin{array}{l}\text { Binary Variable for Use } \\
\text { of Cooling Towers } \ldots \ldots \ldots \ldots \ldots \ldots \ldots\end{array}$ & 0.094 & 0.07 \\
\hline $\begin{array}{l}\text { Binary Variable for Plant Being } \\
\text { Single Unit or First of Multi-Unit .... }\end{array}$ & 0.346 & $0.06 *$ \\
\hline Date of Construction start ${ }^{b} \ldots \ldots \ldots \ldots$ & 0.240 & $0.03 *$ \\
\hline Log of Actual Lead-Time ............ & 1.210 & $0.12 *$ \\
\hline $\begin{array}{l}\text { Experience of Utility That Acts } \\
\text { as Its Own Construction Manager } \ldots . . .\end{array}$ & 8.155 & $3.16 *$ \\
\hline Experience of External Contractor ${ }^{d}$.... & -1.776 & 1.22 \\
\hline $\begin{array}{l}\text { Binary Variable for Plant Being } \\
\text { Constructed by Utility ............. }\end{array}$ & -0.422 & $0.11 *$ \\
\hline Adjusted $\mathrm{R}-$ squared $\ldots \ldots \ldots \ldots \ldots \ldots$ & 0.831 & -- \\
\hline
\end{tabular}

$a_{A n}$ asterisk indicates that the coefficient is significantly different from zero at a 0.95 level of confidence, using a two-tailed test of significance.

bcoeficient and standard error multiplied by 1,000.

CThis is the coefficient associated with the interaction term between the binary variable for utilities that act as their own construction managers and the experience variable (denoted as INTER in the equations presented in the text). This coefficient would measure the difference in the regression coefficients associated with experience for those utilities that act as their own construction managers and those that employ outside contractors.

$\mathrm{d}_{\text {This }}$ is the coefficient associated with the contractor's experience variable (denoted as CST1 in the equations presented in the text). It can be interpreted as the regression coefficient associated with the experience variable for those utilities that employ outside contractors.

Source: Computations based on data from Energy Information Administration, Form EIA-254, "Semiannual Progress Report on Status of Reactor Construction," and predecessor survey forms. 
Table 6. Results of Regression Analysis of Lead-Times, Using a Sample of 70 Units

\begin{tabular}{|c|c|c|}
\hline Variable & $\begin{array}{l}\text { Regression } \\
\text { Coefficient }\end{array}$ & $\begin{array}{c}\text { Standard } \\
\text { Error } \\
\end{array}$ \\
\hline Intercept $\ldots \ldots \ldots \ldots \ldots \ldots \ldots \ldots \ldots$ & 2.887 & $1.32 *$ \\
\hline Log of Net Megawatts $\ldots \ldots \ldots \ldots \ldots \ldots$ & 0.732 & $0.19 *$ \\
\hline $\begin{array}{l}\text { Binary Variable for Plant Being } \\
\text { Located in East of Midwest } \ldots \ldots \ldots \ldots \text {. }\end{array}$ & 0.019 & 0.10 \\
\hline $\begin{array}{l}\text { Binary Variable for Plant Being } \\
\text { Located in South or Southwest } \ldots \ldots \ldots\end{array}$ & 0.015 & 0.10 \\
\hline $\begin{array}{l}\text { Binary Variable for Use } \\
\text { of Cooling Towers } \ldots \ldots \ldots \ldots \ldots \ldots \ldots \ldots\end{array}$ & 0.013 & 0.07 \\
\hline $\begin{array}{l}\text { Binary Variable for Plant Being } \\
\text { Single Unit or First of Multi-Unit .... }\end{array}$ & -0.040 & 0.06 \\
\hline $\begin{array}{l}\text { Binary Variable for Plant Being } \\
\text { Constructed by Utility } \ldots \ldots \ldots \ldots \ldots\end{array}$ & 0.132 & 0.15 \\
\hline Date of Construction start ${ }^{b} \ldots \ldots \ldots$.... & 0.041 & 0.03 \\
\hline Experience of External Contractor ${ }^{c}$.... & 0.106 & 0.28 \\
\hline $\begin{array}{l}\text { Experience of Utility That Acts } \\
\text { as Its Own Construction Manager }{ }^{d} \ldots \ldots\end{array}$ & -0.381 & 0.65 \\
\hline Adjusted $R-$-Squared $\ldots \ldots \ldots \ldots \ldots \ldots$ & 0.298 & -- \\
\hline 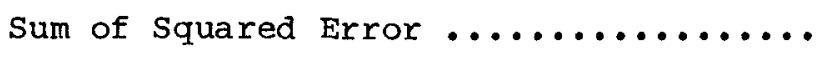 & 3.622 & -- \\
\hline
\end{tabular}

an asterisk indicates that the coefficient is significantly different from zero at a 0.95 level of confidence, using a two-tailed test of significance. Three additional units with estimated completion dates in 1985 that did not have usable cost data were included.

bCoefficient and standard error multiplied by 1,000 .

$c_{\text {This }}$ is the coefficient associated with the contractor's experience variable (denoted as CST1 in the equations presented in the text). It can be interpreted as the regression coefficient associated with the experience variable for those utilities that employ outside contractors.

$d_{T h i s}$ is the coefficient associated with the interaction term between the binary variable for utilities that act as their own construction managers and the experience variable (denoted as INTER in the equations presented in the text). This coefficient would measure the difference in the regression coefficients associated with experience for those utilities that act as their own construction managers and those that employ outside contractors.

Source: Computations based on data from Energy Information Administration, Form EIA-254, "Semiannual Progress Report on Status of Reactor Construction," and predecessor survey forms. 
Table 7. Results of Regression Analysis of Lead-Times, Using a Sample of 67 Units

\begin{tabular}{|c|c|c|}
\hline Variable & $\begin{array}{l}\text { Regression } \\
\text { Coefficient }\end{array}$ & $\begin{array}{l}\text { Standard } \\
\text { Errora } \\
\end{array}$ \\
\hline Intercept $\ldots \ldots \ldots \ldots \ldots \ldots \ldots \ldots$ & 3.035 & $1.38 *$ \\
\hline Log of Net Megawatts .............. & 0.716 & $0.20 *$ \\
\hline $\begin{array}{l}\text { Binary Variable for Plant Being } \\
\text { Located in East or Midwest ........... }\end{array}$ & 0.009 & 0.11 \\
\hline $\begin{array}{l}\text { Binary Variable for Plant Being } \\
\text { Located in South or Southwest } \ldots \ldots \ldots \text {..... }\end{array}$ & 0.005 & 0.11 \\
\hline $\begin{array}{l}\text { Binary Variable for Use } \\
\text { of Cooling Towers } \ldots \ldots \ldots \ldots \ldots \ldots \ldots\end{array}$ & 0.022 & 0.08 \\
\hline $\begin{array}{l}\text { Binary Variable for Plant Being } \\
\text { Single Unit or First of Multi-Unit .... }\end{array}$ & 0.047 & 0.07 \\
\hline $\begin{array}{l}\text { Binary Variable for Plant Being } \\
\text { Constructed by Utility ............ }\end{array}$ & 0.130 & 0.16 \\
\hline 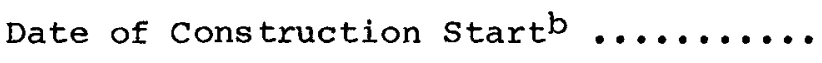 & 0.035 & 0.03 \\
\hline Experience of External Contractor ${ }^{C} \ldots$ & 0.020 & 0.32 \\
\hline $\begin{array}{l}\text { Experience of Utility That Acts } \\
\text { as Its Own Construction Managerd ...... }\end{array}$ & -0.335 & 0.67 \\
\hline 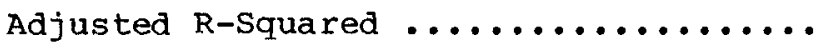 & 0.273 & -- \\
\hline
\end{tabular}

an asterisk indicates that the coefficient is significantly different from zero at a 0.95 level of confidence, using a two-tailed test of significance.

b Coefficient and standard error multiplied by 1,000.

$c_{\text {This }}$ is the coefficient associated with the contractor's experience variable (denoted as CST1 in the equations presented in the text). It can be interpreted as the regression coefficient associated with the experience variable for those utilities that employ outside contractors.

dThis is the coefficient associated with the interaction term between the binary variable for utilities that act as their own construction managers and the experience variable (denoted as INTER in the equations presented in the text). This coefficient would measure the difference in the regression coefficients associated with experience for those utilities that act as their own construction managers and those that. employ outside contractors.

Source: Computations based on data from Energy Information Administration, Form EIA-254, "Semiannual Progress Report on Status of Reactor Construction," and predecessor survey forms. 
Second, even when workers are not scarce, an increase in the lead-time may mean that workers will have to be released for part of the time and then rehired. Given that there are any fixed costs associated with the release and rehire of workers, total costs will increase when these activities are necessary. Even if the workers are not released and rehired, there will be additional costs of keeping idle workers during the interim periods when their skills are not required. This effect would suggest that, as lead-times increase, total costs would also increase.

Another potential consequence of continually stretching out the lead-time is lower worker and management morale. This effect has been associated with lower productivity, suggesting that there is a positive correlation between the time needed to construct a plant and costs. Recent research by Chaim Braun of the Electric Power Research Institute (EPRI) has identified the morale problem associated with plants that are continually delayed as an underlying cause of the divergence between the U.S. and French experience with nuclear power. 11

Finally, there is a regulatory effect of increased lead-times. In an environment in which regulations are changing over time, longer lead-times will imply a greater likelihood that changes associated with new or revised regulations will be required for the unit under construction. This may also lead to more reworking of completed work, which can add to the managerial and productivity problems already present from simply dragging out the project.

Given an increase in the planned lead-time to construct a nuclear unit, savings from "the speedup effect" (or, more accurately, from the converse of "the speedup effect") are likely to be more than balanced by increased costs due to the second, third, and fourth effects. Thus, the net result should be an overall increase in cost per unit of output, especially for a project that undergoes chronic delays.

The results reported in Table 5 indicate that, indeed, increases in "lead-time" are associated with higher real overnight costs. In particular, the results indicate that a 1 percent increase in "lead-time" was associated with an increase of 1.2 percent in the real overnight costs. Detailed case studies would be needed to determine whether the effects of "lead-time" on the real overnight costs were due to regulation-induced cost escalation, time-related diseconomies, or managerial factors. The best that can be concluded from the statistical analysis is that the net effect of all three factors is substantial.

Size of the Unit

The size of a nuclear plant or unit is measured in terms of its net electrical capacity. The relationship between cost and size has important implications for the historical evaluation of nuclear investments. In the past, engineering process approaches have assumed that capital costs per unit of output fall as the size of the unit increases. The basis for this assumption arises from technical relationships inherent in particular plant components. However, these relationships ignore the human aspects of plant construction. While they recognize physical economies of scale, they ignore what economists have labeled "diseconomies of scale." These diseconomies arise from the increased complexity, lower morale, and greater management requirements of a large-scale project in relation to a smaller

${ }^{11}$ Chaim Braun et al., "Comparative Review of U.S. and French Powerplant Construction Projects," paper presented at the ANS/ENS International Conference (Washington, D.C., November 1984). 
one. Obviously, both types of scale effects may be present when they are averaged over all the units. This fact suggests that unit costs may fall with increasing size until a certain size is reached, after which unit costs will increase. An important question for appropriate investment planning is whether the average size of the current generation of nuclear power plants is beyond the cost-minimizing point.

The effect of the size variable on construction costs is interesting in light of expected economies of scale predicted by engineering process approaches. In the regression equations used in the present study, holding all else constant, a 1 percent increase in the size of a plant would lower the cost per kilowatt by about 0.6 percent. In fact, results from many engineering models indicate a reduction of around 0.5 percent for a 1 percent increase in size, 12 which is not statistically different from the above results. However, it should be noted that this result is based on the premise that all other variables are unchanged -- most importantly, that lead-time is constant.

Only the size variable and the intercept term appear to have significant effects on the construction "lead-time" for this sample of plants. A 1.0 percent increase in the size of the unit implies that the time necessary to construct it will grow by 0.7 percent (Table 6 ). It is interesting to note that the other variables are not significant in the relationship. A similar result was obtained for units that were completed before 1977 .

As mentioned, the correlation between "lead-time" and size may indicate diseconomies that appear because the construction of large plants is more difficult to manage, productivity is lower, or regulatory scrutiny is stricter. It may also indicate that larger plants are more likely to be deliberately delayed due to considerations of excess capacity. A separate measure of changes in the expected need for a plant would have contributed to the understanding of this influence. Unfortunately, no such measure was available for the majority of plants in our sample.13

When the smaller sample of 67 plants is used in the lead-time analysis, the results are very similar to those for the initial data set (Table 7). The effect of the size variable decreases slightly, but the hypothesis that the set of estimated coefficients is the same when the three later plants are added cannot be rejected.

The analysis therefore indicates that, if "lead-time" were not related to size, a 1 percent increase in size would be associated with a reduction of 0.6 percent in real overnight costs. The same 1 percent increase in size, however, is also associated with an increase of 0.7 percent in "lead-time," which in turn is associated with an 0.85 percent increase in costs $(0.7$ percent multiplied by the 1.2 percent increase in costs due to the 1 percent increase in "lead-time"). Thus, this secondary effect of size that works through "lead-time" more than offsets the reduction in

12 See H.I. Bowers, L.C. Fuller, and M.L. Myers, Trends in Nuclear Power Plant Capital Investment Cost Estimates -- 1976 to 1982, ORNL/TM-8898 (Oak Ridge National Laboratory, Oak Ridge, Tennessee, 1983).

${ }^{13}$ Such a measure has been investigated for a limited number of plants in a report by the Electric Power Research Institute, An Analysis of Power Plant Construction Leadtimes, Volume I, EPRI-EA-2880 (Palo Alto, California, 1983). 
costs that would be observed if "lead-time" were constant. In short, when the effects of time-related managerial factors and regulatory changes are considered, the negative relationship between size and unit costs disappears.

Regional Differences To identify variations that arise from regional differences, a set of regional indicators were used in the model. These indicators serve to reflect three aspects of plant construction that might lead to either cost or "leadtime" variations. First, regional values of the Handy-Whitman Index were used in the deflation process. Although costs have been deflated for regional input price increases, no correction has been made for possible differences in absolute price levels in different regions. Thus, an area that has a high cost of labor can be expected to have high construction costs per kilowatt, all else being the same.

Regions may also differ in terms of local or state regulatory environments. These differences have been linked to different regulatory attitudes toward the financial consequences of electrical utilities' activities. Different regulatory attitudes may underlie variations in the incentives faced by utility managers. For example, the allowance of construction work in progress (CWIP) in the rate base before the plant goes into operation has been cited as both an impediment and an incentive to lower costs and "lead-times." similarly, different regional attitudes toward excess capacity may influence the deliberate delays tolerated by the utility management. Unfortunately, because many of these effects lead to ambiguous results, it is difficult to formulate particular hypotheses about net regional effects.

The final regional difference which may affect the construction process arises from differences in the relative costs of available energy sources. In regions where alternative energy sources are expensive, higher cost nuclear units will be viable investment choices. In regions where the alternatives are inexpensive, nuclear units that are selected should be, at least initially, at the lower end of the cost range for all nuclear units. Of course, these expectations may not be realized in the actual construction process. Related to this issue is the value of the plant to the utility. As mentioned above, utilities may deliberately adjust the "lead-time" of units under construction depending on the perceived value of such investments. Where the plant will be displacing expensive power, it can be expected to have a higher value to the constructing utility.

It should be noted that the major regional effects on the cost relationship resulted from differences in labor costs. In the lead-time analysis, the demand situation facing the utility probably was the underlying cause of regional variations. To account for the major implications of both labor costs and demand factors, a distinction was made between units in the Northeast/Midwest, South/Southwest, and West/ Northwest regions. It is, however, quite possible that the regions have been defined too broadly to capture the effects of electricity demand on "lead-time."14

14 When the average wage rate in the cities surrounding the plant was used instead of regional binary variables, the results were the same as those presented here. A binary variable taking on the value of 1 if any CWIP was allowed in the rate base was also included in the lead-time analysis. However, the coefficient of this variable was insignificant. Finally, an attempt was made to obtain data on expected demand growth relative to capacity, which would be used to capture the effect of demand considerations on lead-times; however, we were unable to obtain such data for the complete sample of plants. 
With respect to regional cost variations, plants located in the South/Southwest region were found to have 10 percent lower real overnight costs than those in the Northeast/Midwest region (Table 5).15 These results apply to plants that have similar characteristics, in particular, the same "lead-time." Thus, the effects are probably due to real differences in the cost of inputs, especially labor. Regional effects that result from deliberate delays because of demand changes would be reflected in the lead-time variable. However, the regional coefficients in the lead-time equation are not significantly different from zero. This is not to say that demand changes do not influence "lead-times"; however, the effects cannot be distinguished on a regional basis. In short, although regional differences in costs were found, no such differences in lead-times were observed.

Cooling Towers The use of mechanical cooling towers has been claimed to lead to an increase in both the cost and "lead-time" of nuclear units. One reason underlying this argument is the increased environmental stringency applied to units that use these towers. Initially, an indicator variable for the presence of mechanical cooling towers was used, but no evidence of an effect on costs or lead-times could be found. Subsequently, it seemed reasonable that both mechanical towers and other artificial cooling structures might impose similar pressures on the construction process. Therefore, a cooling indicator was used that distinguished natural cooling systems (e.g., an ocean, a river, or an existing lake) from those that had to be constructed specifically for the nuclear unit or units. As can be seen from Tables 5, 6 , and 7 , this change in the definition of the cooling variable failed to alter the original result $-i . e .$, that the effect is not significantly different from zero for both construction cost and "lead-time."

First Unit at a Site In most studies, the fact that a unit is the first unit at a site has been regarded as significant because of the way in which utilities allocate the common costs for multi-unit sites. As was noted in chapter 2, because of the way utilities are regulated, there is a financial incentive to allocate a disproportionate share of the common costs to the first unit, and thus to obtain earlier treatment of these costs in the rate base. Similarly, this incentive may act to "hurry" the construction of the first unit, in order to relieve the financial pressures on the utility.

The experience of constructing the first unit of a multi-unit plant will be of benefit to a utility, reducing the cost of the second unit. Both of these arguments imply that the first unit of a multi-unit plant would be the most expensive. Furthermore, the learning effect implies that the second unit of a multi-unit plant would cost less to build than a single unit would, if all other factors were held constant.

The results are consistent with the hypothesis that a single unit or the first unit of a multi-unit plant costs more per kilowatt than subsequent units. On average, the first unit has 41 percent greater real overnight costs associated with it (Table 5). While some of this difference is probably due to learning, some of the effect may simply be due to accounting practices.

Construction Start Date One of the more controversial issues related to nuclear plant construction is the effect of regulatory changes over time. Unfortunately,

15 This was derived by raising the coefficient associated with the South binary variable to the "e" power. 
there is no direct measure of regulatory changes as they are embodied in the aggregate cost data used in this study. Thus, a proxy variable must be used to detect the influence of changing regulatory requirements. Several variables have been used in other research, all of which are highly correlated with a time trend. This is because cumulative regulatory requirements have been increasing over time. other studies have used two variables that supposedly measure the effects of regulation -cumulative capacity and a regulatory index. When they were included in the regressions, neither of these variables performed better than a simple time trend variable.16 For this reason, the date of construction start was used as a proxy for the regulatory environment when construction on the plant began. As was discussed above, the inclusion of the lead-time variables captures, in part, the effects of changes in regulations during the construction period.

Two other influences that may be reflected in the time variable are related to changes in productivity. On one hand, some authors have referred to a general decline in construction productivity during the 1970's.17 On the other hand, industry experience with nuclear plant construction was definitely increasing at a rapid rate during this time. If significant "learning-by-doing" effects were present because of the additional experience, then they may have compensated for the poor productivity effects and/or increased the ability of the utilities to manage the changes in regulatory requirements. The net effect of the two influences may either increase or decrease the impact of regulations on "lead-time," depending on the magnitude of each influence. A separate measure of the learning effects would have been ideal, but because of the severe correlation with time, it was impossible to distinguish between regulatory and learning effects.

The results presented in Table 5 suggest that the date of construction start is significant in the cost relationship. For two similar plants, the one that started 1 year after the other would cost 9.2 percent more per unit of net electrical capacity. 18 After 2 years, it would cost 19.2 percent more than the first plant, and after 3 years 30.1 percent more.

A surprising result is that the effect of the construction start date variable on the construction "lead-time" is not significantly different from zero. As noted, this is a proxy for requlatory requirements, industry learning, and the general reduction in productivity over time. The results suggest that these three influences may be balanced in the realized "lead-times." Nearly all prior analyses found a positive relationship between the time trend variable and construction lead-times.19 (Again, see Appendix $B$ for a review of the literature.)

16 Appendix $B$ discusses this issue in detail.

17 See, for example, Paul Joskow and Nancy Rose, "The Effects of Technological. Change, Experience, and Envi ronmental Regulations on the Construction Cost of CoalBurning Generating Units," Rand Journal of Economics (Spring 1985), pp. 1-27.

${ }^{18}$ The regression coefficient associated with the construction start date is actually a daily escalation rate, since the day of construction start was used. The daily escalation rate would be 0.0240 percent. The daily compounded annual escalation rate is 9.2 percent per year.

${ }^{19}$ As noted in Chapter 2 , by excluding plants that were not yet complete, many units with long lead-times were excluded from the sample. When the sample was enlarged, the time coefficient became significant. Since the actual lead-times for the incomplete units excluded from the original sample are likely to be equal to or higher than the current reported estimates, this result may be an artifact of the sample. 


\section{Experience of the Constructor}

from the statistical problems of the cumulative industry experience was the experience of the construction firm. A variable reflecting the cumulative experience of each constructor was included in the analysis to test for learning about the construction process and learning about cost and "lead-time" estimates. Three measures of cumulative experience were tried in the definition of the experience variable. One measure, used in other studies, is simply the number of completed reactors. This measure, of course, takes no account of learning during the construction period. To incorporate such effects, two other measures were used. One of these measures reflects the cumulative number of reactor construction years, i.e., the number of reactors under construction or completed, multiplied by the number of years during which such activity took place. The third measure represents a simple summation of the percent complete to date for reactors under construction at various points in time. That is, a reactor that is 10 percent complete would correspond to an experience value of 0.1 , another that is 20 percent complete 0.2 , and so on. Cumulative experience was computed by simply summing $0.1,0.2$, and so on.

In each case, the experience measure was converted into a continuous variable (CST1), between zero and one, by a formula used by other researchers:

\section{$\operatorname{CST} 1=1 /(1+$ cumulative experience measure $)$.}

Thus, as experience increases, the actual variable, $1 /(1$ + cumulative experience), will fall, and a negative (positive) relationship between experience and costs will be reflected in a positive (negative) regression coefficient associated with CST1.

Since an interaction term between the experience variable and the binary variable for utilities that act as their own construction manager is included, the coefficient associated with CST1 measures the effects of experience of external contractors on costs and lead-times. The regression coefficient associated with the experience variable, CST1, in the lead-time equation is not significant, suggesting that the experience of the external constructor did not affect the construction lead-times. A similar result was obtained in the regression analysis of costs (Table 5).

\section{Utility as Construction Manager}

Because of the focus on learning effects, a variable was included to test for a difference between utilities that managed the construction of their own nuclear plants and those that used an external constructor. Two points should be noted about the effect of the utility acting as construction manager. First, others have claimed that utilities that manage their own construction are better able to monitor and control costs and "lead-times." This effect would indicate that both "lead-times" and costs would be lower if the utility acted as the construction manager. Second, a utility that manages its own construction has access to information about the value of the plant (i.e., demand) that an external constructor either would not have or would ignore in construction decisions. In such cases, utilities that act as their own construction manager might have longer lead-times. Thus, in the case of "lead-times," these two effects might work in opposite directions.

The results of the analysis indicate that the type of management regime is significant in the cost relationship but not in the lead-time process. With all other factors held constant, utilities that built their own plants experienced costs that were 35 percent less than the costs experienced by utilities that used outside contractor managers (Table 5). This is an important result in terms of how future construction should be managed. These results are consistent with the hypothesis 
that utilities which managed their own projects were better able to control costs than were those that did not. Thus, the analysis suggests that direct management involvement in the construction process might be an important factor. 20 on the other hand, this effect is due mainly to two utilities -- Duke Power and Commonwealth Edison. The result that utilities which act as their own construction manager have lower costs may simply be due to other factors specific to these two utilities.

It is interesting to note that the effect of the utility as construction manager has been found by other analysts -- most notably, Zimmerman (see Appendix B) -- who have pointed out that the result might indicate a measure of the bias in the estimate of the experience effects because of excess profits obtained by more experienced external constructors. Zimmerman has argued that more experienced nonutility constructors can charge the same price as less experienced ones and then keep the cost savings as profits. On the other hand, utilities that do their own construction must pass the cost savings resulting from greater experience on to ratepayers in the form of a lower cost plant, since regulation prevents them from keeping the savings as profit.

\section{Effects of Experience When the Utility Acts as Construction Manager}

To identify a

further aspect of experience, a variable was included to represent both the utilities that were construction managers and their cumulative construction experience. [In Equations (1) and (2), this variable is denoted as INTER.] This allowed the effects of construction experience to vary according to the two alternative management regimes. Such a distinction was desirable to test for a difference between utilities that have built many units (e.g., Commonwealth Edison, Duke Power, and TVA) and those that have built only a single plant.

The results in Table 5 show that as experience increased, the costs incurred by utilities that acted as their own construction manager fell in relation to the costs incurred by utilities that employed an outside contractor. There is also evidence that as utilities that acted as their own construction manager gained experience, their absolute costs also fell. (The standard error for the sum of the two experience variable coefficients is 3.1.) The evidence is much stronger when experience is defined in terms of the number of completed reactors than when the number of reactor construction years is used to measure experience.

On the other hand, the regression analysis indicates that the management regime did not affect the relationship between experience and lead-times. This result indicates that, although utilities acting as their own construction manager may have been able to reap some cost benefits from a better understanding of the construction process, they did not reap these benefits by building the plants faster than their nonutility constructor counterparts.

$20_{A}$ general discussion of these issues can he found in Nuclear Regulatory Commission, Improving Quality and the Assurance of Quality in the Design and Construction of Nuclear Power Plants, NUREG-1055 (Washington, D.C., May 1984). Also, the general issue of ownership versus management has received a great deal of attention in the economics and finance literature. Included in this literature are discussions about franchising versus direct ownership of fast-food restaurants and motels. Also, the issue of the separation of management from ownership of corporations has received a great deal of attention in the finance literature. 
A few additional points can be made about the effects of the experience variables and the utility as construction manager. First, the use of a binary variable to measure the cost differences between utilities that managed their own construction and those that used an outside contractor was done by necessity. In fact, there may be a range of utility involvement in the construction management, suggesting that a continuous variable for the influence, if one could be derived, would have been a preferable measure. Second, the experience of the constructor (or the interactive term reflecting the experience of utilities that did their own construction) may not fully capture the cost savings due to experience. What may be more relevant, from an institutional perspective, is the interaction between a particular utility, constructor, architect-engineer, and vendor. It may be that particular interactions worked better than others. However, testing for even a subset of the actual combinations in the sample was precluded by the small number of observations. Lastly, to investigate experience further, the constructor's experience was replaced by the experience of the architect-engineex in the regression equation; this did not significantly alter the results.

\section{Analysis of Partial Data Sets}

Whether or not there have been major structural changes in the nuclear construction process is a matter of some debate. If such changes exist, then it is not valid to treat all of the plants as if they make up a consistent sample for analysis. To explore this possibility, the results were examined for groupings of the data set according to the criteria outlined below. Differences between the coefficients of each subset indicate that the cost or lead-time relationships differ for the two groups. This difference can be tested for statistical significance by using a chow test.

In other cases, instead of splitting the sample and performing a chow test on the results, the data were tested for break points by creating spline variables. Essentially, spline variables allow the coefficients to vary for either side of a breaking point for one variable, and make it possible to test whether the difference in the results is significant. 21 If it is, then the relationship between the dependent variable and this variable is not linear. If the difference is not significant, then the hypothesis that the underlying relationship is linear cannot be rejected.

Size Greater Than or Less Than 850 MWe.

A question of interest is whether the construction process for large units is in some way different from that for smaller ones. To investigate this issue for construction costs, two spline variables were formulated, one for plants of size less than or equal to 850 MWe and the other for plants larger than 850 MWe. Thus, two regression coefficients were associated with the variable for size -- one for plants smaller than 850 MWe and a second for plants larger than $850 \mathrm{MWe}$. In the cost equation, this amounts to testing for differences in the effects of size for the two groups (i.e., whether variations in size for units smaller than 850 MWe have effects on costs that differ from those for larger plants). Table 8 shows the results of the regression and the test for a significant difference between the two size coefficients. The test indicates that the hypothesis that the size effects are the same for the two groups cannot be rejected. It appears that size effects on costs are similar for large and for relatively smaller nuclear units.

21 See D. Suits, "The Use of a Spline Variable," Review of Economics and Statistics (December 1977), pp. 240-250. 
Table 8. Results of Regression Analysis of Real Overnight Costs, Using Two Spline Variables for Unit Size

\begin{tabular}{|c|c|c|}
\hline Variable & $\begin{array}{l}\text { Regression } \\
\text { Coefficient }\end{array}$ & $\begin{array}{c}\text { Standard } \\
\text { Errora }\end{array}$ \\
\hline Intercept $\ldots \ldots \ldots \ldots \ldots \ldots \ldots \ldots$ & 0.378 & $2.29 *$ \\
\hline $\begin{array}{l}\text { Log of Net Megawatts } \\
\text { if Less Than or Equal to } 850^{b} \ldots \ldots \ldots \text {. }\end{array}$ & -0.615 & $0.34 *$ \\
\hline $\begin{array}{l}\text { Log of Net Megawatts } \\
\text { if Greater Than } 850^{b} \ldots \ldots \ldots \ldots \ldots \ldots\end{array}$ & -0.535 & $0.28 *$ \\
\hline $\begin{array}{l}\text { Binary Variable for Plant Being } \\
\text { Located in South or Southwest ......... }\end{array}$ & -0.104 & 0.06 \\
\hline $\begin{array}{l}\text { Binary Variable for Plant Being } \\
\text { Located in West } \ldots \ldots \ldots \ldots \ldots \ldots \ldots \ldots \ldots\end{array}$ & 0.114 & 0.09 \\
\hline $\begin{array}{l}\text { Binary Variable for Use } \\
\text { of Cooling Towers } \ldots \ldots \ldots \ldots \ldots \ldots \ldots\end{array}$ & 0.095 & 0.07 \\
\hline $\begin{array}{l}\text { Binary Variable for Plant Being } \\
\text { Single Unit or First of Multi-Unit .... }\end{array}$ & 0.345 & $0.06 *$ \\
\hline Date of Construction start ${ }^{c} \ldots \ldots \ldots \ldots$ & 0.239 & $0.03 *$ \\
\hline 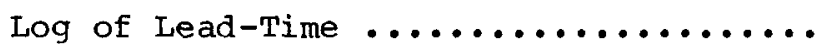 & 1.210 & $0.12 *$ \\
\hline $\begin{array}{l}\text { Experience of Utility That Acts } \\
\text { as Its Own Construction Manager }{ }^{d} \ldots . . .\end{array}$ & 8.269 & $3.27 *$ \\
\hline Experience of External Contractore .... & -1.859 & 1.33 \\
\hline $\begin{array}{l}\text { Binary Variable for Plant Being } \\
\text { Constructed by Utility } \ldots \ldots \ldots \ldots \ldots \ldots\end{array}$ & -0.427 & $0.11 *$ \\
\hline Adjusted $R-$-Squared $\ldots \ldots \ldots \ldots \ldots \ldots \ldots$ & 0.828 & -- \\
\hline
\end{tabular}

$a_{A n}$ asterisk indicates that the coefficient is significantly different from zero at a 0.95 level of confidence, using a two-tailed test of significance.

bThe "F" statistic used to test for the difference between the two coefficients was 0.03 .

CCoefficient and standard error multiplied by 1,000 .

$d_{\text {This }}$ is the coefficient associated with the interaction term between the binary variable for utilities that act as their own construction managers and the experience variable (denoted as INTER in the equations presented in the text). This coefficient would measure the difference in the regression coefficients associated with experience for those utilities that act as their own construction managers and those that employ outside contractors.

eThis is the coefficient associated with the contractor's experience variable (denoted as CST1 in the equations presented in the text). It can be interpreted as the regression coefficient associated with the experience variable for those utilities that employ outside contractors.

Source: Computations based on data from Energy Information Administration, Form EIA-254, "Semiannual Progress Report on Status of Reactor Construction," and predecessor survey forms. 
Table 9 refers to the "lead-time" equation for plants that are larger or smaller than 850 MWe. None of the coefficients for the explanatory variables is significantly different from zero, and the low F-values suggest that the hypothesis that all of the coefficients are zero cannot be rejected. This probably results from the fact that the samples are clustered around two ranges, 1,000 to 1,100 MWe and 800 to 850 MWe. The results of the Chow test imply that the hypothesis that the two sets of regressions are the same cannot be rejected.

Commercial Operation Before and After 1979

Table 10 presents the separate construction cost regressions for units that went into commercial operation before and after 1979. Although the two samples seem to indicate different levels of importance for the explanatory variables, the hypothesis that the two sets of regression coefficients are the same cannot be rejected.

The results for the "lead-time" regressions given in Table 11 show that, in addition to the intercept term and the size variable, the time variable is significant for the post-1979 commercial operation group. The coefficient of the time variable represents the rate at which the lead-time was changing, given a change in the time of construction start. Thus, units with later construction starts had shorter construction durations than identical units that were begun earlier, but for every year's delay, the amount by which the lead-time was shortened decreased. For example, if plant A, which went into commercial operation after 1979 and was started in 1972 is compared with plant $B$, which differed only by its start date being 1 year later, then construction duration was about 6.2 percent shorter for plant $B$ than for plant A. If the starting date of plant $B$ was 2 years later, then lead-time was 12.0 percent shorter; if it started 3 years later, then its total lead-time was 17.3 percent less than that for the first plant. While the decrease in construction lead-time is not enormous over time, it does suggest that utilities may be adjusting to changes in the regulatory environment, learning from their greater experience with nuclear plant construction, and/or making a greater effort to complete the units in a shorter time.

A Chow test was used to test whether plants that entered commercial operation before and after 1979 were the same in terms of their construction "lead-time." In this case, the hypothesis that the regression coefficients in the two equations are not different can be rejected at a 99 percent confidence level. Comparison of the two sets of regression coefficients shows that the greatest differences are due to the effects of the time trend and to regional influences. In the pre-1979 commercial operation sample, location in the Northeast/Midwest and South/Southwest regions added 27 percent and 32 percent, respectively, to lead-times. In the post-1979 group, the effects of the regional indicators are not significantly different from zero. The size and regional influences for the earlier group are, however, consistent with those found by Komanoff for his sample of plants, all of which went into operation before or during 1980. (See Appendix B for a review of Komanoff's study.)

Although the lead-times differ for the pre- and post-1979 commercial operation groups, the underlying causes are not reflected in the construction costs. That is, although the two sets of regression coefficients in the "lead-time" equations differ, the regression coefficients in the two cost equations are the same. Thus, the factors that affected the change in the lead-time relationship did not independently affect the cost relationship. However, since there is a relationship between cost and "lead-time," the factors that caused the change in the lead-time relationship would also indirectly influence costs. 


\section{Table 9. Results of Regression Analysis of Lead-Times: Sample Divided According to Unit Size}

\begin{tabular}{|c|c|c|c|c|}
\hline & \multicolumn{2}{|c|}{ Size $>850$ MWe } & \multicolumn{2}{|c|}{ Size $<850$ MWe } \\
\hline Jariable & $\begin{array}{l}\text { Regression } \\
\text { Coefficient }\end{array}$ & $\begin{array}{l}\text { Standard } \\
\text { Errora }\end{array}$ & $\begin{array}{l}\text { Regression } \\
\text { Coefficient }\end{array}$ & $\begin{array}{c}\text { Standard } \\
\text { Error } \\
\end{array}$ \\
\hline 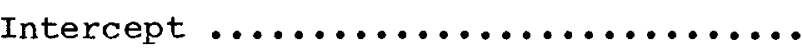 & 5.034 & 3.03 & 24.590 & $3.61 *$ \\
\hline Log of Net Megawatts ...... & 0.423 & 5.44 & 0.755 & 0.52 \\
\hline $\begin{array}{l}\text { Binary Variable for Plant } \\
\text { Being Located in East or Midwest ...... }\end{array}$ & -0.014 & 0.11 & 0.104 & 0.17 \\
\hline $\begin{array}{l}\text { Binary Variable for Plant Being } \\
\text { socated in South or Southwest } \ldots \ldots \text {..... }\end{array}$ & 0.047 & 0.12 & NA & NA \\
\hline fooling Towers $\ldots \ldots \ldots \ldots \ldots \ldots \ldots$ & 0.038 & 0.10 & 0.076 & 0.16 \\
\hline $\begin{array}{l}\text { 3inary Variable for Plant Being } \\
\text { ingle Unit or First of Multi-Unit .... }\end{array}$ & -0.054 & 0.08 & -0.035 & 0.18 \\
\hline $\begin{array}{l}\text { Binary Variable for Plant Being } \\
\text { Constructed by Utility } \ldots \ldots \ldots \ldots \ldots\end{array}$ & 0.151 & 0.20 & -0.215 & 1.76 \\
\hline Date of Construction start ${ }^{b} \ldots$ & 0.046 & 0.04 & 0.046 & 0.10 \\
\hline Experience of External Contractor ${ }^{c} \ldots$ & 0.119 & 0.39 & 0.168 & 0.58 \\
\hline $\begin{array}{l}\text { Experience of Utility That Acts } \\
\text { is Its Own Construction Manager }{ }^{d} \ldots . . .\end{array}$ & -0.575 & 0.98 & 0.850 & 4.48 \\
\hline ddjusted R-Squared $\ldots \ldots \ldots \ldots \ldots \ldots$ & -0.02 & -- & -0.264 & -- \\
\hline Sum of Squared Errors ${ }^{e} \ldots \ldots \ldots \ldots \ldots$ & 2.282 & -- & 1.175 & -- \\
\hline
\end{tabular}

$a_{A n}$ asterisk indicates that the coefficient is significantly different from zero at a 0.95 level of confidence, using a two-tailed test of significance.

bCoefficient and standard error multiplied by 1,000 .

CThis is the coefficient associated with the contractor's experience variable (denoted as CST1 in the equations presented in the text). It can be interpreted as the regression coefficient associated with the experience variable for those utilities that employ outside contractors.

$d_{\text {This }}$ is the coefficient associated with the interaction term between the binary variable for utilities that act as their own construction managers and the experience variable (denoted as INTER in the equations presented in the text). This coefficient would measure the difference in the regression coefficients associated with experience for those utilities that act as their own construction managers and those that employ outside contractors.

e The Chow test for the equality of the two sets of regression coefficients is: $[(3.622-2.282-1.175) / 10] /[(2.282+1.175) / 50]$. The resulting $\mathrm{F}-\mathrm{statistic}$ is 0.24 with 10 degrees of freedom in the numerator and 50 in the denominator.

Source: Computations based on data from Energy Information Administration, Form EIA-254, "Semiannual Progress Report on Status of Reactor Construction," and predecessor survey forms. 
Table 10. Results of Regression Analysis of Real Overnight Costs: Sample Divided According to Date of Commercial Operation

\begin{tabular}{|c|c|c|c|c|}
\hline \multirow[b]{2}{*}{ Variable } & \multicolumn{2}{|c|}{ Operation After 1979} & \multicolumn{2}{|c|}{ Operation Before 1979} \\
\hline & $\begin{array}{l}\text { Regression } \\
\text { Coefficient }\end{array}$ & $\begin{array}{l}\text { Standard } \\
\text { Errora }\end{array}$ & $\begin{array}{l}\text { Regression } \\
\text { Coefficient }\end{array}$ & $\begin{array}{c}\text { Standard } \\
\text { Errora }\end{array}$ \\
\hline Intercept $\ldots \ldots \ldots \ldots \ldots \ldots \ldots \ldots \ldots \ldots \ldots$ & -4.448 & 3.06 & 1.147 & 2.26 \\
\hline Log of Net Megawatts .............. & -1.015 & $0.38 *$ & -0.207 & 0.32 \\
\hline $\begin{array}{l}\text { Binary Variable for Plant Being } \\
\text { Located in South or Southwest ........ }\end{array}$ & 0.008 & 0.09 & -0.120 & 0.09 \\
\hline $\begin{array}{l}\text { Binary Variable for Plant } \\
\text { Being Located in West } \ldots \ldots \ldots \ldots \ldots . .\end{array}$ & 0.320 & $0.15 *$ & -0.263 & 0.20 \\
\hline $\begin{array}{l}\text { Binary Variable for Use } \\
\text { of Cooling Towers } \ldots \ldots \ldots \ldots \ldots \ldots \text {. . . . . }\end{array}$ & 0.069 & 0.10 & 0.038 & 0.11 \\
\hline $\begin{array}{l}\text { Binary Variable for Plant Being } \\
\text { Single Unit or First of Multi-Unit .... }\end{array}$ & 0.395 & $0.08 *$ & 0.352 & $0.10^{*}$ \\
\hline Date of Construction startb $\ldots \ldots \ldots \ldots$ & 0.398 & $0.07 *$ & 0.338 & $0.10 *$ \\
\hline Log of Actual Lead-Time $\ldots \ldots \ldots \ldots \ldots$ & 2.028 & $0.36 *$ & 0.728 & $0.35 *$ \\
\hline $\begin{array}{l}\text { Experience of Utility That Acts } \\
\text { as Its Own Construction Manager }{ }^{\mathrm{C}} \ldots \ldots\end{array}$ & $-1 \cdot 124$ & 14.70 & -0.884 & 5.81 \\
\hline Experience of External Contractor ${ }^{d}$.... & -3.039 & 5.14 & -0.791 & 1.61 \\
\hline $\begin{array}{l}\text { Binary Variable for Plant Being } \\
\text { Constructed by Utility } \ldots \ldots \ldots \ldots \ldots\end{array}$ & -0.308 & 0.23 & -0.039 & 0.29 \\
\hline Adjusted $R$-squared $\ldots \ldots \ldots \ldots \ldots \ldots$ & 0.805 & -- & 0.546 & -- \\
\hline Sum of Squared Errors ${ }^{e} \ldots \ldots \ldots \ldots \ldots$ & 0.766 & -- & 1.088 & -- \\
\hline
\end{tabular}

$a_{A n}$ asterisk indicates that the coefficient is significantly different from zero at a 0.95 level of confidence, using a two-tailed test of significance.

bcoefficient and standard error multiplied by 1,000 .

$c_{\text {This }}$ is the coefficient associated with the interaction term between the binary variable for utilities that act as their own construction managers and the experience variable (denoted as INTER in the equations presented in the text). This coefficient would measure the difference in the regression coefficients associated with experience for those utilities that act as their own construction managers and those that employ outside contractors.

$d_{\text {This }}$ is the coefficient associated with the contractor's experience variable (denoted as CST1 in the equations presented in the text). It can be interpreted as the regression coefficient associated with the experience variable for those utilities that employ outside contractors.

eThe Chow test for the equality of the two sets of regression coefficients is: $[(2.437-0.769-1.088) / 11] /[(0.766+1.088) / 45]$. The resulting F-statistic is 1.29 with 11 degrees of freedom in the numerator and 45 in the denominator.

Source: Computations based on data from Energy Information Administration, Form EIA-254, "Semiannual Progress Report on Status of Reactor Construction," and predecessor survey forms. 
Table 11. Results of Regression Analysis of Lead-Times: Sample Divided According to Date of Commercial Operation

\begin{tabular}{|c|c|c|c|c|}
\hline \multirow[b]{2}{*}{ Variable } & \multicolumn{2}{|c|}{ Operation After 1979} & \multicolumn{2}{|c|}{ Operation Before 1979} \\
\hline & $\begin{array}{l}\text { Regression } \\
\text { Coefficient }\end{array}$ & $\begin{array}{c}\text { Standard } \\
\text { Errora }\end{array}$ & $\begin{array}{l}\text { Regression } \\
\text { Coefficient }\end{array}$ & $\begin{array}{l}\text { Standard } \\
\text { Errora } \\
\end{array}$ \\
\hline Intercept $\ldots \ldots \ldots \ldots \ldots \ldots \ldots \ldots \ldots$ & 5.859 & $1.34^{*}$ & 4.433 & $1.56 *$ \\
\hline Log of Net Megawatts . ........... & 0.465 & $0.19 *$ & 0.501 & $0.17 *$ \\
\hline $\begin{array}{l}\text { Binary Variable for plant } \\
\text { Being Located in East or Midwest ...... }\end{array}$ & 0.018 & 0.07 & 0.236 & 0.13 \\
\hline $\begin{array}{l}\text { Binary Variable for Plant Being } \\
\text { Located in South or Southwest } \ldots . . . \ldots \text {. }\end{array}$ & -0.098 & 0.07 & 0.280 & $0.13 *$ \\
\hline $\begin{array}{l}\text { Binary Variable for Use } \\
\text { of Cooling Towers } \ldots \ldots \ldots \ldots \ldots \ldots \ldots \ldots\end{array}$ & 0.032 & 0.05 & -0.068 & 0.07 \\
\hline $\begin{array}{l}\text { Binary Variable for Plant Being } \\
\text { Single Unit or First of Multi-Unit .... }\end{array}$ & 0.059 & 0.04 & -0.082 & 0.07 \\
\hline $\begin{array}{l}\text { Binary variable for Plant Being } \\
\text { Constructed by Utility } \ldots \ldots \ldots \ldots \ldots . . . .\end{array}$ & 0.048 & 0.11 & 0.082 & 0.26 \\
\hline Date of Construction startb $\ldots . . \ldots \ldots$ & -0.174 & $0.03 *$ & 0.054 & 0.08 \\
\hline Experience of External Contractor ${ }^{c} \ldots$ & 0.312 & 0.23 & 0.275 & 0.26 \\
\hline $\begin{array}{l}\text { Experience of Utility That Acts } \\
\text { as Its Own Construction Manager } \ldots . . .\end{array}$ & -0.438 & 0.57 & -0.644 & 0.79 \\
\hline Adjusted R-squared ................ & 0.651 & -- & 0.233 & -- \\
\hline Sum of Squared Errors ${ }^{e} \ldots \ldots \ldots \ldots \ldots$ & 0.346 & -- & 0.626 & -- \\
\hline
\end{tabular}

$a_{\text {An }}$ asterisk indicates that the coefficient is significantly different from zero at a 0.95 level of confidence, using a two-tailed test of significance.

bCoefficient and standard error multiplied by 1,000.

CThis is the coefficient associated with the contractor's experience variable (denoted as CST1 in the equations presented in the text). It can be interpreted as the regression coefficient associated with the experience variable for those utilities that employ outside contractors.

$d_{T h i s}$ is the coefficient associated with the interaction term between the binary variable for utilities that act as their own construction managers and the experience variable (denoted as INTER in the equations presented in the text). This coefficient would measure the difference in the regression coefficients associated with experience for those utilities that act as their own construction managers and those that employ outside contractors.

The Chow test for the equality of the two sets of regression coefficients is: $[(3.622-0.346-0.626) / 10] /[(0.346+0.626) / 50]$. The resulting F-statistic is 13.63 with 10 degrees of freedom in the numerator and 50 in the denominator.

Source: Computations based on data from Energy Information Administration, Form EIA-254, "Semiannual Progress Report on Status of Reactor Construction," and predecessor survey forms. 
Table 12 presents the results for the construction cost regressions. In this analysis, the sample was split into groups that entered construction before and after the beginning of 1970 . On the basis of the Chow test, the hypothesis that the regression coefficients in the cost equation are not significantly different cannot be rejected. This implies that the effects of the explanatory factors on construction costs are about the same before and after the 1970 benchmark.

Table 13 presents the "lead-time" results for a spline variable for time with a 1970 break point. Again, the spline variables have different signs, implying that the plants with latex construction starts seem to have shorter "lead-times." Unfortunately, one cannot distinguish between the three possible causes mentioned above. It can be concluded only that the net effect of these causes is that lead-times have decreased with time for the most recent units entering commercial operation.

In the 1983 EPRI study, the authors claimed that the relevant distinction in the population of U.S. nuclear power plants is between those started before 1972 and those started after 1972.22 To explore this further, for the cost analysis, the sample was split according to their criterion. The results of the two construction cost regressions are given in Table 14. The Chow test again indicates that the hypothesis that the two sets of regression coefficients are the same cannot be rejected. In the "lead-time" analysis, a spline variable for time was included, with a break point at 1972. These results are shown in Table 15. There is a statistically significant difference between the two spline variables, implying that plants entering construction after 1972 had shorter lead-times than plants that entered construction before 1972 .

To summarize, it appears that nuclear construction durations, on average, have increased with the size of the units being built. However, when the sample is disaggregated into separate populations according to when their construction was started, units of similar size that were started after 1972 and finished after 1979 appear to have suffered less from time-related influences such as cumulative regulations. There are two possible explanations for this finding, one of which is purely statistical. First, units begun after 1972 with long "lead-times" are not yet complete and, therefore, were not included in the sample. The changes in the effects of factors influencing lead-times could be the result of oversampling of "good" units. Second, this result is consistent with other recent detailed case studies. It is therefore posible that the observed changes in the relationship between construction start date and "lead-time" could be due to "real" factors, such as industry-wide learning about the regulatory process. 23

22Electric Power Research Institute, An Analysis of Power Plant Construction Lead Times, Volume I, EPRI-EA-2880 (Palo Alto, California, 1983).

23It should be noted that, in qualitative terms, the same results were obtained when the larger sample of units was used. 
Table 12. Results of Regression Analysis of Actual Costs: Sample Divided According to Date of Construction Start

\begin{tabular}{|c|c|c|c|c|}
\hline \multirow[b]{2}{*}{ Variable } & \multicolumn{2}{|c|}{ Started 1970 or After } & \multicolumn{2}{|c|}{ Started Before 1970} \\
\hline & $\begin{array}{l}\text { Regression } \\
\text { Coefficient }\end{array}$ & $\begin{array}{l}\text { Standard } \\
\text { Errora }\end{array}$ & $\begin{array}{l}\text { Regression } \\
\text { Coefficient }\end{array}$ & $\begin{array}{l}\text { Standard } \\
\text { Errora }\end{array}$ \\
\hline Intercept $\ldots \ldots \ldots \ldots \ldots \ldots \ldots \ldots \ldots \ldots$ & 0.350 & 2.38 & 1.337 & 1.98 \\
\hline 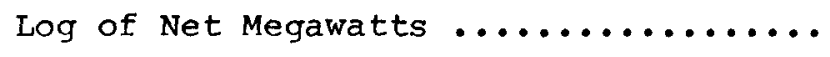 & -1.030 & $0.40^{*}$ & -0.632 & $0.27^{\star}$ \\
\hline $\begin{array}{l}\text { Binary Variable for Plant Being } \\
\text { Located in South or Southwest ........ }\end{array}$ & 0.020 & 0.10 & -0.220 & $0.09 *$ \\
\hline $\begin{array}{l}\text { Binary Variable for Plant } \\
\text { Being Located in west } \ldots \ldots \ldots \ldots \ldots\end{array}$ & 0.342 & 0.18 & -0.031 & 0.19 \\
\hline $\begin{array}{l}\text { Binary Variable for Use } \\
\text { of Cooling Towers } \ldots \ldots \ldots \ldots \ldots \ldots \ldots\end{array}$ & -0.064 & 0.14 & 0.167 & 0.10 \\
\hline $\begin{array}{l}\text { Binary Variable for Plant Being } \\
\text { Single Unit or First of Multi-Unit .... }\end{array}$ & 0.375 & $0.10 *$ & 0.409 & $0.09 *$ \\
\hline Date of Construction startb .......... & 0.338 & $0.07 *$ & 0.207 & $0.11 *$ \\
\hline Log of Actual Lead-Time $\ldots \ldots \ldots \ldots \ldots$ & 1.498 & $0.26 *$ & 1.115 & $0.17 *$ \\
\hline $\begin{array}{l}\text { Experience of Utility That Acts } \\
\text { as Its Own Construction Manager } \ldots . . . \text {. }\end{array}$ & 8.768 & 10.61 & 2.042 & 4.51 \\
\hline Experience of External Contractor ${ }^{d} \ldots$ & 1.123 & 4.41 & -2.819 & 1.50 \\
\hline $\begin{array}{l}\text { Binary Variable for Plant Being } \\
\text { Constructed by Utility } \ldots \ldots \ldots \ldots \ldots\end{array}$ & -0.532 & $0.20 *$ & -0.049 & 0.21 \\
\hline Adjusted R-Squared ................ & 0.745 & -- & 0.741 & -- \\
\hline Sum of Squared Errors ${ }^{e} \ldots \ldots \ldots \ldots \ldots$ & 0.738 & -- & 1.276 & -- \\
\hline
\end{tabular}

$a_{A n}$ asterisk indicates that the coefficient is significantly different from zero at a 0.95 level of confidence, using a two-tailed test of significance.

bCoefficient and standard error multiplied by 1,000.

CThis is the coefficient associated with the interaction term between the binary variable for utilities that act as their own construction managers and the experience variable (denoted as INTER in the equations presented in the text). This coefficient would measure the difference in the regression coefficients associated with

experience for those utilities that act as their own construction managers and those that employ outside contractors.

$d_{\text {This }}$ is the coefficient associated with the contractor's experience variable (denoted as CST1 in the equations presented in the text). It can be interpreted as the regression coefficient associated with the experience variable for those utilities that employ outside contractors.

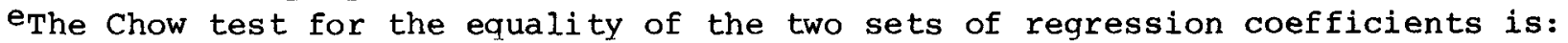
$[(2.418-0.738-1.276) / 11] /[(0.738+1.276) / 45]$. The resulting $F-s$ tatistic is 0.82 with 11 degrees of freedom in the numerator and 45 in the denominator.

Source: Computations based on data from Energy Information Administration, Form EIA-254, "Semiannual Progress Report on Status of Reactor Construction," and predecessor survey forms. 
Table 13. Results of Regression Analysis of Lead-Times: Time Variable Split at 1970

\begin{tabular}{|c|c|c|}
\hline Variable & $\begin{array}{l}\text { Regression } \\
\text { Coefficient }\end{array}$ & $\begin{array}{c}\text { Standard } \\
\text { Errora }\end{array}$ \\
\hline Intercept $\ldots \ldots \ldots \ldots \ldots \ldots \ldots \ldots \ldots$ & 2.406 & 1.36 \\
\hline 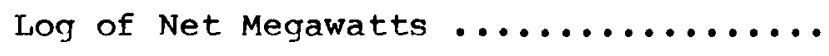 & 0.787 & $0.19 *$ \\
\hline $\begin{array}{l}\text { Binary Variable for Plant Being } \\
\text { Located in South } \ldots \ldots \ldots \ldots \ldots \ldots \ldots\end{array}$ & 0.030 & 0.11 \\
\hline $\begin{array}{l}\text { Binary Variable for Plant Being } \\
\text { Located in North } \ldots \ldots \ldots \ldots \ldots \ldots \ldots . \ldots . \ldots\end{array}$ & 0.014 & 0.10 \\
\hline $\begin{array}{l}\text { Binary Variable for Use } \\
\text { of Cooling Towers } \ldots \ldots \ldots \ldots \ldots \ldots \ldots \ldots\end{array}$ & 0.042 & 0.07 \\
\hline $\begin{array}{l}\text { Binary Variable for Plant Being } \\
\text { Single Unit or First of Multi-Unit .... }\end{array}$ & -0.064 & 0.06 \\
\hline $\begin{array}{l}\text { Date of Construction start, } \\
\text { if Before } 1970^{b} \ldots \ldots \ldots \ldots \ldots \ldots \ldots \ldots \ldots\end{array}$ & 0.258 & $0.11 *$ \\
\hline $\begin{array}{l}\text { Date of Construction Start, } \\
\text { if } 1970 \text { or After }{ }^{b} \ldots \ldots \ldots \ldots \ldots \ldots \ldots\end{array}$ & -0.065 & 0.05 \\
\hline $\begin{array}{l}\text { Binary Variable for Plant Being } \\
\text { Constructed by Utility } \ldots \ldots \ldots \ldots \ldots . . . .\end{array}$ & 0.148 & 0.16 \\
\hline Experience of External Contractor $c$.... & 0.057 & 0.31 \\
\hline $\begin{array}{l}\text { Experience of Utility That Acts } \\
\text { as Its own Construction Manager }{ }^{d} . . . .\end{array}$ & -0.397 & 0.64 \\
\hline Adjusted R-Squared $\ldots \ldots \ldots \ldots \ldots \ldots$ & 0.339 & -- \\
\hline
\end{tabular}

$a_{A n}$ asterisk indicates that the coefficient is significantly different from zero at a 0.95 level of confidence, using a two-tailed test of significance.

bCoefficient and standard error multiplied by 1,000. The F-statistic used to test for the difference between the two coefficients was 10.03 .

CThis is the coefficient associated with the contractor's experience variable (denoted as CST1 in the equations presented in the text). It can be interpreted as the regression coefficient associated with the experience variable for those utilities that employ outside contractors.

$d_{\text {This }}$ is the coefficient associated with the interaction term between the binary variable for utilities that act as their own construction managers and the experience variable (denoted as INTER in the equations presented in the text). This coefficient would measure the difference in the regression coefficients associated with experience for those utilities that act as their own construction managers and those that employ outside contractors.

Source: Computations based on data from Energy Information Administration, Form EIA-254, "Semiannual Progress Report on Status of Reactor Construction," and predecessor survey forms. 


\section{Table 14. Results of Regression Analysis of Actual Costs: Sample Divided According to Date of Construction Start}

\begin{tabular}{|c|c|c|c|c|}
\hline \multirow[b]{2}{*}{ Variable } & \multicolumn{2}{|c|}{ Started 1972 or After } & \multicolumn{2}{|c|}{ Started Before 1972} \\
\hline & $\begin{array}{l}\text { Regression } \\
\text { Coefficient }\end{array}$ & $\begin{array}{l}\text { Standard } \\
\text { Errora }\end{array}$ & $\begin{array}{l}\text { Regression } \\
\text { Coefficient }\end{array}$ & $\begin{array}{c}\text { Standard } \\
\text { Error } \\
\end{array}$ \\
\hline Intercept $\ldots \ldots \ldots \ldots \ldots \ldots \ldots \ldots$ & 9.886 & 9.42 & 0.914 & 1.50 \\
\hline Log of Net Megawatts .............. & -0.689 & 0.97 & -0.688 & $0.22 *$ \\
\hline $\begin{array}{l}\text { Binary Variable for Plant Being } \\
\text { Located in South or Southwest ........ }\end{array}$ & 0.294 & 0.20 & -0.184 & $0.07 *$ \\
\hline 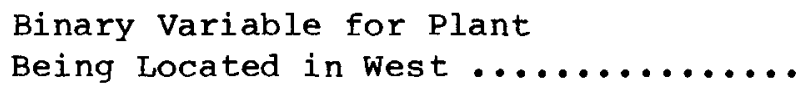 & 0.722 & $0.34 *$ & 0.002 & 0.13 \\
\hline $\begin{array}{l}\text { Binary Variable for Use } \\
\text { of Cooling Towers } \ldots \ldots \ldots \ldots \ldots \ldots \text {. }\end{array}$ & -0.440 & 0.35 & 0.109 & 0.08 \\
\hline $\begin{array}{l}\text { Binary Variable for Plant Being } \\
\text { Single Unit or First of Multi-Unit ... }\end{array}$ & 0.299 & $0.14 *$ & 0.383 & $0.07 *$ \\
\hline Date of Construction $\operatorname{start}^{b} \ldots \ldots \ldots$. & 0.156 & 0.31 & 0.218 & $0.07 *$ \\
\hline Log of Actual Lead-Time ............ & 0.150 & 1.32 & 1.217 & $0.13^{*}$ \\
\hline $\begin{array}{l}\text { Experience of Utility That Acts } \\
\text { as Its Own Construction Manager }{ }^{c} \ldots . .\end{array}$ & -189.606 & 134.10 & 5.947 & 3.77 \\
\hline Experience of External Contractor ${ }^{d}$... & 5.924 & 7.82 & -2.397 & 1.34 \\
\hline $\begin{array}{l}\text { Binary Variable for Plant Being } \\
\text { Constructed by Utility } \ldots \ldots \ldots \ldots \ldots\end{array}$ & 2.154 & 1.74 & -0.264 & 0.16 \\
\hline Adjusted R-squared $\ldots \ldots \ldots \ldots \ldots \ldots$ & 0.391 & -- & 0.806 & -- \\
\hline Sum of Squared Errors ${ }^{e} \ldots \ldots \ldots \ldots \ldots$ & 0.338 & -- & 1.644 & -- \\
\hline
\end{tabular}

$\mathrm{a}_{\mathrm{An}}$ asterisk indicates that the coefficient is significantly different from zero at a 0.95 level of confidence, using a two-tailed test of significance.

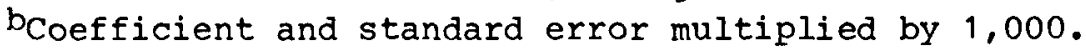

$C_{\text {This }}$ is the coefficient associated with the interaction term between the binary variable for utilities that act as their own construction managers and the experience variable (denoted as INTER in the equations presented in the text). This coefficient would measure the difference in the regression coefficients associated with experience for those utilities that act as their own construction managers and those that employ outside contractors.

dThis is the coefficient associated with the contractor's experience variable (denoted as CST1 in the equations presented in the text). It can be interpreted as the regression coefficient associated with the experience variable for those utilities that employ outside contractors.

e The Chow test for the equality of the two sets of regression coefficients is: $[(2.418-0.338-1.644) / 11] /[(0.339+1.644) / 45]$. The resulting $F-s$ tatistic is 0.89 with 11 degrees of freedom in the numerator and 45 in the denominator.

Source: Computations based on data from Energy Information Administration, Form EIA-254, "Semiannual Progress Report on Status of Reactor Construction," and predecessor survey forms. 
Table 15. Results of Regression Analysis of Lead-Times: Time Variable Split at 1972

\begin{tabular}{|c|c|c|}
\hline Variable & $\begin{array}{l}\text { Regression } \\
\text { Coefficient }\end{array}$ & $\begin{array}{l}\text { Standard } \\
\text { Errora }\end{array}$ \\
\hline Intercept $\ldots \ldots \ldots \ldots \ldots \ldots \ldots \ldots \ldots$ & 2.553 & $1.31 *$ \\
\hline Log of Net Megawatts $\ldots \ldots \ldots \ldots \ldots \ldots$ & 0.771 & $0.18 *$ \\
\hline $\begin{array}{l}\text { Binary Variable for Plant Being } \\
\text { Located in South } \ldots \ldots \ldots \ldots \ldots \ldots \ldots\end{array}$ & 0.057 & 0.10 \\
\hline $\begin{array}{l}\text { Binary Variable for Plant Being } \\
\text { Located in North } \ldots \ldots \ldots \ldots \ldots \ldots \ldots \ldots\end{array}$ & 0.026 & 0.10 \\
\hline $\begin{array}{l}\text { Binary Variable for Use } \\
\text { of Cooling Towers } \ldots . \ldots \ldots \ldots \ldots \ldots . . . . . .\end{array}$ & 0.049 & 0.07 \\
\hline $\begin{array}{l}\text { Binary Variable for Plant Being } \\
\text { Single Unit or First of Multi-Unit .... }\end{array}$ & 0.059 & 0.06 \\
\hline $\begin{array}{l}\text { Date of Construction Start, } \\
\text { if Before } 1972^{b} \ldots \ldots \ldots \ldots \ldots \ldots \ldots \ldots\end{array}$ & 0.195 & $0.06 *$ \\
\hline $\begin{array}{l}\text { Date of Construction Start, } \\
\text { if } 1972 \text { or Afterb } \ldots \ldots \ldots \ldots \ldots \ldots \ldots\end{array}$ & -0.192 & $0.08 *$ \\
\hline $\begin{array}{l}\text { Binary Variable for Plant Being } \\
\text { Constructed by Utility } \ldots \ldots \ldots \ldots \ldots\end{array}$ & 0.138 & 0.15 \\
\hline Experience of External Contractor $c$.... & 0.070 & 0.30 \\
\hline $\begin{array}{l}\text { Experience of Utility That Acts } \\
\text { as Its Own Construction Managerd } \ldots . . .\end{array}$ & -0.442 & 0.63 \\
\hline Adjusted $R-$ squared $\ldots \ldots \ldots \ldots \ldots \ldots$ & 0.373 & -- \\
\hline
\end{tabular}

$a_{A n}$ asterisk indicates that the coefficient is significantly different from zero at a 0.95 level of confidence, using a two-tailed test of significance.

bCoefficient and standard error multiplied by 1,000. The F-statistic used to test for the difference between the two coefficients was 11.23 , with 1 degree of freedom in the numerator and 110 in the denominator.

$C_{T h i s}$ is the coefficient associated with the contractor's experience variable (denoted as CST1 in the equations presented in the text). It can be interpreted as the regression coefficient associated with the experience variable for those utilities that employ outside contractors.

$\mathrm{d}_{\text {This }}$ is the coefficient associated with the interaction term between the binary variable for utilities that act as their own construction managers and the experience variable (denoted as INTER in the equations presented in the text). This coefficient would measure the difference in the regression coefficients associated with experience for those utilities that act as their own construction managers and those that employ outside contractors.

Source: Computations based on data from Energy Information Administration, Form EIA-254, "Semiannual Progress Report on Status of Reactor Construction," and predecessor survey forms. 


\section{Analysis of Time-Related Costs}

Because the cost of electrical capacity to the ratepayer includes not only the overnight construction costs but also the time-related costs described in chapter 2, the effects of several explanatory variables on these costs were examined. of particular interest were the effects of the lead-time, regional variations, a time trend, and experience. Utilities that did not report their costs incurred from borrowing the funds for construction (i.e., the AFUDC costs) were omitted from the sample. (See Appendix A for a list of the plants for which the reported cost data did not include AFUDC.) Thus, the model for time-related costs was:

$$
\begin{aligned}
\ln (t i m e \text { costs })= & R S+\text { RWNW + CONSTRT + CST1 + INTER } \\
& +\ln (\text { lead-time })+\text { BUILD }+e
\end{aligned}
$$

where In(time costs) is the natural logarithm of the cumulative time-related costs, and all other variables are as defined in the previous models.

The results of the regression analysis are presented in Table 16 . The sign of the construction start variable implies that as plants were started later in time, the time-related costs grew. This is consistent with the effect of time on the overnight construction costs, where time had a net positive effect. Similarly, plants with longer lead-times also incurred greater time-related costs for their owners. This effect of lead-time is what is commonly acknowledged by utility analysts, while the effects examined in the previous section are generally ignored. The coefficient of lead-time indicates that for two plants, similar in all respects except that one took 1 percent longer to build than the other, the one with the longer lead-time incurred time-related costs that were 2.56 percent greater than those for the other. Finally, when the utility acted as its own construction manager, the time-related costs were about 50 percent less than the costs to utilities that used an external constructor. This result is consistent with the lower overnight costs obtained by utilities that acted as their own construction manager. similarly, the effect of experience on costs also depended upon whether the utility acted as its own constructor.

\section{Interaction of Size, Lead-Times, and Real Overnight Costs}

The analysis of the actual real overnight costs indicates that, if lead-time were not related to size, a 1 percent increase in size would be associated with a 0.6 percent reduction in costs. These scale economics are consistent with those derived from large engineering cost models. 24

There was also a strong relationship between actual "lead-times" and real overnight costs. As stated above, the lead-time variable acts as a surrogate for a number of unobservable variables and captures the effects of time-related managerial problems and regulatory changes over the construction period. Thus, the relationship between lead-time and costs partly reflects the results of managing the lead-time process in the presence of changing regulations and poor morale and other time-related

24see, for example, H.I. Bowers, L.C. Fuller, and M.I. Myers, Trends in Nuclear Power Plant Capital Investment Cost Estimates - 1976 to 1982, ORNL/TM-8898 (Oak Ridge National Laboratory, Oak Ridge, Tennessee, 1983). 
Table 16. Results of Regression Analysis of Time-Related Costs

\begin{tabular}{|c|c|c|}
\hline Variable & $\begin{array}{l}\text { Regression } \\
\text { Coefficient }\end{array}$ & $\begin{array}{c}\text { Standard } \\
\text { Errora }\end{array}$ \\
\hline Intercept $\ldots \ldots \ldots \ldots \ldots \ldots \ldots \ldots \ldots$ & -16.553 & $1.39 *$ \\
\hline $\begin{array}{l}\text { Binary Variable for Plant Being } \\
\text { Located in South or Southwest } \ldots \ldots \ldots\end{array}$ & -0.195 & $0.10 *$ \\
\hline $\begin{array}{l}\text { Binary Variable for Plant Being } \\
\text { Located in west } \ldots \ldots \ldots \ldots \ldots \ldots \ldots . \ldots\end{array}$ & 0.097 & 0.14 \\
\hline Date of Construction start ${ }^{b} \ldots \ldots \ldots$ & 0.534 & $0.05 *$ \\
\hline Log of Actual Lead-Time ............ & 2.560 & $0.17 *$ \\
\hline Experience of External Contractor $\mathrm{C} \ldots$ & -0.811 & 1.67 \\
\hline $\begin{array}{l}\text { Experience of Utility That Acts } \\
\text { as Its Own Construction Manager }{ }^{\mathrm{d}} \ldots . . .\end{array}$ & 11.148 & $5.04 *$ \\
\hline $\begin{array}{l}\text { Binary variable for Plant Being } \\
\text { Constructed by Utility } \ldots \ldots \ldots \ldots \ldots\end{array}$ & -0.690 & $0.17 *$ \\
\hline Adjusted $R$-squared $\ldots \ldots \ldots \ldots \ldots \ldots$ & 0.921 & -- \\
\hline
\end{tabular}

aAn asterisk indicates that the coefficient is significantly different from zero at a 0.95 level of confidence, using a two-tailed test of significance.

bCoefficient and standard error multiplied by 1,000.

$C_{T h i s}$ is the coefficient associated with the contractor's experience variable (denoted as CST1 in the equations presented in the text). It can be interpreted as the regression coefficient associated with the experience variable for those utilities that employ outside contractors.

$\mathrm{d}_{\text {This }}$ is the coefficient associated with the interaction term between the binary variable for utilities that act as their own construction managers and the experience variable (denoted as INTER in the equations presented in the text). This coefficient would measure the difference in the regression coefficients associated with experience for those utilities that act as their own construction managers and those that employ outside contractors.

Source: Computations based on data from Energy Information Administration, Form EIA-254, "Semiannual Progress Report on Status of Reactor Construction," and predecessor survey forms. 
diseconomies. Given the nature of the data, it was impossible to determine the relative importance of each of these factors.

The analysis indicates that a 1 percent increase in the size of the plant was associated with a 0.7 percent increase in "lead-time," which increased costs by about 0.85 percent $(0.7$ percent times 1.21$)$. Thus, the increase in costs resulting from the increased time required to build large plants and the associated managerial problems offset the independent effect of size. Larger plants, because of their engineering economies of scale, tend to be more attractive to utilities. But larger plants also present diseconomies of scale caused by time-related managerial problems and regulatory changes. All in all, the engineering economies were offset by the time-related diseconomies.

It must be stressed that it would be incorrect to conclude that reducing lead-times per se would cause a reduction in the real overnight costs. First, as was just noted, the lead-time variable acts as a surrogate for time-related managerial problems and regulatory changes, which are the actual causes of the cost increases. second, there are two types of time-related managerial effects that work in opposite directions. On one hand, there are a number of factors relating to productivity and morale that would cause costs to increase as lead-times increase. However, a second set of forces would cause costs to decrease as lead-times increase. Thus, at some point, the second set of forces would offset the first, causing costs to increase as lead-times decrease. Finally, to the extent that the observed correlation between lead-times and real overnight costs measures the effects of regulation, then if the regulatory process were stabilized, increases in lead-times would have no effects on real overnight costs.

Another important result of the statistical analysis is that utilities that act as their own construction manager have lower costs. For such utilities, increased experience seems to be associated with lower costs, both in an absolute sense and in relation to utilities that employ an external contractor. This statistical finding is consistent with the hypothesis that direct utility involvement in the construction process is important. As noted above, however, this result was the consequence of the experience of two utilities that acted as their own construction managers -Commonwealth Edison and Duke Power. It is possible that this finding could be the result of other characteristics that are common to these two utilities. 


\section{Analysis of the Estimation of Costs and Lead-Times}

As was discussed in Chapter 2, there has been almost a universal tendency to underestimate both the overnight and the time-related costs of nuclear power plant construction. For the plants on which construction began in the mid-1960's, the forecast error in the real overnight costs was about 100 percent, increasing to more than 280 percent for units entering construction about 8 years later. Similarly, the time-related costs were underestimated by a multiple of 3 to 4 . This chapter presents an analysis of the forecast errors in the estimates of costs and lead-times.

\section{Method for Statistical Analysis of the Forecast Errors in Costs and Construction Duration}

Multiple regression was used to measure the independent effects of factors such as size, experience, and regulation (time) on the forecast errors in costs and construction duration, as reported on Form EIA-254. However, instead of directly relating the forecast errors to various explanatory variables (as was done in Chapter 3 ), the estimated costs were used as the dependent variable, and the expected construction duration along with the other explanatory variables used in the analysis of the actual data were employed as the independent variables. The regression equation for the forecast errors was then "imputed" by simply subtracting the respective regression coefficients in the actual and estimated cost equations. An "F-test" was then employed to determine the statistical significance of the "imputed" regression coefficients. 1

stated in mathematical terms, the equations used in the regression analysis of the actual and estimated costs were:

$$
\begin{aligned}
\ln (\cos t s / k W)= & a_{0}+a_{1} \ln (\text { size })+a_{2} \text { RWNW }+a_{3} \text { RS }+a_{4} \text { COOL }+a_{5} \text { FIRST } \\
& +a_{6} \ln (\text { lead-time })+a_{7} \text { CONSTRT }+a_{8} \text { BUILD }+a_{9} \text { CST1 } \\
& +a_{10} \text { INTER }+e_{1}
\end{aligned}
$$

and

$$
\begin{aligned}
\ln (e \operatorname{eos} t s / \mathrm{kW})= & \mathrm{b}_{0}+\mathrm{b}_{1} \ln (\text { size })+\mathrm{b}_{2} \mathrm{RWNW}+\mathrm{b}_{3} \mathrm{RS}+\mathrm{b}_{4} \text { COOL }+\mathrm{b}_{5} \text { FIRST } \\
& +\mathrm{b}_{6} \ln (\text { elead-time })+\mathrm{b}_{7} \text { CONSTRT }+\mathrm{b}_{8} \text { BUILD }+\mathrm{b}_{9} \text { CST1 } \\
& +\mathrm{b}_{10} \text { INTER }+\mathrm{e}_{2},
\end{aligned}
$$

respectively. Expected costs and expected construction duration are represented by ecost and elead-time, respectively. All other variables are as defined in Chapter 3. Finally, the imputed regression equation for the forecast errors was determined by subtracting the estimated costs from the actual costs, 2 or:

1 See SAS User's Guide: Statistics, SAS Institute, Cary, North Carolina, 1982, for details of the test.

2Alternatively, the regression equation for the forecast errors could be estimated directly. When this was done, the results were similar to those derived by "imputing" the regression coefficients (see Appendix D for the results). Also, the specification of Equation (6) implies that the forecast error is the result of differences in the effect of lead-time and the misestimation of lead-times. This section of the chapter will focus on the former effect. Later in the chapter, the results of the analysis of forecast errors in lead-times will be presented. 


$$
\begin{aligned}
& \ln (\cos t s / k W)-\ln (e \cos t / k W)=\left(a_{0}-b_{0}\right)+\left(a_{1}-b_{1}\right) \ln (\operatorname{size}) \\
& +\left(a_{2}-b_{2}\right) R W N W+\left(a_{3}-b_{3}\right) R S \\
& +\left(a_{4}-b_{4}\right) \text { COOL }+\left(a_{5}-b_{5}\right) \text { FIRST } \\
& +a_{6} \ln \left(\text { lead-time) - } b_{6} \ln (e l e a d-t i m e)\right. \\
& +\left(a_{7}-b_{7}\right) \text { CONSTRT }+\left(a_{8}-b_{8}\right) \text { BUILD } \\
& +\left(a_{9}-b_{9}\right) \text { CST1 }+\left(a_{10}-b_{10}\right) \text { INTER . }
\end{aligned}
$$

Before the results of the analysis are presented, one comment dealing with the interpretation of the results must be discussed. An important issue in a number of current rate hearings is whether the forecast errors were the result of internal factors that could be controlled by the utilities or the result of unforeseeable external events. Due to the nature of the data, the analysis presented in this chapter cannot directly answer this question. In particular, to address directly the issue of whether the cost overruns were the result of internal factors or external events, two separate sets of variables capturing the effects of each must be included in the analysis. ${ }^{3}$ As discussed in the preceding chapter, many of the variables included in the regression analysis either act as surrogates for a series of unmeasurable variables or capture the effects of two or more measurable variables that are highly correlated. Given this, the best that can be done with the available data is to determine whether the forecast errors are correlated with various measurable variables.

\section{Factors Affecting the Forecast Errors for Real Overnight Costs}

To analyze the forecast errors, a multiple regression analysis of the estimated real overnight costs was first undertaken, using the explanatory variables described in the previous section. The log of the estimated cost per kilowatt (in 1982 dollars) was used as the dependent variable. It should be noted that the utilities did not report their estimated real overnight costs on Form EIA-254. Therefore, these data had to be computed from the reported cost estimates. The computation of estimated overnight costs is described in Chapter 2 and Appendix A. A sensitivity analysis is presented in Appendix D. Sources for the other data are described in Appendix C. The methodology described above was then used to "impute" the regression equations for the forecast errors.

\section{Analysis of Forecast Errors at the Start of Construction}

The results of the regression analysis of the cost estimates made at the start of construction are reported in Table 17. For comparison, the results of the regression analysis of actual costs are also shown. The "imputed" regression results for the forecast error equation, along with the F-statistics used to test the hypothesis that the "imputed" regression coefficients are equal to zero, are shown in Table 18. For the moment, the focus will be on the cost estimates and associated forecast errors made at the start of construction. The effects of each of the major groups of variables will be discussed in turn.

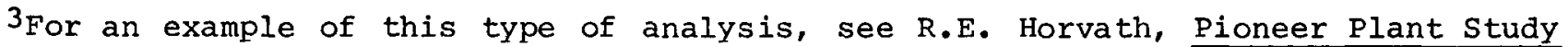
User's Manual, R-2569/1-DOE (Rand Corporation, Santa Monica, California, 1983). 
Table 17. Results of Regression Analysis of Estimated Real Overnight Costs

\begin{tabular}{|c|c|c|c|c|c|c|}
\hline \multirow[b]{3}{*}{ Variable } & \multicolumn{6}{|c|}{ Regression Coefficients ${ }^{a}$} \\
\hline & \multirow{2}{*}{$\begin{array}{l}\text { Actual } \\
\text { Costs }\end{array}$} & Estimatec & \multicolumn{2}{|c|}{$\begin{array}{l}\text { Costs at Diff } \\
\text { of Completion }\end{array}$} & \multirow[b]{2}{*}{$75 \%$} & \multirow{2}{*}{ Stages } \\
\hline & & 08 & 258 & $50 \%$ & & \\
\hline Intercept $\ldots \ldots \cdots \cdots \cdots \cdots \cdots \cdots \cdots \cdots$ & $\begin{array}{r}0.065 \\
(1.27)\end{array}$ & $\begin{array}{r}7.619 \\
(1.92)\end{array}$ & $\begin{array}{r}3.601 \\
(1.55)\end{array}$ & $\begin{array}{r}3.775 \\
(1.15)\end{array}$ & $\begin{array}{l}3.653 \\
(1.36)\end{array}$ & $\begin{array}{r}2.324 \\
(1.28)\end{array}$ \\
\hline Log of Net Megawatts $\ldots \ldots \ldots \ldots \ldots \ldots \ldots$ & $\begin{array}{l}-0.569 \\
(0.19)\end{array}$ & $\begin{array}{l}-0.424 \\
(0.18)\end{array}$ & $\begin{array}{l}-0.407 \\
(0.20)\end{array}$ & $\begin{array}{l}-0.502 \\
(0.16)\end{array}$ & $\begin{array}{l}-0.432 \\
(0.18)\end{array}$ & $\begin{array}{l}-0.587 \\
(0.20)\end{array}$ \\
\hline $\begin{array}{l}\text { Binary Variable for Plant Being } \\
\text { Located in South or Southwest } \ldots \ldots \ldots \ldots \\
\text { Binary Variable for Plant Being }\end{array}$ & $\begin{array}{l}-0.106 \\
(0.05)\end{array}$ & $\begin{array}{l}-0.079 \\
(0.07)\end{array}$ & $\begin{array}{l}0.086 \\
(0.07)\end{array}$ & $\begin{array}{l}-0.102 \\
(0.05)\end{array}$ & $\begin{array}{l}-0.108 \\
(0.05)\end{array}$ & $\begin{array}{l}-0.082 \\
(0.06)\end{array}$ \\
\hline Located in west $\ldots \ldots \ldots \ldots \ldots \ldots \ldots \ldots$ & $\begin{array}{r}0.115 \\
(0.09)\end{array}$ & $\begin{array}{c}0.068 \\
(0.11)\end{array}$ & $\begin{array}{l}-0.034 \\
(0.11)\end{array}$ & $\begin{array}{r}0.019 \\
(0.09)\end{array}$ & $\begin{array}{r}0.122 \\
(0.09)\end{array}$ & $\begin{array}{r}0.121 \\
(0.10)\end{array}$ \\
\hline $\begin{array}{l}\text { Binary Variable for Use } \\
\text { of Cooling Towers } \ldots \ldots \ldots \ldots \ldots \ldots \ldots \ldots \ldots\end{array}$ & $\begin{array}{r}0.094 \\
(0.07)\end{array}$ & $\begin{array}{l}-0.020 \\
(0.07)\end{array}$ & $\begin{array}{r}0.094 \\
(0.07)\end{array}$ & $\begin{array}{r}0.094 \\
(0.06)\end{array}$ & $\begin{array}{r}-0.035 \\
(0.06)\end{array}$ & $\begin{array}{r}0.064 \\
(0.07)\end{array}$ \\
\hline $\begin{array}{l}\text { Binary Variable for Plant Being } \\
\text { Single Unit or First of Multi-Unit } \ldots \ldots\end{array}$ & $\begin{array}{l}0.346 \\
(0.06)\end{array}$ & $\begin{array}{l}0.114 \\
(0.07)\end{array}$ & $\begin{array}{r}0.183 \\
(0.07)\end{array}$ & $\begin{array}{r}0.171 \\
(0.05)\end{array}$ & $\begin{array}{r}0.163 \\
(0.05)\end{array}$ & $\begin{array}{r}0.256 \\
(0.06)\end{array}$ \\
\hline Date of Construction startb $\ldots \ldots \ldots \ldots \ldots$ & $\begin{array}{r}0.240 \\
(0.03)\end{array}$ & $\begin{array}{r}0.295 \\
(0.04)\end{array}$ & $\begin{array}{r}0.159 \\
(0.04)\end{array}$ & $\begin{array}{r}0.157 \\
(0.03)\end{array}$ & $\begin{array}{r}0.246 \\
(0.03)\end{array}$ & $\begin{array}{r}0.252 \\
(0.03)\end{array}$ \\
\hline Log of Lead-Time (Actual or Estimated) .. & $\begin{array}{r}1.210 \\
(0.12)\end{array}$ & $\begin{array}{r}0.019 \\
(0.21)\end{array}$ & $\begin{array}{r}0.608 \\
(0.16)\end{array}$ & $\begin{array}{r}0.699 \\
(0.11)\end{array}$ & $\begin{array}{r}0.651 \\
(0.10)\end{array}$ & $\begin{array}{r}0.942 \\
(0.11)\end{array}$ \\
\hline $\begin{array}{l}\text { Experience of Utility That Acts } \\
\text { as Its Own Construction Manager } \ldots \ldots \ldots\end{array}$ & $\begin{array}{r}8.155 \\
(3.15)\end{array}$ & $\begin{array}{r}0.111 \\
(0.24)\end{array}$ & $\begin{array}{r}2.303 \\
(1.11)\end{array}$ & $\begin{array}{r}2.641 \\
(1.17)\end{array}$ & $\begin{array}{r}4.925 \\
(1.58)\end{array}$ & $\begin{array}{r}4.915 \\
(1.90)\end{array}$ \\
\hline Experience of External Contractor ${ }^{d} \ldots \ldots$ & $\begin{array}{r}-1.776 \\
(1.22)\end{array}$ & $\begin{array}{r}0.006 \\
(0.12)\end{array}$ & $\begin{array}{l}-0.286 \\
(0.47)\end{array}$ & $\begin{array}{r}-0.617 \\
(0.55)\end{array}$ & $\begin{array}{l}-1.071 \\
(0.77)\end{array}$ & $\begin{array}{l}-1.129 \\
(0.98)\end{array}$ \\
\hline $\begin{array}{l}\text { Binary Variable for Plant Being } \\
\text { Constructed by Utility } \ldots \ldots \ldots \ldots \ldots \ldots \ldots\end{array}$ & $\begin{array}{l}-0.422 \\
(0.11)\end{array}$ & $\begin{array}{l}-0.199 \\
(0.09)\end{array}$ & $\begin{array}{l}-0.266 \\
(0.12)\end{array}$ & $\begin{array}{l}-0.309 \\
(0.09)\end{array}$ & $\begin{array}{l}-0.383 \\
(0.09)\end{array}$ & $\begin{array}{l}-0.380 \\
(0.10)\end{array}$ \\
\hline R-Squared $\ldots \ldots \ldots \ldots \ldots \ldots \ldots \ldots \ldots \ldots \ldots$ & 0.831 & 0.608 & 0.552 & 0.687 & 0.753 & 0.791 \\
\hline
\end{tabular}

astandard errors shown in parentheses.

bCoefficient and standard error multiplied by 1,000 .

cRepresents the difference in the regression coefficients associated with experience for those utilities that act as their own construction managers and those that employ outside contractors (denoted as INTER in the equations presented in the text).

$\mathrm{d}_{\text {This }}$ is the coefficient associated with the contractor's experience variable (denoted as CST1 in the equations presented in the text).

Source: Computations based on data from Energy Information Administration, Form EIA-254, "Semiannual Progress Report on Status of Reactor Construction," and predecessor survey forms. 
Table 18. Results of "Imputed" Regression Analysis of Real Overnight Cost Forecast Errors

Results for Estimated Costs at Different Stages of Completiona

\begin{tabular}{|c|c|c|c|c|c|}
\hline Variable & 08 & 258 & 508 & 758 & 908 \\
\hline Intercept .............. & -7.605 & $\begin{array}{c}-3.735 \\
--\end{array}$ & $\begin{array}{l}-4.250 \\
--\end{array}$ & $\begin{array}{c}-3.779 \\
--\end{array}$ & $\begin{array}{c}-2.394 \\
--\end{array}$ \\
\hline $\begin{array}{l}\text { Log of Net Megawatts ............. } \\
\text { Binary Variable for Plant Being }\end{array}$ & $\begin{array}{l}-0.142 \\
(0.28)\end{array}$ & $\begin{array}{l}-0.158 \\
(0.32)\end{array}$ & $\begin{array}{l}-0.009 \\
(0.02)\end{array}$ & $\begin{array}{l}-0.129 \\
(0.23)\end{array}$ & $\begin{array}{l}-0.005 \\
(0.01)\end{array}$ \\
\hline $\begin{array}{l}\text { Located in South or Southwest ....... } \\
\text { Binary Variable for Plant Being }\end{array}$ & $\begin{array}{l}-0.027 \\
(0.10)\end{array}$ & $\begin{array}{l}-0.011 \\
(0.02)\end{array}$ & $\begin{array}{l}-0.004 \\
(0.01)\end{array}$ & $\begin{array}{l}0.008 \\
(0.01)\end{array}$ & $\begin{array}{l}-0.006 \\
(0.01)\end{array}$ \\
\hline $\begin{array}{l}\text { Located in West } \ldots \ldots \ldots \ldots \ldots \ldots \ldots \ldots \\
\text { Binary Variable for Use }\end{array}$ & $\begin{array}{r}0.044 \\
(0.09)\end{array}$ & $\begin{array}{r}0.157 \\
(1.16)\end{array}$ & $\begin{array}{r}0.059 \\
(0.38)\end{array}$ & $\begin{array}{r}0.001 \\
(0.01)\end{array}$ & $\begin{array}{r}0.011 \\
(0.01)\end{array}$ \\
\hline $\begin{array}{l}\text { of Cooling Towers } \ldots \ldots \ldots \ldots \ldots \ldots \ldots \\
\text { Binary Variable for Plant Being }\end{array}$ & $\begin{array}{r}0.120 \\
(1.52)\end{array}$ & $\begin{array}{r}0.009 \\
(0.01)\end{array}$ & $\begin{array}{r}0.002 \\
(0.01)\end{array}$ & $\begin{array}{r}0.071 \\
(0.61)\end{array}$ & $\begin{array}{l}0.036 \\
(0.14)\end{array}$ \\
\hline Single Unit or First of Multi-Unit .. & $\begin{array}{c}0.233 \\
(6.53) *\end{array}$ & $\begin{array}{r}0.154 \\
(3.19)\end{array}$ & $\begin{array}{r}0.141 \\
(3.80)\end{array}$ & $\begin{array}{l}0.175 \\
(5.02) *\end{array}$ & $\begin{array}{r}0.083 \\
(1.02)\end{array}$ \\
\hline Date of Construction $s t a r t^{b} \ldots \ldots \ldots$ & $\begin{array}{r}-0.053 \\
(1.16)\end{array}$ & $\begin{array}{r}0.087 \\
(3.13)\end{array}$ & $\begin{array}{r}0.090 \\
(3.65)\end{array}$ & $\begin{array}{r}0.003 \\
(0.01)\end{array}$ & $\begin{array}{l}-0.056 \\
(0.02)\end{array}$ \\
\hline Log of Actual Lead-Time $\ldots \ldots \ldots \ldots \ldots$ & $\begin{array}{c}1.211 \\
(24.34)^{*}\end{array}$ & $\begin{array}{l}1.216 \\
(9.26) *\end{array}$ & $\begin{array}{c}1.245 \\
(11.34) *\end{array}$ & $\begin{array}{c}1.221 \\
(14.25)^{*}\end{array}$ & $\begin{array}{l}1.241 \\
(4.16) *\end{array}$ \\
\hline Log of Estimated Lead-Time ........ & -0.019 & -0.608 & -0.699 & -0.651 & -0.942 \\
\hline $\begin{array}{l}\text { Experience of Utility That Acts } \\
\text { as Its Own Construction Manager } \ldots\end{array}$ & $\begin{array}{c}-- \\
8.050 \\
(6.45) *\end{array}$ & $\begin{array}{c}-- \\
5.631 \\
(2.78)\end{array}$ & $\begin{array}{c}-- \\
5.211 \\
(2.32)\end{array}$ & $\begin{array}{c}- \\
3.043 \\
(0.73)\end{array}$ & $\begin{array}{c}-- \\
3.562 \\
(0.88)\end{array}$ \\
\hline $\begin{array}{l}\text { Experience of External Contractor }{ }^{d} \text {.. } \\
\text { Binary Variable for Plant Being }\end{array}$ & $\begin{array}{c}-1.782 \\
--\end{array}$ & $\begin{array}{c}-1.280 \\
--\end{array}$ & $\begin{array}{c}-1.041 \\
--\end{array}$ & $\begin{array}{c}-0.480 \\
-\end{array}$ & $\begin{array}{c}-0.677 \\
-\end{array}$ \\
\hline Cons tructed by Utility $\ldots \ldots \ldots \ldots \ldots$ & $\begin{array}{l}-0.223 \\
(2.49)\end{array}$ & $\begin{array}{l}-0.146 \\
(0.82)\end{array}$ & $\begin{array}{r}-0.136 \\
(0.61)\end{array}$ & $\begin{array}{l}-0.028 \\
(0.04)\end{array}$ & $\begin{array}{r}-0.055 \\
(0.13)\end{array}$ \\
\hline
\end{tabular}

awith the exception of the lead-times, entries are the difference in the regression coefficients in the actual and estimated cost equations. That is, the entries are the regression coefficients shown in Equation $(6)$ in the text. Because of small differences in the sample for each of the percent complete equations and variations in the construction start date, the actual cost regression coefficients used to compute the differences are not the same as those reported in Table 17. The F-statistics used to test for the equality of the coefficients are shown in parentheses. In all tests, there was 1 degree of freedom in the numerator and 110 in the denominator. The entries associated with the lead-time variables are the absolute regression coefficients; the F-statistic is the one used to test for the equality of the actual and estimated lead-time coefficients in the actual and estimated cost equations. An asterisk indicates that the "imputed" coefficient is significantly different from zero at a 0.95 level of confidence.

b Coefficient and standard error multiplied by 1,000.

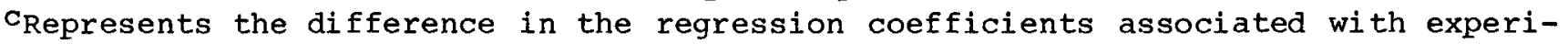
ence for those utilities that act as their own construction managers and those that employ outside contractors (denoted as INTER in the equations presented in the text).

$\mathrm{d}_{\mathrm{Thi}}$ is the coefficient associated with the contractor's experience variable (denoted as CST1 in the equations presented in the text).

Source: Computations based on data from Energy Information Administration, Form EIA-254, "Semiannual Progress Report on Status of Reactor Construction," and predecessor survey forms. 


\section{Regional Effects}

Approximately 60 percent of the direct costs of building a nuclear power plant are labor-related. In the South, some projects are not built with unionized labor. Furthermore, because of the more favorable climate, there are fewer weather-related work stoppages. It is not surprising to observe that, on average, power plants built in the South have lower costs than identical ones constructed in the East and Midwest. As can be seen from Table 17, the initial cost estimates for units located in the South or Southwest were also 8 percent lower than those for units located in the East or Midwest (although the 8 percent difference in estimated costs is not statistically significant). As indicated in Table 18, the imputed regression coefficients associated with the regional binary variables are not significantly different fxom zero, indicating that there were no statistically significant regional differences in the forecast errors. Consequently, it cannot be concluded that incorrect perceptions about regional factors caused the forecast errors.

\section{Experience and Contracting Mechanisms}

As noted in the previous chapter, utilities that acted as their own construction manager had lower real overnight costs than those that did not. This finding is consistent with the hypothesis that utilities which had direct control of the construction process were better able to manage that process, and thus had lower costs.

The regression analysis summarized in Table 17 indicates that utilities acting as their own construction manager also had lower estimated costs. In particular, this analysis found that after controlling the other factors cited above, utilities that acted as their own construction manager had 18 percent lower estimated costs when such estimates were made at the start of construction. However, as shown in Table 18, the imputed regression coefficient associated with the binary variable for plants being constructed by the utility is not statistically different from zero. Thus, on average, utilities that acted as their own construction managers had the same forecast errors as those that employed external construction managers, with all other factors held constant.

One of the most important findings presented in the previous chapter was the lack of any correlation between experience and realized costs when an "outside" contractor managed the construction of the power plant. If there was a correlation between the estimated costs and experience, then this could be one source of the forecast errors. However, there was no statistical correlation between the estimated costs and the experience of outside contractors. Since there were no realized or estimated cost reductions associated with increased experience, this was not a source of the forecast errors.

The story is slightly different for utilities that acted as their own construction manager. As was noted in the previous chapter, there was a statistical correlation between experience and the relative costs when the utility was also the construction manager. There are a number of possible reasons why no such correlation was found in the initial estimated costs (Table 17). First, there are two "learning effects" that work in opposite directions. As the utility gains experience, the realized cost savings should be reflected in the estimated costs. At the same time, as their experience increases, they should also learn of the inherent tendency to underestimate costs and should, therefore, increase their cost estimates. The reason for the absence of any correlation between estimated costs and experience for those utilities that did their own construction could be that these two learning effects 
simply cancel each other. 4 Additionally, the effects of learning might not have been incorporated into the cost estimates.

The imputed regression coefficient associated with the "experience of utility that acts as its own construction manager" variable, shown in Table 18, indicates that the forecast errors by utilities that built their own nuclear power plants, relative to those of utilities that employed outside contractors, fell as they gained experience. The sum of the two experience variables is positive and is marginally significant at the 0.95 level of confidence. The absolute forecast error for those utilities that constructed their own power plants fell as they gained experience. (The associated F-statistic is 3.73, which is significant at the 0.94 level of confidence. $)^{5}$

In summary, the analysis indicates that both estimated and realized costs were lower for utilities that acted as their own construction manager. Moreover, there was no correlation between the forecast error for power plants built by outside contractors and experience. This is due to the fact that there was no correlation between experience and either the estimated or the realized costs. Finally, there is some evidence that learning did reduce the forecast error when the utility acted as its own construction manager, but only when experience is defined as the number of reactor construction years.

\section{Time as Approximation for Regulation}

Regulatory activity has been increasing over time, and thus any time-dependent variable will capture its effects. Since the other measures of regulatory effects were no better as predictors than time, the date of construction start was used in this analysis. The time variable will also capture the effects of industry learning and trends in productivity, since the three are correlated.

The results reported in Table 17 indicate that the initial estimated costs had increased at about 11 percent per year. This escalation, in theory, captures the joint effects of increased regulatory costs, industry learning, and productivity changes. If the time variable only measured the effects of increased regulatory stringency, it could be concluded that regulation of reactor designs and construction caused the estimated costs to increase at a rate of 11 percent per year. 6

4zimmerman obtained the same result, and he used this argument to explain the result. See Martin B. Zimmerman, "Learning Effects and the Commercialization of New Energy Technologies: The Case of Nuclear Power," Bell Journal of Economics and Management Science (Autumn 1982).

5 When experience was defined in terms of the number of reactors completed, instead of the number of reactor construction years, a negative correlation was observed between estimated costs and experience for those utilities that acted as their own construction manager. Moreover, there is no statistical difference between the effects of experience on estimated and actual costs. This is one case where the definition of experience matters.

$6_{\text {Because the time variable is expressed in days, the regression coefficient }}$ associated with the time variable raised to the "e" power is a daily escalation rate. The 11 percent yearly escalation rate is the annualized compound rate consistent with a daily escalation rate of 0.0295 percent. 
More importantly, the imputed coefficient associated with the start of construction variable in the forecast error equation is not significantly different from zero (see Table 18). That is, the forecast exror is not correlated with time. Since time is being used to approximate the effects regulation, industry learning, and productivity changes, it would appear that the forecast errors were not the result of underestimation of these factors.

\section{Size}

One of the major arguments for the increase in nuclear power plant construction costs was the overestimation of economies of scale. In particular, the first generation of commercial nuclear reactors had a capacity of about 400 to 500 MWe. Based upon the experience gained from the construction of these reactors, in the mid-1960's the industry "scaled up" to reactors with a capacity of about 800 MWe, and to over 1,000 MWe for the current generation of plants. Some have argued that "the early cost estimates were based upon an incorrect understanding of the economies of scale."7

The analysis represented in the last chapter and the results reported in Table 17 indicate that size effects would exist if the construction duration were not related to plant size. In the previous chapter, it was found that a 1 percent increase in the size of a power plant was associated with a 0.6 percent reduction in costs per kilowatt. The results of the analysis of estimated costs indicated that a 1 percent increase in the size of a plant was associated with a 0.4 percent reduction in estimated costs. Further, the imputed regression coefficient associated with the size variable (Table 18) indicates that there would be no statistically significant relationship between size and forecast error if the construction duration were not related to plant size.

In short, the size effects reflected in the actual cost data are consistent with the size effects reflected in the costs estimated at the start of construction. It is interesting to note that the estimated scale economies are roughly equal to those derived from CONCEPT -- a large engineering cost model. 8 Simply put, if construction duration did not vary with the size of the plant, there is no evidence that the forecast errors were related to size. As discussed in the concluding section of this chapter, however, when the interaction between size and the real factors approximated by the construction duration is considered, it would be incorrect to conclude that the cost estimates reflected the full effect of size on construction costs.

Engineering studies also suggest that there are economies for building multi-unit plants, which result from the averaging of common costs to a large number of units.9

${ }^{7}$ See M.B. Zimmerman, Bell Journal of Economics and Management Science (Autumn 1982), p. 302

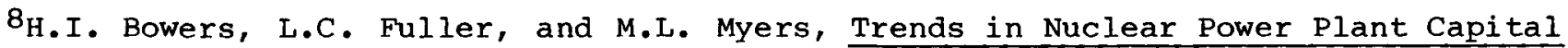
Investment Costs -- 1976 to 1982, ORNL/TM-8898 (Oak Ridge National Laboratory, Oak Ridge, Tennessee, september 1983). Also, see Appendix D for the results of the sensitivity analyses using different assumptions about expected AFUDC and escalation rates.

$9^{9}$ United Engineers and Contractors, Inc., Advanced Engineering Department, Nuclear Power Plant Cost Drivers (Philadelphia, Pennsylvania, July 1983). 
The results of the regression analysis reported in Table 17 indicate that the estimated cost for the second unit of a multi-unit plant was about 11 percent less than that for the first unit or a single-unit plant (although, again, as in the case of regional factors, this difference is not statistically significant). As reported in Appendix D, when the cost equation was estimated using the number of completed reactors as the measure of experience, the coefficient associated with the first unit variable was about the same as the one shown in Table 17, but it is statistically significant. Thus, the evidence for estimated cost savings from building multi-unit plants is not conclusive. As can be seen from Table 18, the imputed regression coefficient associated with the first-unit variable is statistically different from zero. This result implies that the forecast error for the second unit of a multi-unit plant was about 21 percent less than that for the first unit or for a single-unit plant. This implies that the cost estimates for the second unit of a multi-unit plant were more accurate. This result could also be due to a misestimation of the amount of common costs permitted to be allocated to the first unit.

\section{Construction Duration as an Approximation for Managerial Factors and Changes in Regulations Over the Construction Period}

The analysis above indicates that cost overruns for nuclear construction projects were not correlated with size, regional factors, date of construction start, or experience. The same is not true, however, for the effects of managerial factors and regulatory changes associated with longer construction durations.

The expected construction duration variable was included in the regression analysis to capture the effects of expected regulation-induced real cost escalation during the construction period and of perceived time-related management difficulties on the estimated real overnight costs. If these factors were related to the cost estimates, a positive correlation between estimated real overnight costs and the estimated construction duration should be observed. In Table 17, however, no such correlation can be seen between expected costs at the start of construction and expected construction duration. The regression coefficient associated with the variable for expected construction duration is very small and statistically insignificant. In other words, the regression analysis suggests that two plants identical in every respect, except that the expected construction duration for one was twice as long, had the same cost estimates.

This lack of any statistical correlation between estimated construction duration and estimated real overnight costs at the start of construction is to be contrasted with the significant correlation between actual costs and actual construction duration. The analysis in the previous chapter indicated that a 1 percent increase in construction duration was associated with a 1.21 percent increase in the actual real overnight costs. As noted above, this correlation between actual overnight costs and actual lead-time measures the effects of regulation-induced real cost escalation and time-related managerial factors. The lack of any statistical correlation between estimated construction duration and estimated costs implies that neither of these factors was reflected in the cost estimates.

Cost estimates are typically prepared by first computing the overnight costs and then adding AFUDC and cost increases caused by price escalation during the construction 
period.10 Using this approach, the estimated overnight costs would be invariant with time; indeed, this is consistent with the results just presented. Two plants with identical overnight costs but different lead-times would, however, have different final costs, and the analysis indicates that the overnight and the time-related costs should both be functions of time.

To summarize, from a statistical viewpoint, the two major factors explaining the cost overruns in real overnight costs were the absence of any correlation between these costs and expected construction duration and the misestimation of the construction duration. Since the construction duration is being used to approximate the effects of time-related managerial factors and regulatory changes, the analysis suggests that the forecast errors were related to the misestimation of the magnitude of these two problems and their effects on costs.

\section{Changes in the Effects of Lead-Time on Estimated Real Overnight Costs During the Construction Period}

The absence of any correlation between expected lead-times and expected real overnight costs was one determinant of the underestimation of real overnight costs. A question of interest is: At what point in time during the construction period did the cost estimates completely reflect the correlation between costs and lead-times? To answer this question, a regression analysis was performed, identical to the one just described, except that the estimated costs and construction duration for plants that were 25 percent, 50 percent, 75 percent, and 90 percent complete were used. The cost estimates made at some point in time between when the plants were 0 and 100 percent complete should reflect the same statistical relationships as do the actual costs.

The results of this regression analysis are also shown in Table 17 . The regression equation for the forecast errors was imputed using the methodology outlined in the first section of this chapter. The resulting regression coefficients associated with each variable in the forecast error equation, along with the F-statistics, are shown in Table 18. Note that the effects of the different variables -- with the exception of construction duration, experience, and first unit -- on estimated costs are stable regardless of when the cost estimate was made. Even though some of the regression coefficients do vary (with the exceptions just noted), they are never statistically different from the analogous ones in the actual cost equations. (The effect of experience on estimated costs does exhibit some interesting trends, as discussed below.)

Looking at the effects of expected time-related managerial factors and regulatory changes, as measured by the expected construction duration, there is a statistically significant positive correlation between expected lead-time and the cost estimates made at all points during the construction period. More importantly, even for plants that were 90 percent complete, there is a statistical difference between the regression coefficients associated with the construction duration variables in the actual and the estimated cost equation, as shown in Table 18. Thus, even when a unit was

10 For an example of this approach, see Atomic Industrial Forum, A Comparison of the Future Costs of Nuclear and Coal-Fired Electricity (Bethesda, Maryland, November 1984). 
90 percent complete, the cost estimates did not completely reflect the observed correlation between realized lead-times and realized real overnight costs.

To explore this last conclusion in more detail, a similar regression analysis was undertaken, except that the expected construction duration variable was replaced with two others:

- The log of the actual time spent to date

- The $\log$ of the estimated time remaining to complete the plant.

The variable for time spent to date should capture the effects of actual regulationinduced real cost escalation and time-related managerial factors occurring between the start of construction and the time the cost estimates were made. For example, suppose that for one plant it took 2 years to complete the first 25 percent and for a second plant it took 4 years to reach the same point in the construction cycle. With all other factors held constant, any positive difference in the estimated cost of the latter relative to the former would reflect the effects on estimated costs of regulation-induced cost escalation and time-related diseconomies up to that point. The second variable, the remaining time to completion, would capture the effects on costs of perceived future regulation-induced cost escalation and time-related managerial factors, as measured by the estimated time required to complete the plant.

The results of this regression analysis are shown in Table 19. Since the regression coefficients associated with the other variables were similar to those in Table 17, they are not reported. Here is perhaps the most important finding of the study: There is never a statistical relationship between future regulation-induced cost escalation and time-related managerial factors (as measured by the expected time for completion of the project) and estimated real costs. Thus, for two plants identical in every characteristic except that one had a longer estimated time to completion, the estimated costs were the same. This result should be contrasted with the positive correlation between actual costs and actual lead-times. Additionally, there is a positive relationship between the actual time spent to date and expected costs. That is, for two plants with identical estimates of time to complete the project but with different times spent to date, the estimated costs would have been different. This analysis, therefore, reveals a positive correlation between the time it took to reach a certain point in the construction cycle and estimated costs. There is no correlation, however, between the estimated time to complete the project and estimated costs.

The results shown in Table 19 -- specifically, the regression coefficients associated with the time spent to date variable -- suggest that the cost estimates did reflect the regulatory changes and time-related managerial factors that occurred before the cost estimates were made; however, the cost estimates apparently suggest that these factors were not projected forward into the future.

\section{Effects of Experience on Forecast Errors as Plants Approached Completion}

As stated above, there is some evidence that the forecast errors made at the start of construction by utilities that constructed their own plants fell as they gained more experience with the technology. If experience is defined in terms of reactor construction years, the correlation between experience and real overnight costs exists only for estimates made at the start of construction. 


\section{Table 19. Differential Effects of Actual Time Spent to Date and Estimated Time to Completion on Utility Estimates of Real Overnight Costs}

\begin{tabular}{|c|c|c|c|c|}
\hline \multirow[b]{2}{*}{ Time Variable } & \multicolumn{4}{|c|}{$\begin{array}{l}\text { Results for Estimated Costs at } \\
\text { Different Stages of Completion }\end{array}$} \\
\hline & $25 \%$ & $50 \%$ & $75 \%$ & $90 \%$ \\
\hline Log of Time spent to Date $\ldots \ldots \ldots \ldots \ldots$ & $\begin{array}{l}0.340 \\
(0.12) *\end{array}$ & $\begin{array}{l}0.510 \\
(0.09) *\end{array}$ & $\begin{array}{c}0.592 \\
(0.10) *\end{array}$ & $\begin{array}{l}0.850 \\
(0.10) *\end{array}$ \\
\hline Log of Estimated Time to Completion .... & $\begin{array}{c}0.12 \\
(0.12)\end{array}$ & $\begin{array}{l}0.10 \\
(0.12)\end{array}$ & $\begin{array}{c}0.01 \\
(0.10)\end{array}$ & $\begin{array}{c}0.05 \\
(0.04)\end{array}$ \\
\hline
\end{tabular}

\footnotetext{
antries are the regression coefficients associated with the two variables. The other regression coefficients were similar to those shown in Table 15 and thus were omitted from this table. Standard errors are shown in parentheses. An asterisk indicates that the coefficient is significantly different from zero at a 0.95 level of confidence, using a two-tailed test of significance. Source: Computations based on data from Energy Information Administration, Form EIA-254, "Semiannual Progress Report on Status of Reactor Construction," and predecessor survey forms.
}

After that point, however, as can be seen from Table 18, there is no correlation between experience and forecast errors by utilities that acted as their own construction manager, relative to those that employed an outside construction manager. There are several possible reasons for this. First, it could simply be that these utilities underestimated the cost savings as they gained experience, when the estimates in question were prepared while the unit was in an early phase of construction. Thus, early in the construction period, the effect of increases in experience would tend to lower actual costs more than estimated costs, and the forecast errors would fall. Second, when the estimates were prepared later in the construction period, less weight might have been placed on the inherent tendency to underestimate costs. If this were the case, the same relationship between experience and estimated and realized costs would be observed.

When experience is defined in terms of the number of completed reactors, there is a negative relationship between the experience of utilities that did their own construction and the forecast errors in the cost estimates made when the plants were 25, 50, and 75 percent complete. That is, given this definition of experience, at these stages of construction the forecast errors fell as experience increased.

The results of the analysis of experience and the accuracy of the costs estimates is inconclusive. The effect of experience on the forecasts errors depends upon the definition of experience and when the cost estimates were prepared. 


\section{Summary}

The results of this analysis suggest that the cost estimates reflected many of the engineering relationships, in the sense that the implied relationships found in the actual costs were also reflected in the cost estimates. This is particularly true of the size effect. Economies in building large plants were reflected in their cost estimates, and if lead-times had not varied with plant size, in their actual costs. The same, however, was not true of time-related managerial factors and regulatory changes that were associated with longer lead-times. The analysis also suggests that the cost estimates failed to reflect fully the effects of these factors even when the plants were 90 percent complete. Moreover, the analysis appears to suggest that the cost estimates reflected the regulation-induced cost escalation and timerelated diseconomies occurring in the period between the start of construction and the time when their forecasts were made (as measured by the time needed to reach a given point in the construction cycle). There was never a correlation between the estimated time to complete the units and their estimated costs.

There is also some mixed evidence that the forecast errors for those utilities that did their own construction fell as they gained more experience and learned more about the technology. This conclusion depends upon the definition of experience and when the estimates were prepared. The evidence, therefore, is not conclusive.

\section{Factors Affecting the Underestimation of Time-Related Costs}

The preceding section of this chapter presented an analysis of the forecast errors in real overnight costs. This section presents an analysis of the factors that contributed to the other component of total expenditures -- the time-related costs. The factors causing the misestimation of lead-times, the major determinant of the time-related costs, are analyzed below.

The methodology used in this analysis parallels that used in the preceding section. Multiple regression analysis was used to analyze the factors that affected the estimated nominal time-related costs. The imputed regression equation for the errors in the forecasts of time-related costs was derived by subtraction. Stated in mathematical terms, the actual and estimated regression equations for time-related costs were:

$$
\begin{aligned}
\ln (\text { time-costs })= & a_{0}+a_{1} R S+a_{2} R W N W+a_{3} \text { CONSTRT }+a_{4} \text { CST1 }+a_{5} \text { INTER } \\
& +a_{6} \ln (\text { lead-time })+a_{7} \text { BUILD }+e_{1}
\end{aligned}
$$

and

$$
\begin{aligned}
\ln (\text { etime-costs })= & b_{0}+b_{1} R S+b_{2} \text { RWNW }+b_{3} \text { CONSTRT }+b_{4} C S T 1+b_{5} \text { INTER } \\
& +b_{6} \ln (\text { elead-time })+b_{7} \text { BUILD }+e_{2},
\end{aligned}
$$

where the logarithm of the expected time-related costs is represented by In(etimecosts), and all other variables are as defined above.

As before, the regr ssion equation for the forecast errors was "imputed" by subtracting the estimated time-related cost equation from the actual time-related cost equation: 


$$
\begin{aligned}
\ln (\text { time-costs })-\ln (\text { etime-costs })= & \left(a_{0}-b_{0}\right)+\left(a_{1}-b_{1}\right) R S \\
& +\left(a_{2}-b_{2}\right) \text { RINW }+\left(a_{3}-b_{3}\right) \text { CONSTRT } \\
& +\left(a_{4}-b_{4}\right) \text { CST1 }+\left(a_{5}-b_{5}\right) \text { INTER } \\
& +a_{6} \ln (l e a d-t i m e)-b_{6} \ln (\text { elead-time }) \\
& +\left(a_{7}-b_{7}\right) \text { BUILD }
\end{aligned}
$$

The first two variables were included to account for variations in the computation of AFUDC and regional variations in inflation. The date of construction start captures the effects of the general increase in prices over time. The lead-time variable measures the impact of estimated price and interest rate increases over the construction period on the estimated time-related costs.

The results of the regression analysis of estimated time-related costs are shown in Table 20, along with the results of the analysis of actual costs. The imputed regression coefficients for the forecast errors are shown in Table 21 . For the moment, the focus will be on the results for cost estinates made at the start of construction.

As can be seen from Table 20, there was a substantial amount of regional variation in the estimated time-related costs. Estimates of time-related costs for plants located in the South were about 15 percent lower than those for plants located in the North and Midwest. Since the imputed regression coefficients associated with the regional binary variables are not significantly different from zero, as shown in Table 21, the forecast errors for time-related costs cannot be attributed to misestimates of the regional effects on time-related costs.

The date of construction start is included in the regression to measure the effects of general increases in interest rates and the prices of labor and materials used to build a power plant. The results shown in Table 20 indicate that as a result of increases in prices and interest rates, the estimated time-related costs increased at a rate of 21 percent per year. However, the imputed regression coefficient associated with the time variable in the forecast error equation is insignificant (Table 21). It can, therefore, be concluded that the actual historical increases in prices and interest rates were correctly reflected in the estimated time-related costs.

As shown in Table 21, the imputed regression coefficient associated with the time variable in the forecast error equation is not significant. The analysis indicates that the estimated costs did reflect increases in prices prior to the start of construction. The same cannot be said of increases in prices and interest rates during the construction period. In particular, the results reported in Table 20 indicate that a 1 percent increase in the estimated lead-time was associated with a 1.04 percent increase in estimated time-related costs, whereas a 1 percent increase in the actual lead-time resulted in a 2.56 percent increase in the actual time-related costs. A comparison of these two results suggests that the cost estimates did not reflect the increase in prices and interest rates that occurred during the construction period. (Utilities were not the only ones to underestimate the inflation in the 1970 's; the same could be said for all forecasters.)

To determine when the actual escalation in interest rates and inflation was reflected in the estimates of time-related costs, a regression analysis was performed, identical to the one just described except that the cost and lead-time estimates made when plants were 25 percent and 50 percent complete were used. These results are also summarized in Tables 20 and 21. 
Table 20. Results of Regression Analysis of Estimated Time-Related Costs

\begin{tabular}{|c|c|c|c|c|}
\hline \multirow[b]{3}{*}{ Variable } & \multicolumn{4}{|c|}{ Regression Coefficientsa } \\
\hline & \multirow[b]{2}{*}{$\begin{array}{l}\text { Actual } \\
\text { Costs }\end{array}$} & \multicolumn{3}{|c|}{$\begin{array}{c}\text { Estimated Costs at Different } \\
\text { Stages of Completion } \\
\end{array}$} \\
\hline & & 08 & $25 \%$ & 508 \\
\hline Intercept $\ldots \ldots \ldots \ldots \ldots \ldots \ldots \ldots \ldots \ldots \ldots$ & $\begin{array}{r}-16.553 \\
(1.39) *\end{array}$ & $\begin{array}{l}-5.521 \\
(1.95) *\end{array}$ & $\begin{aligned}-11.882 \\
(1.17) *\end{aligned}$ & $\begin{aligned}-10.948 \\
(1.56) *\end{aligned}$ \\
\hline $\begin{array}{l}\text { Binary Variable for Plant Being } \\
\text { Located in South or Southwest } \ldots \ldots \ldots \ldots \\
\text { Binary Variable for Plant Being }\end{array}$ & $\begin{array}{l}-0.195 \\
(0.09) *\end{array}$ & $\begin{array}{l}-0.168 \\
(0.09)\end{array}$ & $\begin{array}{l}-0.153 \\
(0.07) *\end{array}$ & $\begin{array}{l}-0.158 \\
(0.10)\end{array}$ \\
\hline Located in west $\ldots \ldots \ldots \ldots \ldots \ldots \ldots . . . \ldots$ & $\begin{array}{r}0.097 \\
(0.14)\end{array}$ & $\begin{array}{l}-0.181 \\
(0.14)\end{array}$ & $\begin{array}{l}-0.086 \\
(0.11)\end{array}$ & $\begin{array}{r}0.011 \\
(0.14)\end{array}$ \\
\hline Date of Construction startb ............ & $\begin{array}{l}0.534 \\
(0.04) *\end{array}$ & $\begin{array}{l}0.573 \\
(0.05) *\end{array}$ & $\begin{array}{c}0.422 \\
(0.04) *\end{array}$ & $\begin{array}{l}0.520 \\
(0.05) *\end{array}$ \\
\hline Log of Lead-Time (Actual or Estimated) .. & $\begin{array}{l}2.560 \\
(0.17) *\end{array}$ & $\begin{array}{l}1.044 \\
(0.27) *\end{array}$ & $\begin{array}{l}1.981 \\
(0.16) *\end{array}$ & $\begin{array}{l}1.831 \\
(0.20) *\end{array}$ \\
\hline Experience of External Contractor $c \ldots \ldots$ & $\begin{array}{l}-0.811 \\
(1.67)\end{array}$ & $\begin{array}{r}-0.043 \\
(0.16)\end{array}$ & $\begin{array}{r}0.004 \\
(0.47)\end{array}$ & $\begin{array}{r}0.322 \\
(0.99)\end{array}$ \\
\hline $\begin{array}{l}\text { Experience of Utility That Acts } \\
\text { as Its Own Construction Manager } \ldots \ldots \ldots\end{array}$ & $\begin{array}{l}11.15 \\
(5.04) *\end{array}$ & $\begin{array}{l}1.137 \\
(0.31) *\end{array}$ & $\begin{array}{l}2.656 \\
(1.18) *\end{array}$ & $\begin{array}{r}2.851 \\
(2.22)\end{array}$ \\
\hline $\begin{array}{l}\text { Binary Variable for Plant Being } \\
\text { Constructed by Utility } \ldots \ldots \ldots \ldots \ldots\end{array}$ & $\begin{array}{l}-0.690 \\
(0.17)^{*}\end{array}$ & $\begin{array}{l}-0.424 \\
(0.12) *\end{array}$ & $\begin{array}{l}-0.456 \\
(0.11) *\end{array}$ & $\begin{array}{l}-0.569 \\
(0.15) *\end{array}$ \\
\hline
\end{tabular}

astandard errors shown in parentheses. An asterisk indicates that the coefficient is significantly different from zero at a 0.95 level of confidence, using a two-tailed test of significance.

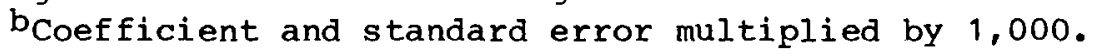

CThis is the coefficient associated with the contractor's experience variable (denoted as CST1 in the equations presented in the text). It can be interpreted as the regression coefficient associated with the experience variable for those utilities that employ outside contractors.

$\mathrm{d}_{\text {This }}$ is the coefficient associated with the interaction term between the binary variable for utilities that act as their own construction managers and the experience variable (denoted as INTER in the equations presented in the text). This coefficient would measure the difference in the regression coefficients associated with experience for those utilities that act as their own construction managers and those that employ outside contractors.

Source: Computations based on data from Energy Information Administration, Form EIA-254, "Semiannual Progress Report on Status of Reactor Construction," and predecessor survey forms. 
Table 21. Imputed Results of Regression Analysis of Time-Related Cost Forecast Errors

\begin{tabular}{|c|c|c|c|}
\hline \multirow[b]{2}{*}{ Variable } & \multicolumn{3}{|c|}{$\begin{array}{l}\text { Results for Estimated Costs at } \\
\text { Different Stages of Completion }\end{array}$} \\
\hline & 08 & $25 \%$ & $50 \%$ \\
\hline Intercept $\ldots \ldots \ldots \ldots \ldots \ldots \ldots \ldots \ldots$ & -11.032 & -4.381 & -4.868 \\
\hline $\begin{array}{l}\text { Binary Variable for Plant Being } \\
\text { Located in South or Southwest } . . . \ldots \ldots \\
\text { Binary Variable for Plant Being }\end{array}$ & $\begin{array}{l}-0.027 \\
(0.04)\end{array}$ & $\begin{array}{l}-0.024 \\
(0.04)\end{array}$ & $\begin{array}{l}-0.014 \\
(0.04)\end{array}$ \\
\hline Located in west $\ldots \ldots \ldots \ldots \ldots \ldots . . . . . . .$. & $\begin{array}{r}0.278 \\
(0.17)\end{array}$ & $\begin{array}{r}0.195 \\
(1.15)\end{array}$ & $\begin{array}{l}-0.093 \\
(0.23)\end{array}$ \\
\hline $\begin{array}{l}\text { Date of Construction start } \ldots \ldots \ldots \ldots \\
\text { Binary Variable for Plant Being }\end{array}$ & $\begin{array}{l}-0.039 \\
(0.31)\end{array}$ & $\begin{array}{r}0.100 \\
(2.37)\end{array}$ & $\begin{array}{l}-0.011 \\
(0.03)\end{array}$ \\
\hline Constructed by Utility $\ldots \ldots \ldots \ldots \ldots$ & $\begin{array}{c}-0.201 \\
--\end{array}$ & $\begin{array}{c}-0.221 \\
--\end{array}$ & $\begin{array}{r}0.070 \\
(0.11)\end{array}$ \\
\hline Log of Actual Lead-Timec $\ldots \ldots \ldots \ldots \ldots$ & $\begin{array}{l}2.560 \\
(21.95) *\end{array}$ & $\begin{array}{l}2.519 \\
(5.29) *\end{array}$ & $\begin{array}{l}2.468 \\
(6.24) *\end{array}$ \\
\hline Log of Estimated Lead-Timec $\ldots \ldots \ldots$ & 1.044 & 1.981 & 1.831 \\
\hline $\begin{array}{l}\text { Experience of Utility That Acts } \\
\text { as Its Own Construction Manager }{ }^{d} \ldots \text {... }\end{array}$ & $\begin{array}{l}10.101 \\
(3.93)\end{array}$ & $\begin{array}{r}7.732 \\
(2.31)\end{array}$ & $(1.956$ \\
\hline Experience of External Contractor ${ }^{e}$.. & $\begin{array}{l}-0.265 \\
(0.21)\end{array}$ & $\begin{array}{l}-0.645 \\
(0.15)\end{array}$ & $\begin{array}{l}-0.669 \\
(0.43)\end{array}$ \\
\hline
\end{tabular}

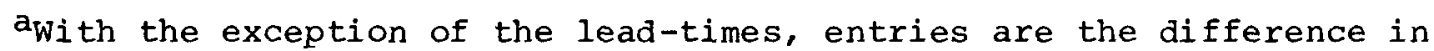
the regression coefficients in the actual and estimated cost equations. The F-statistics used to test for the equality of the coefficients are shown in parentheses. In all tests, there was 1 degree of freedom in the numerator and 110 in the denominator. The entries associated with the lead-time variables are the absolute regression coefficients; the F-statistic is the one used to test for the equality of the actual and estimated lead-time coefficients in the actual and estimated cost equations. An asterisk indicates that the coefficient is significantly different from zero at a 0.95 level of confidence, using a two-tailed test of significance.

bCoefficient and standard error multiplied by 1,000.

$C_{T h e} \mathrm{~F}$-statistic is for the difference between the actual lead-time and estimated lead-time coefficients in the respective equations.

$d_{\text {Represents the difference in the regression coefficients associated }}$ with experience for those utilities that act as their own construction managers and those that employ outside contractors (denoted as INTER in the equations presented in the text).

$\mathbf{e}_{\text {This }}$ is the coefficient associated with the contractor's experience variable (denoted as CST1 in the equations presented in the text).

Source: Computations based on data from Energy Information Administration, Form EIA-254, "Semiannual Progress Report on Status of Reactor Construction," and predecessor survey forms. 
The results presented in Table 20 indicate that a 1 percent increase in estimated lead-time was associated with a 2.0 percent increase in the estimates of time-related costs made when the plants were 25 percent complete. However, the difference between the effects of lead-time on the actual costs and on estimated time-related costs when the plants were 25 percent complete is statistically significant. It would appear, therefore, that the effects of the actual escalation in interest rates and prices were underestimated in the cost forecasts made when the projects were 25 percent complete.

The regression analysis of the estimated costs when the plants were 50 percent complete yielded similar results. As can be seen from Table 20, when the plants were 50 percent complete, a 1 percent increase in estimated lead-time was associated with only a 1.8 percent increase in estimated costs. Again, however, the difference between the effects of lead-times on the actual costs and on estimated time-related costs is statistically significant, as shown in Table 21.

In conclusion, the forecast errors for time-related costs appear to be the result of an underestimation of the increase in prices and costs over the construction period, coupled with a misestimation of lead-times. Interestingly, this finding is true even for cost estimates prepared when the plants were 50 percent complete.

\section{Factors Influencing the Underestimation of Construction Duration}

The analysis just presented indicates that the misestimation of managerial difficulties and regulatory changes, as measured by the forecast error for the construction duration, and the misestimation of their effects on costs were the two major factors contributing to overruns in both real overnight costs and time-related costs. This chapter, therefore, concludes with an analysis of the estimates of construction duration.

The same method that was used to study cost overruns was used for the analysis of construction duration. That is, regression analysis was used to determine the factors that affected actual construction duration. Another set of regressions was then computed using the same explanatory variables but with the estimated construction duration as the dependent variable. To determine which of the factors influenced the forecast errors, the appropriate coefficients in two sets of regressions were compared.

Consequently, a regression analysis of estimated lead-times was undertaken, using the same explanatory variables that were employed in the equation for actual construction duration. The dependent variable was the log of the estimated construction duration, where construction duration is defined as the difference between the date of commercial operation and the date of construction start.

The results of the regression analysis of estimated construction duration are summarized in Table 22. For the moment, the focus will be on the results of the analysis using the estimates made at the start of construction. The results of the regression analysis (Table 22) show no statistical relationship between estimated construction duration and size. The analysis of the estimated construction durations suggested that two plants identical in every aspect except size could be built at the same speed. This result is to be compared with the statistically significant positive relationship between actual construction duration and size. Thus, two plants identical in every aspect except size would have similar estimated construction durations, but very different actual ones. 
Table 22. Results of Regression Analysis of Estimated Lead-Times

Regression Coefficientsa

Estimated Lead-Time at Different Stages of Completion

\begin{tabular}{|c|c|c|c|c|c|c|}
\hline \multirow{2}{*}{\multicolumn{7}{|c|}{ Actual }} \\
\hline & & & & & & \\
\hline Intercept ... & $\begin{array}{c}3.035 \\
(0.88)\end{array}$ & $\begin{array}{c}6.779 \\
(0.77) *\end{array}$ & $\begin{array}{c}4.647 \\
(0.98) *\end{array}$ & $\begin{array}{c}2.672 \\
(1.26) *\end{array}$ & $\begin{array}{c}7.393 \\
(0.89) *\end{array}$ & $\begin{array}{c}7.859 \\
(1.22) *\end{array}$ \\
\hline Log of Net Megawatts $\ldots \ldots \ldots \ldots \ldots \ldots$ & $\begin{array}{c}0.716 \\
(0.20) *\end{array}$ & $\begin{array}{r}0.069 \\
(0.12)\end{array}$ & $\begin{array}{l}0.364 \\
(0.15) *\end{array}$ & $\begin{array}{c}0.743 \\
(0.18) *\end{array}$ & $\begin{array}{r}0.029 \\
(0.12)\end{array}$ & $\begin{array}{l}-0.025 \\
(0.14)\end{array}$ \\
\hline Binary Variable for Plant Being & $\begin{array}{r}0.009 \\
(0.11)\end{array}$ & $\begin{array}{r}0.008 \\
(0.09)\end{array}$ & $\begin{array}{r}0.095 \\
(0.08)\end{array}$ & $\begin{array}{r}0.079 \\
(0.12)\end{array}$ & $\begin{array}{r}0.090 \\
(0.11)\end{array}$ & $\begin{array}{l}0.078 \\
(0.12)\end{array}$ \\
\hline $\begin{array}{l}\text { Located in South or Southwest ....... } \\
\text { Binary Variable for Use }\end{array}$ & $\begin{array}{r}0.005 \\
(0.11)\end{array}$ & $\begin{array}{r}0.006 \\
(0.07)\end{array}$ & $\begin{array}{r}0.101 \\
(0.08)\end{array}$ & $\begin{array}{c}0.096 \\
(0.11)\end{array}$ & $\begin{array}{r}0.094 \\
(0.11)\end{array}$ & $\begin{array}{c}0.043 \\
(0.12)\end{array}$ \\
\hline $\begin{array}{l}\text { of Cooling Towers ........... } \\
\text { Binary Variable for Plant Bein }\end{array}$ & $\begin{array}{c}0.022 \\
(0.08)\end{array}$ & $\begin{array}{r}0.018 \\
(0.04)\end{array}$ & $\begin{array}{c}0.103 \\
(0.05) *\end{array}$ & $\begin{array}{l}-0.007 \\
(0.07)\end{array}$ & $\begin{array}{r}0.016 \\
(0.07)\end{array}$ & $\begin{array}{l}-0.002 \\
(0.08)\end{array}$ \\
\hline $\begin{array}{l}\text { Single Unit or First of Multi-Unit . } \\
\text { Binary Variable for Plant Being }\end{array}$ & $\begin{array}{r}0.047 \\
(0.07)\end{array}$ & $\begin{array}{c}0.151 \\
(0.04) *\end{array}$ & $\begin{array}{r}-0.069 \\
(0.05)\end{array}$ & $\begin{array}{l}-0.169 \\
(0.07)^{*}\end{array}$ & $\begin{array}{c}-0.138 \\
(0.07)\end{array}$ & $\begin{array}{l}-0.124 \\
(0.07)\end{array}$ \\
\hline Constructed by Utility $\ldots \ldots \ldots \ldots \ldots$ & $\begin{array}{r}0.130 \\
(0.16)\end{array}$ & $\begin{array}{l}0.026 \\
(0.11)\end{array}$ & $\begin{array}{l}-0.173 \\
(0.13)\end{array}$ & $\begin{array}{l}-0.100 \\
(0.16)\end{array}$ & $\begin{array}{r}0.216 \\
(0.16)\end{array}$ & $\begin{array}{r}0.321 \\
(0.18)\end{array}$ \\
\hline Date of Construction start ${ }^{b} \ldots \ldots \ldots$ & $\begin{array}{r}0.035 \\
(0.03)\end{array}$ & $\begin{array}{l}0.085 \\
(0.02) *\end{array}$ & $\begin{array}{l}0.123 \\
(0.03) *\end{array}$ & $\begin{array}{l}0.104 \\
(0.03) *\end{array}$ & $\begin{array}{l}0.082 \\
(0.03) *\end{array}$ & $\begin{array}{l}0.082 \\
(0.04) *\end{array}$ \\
\hline $\begin{array}{l}\text { Experience of External Contractor }{ }^{c} \text {. } \\
\text { Experience of Utility That Acts }\end{array}$ & $\begin{array}{r}0.020 \\
(0.32)\end{array}$ & $\begin{array}{l}-0.082 \\
(0.07)\end{array}$ & $\begin{array}{l}-0.242 \\
(0.13)\end{array}$ & $\begin{array}{r}0.005 \\
(0.23)\end{array}$ & $\begin{array}{l}-0.343 \\
(0.30)\end{array}$ & $\begin{array}{l}-0.347 \\
(0.36)\end{array}$ \\
\hline as Its Own Construction Manager ${ }^{d} \ldots$ & $\begin{array}{l}-0.335 \\
(0.67)\end{array}$ & $\begin{array}{l}-0.030 \\
(0.17)\end{array}$ & $\begin{array}{r}0.297 \\
(0.28)\end{array}$ & $\begin{array}{l}-0.054 \\
(0.43)\end{array}$ & $\begin{array}{l}-0.534 \\
(0.58)\end{array}$ & $\begin{array}{l}-0.847 \\
(0.68)\end{array}$ \\
\hline Adjusted R-Squared ............... & 0.273 & 0.382 & 0.433 & 0.281 & 0.188 & 0.135 \\
\hline
\end{tabular}

astandard errors shown in parentheses. An asterisk indicates that the coefficient is significantly different from zero at a 0.95 level of confidence, using a two-tailed test of significance.

bcoefficient and standard error multiplied by 1,000.

CThis is the coefficient associated with the contractor's experience variable (denoted as CST1 in the equations presented in the text). It can be interpreted as the regression coefficient associated with the experience variable for those utilities that employ outside contractors.

$\mathrm{d}_{\text {This }}$ is the coefficient associated with the interaction term between the binary variable for utilities that act as their own construction managers and the experience variable (denoted as INTER in the equations presented in the text). This coefficient would measure the difference in the regression coefficients associated with experience for those utilities that act as their own construction managers and those that employ outside contractors.

Source: Computations based on data from Energy Information Administration, Form EIA-254, "Semiannual Progress Report on Status of Reactor Construction, " and predecessor survey forms. 
Consequently, the incorrect perception that large plants could be built at the same speed as small ones was the most important factor contributing to the misestimation of lead-times. In the previous chapter, it was noted that the positive relationship between actual size and actual construction duration was probably due to managerial and logistical difficulties in building large plants under a fluid regulatory environment. It would appear that these problems were not reflected in the time estimates made at the start of construction.

The date of construction start was used to approximate the effects of increasing regulatory stringency on construction duration. Since the cumulative experience of the industry as a whole is highly correlated with time, the time variable also captures the effects of industry learning on estimated lead-times. Finally, because of decreases in demand projections in the 1970's, estimated lead-times have increased. Thus, the time variable captures the effects of "intentional" delays as well.

The results shown in Table 22 indicate that the net effect of the three factors described above was a 3 percent increase in estimated lead-times. There was, however, no correlation between the construction start dates and actual lead-times. This would imply that the forecast errors for lead-time actually fell over time. This could be the result of overestimation of the effects of regulation (since regulatory stringency has increased over time), underestimation of industry learning, or a greater effect of demand reduction on actual lead-times than on estimated lead-times.

The regression results reported in Table 22 also indicate that single-unit plants or the first units of multi-unit plants had shorter estimated construction durations than the second units of multi-unit plants when the estimates were made at the start of construction. Since the first unit is almost always the first to become operational, this result is not surprising. However, the same effect is not observed in the actual construction duration data.

To repeat, the most important finding of this analysis was the absence of any correlation between size and estimated lead-times. To determine when utilities began to perceive that it took longer to build larger plants, a similar regression analysis was undertaken, except that construction duration estimates made when the plants were 25, 50, 75, and 90 percent complete were used as the dependent variables. At some point in the construction period between when the plant was 0 and 100 complete, a positive relationship between size and construction duration should be observed in the estimated construction duration.

The results of this analysis, also shown in Table 22, yield some conflicting results. The effect of size on estimated lead-time varies substantially depending upon when the estimate was made. There is a statistically significant relationship between size and the construction duration estimated when the plants were either 25 or 50 percent complete. This relationship, however, is not present for the estimates made when the plants were either 75 or 90 percent complete. The evidence as to when utilities began to perceive the relationship between size and construction duration is, therefore, inconclusive.

In conclusion, only a few factors appear to have influenced estimated lead-times. Although there is evidence that estimates of lead-times have increased over time, it is impossible to determine whether this was due to increased regulatory stringency, decreased demand projections, or financial difficulties. The only other factor that influenced lead-time estimates was size. The effects of size on estimated lead-times, however, depend upon when the estimates were made. 


\section{Conclusions}

As stated in Chapter 3, the actual construction duration was used to approximate the effects on actual costs of increased managerial difficulties and regulatory changes associated with longer "lead-times." Similarly, expected construction duration was used to approximate the effects on estimated costs of anticipated managerial difficulties and regulatory changes. Thus, there are two possible reasons why a positive correlation between estimated construction duration and estimated costs was not observed. First, the estimators may not have made the association between increases in expected lead-times and increases in managerial problems and regulatory changes. Second, even if they did make the association, they may have failed to associate increases in managerial difficulties and regulatory changes with higher costs.

Finally, the analysis presented in Chapter 3 indicated that the total effect of size on costs can be decomposed into two parts. The first is the effect of size on costs that is independent of lead-time, and the second consists of the effect of size that works through lead-time. The analysis presented in this chapter suggests that the direct effect of size on costs was reflected in the estimated cost data. More importantly, the statistical analysis suggests that the cost estimates did not reflect the correlation between estimated lead-times and estimated costs. This, in turn, implies that the cost estimates did not reflect the indirect effect of size on costs. In this sense, the full effect of size on costs was not correctly perceived. This failure to perceive correctly the indirect effects of size on costs was not the result of a failure to perceive that larger plants took longer to build. Instead, it was the result of an incorrect perception of the relationship between cost and lead-time. 


\section{Summary and Conclusions}

The analysis presented in the preceding chapters was undertaken to explore the factors underlying the escalation in the construction costs of nuclear plants. The analysis shows that, contrary to the beliefs of some industry analysts, a substantial amount of the real cost increase is the result of factors causing the escalation in real overnight costs, rather than an increase in real costs due to licensing and other delays. By separating real overnight costs from real time-related costs, it was shown that much of the escalation has resulted from increases in the former. The importance of the escalation in real overnight costs has significant implications for current policy decisions. Attempts to use policy to control the costs of units still under construction or planned for future construction must address not only the licensing time required to either start construction or begin commercial operation but also factors related to the design of the reactors and to the construction process.

The escalation in reported, or rate base, costs (in mixed current dollars inclusive of AFUDC) is primarily the result of increases in time-related costs. However, at least part of the escalation in time-related costs is the result of increases in the overnight costs, since borrowing costs are influenced by overnight costs. Thus, attempts to control the reported mixed current dollar costs must also address the issues causing escalation in the overnight costs -- i.e., those factors that influence reactor design and construction.

As a descriptive summary of the sample of plants, this analysis highlights some important general features of the construction process. First, the analysis of historical cost and lead-time estimates indicates that to produce good estimates, engineering process models must be supplemented by socioeconomic information. This is particularly important in the matter of how managerial and regulatory factors influence the total overnight costs of a unit. Furthermore, the results of the analysis indicate that the influence of lead-time was not accurately accounted for in the estimates of time-related costs. To some degree this misestimation was caused by the underestimation of inflation. The misestimation of time-related costs may also follow directly from the failure to recognize the influence of lead-time on the overnight costs, since estimators would not have planned sufficiently for escalation and borrowing costs of lead-time-related increases in the overnight costs.

Also of importance to the economics of completed nuclear units is the relationship of size, lead-time, and overnight costs. Some authors have criticized the industry for attempting to build plants beyond the optimal scale. 1 The results of this study indicate that, on average, the indirect effect of size (i.e., the fact that larger plants took longer to build and therefore had higher real overnight costs) outweighs the direct size effect (economies of scale). Thus, there appears to be some evidence consistent with the hypothesis that internal diseconomies of scale exist for large units -- i.e., they are too large to be efficiently managed by the constructors. This result suggests that smaller multi-unit plants might have been the most efficient to build. 2

1 See Martin B. Zimmerman, "Learning Effects and the Commercialization of New Energy Technologies: The Case of Nuclear Power," Bell Journal of Economics and Management Science (Autumn 1982).

2 It should be noted that a few large units -- namely, McGuire and LaSalle -- were also relatively inexpensive. However, these units were constructed by utilities that acted as their own construction manager. 
The analysis also indicates that the management regime under which a nuclear power plant is constructed is an important statistical determinant of real overnight construction costs. First, utilities that manage their own construction can build power plants at lower costs than utilities employing outside contractors. Second, when an outside contractor manages the construction, there is no correlation between real overnight costs and experience. If outside contractors did benefit from increased experience, such learning effects did not result in lower costs. In contrast, the analysis indicates that when utilities managed their own construction, costs fell as experience increased.

There is some evidence that industry learning has affected lead-times for plants that entered construction after 1972 and were scheduled to become operational by the end of 1985. There could be a purely statistical explanation for this result, since the plants in this category with the longest lead-times are not yet complete and were not included in the sample. The analysis suggests that some utilities are learning to build plants in less time; however, there is no evidence that they are learning to build plants with lower real overnight costs.

Further research is warranted in several areas. First, additional studies should be made of the plants begun after 1972 that were identified by the lead-time analysis as having a time/lead-time relationship significantly different from that for the other units in the sample. In particular, it would be useful to know what causes underlie the result that the effect of the construction start date variable on actual lead-times is both negative and significant for units begun after 1972 .

Second, because the cost increases due to managerial factors and those due to regulatory changes could not be distinguished on the basis of the available data, further work is needed before the influence of these two factors can be separated. Such a task will require more detailed studies of the historical accounts of each unit's construction, specifically focusing on the causes underlying particular changes in design, reworking of completed tasks, scheduling problems, and so on. The importance of distinguishing these influences cannot be overemphasized, because the success of current and future public policies aimed at the problems of the nuclear construction process is ultimately tied to identifying the cause of those problems.

Third, the issue of the management regime under which a power plant is constructed needs additional study. Such research could provide important insights into the problem of determining the most efficient institutional structure for building a nuclear power plant. This is another issue that can be answered only on the basis of detailed case studies.

Fourth, this study has not addressed the subject of the costs of retrofits and other regulation-induced postoperational capital investments. The capital cost data used in this study dealt exclusively with preoperational construction costs. In some cases, however, the same changes required for plants under construction have also been required for operating plants. For example, the costs of design changes because of the accident at Three Mile Island would be reflected in the data for plants under construction but not for plants in operation. It is not clear whether the same increases in the capital costs of nuclear power plants over time would be observed if total costs, for both the construction and postoperation periods, were considered. Although lifetime data are not available for most units, analysis of the available postoperation data could provide some insight into this question. 
Care must be taken not to interpret these results as absolute predictions of the future. Although it is tempting to use the results of a statistical analysis for prediction, one should not make the mistake of forgetting the assumptions that underlie this practice. Most important among these assumptions is that the general conditions defining the sample will also apply to the cases in the forecasts. Analysts must critically evaluate the extent to which past and future situations can be considered to be "the same."

To summarize, this analysis provides some general insights into the historical experience of the current sample of nuclear units, which may be useful for planning purposes. However, before any specific forecasts can be made regarding the construction process for future nuclear plants, several questions about the current sample of plants remain to be answered. 
, 
$$
\text { . }
$$ 


\section{Methodology Used to Compute Real Overnight Costs and Time-Related Costs}

The objective of this appendix is to document in detail the computation of estimated and actual real overnight costs. As was stated in the text, the other studies in this area also recognized that the reported costs are not in a form that is suitable for cost analyses. Because of the availability of large amounts of unpublished but publicly available data, the approach used in the present study differed from those of previous studies. Moreover, some of the results of this analysis differ from those of previous studies -- in all probability, due to the method used to calculate overnight costs. Consequently, a description of the methods used by other researchers to calculate real overnight costs is presented here, followed by a discussion of the approach used in the present study. The appendix concludes with a description of the computation of estimated overnight costs.

Method Used in Previous Studies to Calculate Real Overnight Costs

The following set of equations was used in previous studies ${ }^{1}$ to calculate real overnight costs:

$$
\begin{aligned}
x & =\frac{R}{\sum_{t=0}^{T} P_{t} \cdot\left[\prod_{t=t+1}^{T}\left(1+r_{t}\right) \cdot \prod_{t=0}^{t}\left(1+i_{t}\right)\right]}, \\
c_{t} & =\left\{1-[\cos (\pi / 2 \cdot t / T)]^{4.082}\right\}^{3.250}, \\
P_{t} & =c_{t}-C_{t-1},
\end{aligned}
$$

where: $\mathrm{x}=$ real overnight costs in the dollars of the year construction of the plant began,

$$
\begin{aligned}
& R=\text { reported costs, } \\
& C_{t}= \begin{array}{l}
\text { cumulative real cash outlays at the end of year } t \text { as a percent of the } \\
\text { total, }
\end{array} \\
& P_{t}=\text { real cash outlays in year } t \text { as a percent of the total, } \\
& i_{t}=\text { annual escalation rate in year } t, \\
& r_{t}=\text { the rate used to compute the allowance for funds used during construc- } \\
& \text { tion (AFUDC), and } \\
& T=\text { the number of years in the construction period. }
\end{aligned}
$$

Equation ( $A 1 \mathrm{~b}$ ) is called the cash profile curve, because it represents the cumulative cash outlays as a function of time. Equation (A1C) is simply an identity that states that the incremental cash outlays are equal to the difference between the cumulative outlays at the end of periods $t$ and $t-1$.

1 For a more detailed description, see U.S. Atomic Energy Commission, Power Plant Capital Costs, Current Trends, and Sensitivity to Economic Parameters, WASH-1345 (Washington, D.C., October 1974). 
The derivation of Equation (A1a) is as follows. First, Equation (A1a) can be rewritten as:

$$
R=x\left[\sum_{t=0}^{T} P_{t} \cdot \prod_{t=t+1}^{T}\left(1+r_{t}\right) \cdot \prod_{t=0}^{t}\left(1+i_{t}\right)\right]
$$

Next, $R_{t}$, the incremental cash outlays in current dollars, including AFuDC in the dollars of year $t$, would equal:

$$
\begin{aligned}
& R_{1}=x_{1}\left(1+i_{1}\right)\left(1+r_{2}\right)\left(1+r_{3}\right) \cdot \cdot\left(1+r_{T}\right) \\
& R_{2}=x_{2}\left(1+i_{1}\right)\left(1+i_{2}\right)\left(1+r_{3}\right)\left(1+r_{4}\right) \cdot \cdot \cdot\left(1+r_{T}\right) \\
& R_{3}=x_{3}\left(1+i_{1}\right)\left(1+i_{2}\right)\left(1+i_{3}\right)\left(1+r_{4}\right)\left(1+r_{5}\right) \cdot \cdot \cdot\left(1+r_{T}\right) \\
& \dot{~} \\
& R_{T}=x_{T}\left(1+i_{1}\right)\left(1+i_{2}\right)\left(1+i_{3}\right) \cdot \cdot \cdot\left(1+i_{T}\right),
\end{aligned}
$$

where $x_{t}$ signifies the real cash outlays in year $t$, and

$$
\mathrm{x}_{\mathrm{t}}=\mathrm{xP}_{\mathrm{t}}
$$

By substituting Equation (A4) into Equation (A3), we obtain

$$
\begin{aligned}
& R_{1}=X P_{1}\left(1+i_{1}\right)\left(1+r_{2}\right)\left(1+r_{3}\right) \cdot \cdot\left(1+r_{T}\right) \\
& \dot{ } \\
& R_{T}=X_{T}\left(1+i_{1}\right)\left(1+i_{2}\right)\left(1+i_{3}\right) \cdots \cdot\left(1+i_{T}\right) .
\end{aligned}
$$

Thus, the total reported costs would be $R_{t}$, or

$$
R=\sum_{t=0}^{T} x\left[P_{t} \cdot \prod_{t=t+1}^{T}\left(1+r_{t}\right) \cdot \prod_{t=0}^{t}\left(1+i_{t}\right)\right],
$$

which is simply Equation (A2).

In the studies that examined actual costs, the Handy-Whitman index was used to calculate the annual escalation rate, $i_{t}$, and the average cost of debt was used as a proxy for the AFUDC rate, $r_{t}$. In the one other study that examined estimated costs, the result of 10-year Treasury rates less the real expected rate of interest was used for the expected inflation rate (see Appendix B for a review of these studies). The expected AFUDC rate was assumed to equal the average interest rate on long-term bonds for utilities with the same bond rating as the utility in question. 


\section{Computation of the Actual Real Overnight Costs Used in the Analysis}

As was stated in the text, there are two basic problems (one of which was recognized by the other researchers) with the approach just outlined. First, the generic cash profile curve used in the other studies [Equation (A1b)] was estimated using data from the early 1960's and thus is at best an approximation to the actual ones. ${ }^{2}$ The use of a cash profile curve to calculate the overnight costs for the early generations of plants probably did not result in any serious problems. However, since during the construction period many of the current generation of plants underwent substantial design changes and backfits that required major amounts of rework, using any cash profile curve, especially one estimated in the early 1960's, would not be appropriate. Second, the AFUDC rate, in theory, equals the weighted cost of capital used to calculate the revenue requirements and thus would not equal the rate of interest used in the other studies. Moreover, the effective AFUDC rate is influenced by several important accounting variations that would further distort any relationship between the AFUDC rate and average interest rates.

Because of these two problems, this study used a different approach. First, instead of using a generic cash profile curve, we obtained the actual cumulative expenditures in mixed current dollars, inclusive of AFUDC, from a combination of the information on disbursed costs to date from Form EIA-254 and the cumulative Construction work in Progress (CWIP) data from Form FERC-1. The second step was to estimate the annual AFUDC charge for each year of construction of each nuclear unit. This was done by simultaneously solving the following equations:

$$
\begin{aligned}
\operatorname{CWIP}_{t}= & \operatorname{CWIP}_{t-1}+\text { OUTLAY }_{t}+\text { AFUDC }_{t}, \\
\text { AFUDC }_{t}= & \left(\text { CWIP }_{t-1}+\operatorname{OUTLAY}_{2}\right) \operatorname{RATE}_{t} \\
& +\left(\mathrm{CWIP}_{t-1}+\operatorname{OUTLAY}_{t} / 4\right)(\operatorname{RATE} / 2)^{2},
\end{aligned}
$$

where: $\quad$ CWIP $_{t}=$ cumulative expenditures, including AFUDC, in year $t$, OUTLAY $=$ cash outlays for construction in year $t$, and

RATE $_{t}=$ the AFUDC rate in year $t$.

Equation (A6) is merely a statement of the accounting relationship among the variables. It states that the total CWIP at the end of any year, $t$, is equal to the total CWIP as of the beginning of that year, plus the carrying charges on the average investment balance during the year -- i.e., AFUDC.

Equation (A7) approximately describes the process by which AFUDC is capitalized during the year. It is an approximation because it assumes the following:

- AFUDC is compounded semiannually

- The AFUDC rate used remains constant throughout the year

- Costs and cash outlays are uniformly distributed throughout the year.

The first assumption is reasonable because the Federal Energy Regulatory Commission (FERC) has prescribed semiannual compounding except in rare cases in which the utility can justify deviating from this rule. The second assumption is not precisely

2see U.S. Atomic Energy Commission, Power Plant Capital Costs, Current Trends, and Sensitivity to Economic Parameters, WASH-1345 (Washington, D.C., October 1974). 
correct, because some utilities recalculate the AFUDC rate semiannually or even more frequently. They do that to account for changes in interest rates, in the cost of common and/or preferred equity capital, and in their capital structures. However, these interim adjustments do not substantially change the rates. The third assumption is the most troublesome, because cash outlays are not likely to occur uniformly throughout the year. Still, the plant's AFUDC is accrued on the existing CWIP rather than on the incremental cash investments; thus, the relative amount of error introduced into the approximation is probably not large. Furthermore, adjustments were made to Equation (A7) to account for the exact month a power plant entered service, at which time AFUDC capitalization ceased. Combining Equations (A6) and (A7) yields:

$$
\begin{aligned}
& \text { AFUDC }_{t}={ }^{\left(\mathrm{CWIP}_{t}+\mathrm{CWIP}_{t-1}\right)\left(\mathrm{RATE}_{t} / 2\right)+\left(\mathrm{CWIP}_{t}+3^{\cdot} \mathrm{CWIP}_{t-1}\right)\left(\mathrm{RATE}_{t} / 4\right)^{2}} . \\
& 1+\operatorname{RATE}_{t} / 2+\left(\operatorname{RATE}_{t} / 4\right)^{2}
\end{aligned}
$$

Once the AFUDC is estimated, Equation (A6) is used to calculate the cash outlays in year $t$.

Besides the cumulative expenditures, information about the AFUDC rates is needed. These data, for each utility for each year, were also obtained from Form FERC-1. After the yearly cash outlays were calculated, they were deflated (inflated) to either 1982 or the year that construction began, using the Handy-Whitman Index for Total Nuclear Plant for the appropriate region where the plant was located. The real overnight costs were calculated by simple addition.

Three important accounting variations were also included in the calculations. First, it was assumed that the accrual of AFUDC ceased the month the plant began commercial operation. Thus, the AFUDC rate for the year the plant began operation was appropriately scaled. Second, in many cases, the AFUDC was not compounded, in the sense that the AFUDC was calculated using the cumulative CWIP exclusive of accrued AFUDC, and in almost all cases this was reported on From FERC-1. When the AFUDC was not compounded, the following version of Equation (A8) was used:

$$
\operatorname{AFUDC}_{t}=\frac{\left(\operatorname{CWIP}_{t}+\operatorname{CWIP}_{t-1}\right)\left(\operatorname{RATE}_{t} / 2\right)-\sum_{t=0}^{t-1} \operatorname{AFUDC}_{t} \cdot \operatorname{RATE}_{t}}{1+\operatorname{RATE}_{t} / 2} .
$$

Finally, AFUDC is accrued on that portion of the CWIP that is not included in the rate base. The utilities that were permitted to place some CWIP in the rate base and the annual amounts were identified either from Form FERC-1, from annual reports, or from discussion with state regulatory commissions. The amount of AFUDC was reduced by the amount of CWIP included in the rate base, multiplied by the AFUDC rate for that year.

The plants for which changes were made to account for the second or third accounting variation are shown in Table A1. As can be seen from this table, six utilities did not report any $A F U D C$, which could produce spurious variations in reported costs in the neighborhood of 28 to 40 percent. Moreover, the noncompounding of AFUDC could also result in variations of 10 to 20 percent in the reported costs. Thus, as was noted in the text, the cost data including AFUDC are not comparable. 


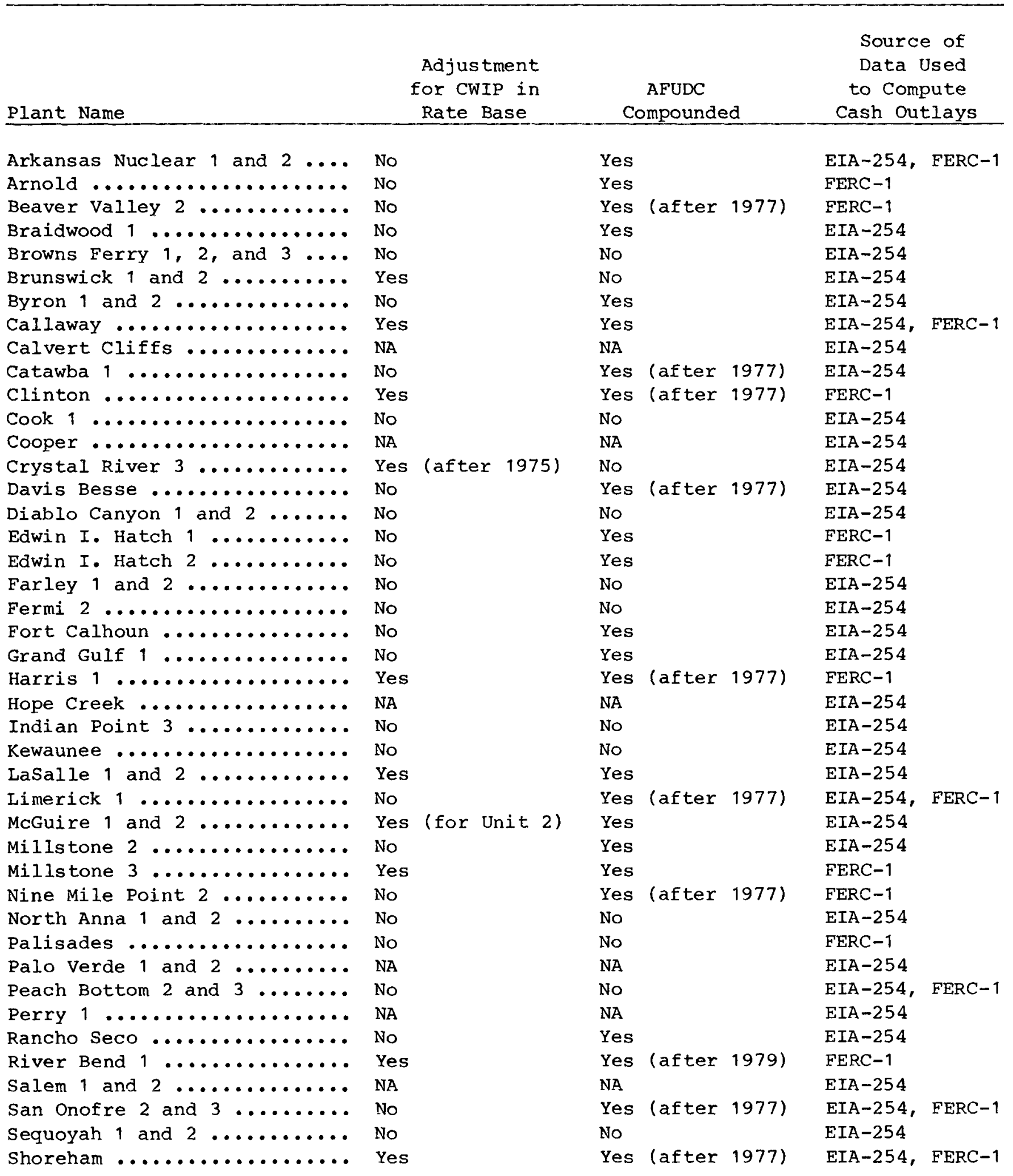


Table A1. Summary of Accounting Variations and Sources of Data (Continued)

\begin{tabular}{|c|c|c|c|}
\hline Plant Name & $\begin{array}{l}\text { Adjustment } \\
\text { for CWIP in } \\
\text { Rate Base }\end{array}$ & $\begin{array}{c}\text { AFUDC } \\
\text { Compounded } \\
\end{array}$ & $\begin{array}{c}\text { Source of } \\
\text { Data Used } \\
\text { to Compute } \\
\text { Cash Outlays }\end{array}$ \\
\hline st. Lucie 1 and $2 \ldots \ldots \ldots \ldots$ & Yes (after 1975) & Yes (after 1982) & EIA-254 \\
\hline Summer $1 \ldots \ldots \ldots \ldots \ldots \ldots$ & No & Yes (after 1977) & $E I A-254$ \\
\hline Surry 1 and $2 \ldots \ldots \ldots \ldots \ldots$ & No & No & EIA -254 \\
\hline Susquehanna 1 and $2 \ldots \ldots \ldots$ & No & Yes (after 1977) & $E I A-254$ \\
\hline Three Mile Island 1 and $2 \ldots$ & No & Yes (after 1977) & EIA-254 \\
\hline $\operatorname{Trojan} \ldots \ldots \ldots \ldots \ldots \ldots \ldots$ & No & No & $E I A-254$ \\
\hline Waterford $\ldots \ldots \ldots \ldots \ldots \ldots$ & Yes & No & EIA-254, FERC-1 \\
\hline Wolf Creek $1 \ldots \ldots \ldots \ldots \ldots$ & No & Yes & FERC -1 \\
\hline WPPSS $2 \ldots \ldots \ldots \ldots \ldots \ldots \ldots$ & No & No & $E I A-254$ \\
\hline zion 1 and $2 \ldots \ldots \ldots \ldots \ldots$ & No & Yes & EIA-254, FERC- \\
\hline
\end{tabular}

NA = not applicable (AFUDC not included in data).

\section{Validation of the Computation of Cash Outlays}

Two attempts were made to validate the computations of cash outlays. One consisted of a comparison of a limited number of actual yearly cash outlays with the computed ones. The cumulative actual cash outlays reported from two sources were also compared to the cumulative computed ones.

The actual yearly cash outlays for about 18 units were obtained from various sources. For some reason, in many cases, the yearly reported cash outlays including AFUDC were different from the ones reported on Form EIA-254 and Form FERC-1. In these cases, comparison of yearly cash outlays obviously is not valid. In the other instances, when the costs including AFUDC from the various sources were comparable, the yearly cash outlays, both calculated and actual, were generally within 5 percent of each other. The amounts of cumulative cash outlay, with and without AFUDC, for a large number of units are published by the Tennessee valley Authority. ${ }^{3}$ Similar data for plants currently under construction or just completed are now reported on Form EIA-254.4

${ }^{3}$ Tennessee Valley Authority, Office of Engineering, U.S. Nuclear Plants Cost Per kW Report (Chattanooga, Tennessee, March 1985).

${ }^{4}$ The revised Form EIA-254 specifies that all common costs for a multi-unit plant be allocated to the first unit. In the data used in the present study, the allocation was dictated by the appropriate regulatory commission, which usually required that only about 50 to 60 percent of these costs be allocated to the first unit. Thus, in some cases, comparing the cash outlays from the new Form EIA-254 to the ones used in this study will not be strictly valid. 
A comparison of the cash outlays from the TVA report with the calculated ones is displayed in Table A2.5 As can be seen from this table, the calculated cash outlays are again generally within 5 percent of the actual amounts. The only three units for which the difference between the actual and the calculated cash outlays was larger than 10 percent were Limerick 1, Susquehanna 2, and Shoreham. For Susquehanna 2 , the difference was due to a major reallocation of the common costs in the late 1970 's. Because the AFUDC is in many cases compounded, the calculation of AFUDC depends upon the time distribution of the expenditures as well as the totals. Hence, any major distortion in the time distribution of the cash outlays -- distortions caused by reallocation of the common costs -- will influence the results. For Shoreham, the difference was due to the fact that the Form EIA-254 data may not have included capitalized property taxes.

\section{Comparison of the Real Overnight Costs Used in This Study With Those Used by Others}

As stated above, the method used to calculate the overnight costs in the present study differed from those used in other studies. An interesting question is whether the different methods produced different results.

The other empirical studies of construction costs used a sample of plants that became operative before the late 1970's. In all probability, using a cash profile curve for plants of this vintage did not result in any serious biases. Indeed, an inspection of the calculated cash profile curve for several plants suggested that using a generic cash profile curve was reasonable. Using average debt rates, however, did create some problems.

The average of the actual AFUDC rates used in the present analysis and the average debt rates used in the other studies are plotted in Figure A1. As can be seen, until the early 1980's the AFUDC rates were higher than average debt rates, which implies that the use of the latter will overstate the cash outlays. Thus, using average debt rates will lead to overnight costs that are "too high," a conclusion confirmed by comparing overnight costs from Komanoff's study with the ones used in the present study. Furthermore, as can be seen from Figure A1, the bias will decrease over time. Thus, the bias will correlate negatively with time and with any other time-trended variable. That relationship is significant because all the other studies used a time variable and other time-trended variables as independent variables in their regression analyses. It can easily be seen that in such cases the regression coefficient associated with any variable that is increasing over time will be biased in a downward direction.

5The computed amount of AFUDC was also compared to the amount reported on Form EIA-254. Because of confidentiality requirements, the results of that comparison cannot be reported here. The comparison was favorable. 
Table A2. Comparison of Computed Cash Outlays With Cash Outlays Reported by TVA

\begin{tabular}{|c|c|c|c|}
\hline Plant Name & $\begin{array}{c}\text { Cumulative } \\
\text { Cash Outlays } \\
\text { Computed }\end{array}$ & $\begin{array}{c}\text { Cumulative } \\
\text { Cash Outlays } \\
\text { Reported by TVA }\end{array}$ & $\begin{array}{c}\text { Percent } \\
\text { Difference } \\
\end{array}$ \\
\hline Arkansas Nuclear $1 \ldots$ & 188,078 & 199,000 & -0.0581 \\
\hline Arkansas Nuclear $2 \ldots$ & 467,084 & 488,000 & -0.0448 \\
\hline Beaver valley $2 \ldots \ldots$. & $2,340,000$ & $2,340,000$ & 0.0000 \\
\hline Braidwood 1 ......... & $1,583,742$ & $1,583,742$ & 0.0000 \\
\hline Browns Ferry $1, \ldots \ldots \ldots$ & 260,766 & 275,600 & -0.0569 \\
\hline Browns Ferry $2 \ldots \ldots \ldots$ & 199,574 & 206,700 & -0.0357 \\
\hline Browns Ferry $3 \ldots \ldots \ldots$ & 199,574 & 206,700 & -0.0357 \\
\hline Brunswick $1 \ldots \ldots \ldots \ldots$ & 248,467 & 250,000 & -0.0062 \\
\hline Brunswick $2 \ldots \ldots \ldots$ & 302,667 & 313,000 & -0.0341 \\
\hline Byron $1 \ldots \ldots \ldots \ldots$ & $1,655,446$ & $1,627,000$ & 0.0172 \\
\hline Byron $2 \ldots \ldots \ldots \ldots$ & $1,021,594$ & $1,244,000$ & $-0.2177^{b}$ \\
\hline Callaway ............. & $2,019,022$ & $1,950,000$ & 0.0342 \\
\hline Calvert cliffs $1 \ldots \ldots$ & 349,677 & 351,000 & -0.0038 \\
\hline Calvert Cliffs $2 \ldots .$. & 250,587 & 237,000 & 0.0542 \\
\hline Crystal River $3 \ldots \ldots$ & 319,977 & 326,000 & -0.0188 \\
\hline Davis-Besse $1 \ldots \ldots \ldots$ & 527,542 & 553,000 & -0.0483 \\
\hline Diablo Canyon $1 \ldots . .$. & $2,237,599$ & $2,136,000$ & 0.0454 \\
\hline Diablo Canyon $2 \ldots .$. & $1,374,217$ & $1,393,000$ & -0.0137 \\
\hline Edwin I. Hatch $1 \ldots \ldots$ & 294,377 & 307,000 & -0.0429 \\
\hline Edwin I. Hatch $2 \ldots \ldots$ & 405,142 & 425,000 & -0.0464 \\
\hline Fermi $2 \ldots \ldots \ldots \ldots \ldots$ & $2,391,929$ & $2,543,000$ & -0.0632 \\
\hline Fort Calhoun $1 \ldots \ldots$. & 150,556 & 150,000 & 0.0037 \\
\hline Grand Gulf 1 ........ & $1,983,637$ & $2,100,000$ & -0.0587 \\
\hline Hope Creek 1 ........ & $2,865,000$ & $2,865,000$ & 0.0000 \\
\hline Joseph M. Farley 1 ... & 542,297 & 551,000 & -0.0160 \\
\hline Joseph M. Farley $2 \ldots$ & 601,130 & 613,000 & -0.0197 \\
\hline LaSalle $1 \ldots \ldots \ldots \ldots$ & $1,031,862$ & $1,022,000$ & 0.0096 \\
\hline LaSalle $2 \ldots . . . \ldots$ & 798,824 & 813,000 & -0.0177 \\
\hline Limerick $1 \ldots \ldots \ldots$ & $2,533,652$ & $2,266,000$ & 0.1056 \\
\hline McGuire 1 .......... & 630,855 & 624,000 & 0.0109 \\
\hline McGuire 2 .......... & 670,526 & 690,000 & -0.0290 \\
\hline Millstone $2 \ldots \ldots \ldots$.... & 323,463 & 348,000 & -0.0759 \\
\hline Millstone $3 \ldots \ldots \ldots$ & $2,634,000$ & $2,634,000$ & 0.0000 \\
\hline Nine Mile Point $2 \ldots$. & $3,298,572$ & $3,370,000$ & -0.022 \\
\hline North Anna 1 ......... & 563,288 & 596,000 & -0.0581 \\
\hline North Anna $2 \ldots \ldots \ldots$ & 387,875 & 378,000 & 0.0255 \\
\hline Palisades ............ & 107,652 & 109,000 & -0.0125 \\
\hline Rancho Seco .......... & 280,083 & 282,000 & -0.0068 \\
\hline River Bend $1 \ldots \ldots \ldots$ & $2,820,000$ & $2,820,000$ & 0.0000 \\
\hline Salem 1 ............. & 693,990 & 693,990 & 0.0000 \\
\hline Salem $2 \ldots \ldots \ldots \ldots$ & 567,810 & 567,810 & 0.0000 \\
\hline San Onofre $2 \ldots \ldots \ldots$ & $1,904,622$ & $1,832,000$ & 0.0381 \\
\hline San Onofre $3 \ldots \ldots \ldots$ & $1,168,885$ & $1,128,000$ & 0.0350 \\
\hline
\end{tabular}

See footnotes at end of table. 


\section{Table A2. Comparison of Computed Cash Outlays With Cash Outlays Reported by TVA (Continued)}

\begin{tabular}{|c|c|c|c|}
\hline Plant Name & $\begin{array}{c}\text { Cumulative } \\
\text { Cash Outlays } \\
\text { Computed } \\
\end{array}$ & $\begin{array}{c}\text { Cumulative } \\
\text { Cash Outlays } \\
\text { Reported by TVA } \\
\end{array}$ & $\begin{array}{c}\text { Percent } \\
\text { Difference }\end{array}$ \\
\hline Sequoyah $1, \ldots \ldots \ldots \ldots$ & 712,614 & 742,350 & -0.0417 \\
\hline Sequoyah $2 \ldots \ldots \ldots \ldots$ & 583,078 & 592,650 & -0.0164 \\
\hline Shoreham ........... & $2,462,794$ & $2,784,000$ & $-0.1304 b$ \\
\hline st. Lucie $1 \ldots \ldots \ldots \ldots$ & 396,209 & 422,000 & -0.0651 \\
\hline st. Lucie $2 \ldots \ldots \ldots \ldots$ & $1,180,381$ & $1,154,000$ & 0.0223 \\
\hline surry $1 \ldots \ldots \ldots \ldots \ldots$ & 200,086 & 204,000 & -0.0196 \\
\hline surry $2 \ldots \ldots \ldots \ldots$ & 119,700 & 122,000 & -0.0192 \\
\hline Susquehanna $1, \ldots \ldots \ldots$ & $1,476,157$ & $1,581,000$ & -0.0710 \\
\hline Susquehanna $2 \ldots \ldots \ldots$ & $1,679,889$ & $1,478,000$ & 0.1202 \\
\hline Three Mile Island $1 \ldots$ & 302,299 & 321,000 & -0.0619 \\
\hline Three Mile Island $2 \ldots$ & 498,969 & 518,000 & -0.0381 \\
\hline $\operatorname{Trojan} \ldots \ldots \ldots \ldots \ldots$ & 381,387 & 377,000 & 0.0115 \\
\hline virgil summer $1 \ldots \ldots$ & 933,343 & 983,000 & -0.0532 \\
\hline waterford $3 \ldots \ldots \ldots \ldots$ & $2,173,531$ & $2,154,000$ & 0.0090 \\
\hline Wolf Creek $1 \ldots \ldots \ldots \ldots$ & $1,901,895$ & $1,991,000$ & -0.0469 \\
\hline WPPSS $2 \ldots \ldots \ldots \ldots \ldots$ & $2,441,622$ & $2,471,000$ & -0.0120 \\
\hline Zion $1 \ldots \ldots \ldots \ldots \ldots$ & 223,680 & 228,000 & -0.0193 \\
\hline Zion $2 \ldots \ldots \ldots \ldots$ & 232,338 & 221,000 & 0.0488 \\
\hline
\end{tabular}

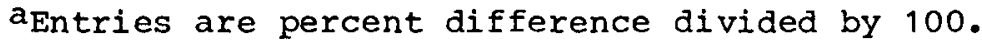

berrors due to difference in costs reported to TVA and costs reported on Form EIA-254.

\section{Computation of Estimated Real Overnight Costs}

The procedure used to calculate estimated costs was in general quite similar to the one used by Zimmerman. 6 Since Zimmerman's study used only the cost estimates made at the beginning of construction, the method used in this study to deflate the initial cost estimates was virtually identical to his. However, this method became less appropriate for the estimates made during the construction period. A slightly different approach was therefore used to deflate the cost estimates for plants that were 75 percent complete and 90 percent complete. The method used in this study to deflate the cost estimates for plants that were between 0 percent and 50 percent complete will be discussed first, followed by the computation of estimated overnight costs for plants that were 75 percent and 90 percent complete when the estimates were made.

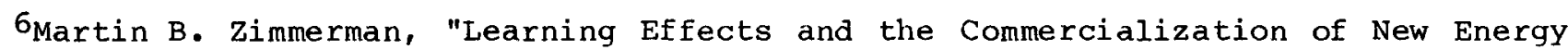
Technologies: The Case of Nuclear Power," Bell Journal of Economics and Management Science (Autumn 1982). 
Figure A1. Allowance for Funds Used Durlng Construction (AFUDC) and Average Debt Rates

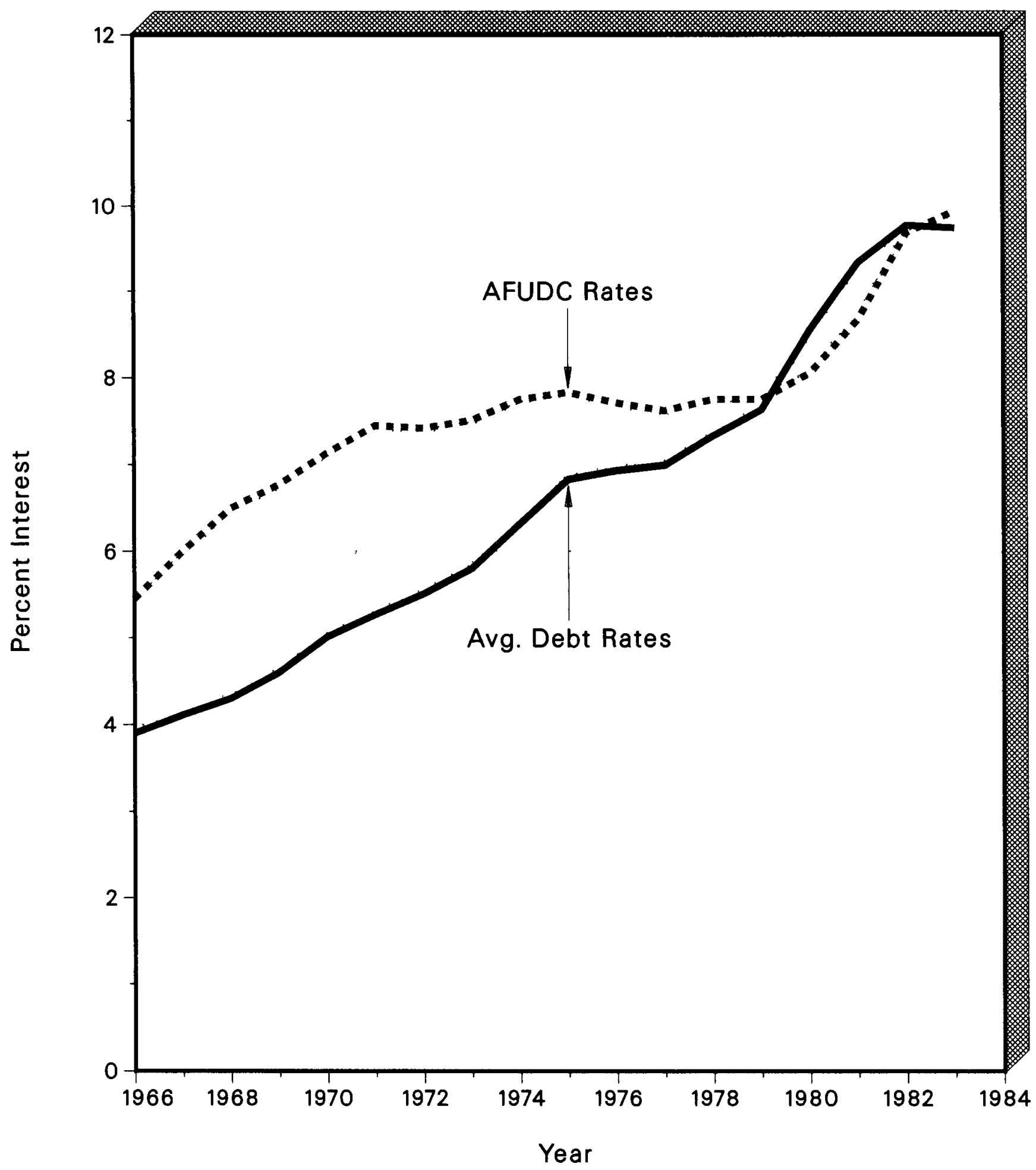

Note: Average debt rates are equal to total interest payments as a percent of total debt. Source: Form FERC-1, and predecessor survey forms. 


\section{Deflation of Estimated Overnight Costs for Plants Between 0 and 50 Percent Complete}

The method used to derive the estimated overnight costs in first-year dollars, $x$, involved a two-part procedure. First, escalation and the allowance for funds used during construction were removed from the reported estimate. This removal yielded the initial year's deflated cost. Second, this value was reinflated to its 1982 value. The general equations that were used to derive $x$ are given below. The variables are defined as follows:

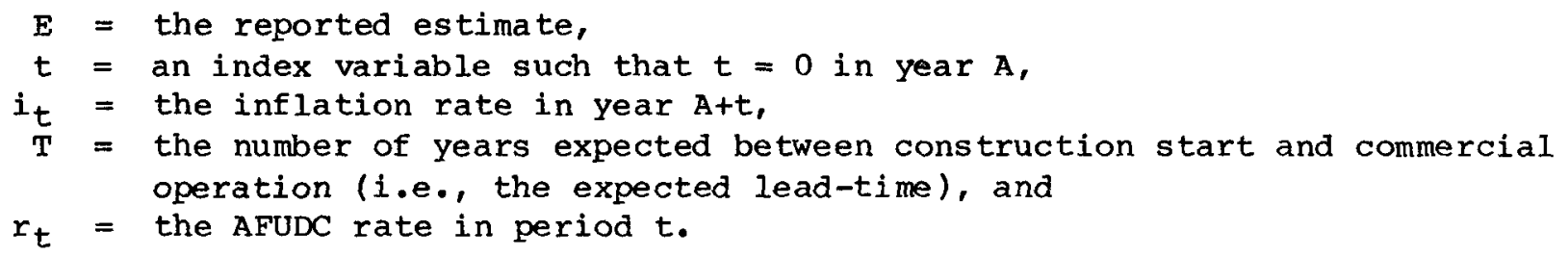

Annual cash flow percents can be calculated from the following S-shaped curve: 7

$$
\begin{aligned}
D_{t} & =\left\{1-\left[\cos (\pi / 2)\left(C_{t}\right)\right]^{4.08198}\right\}^{3.24948,}, \\
P(t-1) & =D_{t}-D_{t-1},
\end{aligned}
$$

where $C_{t}$ is the fraction of total time elapsed (i.e., $t / T$ ).

Finally, reported costs are related to constant-dollar costs by:

$$
E=X \cdot \sum P_{t}\left[\prod_{t+1}^{T}\left(1+r_{t}\right) \prod_{0}^{t-1}\left(1+i_{t}\right)\left(1+0.5 r_{t}\right)\left(1+0.5 i_{t}\right)\right]
$$

Since information on expected escalation and AFUDC rates was unavailable from Form EIA-254, two series were constructed to reflect the expectations of the utilities. As part of the Environmental Impact statement for nuclear power plants, the U.S. Atomic Energy Commission (AEC) and later the Nuclear Regulatory Commission (NRC) required that cost estimates be made using CONCEPT, a large engineering model for cost estimation. Generally, the utilities provided the rates of escalation and cost of capital (through the Environmental Report submitted to the NRC) for their estimated plant costs. These values reflected the utilities' expectations of the annual rates they would encounter during the construction period. Regional values for the escalation rates were obtained by averaging the expectations reflected in all the estimates prepared for a region in the years 1973-1981. Similarly, the AFUDC rate was averaged from all estimates submitted in a region in a particular year. For the earlier years, 1966 through 1972, estimated rates were taken from a report by the AEC. 8

7 This cash flow curve is commonly used for nuclear units (see footnote 1 ).

${ }^{8}$ See U.S. Atomic Energy Commission, Power Plant Capital Costs, Current Trends, and Sensitivity to Economic Parameters, WASH-1345 (Washington, D.C., October 1974). 
These series were founded on several assumptions. First, it was assumed that the CONCEPT estimates not only reflected the expectations for a project in the early stages of construction but also could serve as estimates for the rates that were expected to prevail until a project well underway was completed. Second, the expected rates were assumed to reflect rates averaged throughout the construction period, rather than an estimate for one particular year. Thus the basis of the estimates is substantially different from the actual rates.

Given the time series described above, three more pieces of information are needed to construct $i(T)$ and $r(T)$ : the date of the report, the date of construction start, and the date of commercial operation. Except for the report date, these variables may be either estimated or actual values. Using these dates, a unique $i(T)$ and $r(T)$ were constructed for each report. The following indicate how the series was constructed:

- $i(t)$ and $r(t)$ were set equal to the actual rates for all years of the construction period before the report year. Construction start was rounded to the nearest whole year. ${ }^{9}$

- $i(t)$ and $r(t)$ were set equal to the estimated rates corresponding to the report year. These rates were assumed to prevail for the rest of the expected construction years after the report date.

For example, consider a plant which entered construction in 1970 and for which the report was filed in 1974. The plant was expected to be completed in 1980. To deflate the estimated cost of the plant, actual rates were used for the years 19701973 and the estimated rates in 1974 were used for 1974-1980. If, when another report was filed, either the date of commercial operation or the report year changed, the $i(T)$ and $r(T)$ series would change.

Finally, it was also assumed that the regulatory accounting practices in place when the cost estimates were prepared would remain in place for the entire construction period. Thus, if the relevant regulatory commission did not permit compounding of the AFUDC when a cost estimate was made, the estimated AFUDC was computed without compounding. There was only one unit for which the state regulatory commission permitted any CWIP to be included in the rate base at the time the cost estimate was made. Time and resource constraints did not permit modification of the programming to incorporate this accounting variation for one unit.

After the real overnight cost in first-year dollars was calculated, the following equation was used to derive the overnight costs in 1982 dollars ( $Y$ ):

$$
Y=X \cdot \prod_{t=A}^{1982}[1+i(t)] \text {. }
$$

${ }^{9}$ If construction started after July 1 of a particular year, the construction start was rounded to the following year. 


\section{Deflation of Overnight Costs Estimated for Plants More Than 50 Percent Complete}

The data for the sample of plants used in this analysis showed that in almost all cases, when a unit was 75 percent or 90 percent complete, the estimated cost to complete the plant was very small in relation to the actual expenditures to date. When the bulk of the costs being deflated had not yet been spent, it was reasonable to use a cash profile curve. It was not reasonable to do so when the bulk of the total estimated costs had already been paid. In such cases, a different method of deflating the costs was used.

When a unit was more than 50 percent complete, Equations (A9) through (A12) were used just to deflate the estimated cost of completing the project. Then, the same method that had been used to calculate the actual real overnight costs was used to deflate the disbursed costs to date. The total deflated estimated costs were then calculated by simply adding to deflated expenditures to date the deflated estimated cost to complete the plant.

When plants were at least 75 percent complete, the estimated time required to complete the project was no more than 2 years. Using the data obtained from the Enviromental Impact Statements in this case was not completely valid, because they were estimates of long-term AFUDC and escalation rates. Study of the AFUDC rates indicated that they changed very slowly over time. Therefore, it was assumed that the expected 1-year AFUDC rates would equal the actual rates. One-year inflation rates obtained from Data Resources, Inc. (DRI) forecasts made in the years the cost estimates were prepared were used as the expected escalation rates. Issues having to do with the deflation of these data are not so important, because the estimated costs of completion were small in relation to the funds expended.

\section{Computation of Real Time-Related Costs}

To compute the real time-related costs, the reported costs inclusive of AFUDC were deflated using the fixed-weight GNP price deflator. Again, this was done by deflating each year's reported expenditures to a given year and then adding. By definition, the real reported costs are equal to the real overnight costs plus the real timerelated costs. Thus, the real time-related costs were computed by subtracting the real overnight costs from the real reported costs. The real time-related costs were also computed by deflating the AFUDC payments and escalation separately and then adding the two. The amount of real escalation was computed by deflating the cash outlays using the GNP price deflator and subtracting that amount from the cash outlays deflated by the Handy-Whitman index. Both methods yielded the same results for the plants that entered construction after 1970-1971. However, the real timerelated costs computed using the second method were about $\$ 100$ per kWe higher for the earlier units. Thus, the escalation rate obtained with the second method of computing the real time-related costs was smaller than the escalation rate obtained in the body of the report.

Another way of computing the real time-related costs would be to use the actual cash profile curves plus the real AFUDC rates and real escalation rates. To produce results consistent with the deflated reported costs, all the accounting variations must be included. This was done for two plants with no construction work in progress (CWIP) in the rate base and with the AFUDC compounded. The results were similar to the ones presented in the text. However, to do this for all 75 units was not feasible from a computational standpoint. 

Appendix A

Methodology Used

to Compute

Real Overnight

Costs and

Time-Related Costs 



\section{Review of Previous Cost and Lead-Time Analyses}

This appendix is a review of some prior work in which the costs and lead-times of nuclear power plants were analyzed. All of the studies reviewed here (except for one) used multivariable regression analysis to explore the relationships of costs and lead-time with several factors.

\section{Mooz}

William E. Mooz conducted two analyses of the capital costs of light-water reactors (LWR's); the second study was basically an update of the first.1,2 In both studies, mixed current dollar capital costs were converted to constant dollar costs by a method using the Handy-Whitman Index (see Appendix A for a full description of the method used). Multivariate regression analysis was used to analyze the factors affecting unit capital costs (dollars per kWe), as well as those affecting the following two lead-times: (1) $\mathrm{T} 1$, the time needed to obtain a construction permit $[\mathrm{T}]$ = the time from the date of the permit application (CPAP) to the date of issuance of the permit (CPIS)]; and (2) $T 2$, the construction time [(T2 = the time from CPIS to the date of issuance of the operating license (OLIC)]. Tables B1 through B3 list the regression results from the two studies. The variables were defined as follows:

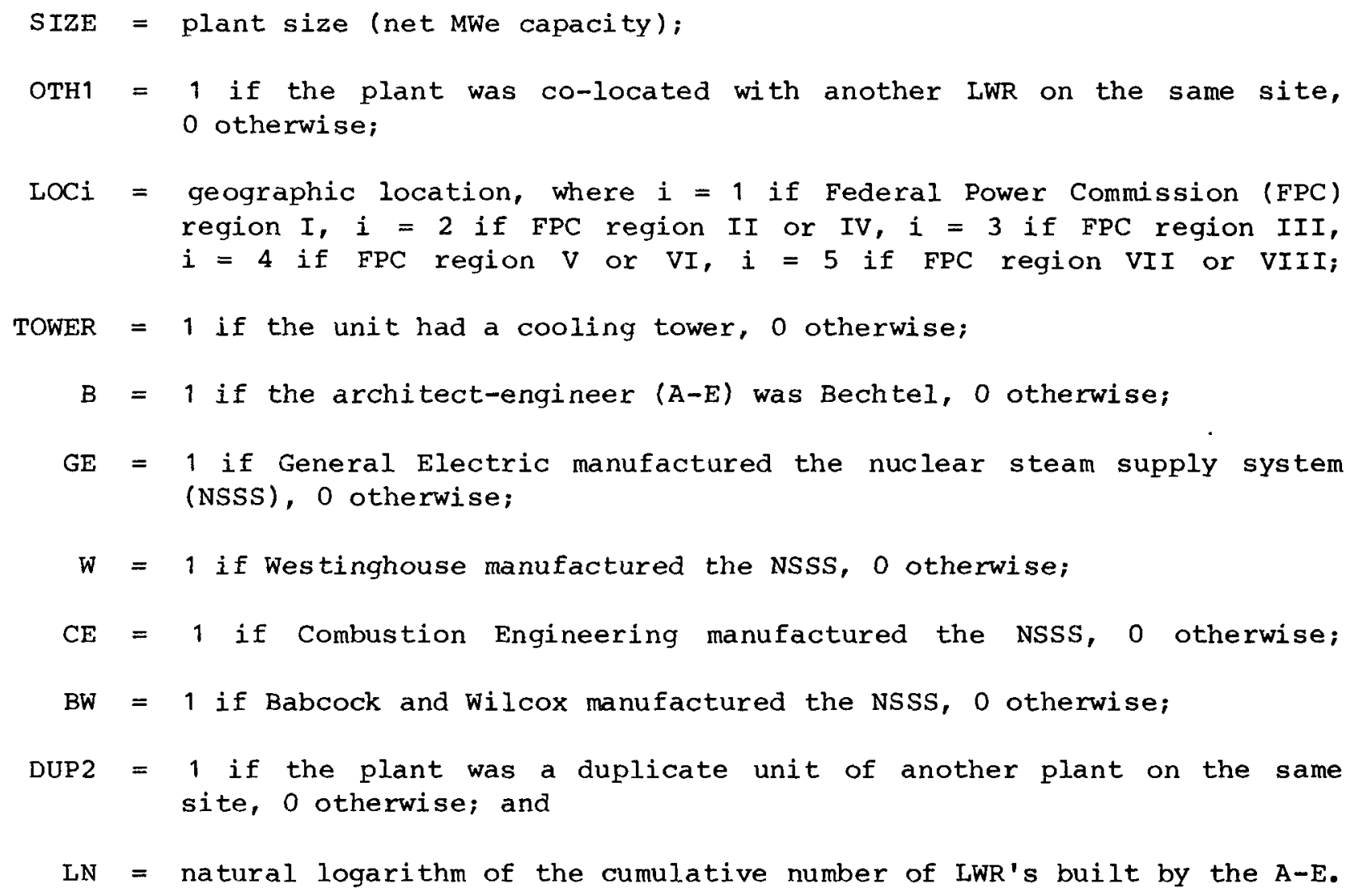

1 William E. Mooz, Cost Analysis of Light Water Reactor Power Plants, R-2304-DOE (Rand Corporation, June 1978).

2William E. Mooz, A Second Cost Analysis of Light Water Reactor Power Plants, R-2594-RC (Rand Corporation, December 1979). 
Table B1. Comparison of Regression Results for Dependent Variable T1 From the Two Studies by Mooz

\begin{tabular}{|c|c|c|}
\hline \multirow[b]{2}{*}{$\begin{array}{l}\text { Independent } \\
\text { Variable }\end{array}$} & \multicolumn{2}{|c|}{ Regression Coefficientb } \\
\hline & First Studyc & Second studyd \\
\hline Constant ....... & $\begin{array}{l}-341.10 \\
(-7.63)\end{array}$ & $\begin{array}{l}-256.00 \\
(-5.5)\end{array}$ \\
\hline CPAP $\cdots \cdots \cdots \cdots$ & $\begin{array}{r}5.20 \\
(7.60)\end{array}$ & $\begin{array}{l}4.10 \\
(5.6)\end{array}$ \\
\hline $\operatorname{sIZE} \ldots \ldots \ldots$ & $\begin{array}{l}0.003 \\
(0.55)\end{array}$ & $\begin{array}{r}-0.01 \\
(-1.20)\end{array}$ \\
\hline отн1 $\ldots . . \ldots \ldots$ & $\begin{array}{r}-2.67 \\
(-1.04)\end{array}$ & -- \\
\hline LOC1 $\ldots \ldots \ldots \ldots$ & $\begin{array}{r}8.17 \\
(2.27)\end{array}$ & $\begin{array}{r}1.50 \\
(0.20)\end{array}$ \\
\hline LOC $2 \ldots \ldots \ldots$ & $\begin{array}{r}1.03 \\
(0.29)\end{array}$ & $\begin{array}{r}1.00 \\
(0.20)\end{array}$ \\
\hline$L O C 3 \ldots \ldots \ldots$ & $\begin{array}{r}6.32 \\
(1.62)\end{array}$ & $\begin{array}{r}0.10 \\
(0.02)\end{array}$ \\
\hline LOC4 $\ldots \ldots \ldots \ldots$ & $\begin{array}{r}7.75 \\
(1.53)\end{array}$ & $\begin{array}{r}-4.20 \\
(-0.50)\end{array}$ \\
\hline TOWER $\ldots \ldots \ldots \ldots$ & $\begin{array}{r}-3.28 \\
(-1.63)\end{array}$ & $\begin{array}{r}2.70 \\
(0.90)\end{array}$ \\
\hline в $\ldots \ldots \ldots \ldots$ & $\begin{array}{r}2.32 \\
(1.15)\end{array}$ & $\begin{array}{r}-1.50 \\
(-0.50)\end{array}$ \\
\hline GE $\ldots \ldots \ldots \ldots$ & -- & $\begin{array}{r}3.60 \\
(0.80)\end{array}$ \\
\hline w $\ldots \ldots \ldots \ldots$ & -- & $\begin{array}{r}1.50 \\
(0.30)\end{array}$ \\
\hline CE $\ldots \ldots \ldots \ldots$ & -- & $\begin{array}{r}6.80 \\
(1.20)\end{array}$ \\
\hline DUP2 $\ldots \ldots \ldots \ldots$ & -- & $\begin{array}{r}-1.00 \\
(-0.40)\end{array}$ \\
\hline $\mathrm{R}^{2} \ldots \ldots \ldots \ldots$ & 0.5672 & 0.33 \\
\hline
\end{tabular}

asee text for discussion of the two studies. b"t" statistics are shown in parentheses.

$C_{T h e}$ data base consisted of 93 plants with construction permits approved before September 1971.

dThe data base consisted of 115 plants with construction permits approved before August 1983 and operating licenses not issued at the time of the study (December 1979). 


\section{Table B2. Comparison of Regression Results for Dependent Variable T2 From the Two Studies by $\mathrm{Mooz}^{\mathrm{a}}$}

\begin{tabular}{|c|c|c|}
\hline \multirow{2}{*}{$\begin{array}{l}\text { Independent } \\
\text { Variable }\end{array}$} & \multicolumn{2}{|c|}{ Regression Coefficientb } \\
\hline & First Studyc & Second studyd \\
\hline Constant ...... & $\begin{array}{l}-270.82 \\
(-3.12)\end{array}$ & $\begin{array}{l}-268.37 \\
(-3.63)\end{array}$ \\
\hline CPIS $\ldots \ldots \ldots \ldots$ & $\begin{array}{r}4.55 \\
(3.47)\end{array}$ & $\begin{array}{r}4.53 \\
(4.03)\end{array}$ \\
\hline SIZE $\ldots . . . \ldots$ & $\begin{array}{r}0.04 \\
(4.89)\end{array}$ & $\begin{array}{c}0.035 \\
(4.17)\end{array}$ \\
\hline BW $\ldots \ldots \ldots \ldots$ & $\begin{array}{r}13.07 \\
(2.68)\end{array}$ & $\begin{array}{r}15.92 \\
(3.80)\end{array}$ \\
\hline LN $\ldots \ldots \ldots \ldots$ & $\begin{array}{r}-8.00 \\
(-4.10)\end{array}$ & $\begin{array}{r}-6.91 \\
(-4.12)\end{array}$ \\
\hline DUP2 $\ldots . . . \ldots$ & -- & $\begin{array}{r}11.54 \\
(3.37)\end{array}$ \\
\hline $\mathrm{R}^{2} \ldots \ldots \ldots \ldots$ & 0.5355 & 0.63 \\
\hline
\end{tabular}

asee text for discussion of the two studies. b"t" statistics are shown in parentheses.

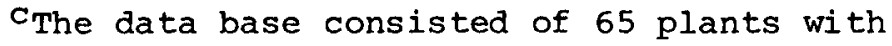
construction permits issued between January 1966 and June 1972.

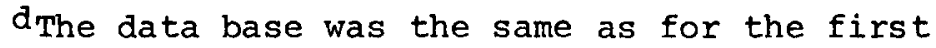
study, minus three plants (Fort st. Vrain, Diablo Canyon 1, and Salem 2).

The results of both studies indicated that the only statistically significant variable affecting $\mathrm{T} 1$ was the date on which the construction permit was applied for (CPAP). Mooz also found that time (as measured by the date the construction permit was issued), size, and experience were related to the construction time.

In his analysis of plant costs, Mooz chose the date on which the construction permit was issued (CPIS) rather than the date on which the construction permit was applied for (CPAP) to serve as an indicator of the changes in regulations and standards, arguing that CPIS "should be more indicative of power plant design criteria" than the earlier CPAP. In both studies, CPIS was determined to be a statistically significant factor affecting unit capital costs. Furthermore, both analyses found $\mathrm{LN}$ and $L O C 1$ to be statistically significant. The A-E learning effect, measured by LN, was slightly greater in the second study than in the first. Mooz found no statistical evidence for industry-wide learning. The cost differential between plants in the Northeastern United States (FPC region I) and those in other areas was greater in 


\section{Table B3. Comparison of Regression Results for Dependent Variable Cost/kWe From the Two Studies by Mooz ${ }^{\text {a }}$}

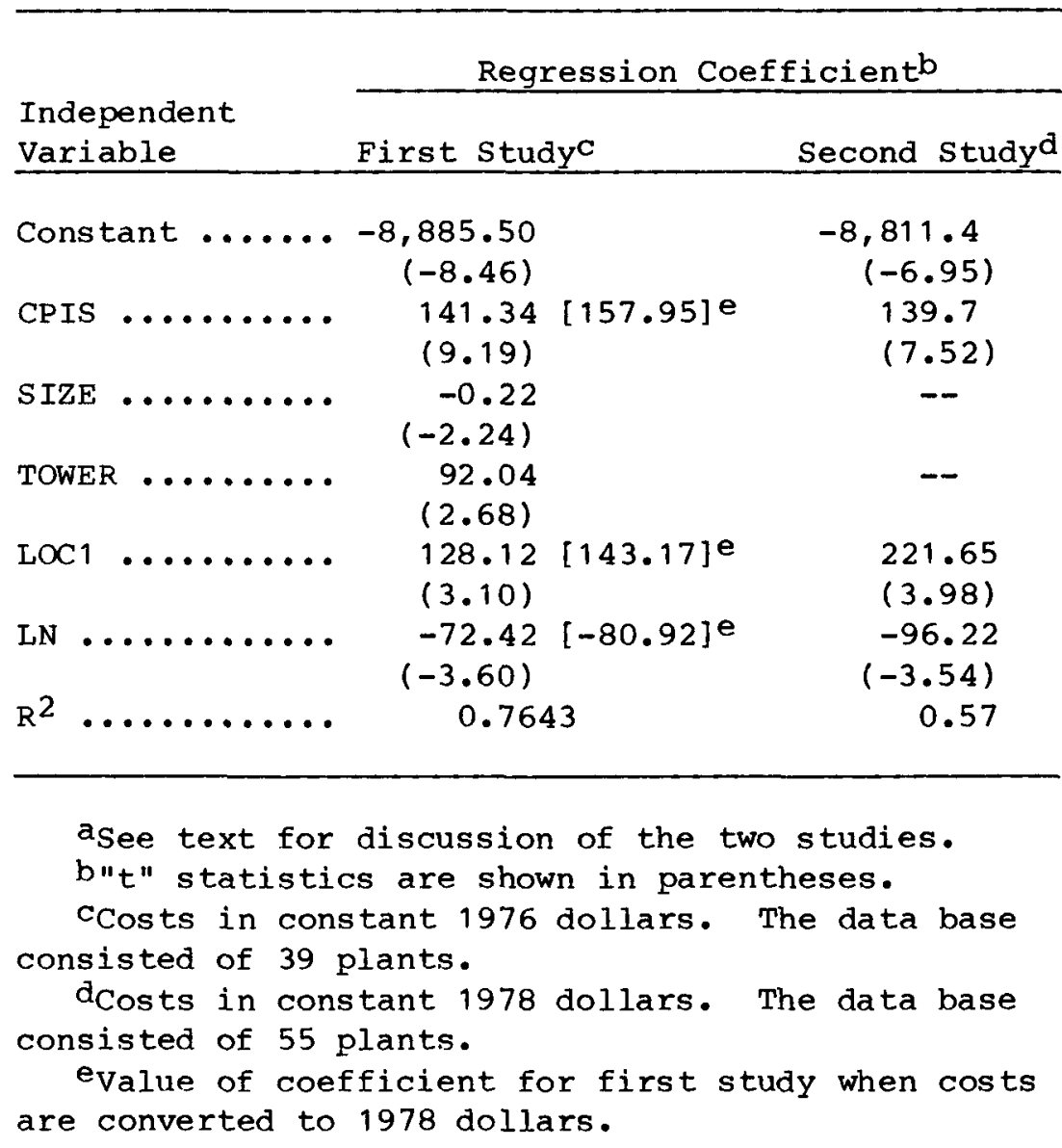

the second study than in the first. In particular, plants in FPC region I were determined to cost an average of $\$ 143$ per kWe (in 1978 dollars) more than plants elsewhere in the country in the first study, compared with $\$ 221$ per kwe (in 1978 dollars) in the second study. Mooz's second study indicated that a plant with a cooling tower did not have a significant cost disadvantage in comparison to one that lacked a tower; the opposite conclusion was reached in the initial study. Another noteworthy comparison between the two studies is that, in the second one, Mooz found a logarithmic specification to be a better fit of the data than the linear specification of the first analysis.

Finally, Mooz claimed that size, experience, and time variables reflected the effects of lead-times on capital costs, and that delays caused by other factors did not appear to affect costs, "which is a tribute to good management." 


\section{Komanoff}

Two studies by Charles Komanoff are reviewed here.3,4 The first was a statistical analysis of the capital costs for 46 reactors completed between 1972 and December 1978, for which construction permits were issued between 1967 and early 1971 (with one exception). The sample excluded turnkey plants. Unit costs, excluding interest during construction (IDC), were converted to constant dollars by using the HandyWhitman Index.

Komanoff's analysis of costs yielded seven statistically significant explanatory variables. (In the following equations, the t-statistics for the regression coefficients are given in parentheses.) The regression equation, with an $\mathrm{R}$-squared value of 0.923 , was as follows:

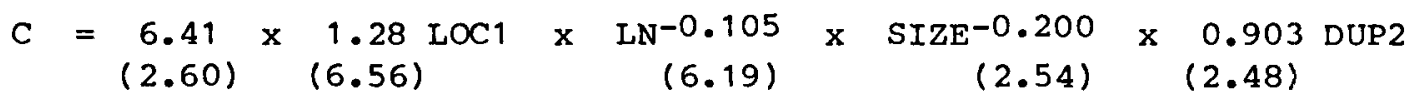

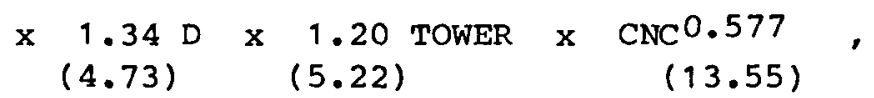

where: $\quad C=$ unit capital cost (in 1979 dollars and without IDC);

$D=1$ if the plant was a dangling unit (four first units whose successors had not been completed at the time of the study), 0 otherwise;

CNC = cumulative nuclear capacity or nuclear sector size (MWe);

and all other variables were as defined above.

Komanoff used cumulative nuclear capacity to capture the effects of increased regulations occurring with growth of the nuclear industry. He used two measures of regulation: time, as measured by date on which the construction permit was issued (the same measure that was used by Mooz), and megawatts of capacity, or sector size. Sector size was deemed preferable because it "appears to capture more of the societal processes that give rise to new standards" and because it "also yields a higher R-square value in the regression model." Komanoff found evidence of a learning effect for A-E's, claiming that, on the average, if the number of plants they engineered doubled, costs were reduced by 7 percent. However, he pointed out that, for six plants in his sample, the utility was the designer and builder, and their costs were higher than those for the other 40 plants -- "suggesting that utility management of reactor design and construction is not a path to lower costs." It is also interesting to note that Komanoff estimated a 13 percent annual real escalation rate, which is about 50 percent higher than the rate estimated in this study. Further, it should be noted that this result could be due to a difference in the sample.

${ }^{3}$ Charles Komanoff, Power Plant Cost Escalation (Van Nostrand Reinhold, New York, New York, 1981).

${ }^{4}$ Charles Komanoff, "Assessing the High Costs of New Nuclear Power Plants, " public Utilities Fortnightly (October 11, 1984), pp. 33-38. 
Komanoff's lead-time regression equation was as follows:

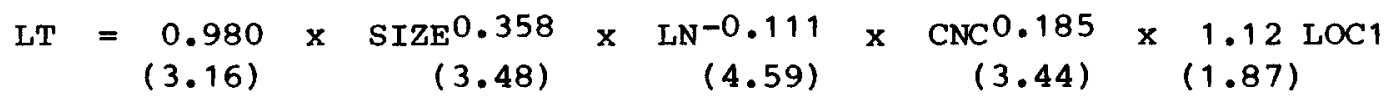

$$
\begin{aligned}
& \begin{array}{c}
1.13 \text { LOC3 } \\
(2.17) \\
(3.60)
\end{array} \quad \begin{array}{c}
1.11 \text { TOWER } \\
(2.19)
\end{array} \quad \begin{array}{c}
1.17 \text { BW } \\
(2.72)
\end{array}
\end{aligned}
$$

where lead-time, LT, was defined as the time from CPIS to the date of commercial operation (in months), and all other variables were as defined above. The R-squared value was 0.661 . The sample included 45 of the 46 plants in Komanoff's cost analysis, plus 4 others.

Komanof found that the factors affecting lead-time were basically the same as those identified in Mooz's analyses. The noteworthy exception was, again, cumulative nuclear capacity -- which indicates that lead-time increases as the size of the nuclear sector increases. Komanoff's basic conclusion about both lead-time and costs was that regulation creates a negative learning effect. That is, as more plants are built, the number of regulations grows, so that both costs and lead-times increase with an expanding sector.

The second Komanoff study reviewed here was aimed at surveying the effects of various factors, including management efficiency, on the costs of plants built during the 1980's. In this analysis, Komanoff examined the capital costs (excluding AFUDC and converted to 1982 dollars using the Handy-Whitman Index) of 34 nuclear plants under construction in 1982. Regression analysis was used, although the functional form was not presented. Six variables were found to be statistically significant determinants of unit capital costs, with an R-squared of 0.83 . These variables were prevailing construction wages, utility nuclear experience, number of units, Westinghouse design, Stone and Webster engineering, and stop-work orders. Table B4 summarizes the average effects that changes in each of these six variables were found to have on capital costs.

\section{Zimmerman}

In his analysis of capital costs, Martin B. Zimmerman used a sample of 41 nuclear plants completed between 1968 and 1980 for which cost data were available.5 Two equations were estimated, using Zellner's iterative generalized least squares. The dependent variables were unit capital costs and the error in expected unit costs, where the error was defined as the difference between actual and expected costs. Actual costs were converted to 1979 constant dollars using the GNP implicit price deflator, and expected costs were converted to 1979 dollars using the 10-year bond rate on U.S. Treasury securities minus an expected inflation rate of 1.7 percent. AFUDC was excluded from both costs (see Appendix A for details of the method used).

The purpose of zimmerman's analysis was to estimate learning effects in the commercialization of nuclear plants. zimmerman's results show that the average error in estimating costs was 95 percent. He attributed this to several factors:

5 Martin B. Zimmerman, "Learning Effects and the Commercialization of New Energy Technologies," Bell Journal of Economics (Autumn 1982), pp. 297-310. 


\section{Table B4. Summary of Average Effects of Changes in Variables From the Komanoff Study on Capital Costs}

\begin{tabular}{|c|c|c|}
\hline Independent Variable & Condition & Effects on Costs \\
\hline Prevailing Construction Wages ... & $\begin{array}{l}\text { If } 20 \text { percent higher } \\
\text { than in other regions }\end{array}$ & $\begin{array}{l}10 \text { percent } \\
\text { moxe costly }\end{array}$ \\
\hline Utility Nuclear Experience ..... & One more plant built & $\begin{array}{l}7 \text { percent } \\
\text { less expensive }\end{array}$ \\
\hline$\ldots \ldots \ldots \ldots \ldots \ldots$ & $\begin{array}{l}\text { Two units as opposed } \\
\text { to one unit }\end{array}$ & $\begin{array}{l}28 \text { percent } \\
\text { cheaper }\end{array}$ \\
\hline Wesinghouse Design ......... & $\begin{array}{l}\text { Westinghouse as opposed } \\
\text { to General Electric, } \\
\text { Combustion Engineering, } \\
\text { or Babcock \& Wilcox }\end{array}$ & $\begin{array}{l}13 \text { percent } \\
\text { saving }\end{array}$ \\
\hline Engineering $\ldots$. & $\begin{array}{l}\text { Stone \& Webster as } \\
\text { opposed to other } \\
\text { architect-engineers }\end{array}$ & $\begin{array}{l}30 \text { percent } \\
\text { more expensive }\end{array}$ \\
\hline Stop-Work orders & Five projects had these & $\begin{array}{l}15 \text { percent } \\
\text { higher costs }\end{array}$ \\
\hline
\end{tabular}

(1) incorrect understanding of economies of scale; (2) lack of understanding of basic technology; (3) a utility's belief that the costs would be affected to only a small degree by the anticipated construction period; and (4) his belief that forecasters "must have assumed that real factor prices as well as regulatory requirements would be constant." The present study found the third and fourth factors to be the only ones that affected forecast errors.

With respect to the learning effect, Zimmerman found statistical evidence for significant learning. He used two experience variables. One of these experience variables was a measure of the constructor's experience, defined as the cumulative number of plants completed by a given constructor. The other experience proxy measured industry experience and was intended to be a reflection of the constructor's external learning that accrued from industry-wide learning. The parameter estimates indicated significant learning effects on all levels. Thus, it was concluded that learning-by-doing lowers construction costs: "this learning-by-doing is partially internalized by the construction firm, and it partially accrues to the industry as a whole." Significant learning about costs was also indicated, with half accruing to individual firms and half to the industry as a whole. When the cumulative number of reactor construction years was used as a measure of experience, the regression results indicated that externally gained experience is not measured well by reactor construction years, 
whereas private learning is correlated with experience as measured by reactor construction years. [However, his analysis included both a measure of time and a measure of cumulative industry experience. Thus, it suffered from problems of multicollinearity (see Appendix D).] zimmerman claimed that his and Mooz's results suggested that "learning diffuses to the industry at the end of the construction process."

Finally, zimmerman concluded that the learning effect, with respect to the initial cost differential, was too small to have had much effect on the rate of commercialization of nuclear plants. Furthermore, he stated:

". . had the government built or subsidized earlier construction, there would have been only a slight effect on the future rate of commercialization. Since investment behavior would have been similar with or without subsidy, the value of the better cost information was small. Furthermore, learning would have reduced the rate of diffusion of the technology."

\section{United Engineers and Constructors, Inc.}

United Engineers \& Constructors, Inc. (UE\&C) conducted a case study to determine the factors responsible for the continuing increases in both commodities and labor hours for constructing nuclear power plants. ${ }^{6}$ The sample they used was composed of nuclear plants that received their operating licenses in 1982 or later.

Industry regulations were found to be major drivers of costs for both equipment and commodities. Double units were said to display a significant commodity cost advantage, whereas the significant engineering costs of shared facilities overrode their initial advantages in the costs of commodities and equipment.

Multiple units were shown to have an obvious labor cost advantage. However, UE\&C claimed that whether the multiple units were built in series or in parallel would "determine if a learning curve is possible." The UE\&C case study also showed that "learning curve effects often result in approximately 20 percent unit rate reductions for second units on site," where unit rate is equal to man-hours per unit commodity. Also, the study stated that "the best plants in terms of labor content are all making use of learning curves of one sort or another." Regional location was found to affect labor costs. Furthermore, utilities with large nuclear programs tended to have a cost advantage in plant construction.

\section{Paik and Schriver}

The objective of the Paik and Schriver study was to determine what effects increased regulations had on costs for LWR plants. ${ }^{7}$ To do this, the authors attempted to:

6United Engineers \& Constructors, Inc., Nuclear Power Plant Cost Drivers, report prepared for the U.S. Department of Energy (Washington, D.C., July 1983).

${ }^{7}$ Soon Paik and William R. Schriver, "The Effect of Increased Regulation on Capital Costs and Manual Labor Requirements of Nuclear Power," The Engineering Economist, Vol. 26, No. 3 (1979), pp. 223-244. 
". - isolate two opposing sets of forces which have been in operation during the period of major regulatory expansion: learning based upon plant design experience and economies of scale with increasing size (operating capacity) of newer plants."

The model used by Paik and Schriver was basically the Mooz model, with the addition of an annual "regulation impact index," denoted as RI in the equation below. Their results differed from those reported by Mooz, in that they found statistically significant economies of scale, whereas Mooz did not. The explanation for this was said to be the data base used, which consisted of 54 of Mooz's 55 plants (those that entered construction between 1966 and 1972 and were completed by 1979) plus 11 more units completed, or expected to be completed, before 1981 .

Mixed-dollar capital costs were converted to constant 1975 dollars using a cash flow model and the Handy-Whitman Index. The regression equation, with a corrected R-squared of 0.78 , was as follows:

$$
\begin{aligned}
& \ln C=\underset{(13.61)}{4.5382}\left(\begin{array}{c}
0.2404 \\
(-3.77)
\end{array}-\underset{(-2.00)}{0.2615} \mathrm{D} 4+\underset{(5.21)}{0.7776} \operatorname{lnSIZE}-\underset{(-3.64)}{0.3577} \operatorname{lnN}\right. \\
& +\underset{(4.24)}{0.8391} \operatorname{lnRI}-\underset{(-2.65)}{0.0744} \operatorname{lnRI} 2+\underset{(3.31)}{0.866}(\operatorname{lnRI} \times \operatorname{lnN}) .
\end{aligned}
$$

When comparing plants that entered construction in 1967 with plants that entered construction in 1974, the authors found that real capital costs increased by 54.6 percent during the period. This translates into about a 7 percent annual escalation rate, which is roughly consistent with the one estimated in the present study. However, Paik and Schriver claimed that without the dampening effects of design learning and scale economies, real costs would have increased by approximately 69.2 percent.

\section{Applied Decision Analysis}

Applied Decision Analysis, Inc. (ADA) used both qualitative and quantitative techniques to analyze lead-time, which was defined as the period from the date of the issuance of a construction permit to the date of the first fuel loading. 8,9 ADA's method had three stages: case studies, separation of plants into groups, and statistical testing of models.

The results of the ADA study indicated that:

8 Applied Decision Analysis, Inc., An Analysis of Power Plant Construction Leadtimes, EPRI-2880, Vol. 1, "Analysis and Results" (Electric Power Research Institute, February 1983).

9Applied Decision Analysis, Inc., An Analysis of Power Plant Construction Leadtimes, EPRI-2880, Vol. 2, "Supporting Documentation and Appendixes" (Electric Power Research Institute, February 1984). 
". . the average nuclear unit from the case studies has experienced 43 months of construction-related delay -- of which 78 percent were related to out-ofscope work and 22 percent were deliberate delays. The dominant cause of all delays was redesign and rework problems, which account for 53 percent of the delays. Thus, the majority of delays are outside the scope of normal estimating procedures."

In their statistical analysis of lead-time, ADA used multiple-variable regression analysis to analyze the plants that were not deliberately delayed or that had only a small amount of deliberate delay. The regression results indicated that, for plants begun before 1972, the statistically significant variables affecting lead-time were size, experience, regional factors, the existence of a cooling tower, and unit multiplicity (i.e., whether it was a single unit, first of a multi-unit plant, or later unit of a multi-unit plant). Plant multiplicity was the only statistically significant determinant of lead-time for post-1972 plants other than the regulatory environment, as represented by time, cumulative nuclear capacity, or regulations in effect. ADA found approximately equal effectiveness for each of the three proxies for prevailing regulatory environment.

ADA concluded that the residual variation in lead-time may be due to qualitative factors that are difficult to measure, such as the quality of the characteristics of project management. A few of these are utility experience, designer/constructor experience, and organizational and management structures. 
Appendix B

Review of Previous Cost and Lead-Time Analyses 
. 
Appendix C

The Data Base Used in the Analysis 


\section{.}




\section{The Data Base Used in the Analysis}

The data base used in the analysis, the definitions of the explanatory variables, and the sources of the data for the explanatory variables are reported in this appendix. The sample of plants used in the analysis is shown in Table C1, and the actual data base is presented in Tables $\mathrm{C} 2$ and $\mathrm{C} 3$. The means of the dependent and independent variables used in the actual real overnight cost regression are shown in Table c4. The following text describes the sources and important features of the explanatory variables.

\section{Actual and Estimated Dates of Commercial Operation and Start of Construction}

The chronological data were obtained from Form EIA-254, and the time data used in the regressions of estimated cost and lead-times for plants in various stages of completion were obtained from the same reports as were the cost data. In some cases, the data on the start of construction were found to vary from one report to the next. It should be noted that the lead-times are expressed in days. Similarly, the construction start date is the day on which construction started. The statistical package, Statistical Analysis System (SAS), was used. SAS converts each calendar date to a number that is the equal to the number of days between January 1, 1960, and the date in question. Thus, the construction start date variable for a unit that entered construction on January 1, 1961, would be 366 (because 1960 was a leap year). Similarly, the construction start date for a unit that entered construction on January 1, 1959, would be -365 .

\section{Size}

The design capacity, measured in net megawatts-electric, was used. These data were obtained from Form EIA-254, as reported in the Survey of Nuclear Power Plant Construction Costs 1984, DOE/EIA-0439(84).

\section{Multiple Units and Cooling Mechanism}

As described in the text, a binary variable, taking on the value of 1 if the unit was either the first of a multi-unit plant or a single unit, was included in the regressions. A "plant" was defined as the second or subsequent unit of a multi-unit plant if its date of construction start was before the date of commercial operation for the first unit.

Another binary variable that took on the value of 0 if the unit had a cooling tower or used a manmade source of water was also included in the regressions. This information was obtained from the NUS Corporation.

\section{Experience of Contractor}

Three different measures of experience were used in the analysis:

- Number of completed reactors

- Number of reactor construction years

- Cumulative percent complete. 
Table C1. List of Plants Used in the Analysis

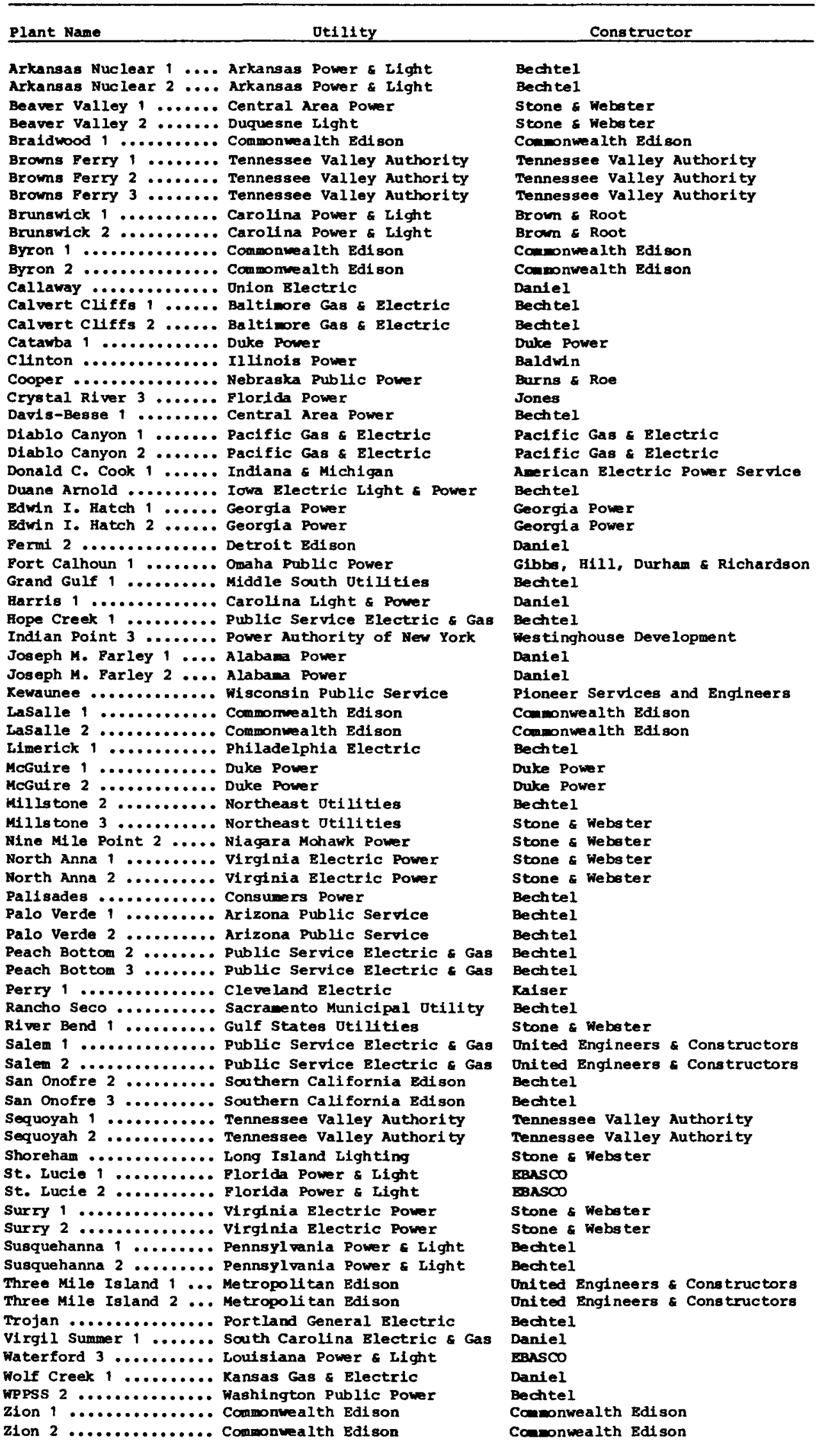


Table C2. Data Base Used in the Analysis of Actual Costs

\begin{tabular}{|c|c|c|c|c|c|c|c|c|c|c|c|}
\hline \multirow[b]{3}{*}{ Plant Nawe } & \multirow[b]{3}{*}{$\begin{array}{c}\text { Capacity } \\
\text { (Mwe) }\end{array}$} & \multirow{3}{*}{$\begin{array}{c}\text { Con- } \\
\text { structor } \\
\text { Experi- } \\
\text { once } \\
\text { (Reactor- } \\
\text { Years) } \\
\end{array}$} & \multirow{3}{*}{$\begin{array}{c}\text { Construc- } \\
\text { tion } \\
\text { Start } \\
\text { Date }\end{array}$} & & & & & Bin & ary Variabl & les & \\
\hline & & & & $\begin{array}{l}\text { Comber- } \\
-\quad \text { cilel }\end{array}$ & Realized & d costen & Locatic & & UtiLty & & \\
\hline & & & & $\begin{array}{l}\text { tion } \\
\text { Dste } \\
\end{array}$ & $\begin{array}{l}\text { Curzent } \\
\text { Dollars }\end{array}$ & $\begin{array}{c}1982 \\
\text { Dollars }\end{array}$ & $\begin{array}{l}\text { South or } \\
\text { Southwest }\end{array}$ & west & $\begin{array}{c}\text { tion } \\
\text { Manager }\end{array}$ & $\begin{array}{c}\text { Single } \\
\text { Unit }\end{array}$ & $\begin{array}{c}\text { Cooling } \\
\text { Tomer }\end{array}$ \\
\hline Arkansas Nuclear $1 \ldots$ & 850 & 142 & $11 / 01 / 68$ & $12 / 04 / 74$ & 238,894 & 468,892 & 1 & 0 & 0 & 1 & 0 \\
\hline Arkansas Nuclear $2 \ldots$ & 912 & 257 & $07 / 01 / 71$ & $03 / 25 / 80$ & 633,000 & 812,294 & $i$ & 0 & 0 & 0 & 0 \\
\hline Beaver valley,$\ldots . .$. & 852 & 64 & $03 / 01 / 69$ & $10 / 15 / 76$ & 583,400 & 883,708 & o & o & o & 1 & 0 \\
\hline Beaver valley $2^{b}$.. & 833 & 118 & $05 / 01 / 75$ & $10 / 15 / 86$ & $3,466,000$ & $3,079,681$ & 0 & o & 0 & 0 & 0 \\
\hline Braidwood ib .......... & 1,120 & 110 & $08 / 01 / 75$ & $10 / 15 / 86$ & $2,450,000$ & $2,045,455$ & 0 & 0 & 1 & 1 & $i$ \\
\hline Browns Perry , ...... & 1,065 & 37 & $09 / 01 / 66$ & $08 / 15 / 74$ & 347,520 & 657.872 & 1 & o & 1 & , & 0 \\
\hline Browne Perry $2 \ldots \ldots$. & 1,065 & 43 & $09 / 01 / 66$ & $03 / 01 / 75$ & 260,640 & 493,404 & 1 & o & 1 & 0 & $\mathbf{0}$ \\
\hline Brown: Ferry 3 ... & 1,065 & 53 & $09 / 01 / 66$ & $03 / 01 / 77$ & 260,640 & 493,404 & 1 & 0 & 1 & 0 & 0 \\
\hline Bronswick 1 .......... & 821 & 29 & $09 / 01 / 69$ & $03 / 01 / 77$ & 315,919 & 539.650 & $i$ & 0 & 0 & 1 & 1 \\
\hline Brunswick $2 \ldots . .$. & 821 & 23 & $09 / 01 / 69$ & $11 / 01 / 75$ & 378,827 & 700,647 & 1 & 0 & 0 & 0 & $i$ \\
\hline Byron $1 \ldots \ldots$ & 1,120 & 105 & $03 / 15 / 75$ & $04 / 15 / 85$ & $2,374,000$ & $1,891,608$ & 0 & 0 & $i$ & $i$ & 0 \\
\hline Byr $2 \ldots \ldots$ & 1.120 & 110 & $03 / 15 / 75$ & $10 / 15 / 86$ & $1,776,000$ & $1,556,548$ & 0 & 0 & 1 & 0 & 0 \\
\hline callaway ......... & 1,120 & 77 & $08 / 15 / 75$ & $06 / 15 / 85$ & $3,070,000$ & $2,253,092$ & 0 & o & o & 1 & o \\
\hline Calvert cliffs 1 . & 845 & 163 & $06 / 01 / 68$ & $05 / 22 / 75$ & 429,000 & 858,098 & ${ }_{1} \mathrm{c}$ & 0 & 0 & 1 & 1 \\
\hline Calvert cliffs 2. & 845 & 203 & $06 / 01 / 68$ & $04 / 01 / 77$ & 310,000 & 574,988 & ${ }_{1} \mathrm{c}$ & $\mathbf{0}$ & 0 & 0 & 1 \\
\hline Catawbe $1, \ldots \ldots \ldots$ & 1,145 & 67 & $05 / 15 / 74$ & $06 / 15 / 85$ & $1,936,000$ & $1,558,099$ & 1 & 0 & 1 & 1 & 0 \\
\hline 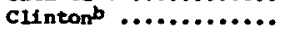 & 933 & 11 & $10 / 01 / 75$ & $07 / 15 / 86$ & $3,145,000$ & $3,048,987$ & 0 & 0 & 0 & $i$ & 1 \\
\hline Cooper...$\ldots \ldots$ & 778 & 19 & $02 / 01 / 68$ & $07 / 01 / 74$ & 232,253 & 791,486 & 0 & 0 & 0 & 1 & 1 \\
\hline Crystal River 3 .. & a25 & 10 & $06 / 01 / 68$ & $03 / 01 / 77$ & 414,152 & 712,103 & 1 & 0 & 0 & 1 & 1 \\
\hline Davis-Besse,$\ldots$ & 906 & 221 & $06 / 01 / 70$ & $08 / 15 / 78$ & 635,707 & $1,020,690$ & o & 0 & 0 & 1 & 0 \\
\hline Diablo Canyon $1 \ldots$ & 1,084 & 33 & $06 / 01 / 68$ & $04 / 15 / 85$ & $3,226,000$ & $2,817,185$ & 0 & $i$ & $i$ & 1 & 1 \\
\hline Diablo Canyon $2 \ldots .$. & 1,106 & 33 & $03 / 01 / 71$ & $08 / 15 / 85$ & $2,113,600$ & $1,752,767$ & 0 & 1 & 1 & 0 & 1 \\
\hline Donald $c$. Cook $1 \ldots .$. & 1,054 & 14 & $09 / 01 / 68$ & $08 / 23 / 75$ & 536,000 & 978,601 & o & o & 0 & 1 & 1 \\
\hline Duane Arnold ...... & 538 & 163 & $10 / 01 / 69$ & $02 / 01 / 75$ & 287,142 & 537,893 & 0 & 0 & 0 & 1 & o \\
\hline Edwin $I$, Hatch 1 .. & 777 & 15 & $09 / 01 / 68$ & $12 / 31 / 75$ & 365,137 & 714,341 & 1 & 0 & 1 & 1 & 0 \\
\hline Edwin $I$. Hatch $2 \ldots$ & 784 & 27 & $11 / 01 / 71$ & $09 / 05 / 79$ & 511,000 & 693,055 & 1 & 0 & 1 & 0 & 0 \\
\hline Perni $2 \ldots \ldots$ & 1,093 & 77 & $07 / 15 / 70$ & $06 / 15 / 85$ & $3,371,000$ & $2,842,054$ & 0 & 0 & 0 & 1 & 0 \\
\hline Fort Calhoun 1 .. & 478 & 6 & $02 / 01 / 68$ & $09 / 15 / 73$ & 174,323 & 390,795 & 0 & 0 & 0 & 1 & 1 \\
\hline Grand Gulf I & 1,250 & 335 & $04 / 01 / 74$ & $06 / 15 / 85$ & $3,139,950$ & $2,609,000$ & $i$ & 0 & o & 1 & o \\
\hline Harri. $q^{b} \ldots$ & 900 & 78 & $01 / 01 / 74$ & $09 / 15 / 86$ & $3,411,272$ & $3,004,815$ & 1 & 0 & 0 & 1 & 0 \\
\hline Hope Creek ib $\ldots \ldots \ldots$ & 1,067 & 347 & $03 / 02 / 76$ & $12 / 15 / 86$ & $3,756,000$ & $3,454,272$ & 0 & 0 & 0 & 1 & 0 \\
\hline Indlan polnt $3 \ldots \ldots$ & 965 & 8 & $09 / 01 / 67$ & $08 / 30 / 76$ & 383,000 & 645,442 & 0 & 0 & 0 & 0 & i \\
\hline Joseph M. Parley 1 ... & 829 & 26 & $08 / 01 / 70$ & $12 / 01 / 77$ & 686,386 & $1,098,921$ & 1 & 0 & 0 & $i$ & 0 \\
\hline Joseph M. Farley 2 .. & 829 & 54 & $10 / 01 / 70$ & $07 / 30 / 81$ & 780,879 & 922,643 & 1 & 0 & 0 & 0 & 0 \\
\hline dewaunee.$\ldots \ldots \ldots \ldots \ldots$. & 535 & 7 & $12 / 01 / 67$ & $06 / 16 / 74$ & 201,221 & 420,274 & 0 & 0 & 0 & 1 & 1 \\
\hline Lasalle $1 \ldots \ldots \ldots \ldots$ & 1,078 & 99 & $10 / 01 / 73$ & $01 / 15 / 84$ & $1,342,888$ & $1,441,325$ & 0 & 0 & 1 & 1 & 0 \\
\hline Lesalle $2 \ldots$ & 1,078 & 99 & $10 / 15 / 73$ & $06 / 15 / 84$ & $1,028,929$ & 942,595 & o & 0 & 1 & 0 & 0 \\
\hline Ltentek,$\ldots \ldots \ldots \ldots$ & 1,055 & 335 & $07 / 15 / 70$ & $08 / 15 / 85$ & $3,857,000$ & $2,990,034$ & 0 & 0 & 0 & 1 & o \\
\hline MeGatre,$\ldots \ldots \ldots \ldots$ & 1,180 & 56 & $01 / 01 / 71$ & $12 / 01 / 81$ & 919,000 & 975,602 & 1 & 0 & 1 & 1 & o \\
\hline McGuire $2 \ldots .$. & 1,180 & 65 & $12 / 15 / 71$ & $03 / 15 / 84$ & $1,022,000$ & 953,535 & 1 & 0 & 1 & 0 & 0 \\
\hline Mallatone 2 .......... & 870 & 163 & $11 / 01 / 69$ & $12 / 01 / 75$ & 413,683 & 703,265 & 0 & 0 & 0 & 0 & 1 \\
\hline Milletone $3^{b} \ldots \ldots \ldots$. & 1,156 & 118 & $06 / 01 / 76$ & $06 / 15 / 86$ & $3,825,000$ & $3,003,760$ & 0 & o & 0 & 0 & 1 \\
\hline Nine Mile Point $2^{b} \ldots$ & 1,099 & 118 & $06 / 01 / 75$ & $10 / 15 / 86$ & $5,100,000$ & $3,967,476$ & 0 & o & 0 & 1 & o \\
\hline North anna,$\ldots \ldots \ldots$ & 907 & 78 & $06 / 01 / 69$ & $06 / 06 / 78$ & 779,429 & $1,968,619$ & 1 & 0 & $\mathbf{0}$ & 1 & o \\
\hline Worth Anne 2 .......... & 907 & 90 & $07 / 15 / 69$ & $12 / 14 / 80$ & 540,919 & 700,519 & 1 & 0 & 0 & 0 & 0 \\
\hline Pallsades ............ & 805 & 83 & $03 / 01 / 67$ & $12 / 01 / 71$ & 137,029 & 317,124 & 0 & 0 & 0 & 1 & o \\
\hline Palo verde 1 ... & 1,270 & 335 & $05 / 15 / 76$ & $12 / 15 / 85$ & (d) & $3,144,500$ & 1 & 0 & 0 & 1 & 0 \\
\hline Palo verde 2 .......... & 1,270 & 339 & $05 / 15 / 76$ & $04 / 15 / 86$ & (d) & $1,721,135$ & 1 & 0 & 0 & 0 & 0 \\
\hline Peach Bottom 2 ....... & 1,065 & 142 & $02 / 01 / 67$ & $07 / 01 / 74$ & 520,000 & $1,065,370$ & 0 & 0 & 0 & $i$ & 0 \\
\hline Peach Bottom 3 ........ & 1,065 & 142 & $02 / 01 / 67$ & $12 / 01 / 74$ & 219,600 & 421,094 & 0 & 0 & 0 & 0 & 0 \\
\hline Perry 1 ........... & 1,205 & 23 & $10 / 15 / 74$ & $12 / 15 / 85$ & $3,945,000$ & $2,801,589$ & 0 & 0 & 0 & 9 & 0 \\
\hline Rancho Seco ....... & 918 & 163 & $03 / 01 / 69$ & $04 / 18 / 75$ & 337,408 & 657,901 & 0 & 1 & 0 & $i$ & 0 \\
\hline River Bend $1 \mathrm{~b} . . . \ldots$. & 934 & 118 & $09 / 01 / 75$ & $12 / 15 / 85$ & (d) & $3,073,347$ & 1 & 0 & 0 & $i$ & 0 \\
\hline Salew $1, \ldots . . . . . .$. & 1,090 & 74 & $01 / 01 / 680$ & $06 / 30 / 77$ & 935,550 & $1,374,381$ & 0 & 0 & 0 & 1 & 1 \\
\hline salen 2 ............ & 1,115 & 87 & $01 / 01 / 68$ & $10 / 13 / 81$ & 765,450 & $1,124,493$ & 0 & 0 & 0 & 0 & $i$ \\
\hline San Onofre $2 \ldots \ldots \ldots$ & 1,100 & 308 & $03 / 01 / 740$ & $08 / 15 / 83$ & $2,569,028$ & $2,511,826$ & 0 & 1 & 0 & 1 & $i$ \\
\hline San Onofre $3 \ldots \ldots \ldots$ & 1,100 & 323 & $03 / 01 / 74$ & $04 / 15 / 84$ & $1,749,106$ & $1,560,930$ & 0 & 1 & 0 & 0 & 1 \\
\hline sequoyah $1, \ldots \ldots \ldots$ & 1,148 & 69 & $05 / 01 / 69$ & $07 / 15 / 82$ & 912,615 & $1,172,007$ & 1 & 0 & $i$ & 1 & 0 \\
\hline Sequoyah $2 \ldots \ldots \ldots$....... & 1,148 & 72 & $05 / 15 / 69$ & $06 / 15 / 82$ & 746,685 & 958,915 & 1 & 0 & , & 0 & o \\
\hline Shorehan ............ & 820 & 115 & $03 / 15 / 68$ & $10 / 15 / 85$ & $4,231,000$ & $3,109,526$ & 0 & 0 & 0 & 1 & 1 \\
\hline st. Iacle 1 .......... & 830 & 31 & $03 / 01 / 69$ & $12 / 21 / 76$ & 463,000 & 849,302 & 1 & 0 & 0 & 1 & 1 \\
\hline st. Lacie $2 \ldots$. & 810 & 77 & $06 / 15 / 76$ & $08 / 15 / 83$ & $1,431,271$ & $1,409,509$ & $i$ & 0 & 0 & 0 & $i$ \\
\hline surry $1, \ldots \ldots \ldots \ldots$ & 788 & 35 & $12 / 01 / 66$ & $12 / 22 / 72$ & 247.358 & 571,767 & $i$ & 0 & 0 & 1 & 1 \\
\hline surry $2 \ldots \ldots \ldots \ldots$ & 788 & 41 & $12 / 01 / 66$ & $05 / 01 / 73$ & 147,649 & 328,394 & 9 & 0 & 0 & o & 1 \\
\hline Susquehanna,$\ldots \ldots$. & 1,050 & 308 & $11 / 01 / 730$ & $06 / 15 / 83$ & $2,256,742$ & $1,993,771$ & 0 & 0 & 0 & $i$ & o \\
\hline Susquehanna $2 \ldots$. & 1,050 & 335 & $11 / 15 / 730$ & $02 / 15 / 85$ & $2,159,000$ & $1,708,565$ & o & 0 & 0 & 0 & 0 \\
\hline Three mile Island $1 \ldots$ & 819 & 61 & $08 / 01 / 67$ & $09 / 01 / 74$ & 402,016 & 757,256 & $\mathbf{a}$ & 0 & 0 & 1 & 0 \\
\hline Three mile I land $2 \ldots$ & 906 & 78 & $09 / 01 / 69$ & $12 / 01 / 78$ & 714,873 & 966,834 & 0 & 0 & 0 & 0 & 0 \\
\hline Trojan .............. & 1,130 & 183 & $02 / 01 / 70$ & $05 / 01 / 76$ & 443,065 & 860,040 & 0 & 1 & 0 & 1 & 0 \\
\hline virgil Summer $1 \ldots$ & 900 & 72 & $04 / 01 / 730$ & $01 / 15 / 84$ & $1,283,035$ & $1,282,782$ & 1 & $\mathbf{0}$ & 0 & 1 & 0 \\
\hline waterford $3 \ldots \ldots$...... & 1,164 & 89 & $12 / 15 / 71$ & $06 / 15 / 85$ & $2,730,000$ & $2,481,863$ & $i$ & 0 & 0 & 1 & 1 \\
\hline wolf Creek $1, \ldots . . . .$. & 1,150 & 77 & $01 / 15 / 770$ & $08 / 15 / 85$ & $2,864,000$ & $2,130,092$ & 0 & 0 & 0 & 1 & 0 \\
\hline WPPSS $2 \ldots \ldots \ldots \ldots \ldots$ & 1,100 & 323 & $08 / 15 / 72$ & $12 / 15 / 84$ & $3,200,000$ & $3,011,540$ & 0 & ; & D & $\infty$ & 0 \\
\hline zion $1, \ldots \ldots \ldots \ldots$ & 1,040 & 14 & $02 / 01 / 68$ & $10 / 02 / 73$ & 264,630 & 577,032 & 0 & 0 & 1 & 1 & 1 \\
\hline zion $2 \ldots \ldots \ldots \ldots$ & 1,040 & 19 & $04 / 01 / 68$ & $11 / 01 / 74$ & 277,577 & 565,119 & 0 & 0 & 1 & o & 1 \\
\hline
\end{tabular}

aThougand dollars. Constant dollar costs exclude Afudc.

bithese units we not included in the regression analyses.

In the lead-time analyals, these two units were considered to be in the Bast/Midwest region.

dmixed current dollar costs for Palo verde 1 and 2 and River Bend 1 do not tnclude AFuDC and thus are not comparable

With those for other units; therefore, they are not reported here.

In the lead-timo analysis, WPPSS 2 was considered to be the first unit at the site.

Scarce: Energy Information Administration, Porm Ela-254, -Semiannual Progress Report on status of Reactor Construction," and predecessor survey forms. 


\begin{tabular}{|c|c|c|c|c|c|c|c|c|c|c|}
\hline \multirow[b]{2}{*}{ Plant } & \multicolumn{5}{|c|}{$\begin{array}{l}\text { Eatimated Completion Dates at } \\
\text { Different Stages of Completion }\end{array}$} & \multicolumn{5}{|c|}{$\begin{array}{l}\text { Estimated Overnight Costs at } \\
\text { Different stages of Completiona }\end{array}$} \\
\hline & O* & 25* & $50:$ & $75 *$ & $90 *$ & 02 & 25* & 50. & $75 *$ & 908 \\
\hline $\begin{array}{l}\text { Arkansas Nuclear } 1 \\
\text { Arkansas Nuclear } 2\end{array}$ & $12 / 01 / 72$ & $09 / 01 / 73$ & $01 / 73$ & $09 / 01 / 73$ & $10 / 01 / 73$ & 81,882 & 300,811 & 326,237 & 384,984 & 414,804 \\
\hline $\begin{array}{l}\text { Arkansas Nuclear } 2 \ldots \\
\text { Beaver valley } 1 \ldots \ldots\end{array}$ & $\begin{array}{l}10 / 01 / 75 \\
06 / 01 / 73\end{array}$ & $\begin{array}{l}02 / 01 / 77 \\
12 / 01 / 73\end{array}$ & $\begin{array}{l}01 / 01 / 78 \\
10 / 01 / 74\end{array}$ & $\begin{array}{l}07 / 01 / 78 \\
05 / 01 / 75\end{array}$ & $\begin{array}{l}08 / 01 / 78 \\
10 / 01 / 75\end{array}$ & $\begin{array}{l}345,532 \\
385,518\end{array}$ & $\begin{array}{l}402,212 \\
409,792\end{array}$ & $\begin{array}{l}479,191 \\
597,963\end{array}$ & $\begin{array}{l}683,280 \\
780,338\end{array}$ & $\begin{array}{l}716,295 \\
796,509\end{array}$ \\
\hline Beaver valley $2^{b} \ldots \ldots$ & $06 / 15 / 79$ & $05 / 15 / 84$ & $05 / 15 / 86$ & $05 / 15 / 86$ & $10 / 15 / 86$ & 685,964 & $1,106,400$ & $1,449,292$ & $2,358,652$ & $3,079,681$ \\
\hline Braidwood ib & $10 / 15 / 81$ & $10 / 15 / 81$ & $10 / 15 / 81$ & $04 / 15 / 86$ & $10 / 15 / 86$ & 572,684 & 755,359 & 840,511 & $1,407,194$ & $2,045,455$ \\
\hline Browns Ferry & $10 / 01 / 70$ & $10 / 01 / 70$ & $04 / 01 / 72$ & $10 / 01 / 73$ & $08 / 01 / 74$ & 227,395 & 376,468 & 395,320 & 613,992 & 616,796 \\
\hline $\begin{array}{l}\text { Browns Ferry } 2 \ldots \ldots \ldots \\
\text { Browns Ferry } 3 \ldots \ldots\end{array}$ & $\begin{array}{l}10 / 01 / 70 \\
10 / 01 / 70\end{array}$ & $\begin{array}{l}10 / 01 / 70 \\
10 / 01 / 70\end{array}$ & $\begin{array}{l}01 / 01 / 73 \\
10 / 01 / 73\end{array}$ & $\begin{array}{l}04 / 01 / 74 \\
10 / 01 / 74\end{array}$ & $\begin{array}{l}12 / 01 / 74 \\
09 / 01 / 75\end{array}$ & $\begin{array}{l}170,546 \\
170,546\end{array}$ & $\begin{array}{l}282,351 \\
282,351\end{array}$ & $\begin{array}{l}296,490 \\
296,490\end{array}$ & $\begin{array}{l}460,494 \\
460,494\end{array}$ & $\begin{array}{l}462,597 \\
462,597\end{array}$ \\
\hline Brunswick $1 \ldots \ldots \ldots$ & $03 / 01 / 76$ & $03 / 01 / 75$ & $12 / 01 / 75$ & $06 / 01 / 76$ & $03 / 01 / 77$ & 323,177 & 332,710 & 436,755 & 500,868 & 591,011 \\
\hline Brungwlck $2 \ldots \ldots$ & $03 / 01 / 76$ & $03 / 01 / 74$ & $03 / 01 / 74$ & $12 / 01 / 74$ & $01 / 01 / 75$ & 264,417 & 386,528 & 409,667 & 547,829 & 732,076 \\
\hline Byron $1 \ldots \ldots \ldots$ & $10 / 15 / 80$ & $03 / 15 / 81$ & $09 / 15 / 81$ & $10 / 15 / 83$ & $06 / 15 / 84$ & 56,370 & 826,377 & 804,866 & $1,417,628$ & $1,621,337$ \\
\hline Byron $2 \ldots$ & $5 / 82$ & $10 / 15 / 82$ & $10 / 15 / 83$ & $02 / 15 / 85$ & (c) & 414,763 & 451,615 & 546,784 & 963,837 & 1,124 \\
\hline Callaway .... & $5 / 81$ & $10 / 15 / 82$ & $10 / 15 / 82$ & $01 / 15 / 84$ & $12 / 15 / 85$ & 853,699 & 965,844 & 949,058 & $1,943,763$ & $2,052,471$ \\
\hline Calvert CllfEs & $01 / 01 / 73$ & $01 / 73$ & $01 / 01 / 73$ & $02 / 01 / 74$ & $07 / 01 / 74$ & 268,461 & 354,144 & 346,309 & 654,792 & 740,358 \\
\hline Calvert Cliffs 2 . & $01 / 01 / 74$ & $01 / 01 / 74$ & $06 / 01 / 74$ & $09 / 01 / 75$ & $01 / 01 / 77$ & 215,745 & 241,400 & 392,206 & 603,477 & 09 \\
\hline Catawba $1 \ldots \ldots \ldots \ldots$ & $07 / 15 / 79$ & $07 / 15 / 81$ & $07 / 15 / 81$ & $03 / 15 / 84$ & $06 / 1$ & 420,188 & 675,803 & 791,272 & $1,095,614$ & 1,128, \\
\hline clintonb $\ldots \ldots \ldots \ldots \ldots$ & $5 / 81$ & $12 / 15 / 82$ & $12 / 15 / 82$ & $09 / 15 / 83$ & $07 / 15 / 86$ & 533.530 & $1,104,105$ & $1,152,515$ & $1,603,065$ & $3,048,987$ \\
\hline Cooper ............... & $01 / 72$ & $04 / 01 / 72$ & $04 / 01 / 73$ & $04 / 01 / 73$ & $11 / 01 / 73$ & 84,213 & 277,832 & 413,459 & 529,283 & 446 \\
\hline Crystal R1var 3 ...... & $1 / 72$ & $09 / 01 / 73$ & $09 / 01 / 73$ & $12 / 01 / 74$ & $03 / 01 / 75$ & 271,995 & 401,967 & 400,119 & 581,483 & 185 \\
\hline $\begin{array}{l}\text { Davis-Besse } 1, \ldots \ldots \ldots \\
\text { Diablo Canyon } 1 \ldots \ldots . . .\end{array}$ & $\begin{array}{l}12 / 01 / 74 \\
01 / 01 / 73\end{array}$ & $\begin{array}{l}12 / 01 / 74 \\
05 / 01 / 74\end{array}$ & $\begin{array}{l}05 / 01 / 75 \\
03 / 01 / 75\end{array}$ & $\begin{array}{l}06 / 01 / 76 \\
09 / 01 / 75\end{array}$ & $\begin{array}{l}09 / 01 / 76 \\
05 / 01 / 76\end{array}$ & $\begin{array}{l}31 \\
31\end{array}$ & & $\begin{array}{l}614,221 \\
584,131\end{array}$ & $\begin{array}{l}837,867 \\
853,158\end{array}$ & 344 \\
\hline Diablo Canyon $2 \ldots .$. & $05 / 01 / 75$ & $03 / 01 / 76$ & $03 / 01 / 77$ & $01 / 01 / 77$ & $01 / 01 / 78$ & 344,988 & 486,123 & 579,454 & 795,578 & 853,864 \\
\hline Donald c. Cook $1, \ldots$. & $04 / 01 / 72$ & $03 / 01 / 73$ & $10 / 01 / 73$ & $04 / 01 / 75$ & (c) & 493,711 & 682,696 & 787,520 & 833,314 & \\
\hline Duane Arnold .......... & $12 / 01 / 73$ & $12 / 01 / 73$ & $12 / 01 / 73$ & $01 / 01 / 74$ & $01 / 01 / 74$ & 255,153 & 278,723 & 333,565 & 437,074 & 408,183 \\
\hline Edwin I. Hatch $1 \ldots \ldots$ & $06 / 01 / 73$ & $04 / 01 / 73$ & $04 / 01 / 73$ & $04 / 01 / 74$ & $04 / 01 / 74$ & 313,101 & 384,334 & 381,654 & 596,799 & 660,393 \\
\hline Edwin I. Hatch 2 & $01 / 78$ & $01 / 78$ & $04 /$ & 1/79 & $04 / 01 / 79$ &, 764 & 0,095 & 622,609 & 740,086 & 752, \\
\hline Permi $2 \ldots \ldots \ldots \ldots$ & $15 / 74$ & $04 / 15 / 76$ & $12 / 15 / 80$ & $12 / 15 / 80$ & $11 / 15 / 83$ & 447,882 & 688,848 & 924,793 & $1,266,638$ & $1,735,5$ \\
\hline Fort Calhoun 1 & $01 / 71$ & $05 / 01 / 71$ & $06 / 01 / 72$ & $11 / 01 / 72$ & $05 / 01 / 73$ & 166,771 & 214,404 & 274,367 & 306,043 & 369,769 \\
\hline Grand Gulf 1 & $11 / 79$ & $01 / 80$ & $04 / 01 / 81$ & 04/01/81 & $04 / 01 / 81$ & 830,459 & 751,865 & 938,896 & $1,823,418$ & $1,827,154$ \\
\hline Harris t $^{\mathbf{b}} \ldots$ & 03 & $15 / 84$ & $09 / 15 / 85$ & $03 / 15 / 86$ & $09 / 15 / 86$ & 674,532 & 709,920 & $1,227,058$ & $2,194,440$ & $3,004,815$ \\
\hline Hope Creek it & $12 / 15 / 82$ & $12 / 15 / 86$ & $12 / 15 / 86$ & $12 / 15 / 86$ & $12 / 15 / 86$ & $1,195,824$ & $1,561,891$ & $2,239,658$ & $3,569,532$ & $3,454,272$ \\
\hline Indian Foint & $1 / 71$ & $05 / 01 / 73$ & $12 / 01 / 73$ & $10 / 01 / 74$ & $06 / 01 / 75$ & 58,539 & 309,159 & 487,120 & 616,325 & 709,204 \\
\hline Joseph M. Fa & $01 / 75$ & $04 / 01 / 75$ & $12 / 01 / 75$ & $02 / 01 / 76$ & $06 / 01 / 77$ & 291,068 & 475,844 & 509,924 & 892,496 & $1,096,320$ \\
\hline Joseph H. Fax & $01 / 77$ & $01 / 01 / 77$ & $04 / 01 / 80$ & $04 / 01 / 80$ & $09 / 01 / 80$ & 305,044 & 519,835 & 737,962 & 854,473 & 836 \\
\hline Kewaunee $\ldots$ & & $09 / 01 / 72$ & $09 / 01 / 72$ & $01 / 72$ & $06 / 01 / 73$ & 23,427 & 252,119 & 244,376 & 337,611 & 382,693 \\
\hline Lasalle $1 \ldots$ & $12 / 01 / 78$ & $12 / 01 / 78$ & $09 / 01 / 79$ & $09 / 01 / 79$ & $12 / 01 / 80$ & 536,848 & 587,409 & 628,759 & $1,032,214$ & $1,198,639$ \\
\hline $\begin{array}{l}\text { Lasalle } 2, \ldots \ldots \ldots \ldots \ldots \\
\text { Limerick }, \ldots \ldots \ldots \ldots \ldots\end{array}$ & $\begin{array}{l}05 / 15 / 79 \\
03 / 15 / 75\end{array}$ & $\begin{array}{l}10 / 15 / 79 \\
04 / 15 / 83\end{array}$ & $\begin{array}{l}09 / 15 / 80 \\
04 / 15 / 83\end{array}$ & $\begin{array}{l}12 / 15 / 81 \\
04 / 15 / 85\end{array}$ & $\begin{array}{l}10 / 15 / 83 \\
04 / 15 / 85\end{array}$ & $\begin{array}{l}399,488 \\
691,836\end{array}$ & $\begin{array}{l}436,379 \\
943,074\end{array}$ & $\begin{array}{r}506,928 \\
1,294,899\end{array}$ & $\begin{array}{r}800,870 \\
2,194,790\end{array}$ & $\begin{array}{r}998,725 \\
2,309,235\end{array}$ \\
\hline MoGuire $1 \ldots \ldots \ldots \ldots$ & $11 / 01 / 75$ & $11 / 01 / 76$ & $01 / 01 / 78$ & $01 / 01 / 79$ & $07 / 01 / 79$ & 311,191 & 332,251 & 506,102 & 629,994 & 821,025 \\
\hline McGuire $2 \ldots \ldots \ldots \ldots$ & $03 / 15 / 77$ & $09 / 15 / 77$ & $01 / 15 / 79$ & $04 / 15 / 82$ & $06 / 15 / 83$ & 354,556 & 309,692 & 467,459 & 788,034 & 922,381 \\
\hline Millstone $2 \ldots \ldots \ldots$ & $04 / 01 / 74$ & $04 / 01 / 74$ & $04 / 01 / 74$ & $05 / 01 / 75$ & $08 / 01 / 75$ & 56,334 & 474,094 & 521,897 & 765,944 & 688,2 \\
\hline Millstone $3^{b} \ldots \ldots \ldots \ldots$ & $5 / 79$ & $05 / 15 / 82$ & $05 / 15 / 86$ & $05 / 15 / 86$ & $06 / 15 / 86$ & 785,817 & $1,827,434$ & $2,261,156$ & $3,242,362$ & $3,003,760$ \\
\hline Nine Mile Point $2 b \ldots$ & $05 / 15 / 79$ & $10 / 15 / 84$ & $10 / 15 / 86$ & $/ 15 / 86$ & $10 / 15 / 86$ & 757,353 & $1,652,841$ & $2,577,091$ & $3,002,457$ & $3,967,476$ \\
\hline North Anna 1 ........... & $03 / 01 / 74$ & $03 / 01 / 74$ & $12 / 01 / 74$ & $05 / 01 / 76$ & $04 / 01 / 77$ & 386,655 & 557,534 & 704,660 & 852,402 & $1,076,127$ \\
\hline North Anna 2 .......... & $03 / 15 / 75$ & $07 / 01 / 75$ & $11 / 01 / 76$ & $05 / 01 / 78$ & $03 / 01 / 79$ & 334,315 & 382,732 & 403,491 & 592,645 & 661,156 \\
\hline Palisades $\ldots \ldots \ldots$ & $05 / 01 / 70$ & $05 / 01 / 70$ & $05 / 01 / 70$ & $05 / 01 / 70$ & $05 / 01 / 70$ & 221,053 & 221,053 & 221,053 & 290,381 & 290,381 \\
\hline Palo Verde 1 ... & 15/82 & $05 / 15 / 82$ & $05 / 15 / 83$ & $05 / 15 / 83$ & $05 / 15 / 83$ & 927,249 & $1,186,905$ & 781,311 & $1,984,183$ & $1,961,434$ \\
\hline Palo Verde $2 \ldots$ & $05 / 15 / 84$ & $05 / 15 / 84$ & $05 / 15 / 84$ & $05 / 15 / 84$ & $05 / 15 / 84$ & 690,974 & 452,712 & 686,760 & $1,265,012$ & $1,557,118$ \\
\hline Peach Bottom 2 ... & $03 / 01 / 71$ & $03 / 01 / 71$ & $05 / 01 / 72$ & $03 / 01 / 73$ & $09 / 01 / 73$ & 399,923 & 392,222 & 516,795 & 624,369 & 800,005 \\
\hline Peach Bottom $3 \ldots$ & $03 / 01 / 73$ & $03 / 01 / 73$ & $04 / 01 / 74$ & $09 / 01 / 74$ & $12 / 01 / 74$ & 318,030 & 465,928 & 497,341 & 626,853 & 480,969 \\
\hline Perry $1 \ldots \ldots$ & $06 / 15 / 79$ & $12 / 15 / 81$ & $05 / 15 / 83$ & $05 / 15 / 84$ & $05 / 15 / 85$ & 736,829 & 920,802 & 923,404 & $1,489,825$ & $1,801,225$ \\
\hline Rancho Seco & $05 / 01 / 73$ & $05 / 01 / 73$ & $05 / 01 / 73$ & $101 / 73$ & $10 / 01 / 74$ & 292,296 & 283,748 & 454,241 & 661,810 & 700,604 \\
\hline River Bend 1 & $15 / 81$ & $04 / 15 / 84$ & $12 / 15 / 85$ & /15/85 & $15 / 85$ & 539,344 & $1,210,513$ & $1,444,092$ & $2,448,073$ & $3,073,3$ \\
\hline Salem 1 ........ & $03 / 01 / 72$ & $12 / 01 / 72$ & $10 / 01 / 74$ & $101 / 75$ & $1 / 76$ & 347,229 & 546,861 & 651,274 & 907,369 & 1,07 \\
\hline Salew 2 & $1 / 73$ & $07 / 01 / 73$ & $1 / 79$ & $04 / 01 / 79$ & $1 / 79$ & 284,096 & 447,431 & 532,860 & 742,393 & 877 \\
\hline San Onofre $2 \ldots$ & $01 / 01 / 79$ & $10 / 01 / 81$ & $10 / 01 / 81$ & $10 / 01 / 81$ & $12 / 0$ & 851,659 & $1,207,223$ & $1,240,671$ & 223 & \\
\hline San Onofre 3 .. & & $01 / 01 / 83$ & $1 / 83$ & $5 / 83$ & $/ 83$ & 793,455 & 3,769 & 68 & 101 & 1,6 \\
\hline Sequoyah $1 \ldots \ldots$ & $11 / 73$ & $07 / 01 / 74$ & $04 / C$ & $1 / 78$ & $10 / 0$ & 393,724 & 104 & 460,127 & 818,650 & 967 \\
\hline Sequoyah $2 \ldots \ldots$ & & $03 / 15 / 75$ & $12 / 15 / 75$ & $03 / 15 / 80$ & $06 /$ & & & 376,467 & 69,805 & 91 \\
\hline Shoreham ....... & $05 / 15 / 73$ & $05 / 15 / 78$ & $05 / 15 / 79$ & $09 / 15 / 80$ & $02 / 15 / 83$ & 225,735 & 851,042 & 737,396 & $1,664,071$ & 3.971 \\
\hline t. Lucte $1 \ldots \ldots$ & $01 / 73$ & $01 / 75$ & & $1 / 75$ & & & & 7,739 & 36,569 & 694 \\
\hline St. Lucie $2 \ldots$ & $12 / 15 / 80$ & $05 / 15 / 83$ & $05 / 15 / 83$ & $05 / 15 / 83$ & $5 / 83$ & 600 & .596 & 903,948 & 0,737 & 1,37 \\
\hline Surry $1 \ldots \ldots$ & $03 / 01 / 71$ & $03 / 01 / 71$ & $06 / 01 / 71$ & $10 / 01 / 71$ & $02 / 01 / 72$ & 315,018 & 416,376 & 0,649 &, 849 & 46 \\
\hline Surry $2 \ldots \ldots$ & $03 / 01 / 72$ & $04 / 01 / 72$ & $10 / 01 / 72$ & $12 / 01 / 72$ & $03 / 0$ & 275 & 323,502 & 504 & 908 & 317 \\
\hline Susquehanna 1 & $01 / 01 / 79$ & $11 / 01 / 80$ & $11 / 01 / 80$ & $01 / 01 / 82$ & $04 / 0$ & 844 & 1,042 & 1,06 & 574 & 2, \\
\hline Susquehanna 2 .. & $12 / 15 / 81$ & $05 / 15 / 82$ & $05 / 15 / 82$ & $11 / 15 / 84$ & $11 / 15 / 84$ & 409 & 151 & 718,978 & 0,255 & 1.0 \\
\hline Three Mile Island $1 \ldots$ & $1 / 71$ & $05 / 01 / 72$ & 1/72 & $11 / 01 / 73$ & & & & & 664 & \\
\hline Three Mile Island & & & & $05 / 01 / 78$ & $1 / 78$ & & 89 & 26 & 841 & 479 \\
\hline $\operatorname{Trojan} \ldots \ldots \ldots \ldots \ldots$ & $09 / 01 / 74$ & $09 / 01 / 74$ & $09 / 01 / 74$ & $07 / 01 / 75$ & $01 / 0$ & 437,011 & 420,480 & 447,787 & 704,677 & 761,772 \\
\hline Virgtl Summer 1 & $11 / 01 / 77$ & $05 / 01 / 79$ & $05 / 01 / 80$ & $05 / 01 / 80$ & $12 /$ & .600 & 430,954 & 709,911 & 7,577 & 1,0 \\
\hline aterford 3 ........ & $11 / 15 / 77$ & $04 / 15 / 81$ & $10 / 15 / 81$ & $02 / 15 / 81$ & $04 / 15 / 83$ & 760 & 4,978 & $1,022,443$ & $3,493,973$ & 1,8 \\
\hline lolf creek $1 \ldots$ & $04 / 15 / 82$ & $04 / 15 / 83$ & $04 / 15 / 83$ & $04 / 15 / 84$ & $02 / 15 / 85$ & 3,778 & 569 & $1,097,394$ & $1,712,597$ & $2,055,654$ \\
\hline PPSS $2 \ldots \ldots \ldots \ldots$ & $09 / 15 / 77$ & $07 / 15 / 79$ & $09 / 15 / 80$ & $09 / 15 / 81$ & $02 / 15 / 84$ & 41 & 666, & 304 & $2,285,447$ & $2,926,758$ \\
\hline ion $1, \ldots \ldots \ldots \ldots \ldots$ & $04 / 01 / 72$ & $04 / 01 / 72$ & $04 / 01 / 72$ & $08 / 01 / 72$ & $08 / 01 / 72$ & 445,452 & 58 & 507,081 & 603,530 & 540,473 \\
\hline zion $2 \ldots \ldots \ldots \ldots \ldots$ & $05 / 01 / 73$ & $05 / 01 / 73$ & $05 / 01 / 73$ & $05 / 01 / 73$ & $11 / 01 / 74$ & 323,029 & 397,526 & 423,410 & 561,067 & 580,965 \\
\hline
\end{tabular}

AThousand 1982 dollars.

b These units were not included in the regression analyses.

contt not included in regression analysis of estimates made at 90 percent completion.

Source: Energy Information Administration, Form EIA-254, "Semiannual Progress Report on 5 tatus of Reactor Construction," and predecessor survey forms. 
Table C4. Means and Variances of Variables Used in the Regression Analysis of Real Overnight Costs

\begin{tabular}{|c|c|c|}
\hline Variable & Mean & $\begin{array}{l}\text { Standard } \\
\text { Deviation }\end{array}$ \\
\hline Log of Real Overnight Costs Per kWe ... & 7.003 & 0.510 \\
\hline 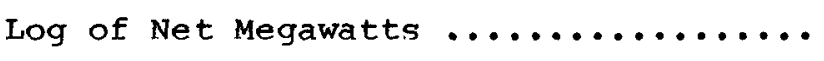 & 6.868 & 0.191 \\
\hline $\begin{array}{l}\text { Binary Variable for Plant Being } \\
\text { Located in South or Southwest ......... }\end{array}$ & 0.439 & 0.500 \\
\hline 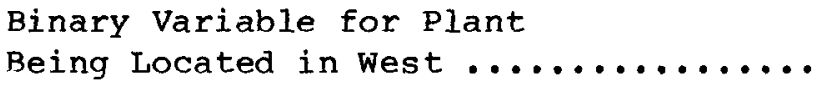 & 0.106 & 0.310 \\
\hline $\begin{array}{l}\text { Binary Variable for Use } \\
\text { of Cooling Towers } \ldots \ldots \ldots \ldots \ldots \ldots . . . \ldots\end{array}$ & 0.379 & 0.489 \\
\hline $\begin{array}{l}\text { Binary Variable for Plant Being } \\
\text { Single Unit or First of Multi-Unit .... }\end{array}$ & 0.606 & 0.492 \\
\hline Date of Construction start ........... & 3,863 & 1,065 \\
\hline 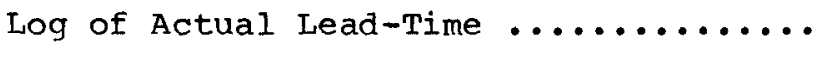 & 8.102 & 0.288 \\
\hline $\begin{array}{l}\text { Experience of Utility That Acts } \\
\text { as Its Own Construction Manager }{ }^{a} \ldots . .\end{array}$ & 0.007 & 0.015 \\
\hline Experience of External Contractorb .... & 0.024 & 0.030 \\
\hline $\begin{array}{l}\text { Binary Variable for Plant Being } \\
\text { Constructed by Utility } \ldots \ldots \ldots \ldots \ldots . . .\end{array}$ & 0.272 & 0.449 \\
\hline
\end{tabular}

aThis is the coefficient associated with the interaction term between the binary variable for utilities that act as their own construction managers and the experience variable (denoted as INTER in the equations presented in the text). This coefficient would measure the difference in the regression coefficients associated with experience for those utilities that act as their own construction managers and those that employ outside contractors.

$b_{\text {This }}$ is the coefficient associated with the contractor's experience variable (denoted as CST1 in the equations presented in the text). It can be interpreted as the regression coefficient associated with the experience variable for those utilities that employ outside contractors.

Source: Computations based on data from Energy Information Administration, Form EIA-254, "Semiannual Progress Report on status of Reactor Construction," and predecessor survey forms. 
In all three cases, all nonexperimental light-water reactors were used to compute the three measures of experience. Since it is conceivable that the experience from constructing small reactors was not transferable to large ones, the experience variables were recomputed with the small reactors excluded. When this measure of experience was included in the regressions, the results were the same as reported in the text. The experience of the architect-engineer and the experience of the utility were also computed. The inclusion of these measures of experience did not affect the results.

In the computation of the experience variables used in the cost analysis, all plants completed in the same calendar year were assumed to be completed at the same time. The computation of the experience variable also included work on the unit in question. For example, Lasalle 1 and 2 were completed in January and June of 1984, respectively, and were the third and fourth units constructed by Commonwealth Edison. Since both were completed in the same year, they were assumed to be completed at the same time. Thus, an experience variable of 4 finished reactors was associated with each unit. The same assumptions were also used for the lead-time analysis; however, if the commercial operation date for a given unit was after July 1 of a particular year, it was rounded to the following year.

\section{Regions and Costs}

The regional definitions used in The Handy-Whitman Index of Public Utility Construction costs were used. Issues relating to the cost data are described in detail in Appendix A. For three multi-unit plants, the costs were not broken down by unit. Initially, these multi-unit plants were treated as three "large" ones. Because the capacity of these "large" plants was two to three times that of all the others, a serious outlier problem resulted. Thus, the total plant costs were broken down into unit-level data, using either a 40-30-30 or a 55-45 split. When the cost equation was reestimated with these units excluded from the sample, the coefficient associated with the first unit variable was about the same. It should be noted that all the previous studies (reviewed in Appendix B) encountered the same type of problem.

\section{Percent Complete}

The data on percent complete for nuclear construction projects were also obtained from Form EIA-254. Although it was not specified on the form, the percent complete data probably refer to man-hours rather than costs. It is standard practice for engineers to compute percent completion in this fashion, and there is no reason to believe that the percent complete data were computed in a manner inconsistent with general engineering practices. 
$$
\text { . }
$$ 


\section{Statistical and Econometric Issues}

This appendix presents a discussion of a number of statistical and econometric issues that are mentioned in the text. The appendix begins with the presentation of estimates of the real overnight cost equations when experience is defined in terms of the number of completed reactors. A general discussion of the use of binary or "dummy" variables follows, and the appendix concludes with a discussion of the problem of multicollinearity and other econometric issues.

\section{Estimates of Real Overnight Cost Equations Using the Number of Completed Reactors as a Measure of Experience}

The results reported in the text were obtained using the number of reactor construction years as a measure of experience. To test the sensitivity of the results to the definition of experience, the cost equations were reestimated with experience defined as the number of reactors completed. This definition assumes that there is no learning from reactors under construction, whereas the definition used in the text does allow for learning over the construction period. Defining experience in terms of the number of reactor construction years, however, assumes that there is an equal amount of learning when one contractor builds a plant in 10 years and when a second contractor builds two plants in 5 years.

The estimates of the real overnight cost equations are shown in Tables D1 and D2. As stated in the text, when the alternative definition of experience as the number of reactors completed is used, the major difference in the results deals with the relative effects of experience when the utility acts as its own construction manager. From Table D2, when the alternative definition of experience is used, there is a negative correlation between the experience of utilities that act as their own construction manager and the forecast errors when the units were 25 percent, 50 percent, and 75 percent complete. When experience is defined as the number of reactor construction years, such a negative correlation is observed only for cost estimates made at the start of construction.

It should also be noted that the estimated cost saving when the utility acts as its own construction manager is about 67 percent. This estimate is substantially higher than the estimate presented in the text. The experience variable for those utilities that act as their own construction manager has only a few discrete values: 1.0, $0.5,0.33$, and 0.25 . Thus, it tends to act as a binary variable. Apparently, some of the effects of learning are captured in the coefficient associated with the binary variable instead of the experience variable for utilities that act as their own construction manager.

\section{Results of Sensitivity Analyses Using Different Assumptions About Expected AFUDC and Escalation Rates}

As stated in the text and in Appendix A, expected AFUDC and escalation rates are not reported on Form EIA-254. Thus, to compute the estimated real overnight costs, these rates must be inferred. The estimated overnight costs used in the analysis described in this report were based on a series of estimated AFUDC and escalation rates that were reported in Environmental Impact statements.

To determine the sensitivity of the results to the assumptions made about expected AFUDC and escalation rates, a sensitivity analysis was undertaken. The estimated real overnight costs were recomputed using two different assumptions about the 


\section{Table D1. Results of Regression Analysis of Estimated Real Ovemight Costs: Experience Defined in Terms of the Number of Completed Reactors}

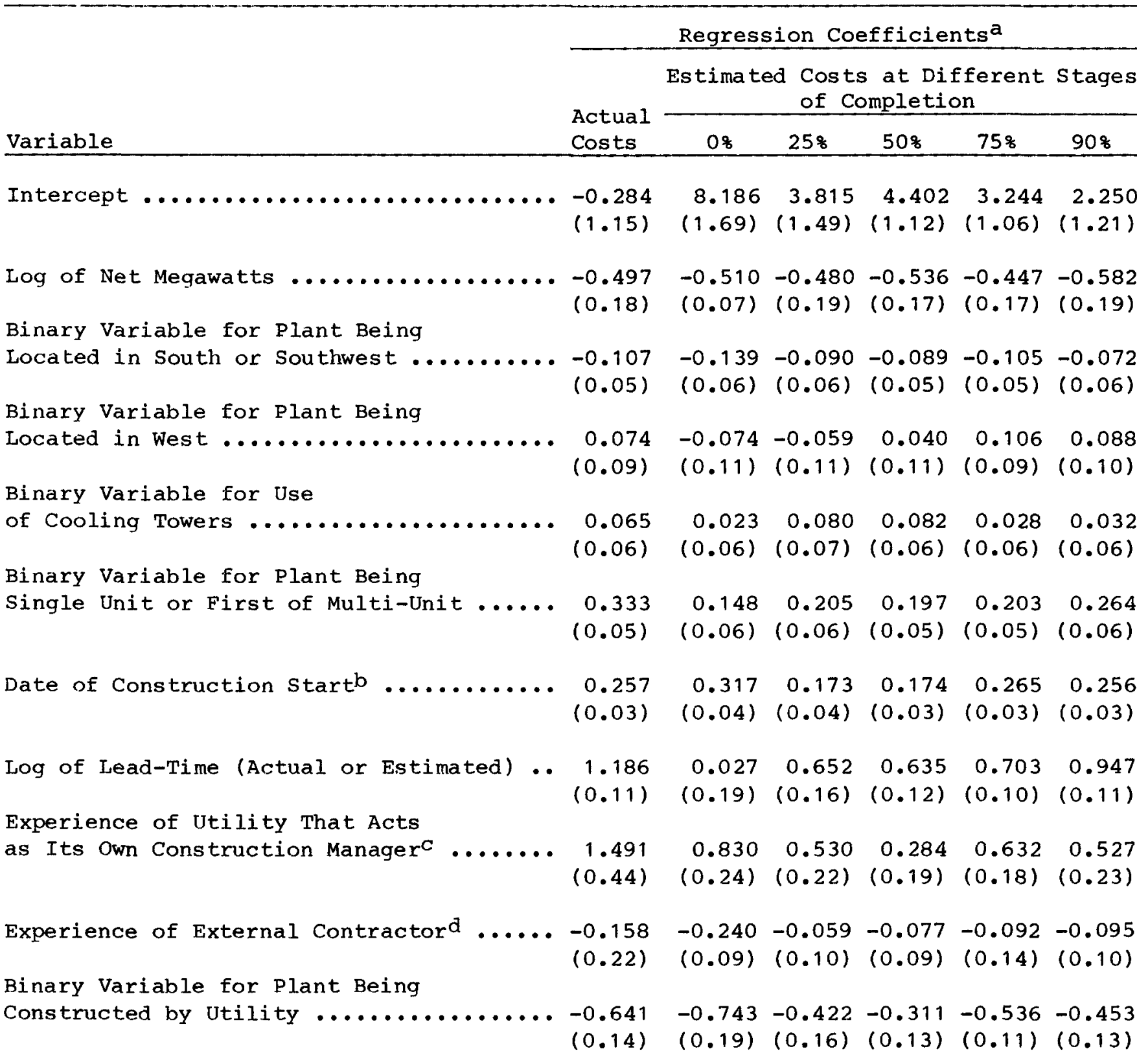

astandard errors shown in parentheses.

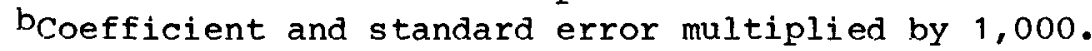

CRepresents the difference in the regression coefficients associated with experience for those utilities that act as their own construction managers and those that employ outside contractors (denoted as INTER in the equations presented in the text).

$d_{\text {This }}$ is the coefficient associated with the contractor's experience variable (denoted as CST1 in the equations presented in the text).

Source: Computations based on data from Energy Information Administration, Form EIA-254, "Semiannual Progress Report on Status of Reactor Construction," and predecessor survey forms. 
Table D2. Implied Results of Regression Analysis of Real Overnight Cost Forecast Errors: Experience Defined in Terms of the Number of Completed Reactors

\begin{tabular}{|c|c|c|c|c|c|}
\hline \multirow[b]{2}{*}{ Variable } & \multicolumn{5}{|c|}{$\begin{array}{c}\text { Results for Estimated Costs at Different Stages } \\
\text { of Completiona }\end{array}$} \\
\hline & 08 & 258 & 508 & 758 & 908 \\
\hline Intercept $\ldots \ldots \ldots \ldots \ldots \ldots \ldots \ldots \ldots$ & $\begin{array}{c}-8.444 \\
\mathrm{NA}\end{array}$ & $\begin{array}{c}-4.309 \\
\text { NA }\end{array}$ & $\begin{array}{l}-4.957 \\
\text { NA }\end{array}$ & $\begin{array}{l}-3.868 \\
\mathrm{NA}\end{array}$ & $\begin{array}{c}-2.624 \\
\mathrm{NA}\end{array}$ \\
\hline Log of Net Megawatts $\ldots \ldots \ldots \ldots \ldots \ldots$ & $\begin{array}{r}0.010 \\
(0.01)\end{array}$ & $\begin{array}{l}-0.044 \\
(0.03)\end{array}$ & $\begin{array}{r}0.029 \\
(0.01)\end{array}$ & $\begin{array}{l}-0.060 \\
(0.06)\end{array}$ & $\begin{array}{r}0.011 \\
(0.02)\end{array}$ \\
\hline $\begin{array}{l}\text { Located in South or Southwest ........ } \\
\text { Binary Variable for Plant Being }\end{array}$ & $\begin{array}{r}0.034 \\
(0.17)\end{array}$ & $\begin{array}{r}-0.009 \\
(0.01)\end{array}$ & $\begin{array}{l}-0.010 \\
(0.02)\end{array}$ & $\begin{array}{r}0.004 \\
(0.01)\end{array}$ & $\begin{array}{l}-0.017 \\
(0.04)\end{array}$ \\
\hline Located in West $\ldots \ldots \ldots \ldots \ldots \ldots \ldots$ & $\begin{array}{r}0.148 \\
(1.13)\end{array}$ & $\begin{array}{r}0.155 \\
(1.15)\end{array}$ & $\begin{array}{l}0.062 \\
(0.23)\end{array}$ & $\begin{array}{l}0.002 \\
(0.01)\end{array}$ & $\begin{array}{r}0.019 \\
(0.02)\end{array}$ \\
\hline $\begin{array}{l}\text { Binary Variable for Use } \\
\text { of Cooling Towers } \ldots \ldots \ldots \ldots \ldots \ldots \ldots \ldots \\
\text { Binary Variable for Plant Being }\end{array}$ & $\begin{array}{r}0.044 \\
(0.25)\end{array}$ & $\begin{array}{r}0.002 \\
(0.01)\end{array}$ & $\begin{array}{r}-0.001 \\
(0.01)\end{array}$ & $\begin{array}{r}0.052 \\
(0.40)\end{array}$ & $\begin{array}{r}0.052 \\
(0.36)\end{array}$ \\
\hline Single Unit or First of Multi-Unit... & $\begin{array}{c}0.184 \\
(4.78)^{\star}\end{array}$ & $\begin{array}{r}0.137 \\
(2.65)\end{array}$ & $\begin{array}{r}0.139 \\
(3.15)\end{array}$ & $\begin{array}{r}0.132 \\
(3.03)\end{array}$ & $\begin{array}{r}0.083 \\
(1.04)\end{array}$ \\
\hline Date of Construction startb $\ldots \ldots \ldots$ & $\begin{array}{l}-0.058 \\
(1.63)\end{array}$ & $\begin{array}{r}0.090 \\
(3.31)\end{array}$ & $\begin{array}{c}0.087 \\
(4.17)^{*}\end{array}$ & $\begin{array}{c}-0.031 \\
(0.01)\end{array}$ & $\begin{array}{c}0.006 \\
(0.04)\end{array}$ \\
\hline Log of Actual Lead-Time $\ldots \ldots \ldots \ldots \ldots$ & $\begin{array}{c}1.186 \\
(28.08)\end{array}$ & $\begin{array}{c}1.238 \\
(8.75) *\end{array}$ & $\begin{array}{c}1.224 \\
(13.30)\end{array}$ & $\begin{array}{c}1.231 \\
(12.66) *\end{array}$ & $\begin{array}{c}1.249 \\
(4.14) *\end{array}$ \\
\hline Log of Estimated Lead-Time $\ldots \ldots \ldots \ldots$ & $\begin{array}{c}-0.027 \\
\text { NA }\end{array}$ & $\begin{array}{c}-0.652 \\
\text { NA }\end{array}$ & -0.635 & $\begin{array}{c}-0.704 \\
\mathrm{NA}\end{array}$ & $\begin{array}{c}-0.947 \\
\mathrm{NA}\end{array}$ \\
\hline $\begin{array}{l}\text { Experience of Utility That Acts } \\
\text { as Its own Construction Managerc .... }\end{array}$ & $\begin{array}{r}0.673 \\
(1.78)\end{array}$ & $\begin{array}{c}1.051 \\
(4.09) \star\end{array}$ & $\begin{array}{c}1.227 \\
(5.66)\end{array}$ & $\begin{array}{c}0.884 \\
(4.64)\end{array}$ & $\begin{array}{c}1.205 \\
(4.95) *\end{array}$ \\
\hline $\begin{array}{l}\text { Experience of External Contractord .. } \\
\text { Binary Variable for Plant Being }\end{array}$ & $\begin{array}{c}0.067 \\
\text { NA }\end{array}$ & $\begin{array}{c}-0.108 \\
\mathrm{NA}\end{array}$ & $\begin{array}{c}-0.046 \\
\mathrm{NA}\end{array}$ & $\begin{array}{c}-0.014 \\
\mathrm{NA}\end{array}$ & $\begin{array}{c}-0.127 \\
\mathrm{NA}\end{array}$ \\
\hline Constructed by Utility $\ldots \ldots \ldots \ldots \ldots$ & $\begin{array}{r}0.100 \\
(0.18)\end{array}$ & $\begin{array}{l}-0.228 \\
(1.18)\end{array}$ & $\begin{array}{l}-0.317 \\
(2.71)\end{array}$ & $\begin{array}{l}-0.100 \\
(0.30)\end{array}$ & $\begin{array}{l}-0.237 \\
(1.06)\end{array}$ \\
\hline
\end{tabular}

aw1 th the exception of the lead-times, entries are the difference in the regression coefficients in the actual and estimated cost equations. That is, the entries are the regression coefficients shown in Equation $(6)$ in the text. Because of small differences in the sample for each of the percent complete equations and variations in the construction start date, the actual cost regression coefficients used to compute the differences are not the same as those reported in Table D1. The F-statistics used to test for the equality of the coefficients are shown in parentheses. In all tests, there was 1 degree of freedom in the numerator and 110 in the denominator. The entries associated with the lead-time variables are the absolute regression coefficients; the F-statistic is the one used to test for the equality of the actual and estimated lead-time coefficients in the actual and estimated cost equations. An asterisk indicates that the "imputed" coefficient is significantly different from zero at a 0.95 level of confidence.

boefficient and standard error multiplied by 1,000 .

CRepresents the difference in the regression coefficients associated with experience for those utilities that act as their own construction managers and those that employ outside contractors (denoted as INTER in the equations presented in the text).

dThis is the coefficient associated with the contractor's experience variable (denoted as CST1 in the equations presented in the text).

Source: Computations based on data from Energy Information Administration, Form EIA-254, "Semianmual Progress Report on Status of Reactor Construction," and predecessor survey forms. 
generation of expected AFUDC and escalation rates. The first set of expected AFUDC and escalation rates were derived using the "rational expectations" hypothesis, which was the procedure used by Zimmerman (see Appendix B). Thus, the expected escalation rate was assumed to equal the nominal rate of inflation as measured by the GNP implicit price deflation minus the real rate of interest ( 1.7 percent). The expected AFUDC rate was set equal to the interest rate on long-term bonds with the same bond rating as those of the utility in question. As a bracketing case, a second set of AFUDC and escalation rates were computed, using the assumption that the utilities were "myopic" (the "irrational expectations" hypothesis). In this case, the expected AFUDC rate was set equal to 1.5 plus the average cost of debt as of the date of the report. Similarly, the expected escalation rate was assumed to equal the actual escalation rate as of the date the cost estimate was made.

The estimated cost equation at the start of construction and the implied equation for the forecast error using the expected AFUDC and escalation rates generated using the "rational expectations" hypothesis are shown in Tables D3 and D4, respectively. Similar results using the set of expected AFUDC and escalation rates generated using the "irrational expectations" hypothesis are shown in the same tables for comparison.

As can be seen from these tables and from Tables 17 and 18 in the text, the results are surprisingly insensitive to the assumptions about expected AFUDC and escalation rates. Indeed, except for the intercept, the regression coefficients are quite stable. This probably is due to the fact that the expected lead-times were not large, and the expected AFUDC and escalation rates were therefore relatively small regardless of the assumptions used. Thus, the absolute differences in the estimated real overnight costs produced by a variation of 1 to 2 percentage points in expected AFUDC and escalation rates would also be very small.

\section{Use of Binary Variables and Interaction Terms}

In the text, a number of binary or "dummy" variables were used to capture the effects of qualitative factors, such as regional influences. This section of the appendix presents a brief description of the interpretation of the coefficients associated with binary variables. 1

To get some idea about the use of binary variables, consider the following equation:

$$
A C=a_{0}+a_{1} D_{1}+a_{2} D_{2}+a_{3} Z,
$$

where: $\mathrm{AC}=$ average construction costs;

$D_{1}=a$ binary variable that takes on a value of 1 if the unit is located in the South or Southwest, 0 otherwise;

$D_{2}=$ a binary variable that takes on a value of 1 if the unit is located in the West, 0 otherwise; and

$z=a$ vector of all other relevant variables.

\footnotetext{
${ }^{1}$ For a more detailed discussion of the use of dummy variables, see D. Gujarati, "Use of Dummy Variables in Testing for Equality Between sets of Coefficients in Linear Regressions: A Generalization," American Statistician (December 1970), pp. 18-22.
} 
Table D3. Results of Regression Analysis of Estimated Real Overnight Costs Using Different Assumptions About Expected AFUDC and Escalation Rates

\begin{tabular}{|c|c|c|}
\hline \multirow[b]{2}{*}{ Variable } & \multicolumn{2}{|c|}{ Regression Coefficients ${ }^{a}$} \\
\hline & $\begin{array}{l}\text { "Rational } \\
\text { Expectations" }\end{array}$ & $\begin{array}{c}\text { "Myopic } \\
\text { Expectations" }\end{array}$ \\
\hline Intercept $\ldots \ldots \ldots \ldots \ldots \ldots \ldots \ldots \ldots \ldots$ & $\begin{array}{l}7.011 \\
(1.95) *\end{array}$ & $\begin{array}{l}6.814 \\
(2.00) *\end{array}$ \\
\hline Log of Net Megawatts $\ldots \ldots \ldots \ldots \ldots \ldots \ldots$ & $\begin{array}{l}-0.382 \\
(0.19) *\end{array}$ & $\begin{array}{l}-0.332 \\
(0.20)\end{array}$ \\
\hline $\begin{array}{l}\text { Binary Variable for Plant Being } \\
\text { Located in South or Southwest } \ldots \ldots \ldots \ldots \text {. }\end{array}$ & $\begin{array}{l}-0.086 \\
(0.07)\end{array}$ & $\begin{array}{l}-0.097 \\
(0.07)\end{array}$ \\
\hline $\begin{array}{l}\text { Binary Variable for Plant Being } \\
\text { Located in west } \ldots \ldots \ldots \ldots \ldots \ldots \ldots \ldots \ldots\end{array}$ & $\begin{array}{l}-0.011 \\
(0.11)\end{array}$ & $\begin{array}{l}-0.030 \\
(0.11)\end{array}$ \\
\hline $\begin{array}{l}\text { Binary Variable for Use } \\
\text { of Cooling Towers } \ldots \ldots \ldots \ldots \ldots \ldots \ldots\end{array}$ & $\begin{array}{l}-0.001 \\
(0.07)\end{array}$ & $\begin{array}{l}-0.030 \\
(0.33)\end{array}$ \\
\hline $\begin{array}{l}\text { Binary Variable for Plant Being } \\
\text { Single Unit or First of Multi-Unit ...... }\end{array}$ & $\begin{array}{r}0.100 \\
(0.07)\end{array}$ & $\begin{array}{r}0.110 \\
(0.08)\end{array}$ \\
\hline Date of Construation startb $\ldots \ldots \ldots \ldots$ & $\begin{array}{l}0.287 \\
(0.04) *\end{array}$ & $\begin{array}{l}0.286 \\
(0.04) *\end{array}$ \\
\hline Log of Lead-Time (Actual or Estimated) .. & $\begin{array}{r}0.075 \\
(0.22)\end{array}$ & $\begin{array}{r}0.051 \\
(0.22)\end{array}$ \\
\hline $\begin{array}{l}\text { Experience of Utility That Acts } \\
\text { as Its Own Construction Managerc } \ldots \ldots \ldots\end{array}$ & $\begin{array}{r}0.233 \\
(0.25)\end{array}$ & $\begin{array}{l}0.242 \\
(0.25)\end{array}$ \\
\hline Experience of External Contractord $\ldots \ldots$ & $\begin{array}{r}-0.018 \\
(0.13)\end{array}$ & $\begin{array}{l}-0.012 \\
(0.13)\end{array}$ \\
\hline $\begin{array}{l}\text { Binary Variable for Plant Being } \\
\text { Constructed by Utility ............... }\end{array}$ & $\begin{array}{l}-0.257 \\
(0.09) *\end{array}$ & $\begin{array}{l}-0.277 \\
(0.09) *\end{array}$ \\
\hline
\end{tabular}

astandard errors shown in parentheses.

bcoeficient and standard error multiplied by 1,000 .

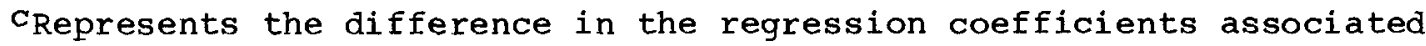
with experience for those utilities that act as their own construction managers and those that employ outside contractors (denoted as INTER in the equations presented in the text).

$\mathrm{d}_{\text {This }}$ is the coefficient associated with the contractor's experience variable (denoted as CST1 in the equations presented in the text).

Source: Computations based on data from Energy Information Administration, Form EIA-254, "Semiannual Progress Report on Status of Reactor Construction," and predecessor survey forms. 


\section{Table D4. Results of Regression Analysis of Forecast Errors in Real Overnight Costs Using Different Assumptions About Expected AFUDC and Escalation Rates}

\begin{tabular}{|c|c|c|}
\hline \multirow[b]{2}{*}{ Variable } & \multicolumn{2}{|c|}{ Results for Different Assumptions } \\
\hline & $\begin{array}{c}\text { "Rational } \\
\text { Expectations" }\end{array}$ & $\begin{array}{c}\text { "Hyopic } \\
\text { Expectations }\end{array}$ \\
\hline Intercept $\ldots \ldots \ldots \ldots \ldots \ldots \ldots \ldots \ldots \ldots \ldots \ldots \ldots \ldots \ldots \ldots$ & $\begin{array}{c}-6.296 \\
N A\end{array}$ & $\begin{array}{c}-6.092 \\
\mathrm{NA}\end{array}$ \\
\hline Iog of Net Megawatts $\ldots \ldots \ldots \ldots \ldots \ldots \ldots \ldots \ldots$ & $\begin{array}{r}-0.308 \\
(1.28)\end{array}$ & $\begin{array}{r}-0.358 \\
(1.69)\end{array}$ \\
\hline $\begin{array}{l}\text { Binary Varlable for Plant Being } \\
\text { Located in south or southrest } \ldots \ldots \ldots \ldots \ldots \ldots\end{array}$ & $\begin{array}{l}-0.03 ! \\
(0.12)\end{array}$ & $\begin{array}{r}-0.019 \\
(0.05)\end{array}$ \\
\hline $\begin{array}{l}\text { Binary Variable for Plant Being } \\
\text { Located in West } \ldots \ldots \ldots \ldots \ldots\end{array}$ & $\begin{array}{l}0.116 \\
(0.34)\end{array}$ & $\begin{array}{r}0.158 \\
(1.14)\end{array}$ \\
\hline $\begin{array}{l}\text { Binary Variable for Use } \\
\text { of Cooling Towers } \ldots \ldots \ldots \ldots \ldots \ldots \ldots \ldots \ldots \ldots\end{array}$ & $\begin{array}{r}0.094 \\
(0.33)\end{array}$ & $\begin{array}{r}0.059 \\
(0.51)\end{array}$ \\
\hline $\begin{array}{l}\text { Binary Variable for Plant Being } \\
\text { Single Unit or First of Multi-Unit } \ldots \ldots \ldots \ldots\end{array}$ & $\begin{array}{l}0.266 \\
(5.96) *\end{array}$ & $\begin{array}{c}0.216 \\
(5.29)\end{array}$ \\
\hline Date of Construction startb $\ldots \ldots \ldots \ldots \ldots \ldots$ & $\begin{array}{r}0.070 \\
(2.04)\end{array}$ & $\begin{array}{r}0.069 \\
(2.27)\end{array}$ \\
\hline Log of Actual Lead-Time $\ldots \ldots \ldots \ldots \ldots \ldots \ldots$ & $\begin{array}{c}1.245 \\
(22.38)\end{array}$ & $\begin{array}{c}1.245 \\
(22.40) *\end{array}$ \\
\hline Log of Estimated Lead-Time $\ldots \ldots \ldots \ldots \ldots \ldots$ & $\begin{array}{l}0.075 \\
\text { NA }\end{array}$ & $\begin{array}{c}0.050 \\
\mathrm{NA}\end{array}$ \\
\hline $\begin{array}{l}\text { Experience of Utility That Acts } \\
\text { as Its Own Construction Managerc } \ldots \ldots \ldots \ldots \ldots\end{array}$ & $\begin{array}{l}9.115 \\
(7.90)\end{array}$ & $\begin{array}{l}9.107 \\
(7.88) *\end{array}$ \\
\hline Experience of External Contractord $\ldots \ldots \ldots \ldots$ & $\begin{array}{r}2.414 \\
(3.74)\end{array}$ & $\begin{array}{r}2.411 \\
(3.76)\end{array}$ \\
\hline $\begin{array}{l}\text { Binary Variable for Plant Being } \\
\text { Constructed by dtility } \ldots \ldots \ldots \ldots\end{array}$ & $\begin{array}{l}-0.180 \\
(1.60)\end{array}$ & $\begin{array}{c}-0.160 \\
(1.24)\end{array}$ \\
\hline
\end{tabular}

\footnotetext{
awith the exception of the lead-times, entries are the difference in the regression coefficients in the actual and estimated cost equations. The F-statistics used to test for the equality of the coefficients are shown in parentheses. In all tests, there was 1 degree of freedom in the numerator and 110 in the denominator. The entries associated with the lead-time variables are the absolute regression coefficients; the F-statistic is the one used to test for the equality of the actual and estimated lead-time coefficients in the actual and estimated cost equations. An asterisk indicates that the coefficient is significantly different from zero at a 0.95 level of confidence, using a two-tailed test of significance.

boefficient and standard error multiplied by 1,000.

CRepresents the difference in the regression coefficients associated with experience for those utilities that act as their ow construction managers and those that employ outside contractors (denoted as INTER in the equations presented in the text).

dTis is the coefficient associated with the contractor's experience variable (denoted as CST1 in the equations presented in the text).

Source: Computations based on data from Energy Information Administration, Form EIA-254, "Semiannual Progress Report on Status of Reactor Construction," and predecessor survey forms.
} 
The regression equation can be expressed as:

$$
\begin{aligned}
& A C=a_{0}+a_{1}+a_{3} Z \text {, when } D_{1}=1 \\
& A C=a_{0}+a_{2}+a_{3} z \text {, when } D_{2}=1 \\
& A C=a_{0}+a_{3} Z \text {, when } D_{1}=0 \text { and } D_{2}=0 \text {. }
\end{aligned}
$$

As can be seen from Equations (D1a) through (D1C), the coefficients associated with the two binary variables $a_{1}$ and $a_{2}$ would represent the difference in the intercept, or the difference between the costs, for plants located in the south/southwest or West, respectively, and those located in the East. Thus, the use of simple binary variables is effectively the same as estimating the following equation:

$$
\mathrm{AC}=\mathrm{b}_{0}+\mathrm{b}_{1} \mathrm{z},
$$

with the data stratified by region but constraining the slope term, $b_{1}$, to be equal across regions.

An interaction term can be used to permit variations in the slope term. For example, consider the following simplified cost equation:

$$
A C=a_{0}+a_{1} D+a_{2} x+a_{3} D_{1} x,
$$

where: $\mathrm{x}=$ experience; and

$\mathrm{D}_{1}=\mathrm{a}$ binary variable that takes on a value of 1 if the utility acted as the construction manager, 0 otherwise.

As before, Equation (D3) can be rewritten as

$$
\begin{aligned}
& A C=\left(a_{0}+a_{1}\right)+\left(a_{2}+a_{3}\right) x, \quad \text { when } D_{1}=1 \\
& A C=a_{0}+a_{2} x, \text { when } D_{1}=0
\end{aligned}
$$

Thus, the regression coefficient $a_{3}$ represents the difference between the regression coefficient associated with experience for utilities that act as their own construction manager $\left[a_{2}+a_{3}\right.$ in Equation (D3a)] and the regression coefficient associated with experience for utilities that employ outside contractors [ $a_{2}$ in Equation (D3b)]. The use of a binary variable and interaction term is therefore equivalent to estimating the following equation:

$$
A C=b_{0}+b_{1} x,
$$

with data stratified by the type of management regime. In this case, both the intercept and the slope term would be permitted to vary.

\section{The Econometric Issue of Multicollinearity}

The specification of the cost equation estimated in this report included lead-time as an explanatory variable. It has been argued that the inclusion of lead-time in the cost equation will result in so much collinearity that the lead-time variable 
should also be excluded.2 This is due to the fact that lead-times will also be a function of the other explanatory variables in the cost equation. Consequently, some discussion of multicollinearity is in order.

Two methods were used in this analysis to test for multicollinearity. The first and simplest method was to look at the simple R-squared in the lead-time equation. As shown in Table 6 in the text, the multiple R-squared was around 0.3 , which implies that about 70 percent of the variance in lead-times is not "explained" by the other explanatory variables in the cost equation. This would seem to indicate that multicollinearity between the lead-time variable and the other explanatory variables is not a major problem.

The second method used the variance decomposition technique developed by Belsley, Kuh, and Welsch. ${ }^{3}$ This technique involves first computing the eigenvalues associated with the principal components of all the explanatory variables; then computing the condition index, which is the square root of the ratio of the largest eigenvalue to each individual eigenvalue; and finally, computing the proportion of the variance of each eigenvalue caused by each principal component. A collinearity problem occurs when a principal component associated with a high condition index contributes strongly to the variance of two or more variables. This is indicated by variance proportions greater than 0.5 for two variables in an individual principal component factor with an index of 35 or greater.

The results of this analysis are shown in Table D5. As can be seen from the table, two principal components (the 10 th and 11 th components) have high condition indices. of these two, only the 11th has two variables -- the intercept and size -- with variance proportions greater than 0.5. Thus, there is a collinearity problem with the size variable and the intercept. Although inspection of the variance proportions associated with the 10th factor indicates that there is some collinearity between lead-time, the intercept, size, and the experience variables, it does not appear to be severe.

\section{The Issues of Heteroskedasticity and Least Squares Bias}

The equations in the text were estimated using ordinary least squares. This estimation technique yields results that are unbiased, efficient, and consistent if the residuals are uncorrelated with the explanatory variables and have constant variances. There is, however, a possibility that neither of these conditions will be met.

First, it has been argued that, over time, some utilities have been better able than others to cope with changing regulations. This might imply that the variance in the residuals will not be constant but will be related to time. If this is the case, the regression estimates will still be unbiased, but they will not be efficient. More importantly, the standard errors will be "too low," which in turn implies that the "t" statistics will be overstated.

2See William E. Mooz, Cost Analysis of Light Water Reactor Power Plants, R-2304DOE (Rand Corporation, Santa Monica, California, June 1978).

${ }^{3}$ D. Belsley, E. Kuh, and R. Welsch, Regression Diagnostics (John Wiley and Sons, New York, 1980). 
Table D5. Results of Multicollinearity Diagnostics for the Cost Equation

\begin{tabular}{|c|c|c|c|c|c|c|c|c|c|c|c|c|}
\hline \multirow{2}{*}{\multicolumn{2}{|c|}{$\begin{array}{l}\text { Condi tion } \\
\text { Index }\end{array}$}} & \multicolumn{11}{|c|}{ Variance Proportions for Variable } \\
\hline & & 1 & 2 & 3 & 4 & 5 & 6 & 7 & 8 & 9 & 10 & 11 \\
\hline 1.000 & $\ldots$ & 0.00 & 0.00 & 0.00 & 0.00 & 0.00 & 0.00 & 0.0010 & 0.00 & 0.00 & 0.00 & 0.00 \\
\hline 2.220 & $\ldots$ & 0.00 & 0.00 & 0.00 & 0.00 & 0.02 & 0.01 & 0.0004 & 0.00 & 0.07 & 0.00 & 0.06 \\
\hline 2.551 & ... & 0.00 & 0.00 & 0.08 & 0.55 & 0.00 & 0.00 & 0.00 & 0.00 & 0.00 & 0.0052 & 0.0018 \\
\hline 2.816 & ... & 0.00 & 0.00 & 0.05 & 0.02 & 0.15 & 0.00 & 0.00 & 0.00 & 0.02 & 0.16 & 0.00 \\
\hline 3.647 & ... & 0.00 & 0.00 & 0.38 & 0.07 & 0.15 & 0.24 & 0.00 & 0.00 & 0.00 & 0.01 & 0.00 \\
\hline 4.857 & ... & 0.00 & 0.00 & 0.43 & 0.26 & 0.11 & 0.33 & 0.01 & 0.00 & 0.01 & 0.09 & 0.02 \\
\hline 5.068 & $\ldots$ & 0.00 & 0.00 & 0.00 & 0.07 & 0.43 & 0.31 & 0.00 & 0.00 & 0.07 & 0.47 & 0.00 \\
\hline 7.067 & ... & 0.00 & 0.00 & 0.00 & 0.00 & 0.09 & 0.09 & 0.00 & 0.00 & 0.72 & 0.01 & 0.78 \\
\hline 13.090 & $\ldots$ & 0.00 & 0.00 & 0.03 & 0.00 & 0.03 & 0.00 & 0.90 & 0.00 & 0.02 & 0.05 & 0.00 \\
\hline 114.764 & ... & 0.18 & 0.09 & 0.00 & 0.00 & 0.00 & 0.00 & 0.00 & 0.99 & 0.07 & 0.01 & 0.09 \\
\hline 169.345 & ... & 0.82 & 0.91 & 0.01 & 0.01 & 0.00 & 0.00 & 0.07 & 0.01 & 0.00 & 0.19 & 0.04 \\
\hline
\end{tabular}

a Key to Variables: $1=$ Intercept; 2 = Log of Net Megawatts; $3=$ Binary Variable for Plant Being Located in South or Southwest; 4 = Binary Variable for Plant Being Located in West; 5 = Binary Variable for Use of Cooling Towers; 6 = Binary Variable for Plant Being Single Unit or First of Multi-Unit; 7 = Date of Construction Start; $8=$ Log of Actual Lead-Time; $9=$ Experience of Utility That Acts as Its Own Construction Manager; $10=$ Experience of External Contractor; 11 = Binary Variable for Plant Being Constructed by Utility.

The standard solution to the problem of heteroskedasticity is to employ some type of weighted regression. Since there is reason to believe that the variance of the residuals will be related to time, either the time variable or its square root should be used as the weight. The cost equations were therefore reestimated using the weighted regression technique, with either the time variable or its square root used as the weight. The results were similar to those presented in the text, suggesting that heteroskedasticity is not a problem.

Second, as currently specified, the actual cost and lead-time equations can be considered as a recursive system of equations. In particular, the two equations can be rewritten as:

$$
\begin{aligned}
& a_{11} C-a_{12} L T+b_{1} z_{1}=U_{1} \\
& a_{21} O-a_{22} L T+b_{2} z_{2}=U_{2},
\end{aligned}
$$

where: $C=$ costs,

$L T=$ lead-time,

$z_{1}$ and $z_{2}$ are vectors of the explanatory variables, and

$\mathrm{U}_{1}$ and $\mathrm{U}_{2}$ are population error terms.

$z_{1}$ and $z_{2}$ are considered to be exogenous variables, and $C$ and $L T$ are the endogenous variables. 
Equation (D5) can be rewritten as:

$$
\text { where: } \begin{aligned}
a & =\left[\begin{array}{ll}
a_{11} & a_{21} \\
a_{12} & a_{22}
\end{array}\right], b y=u, \\
x & =\left[\begin{array}{ll}
C & L T \\
0 & L T
\end{array}\right], \\
b & =\left[\begin{array}{ll}
b_{1} & b_{2}
\end{array}\right], \\
y & =\left[\begin{array}{l}
z_{1} \\
z_{2}
\end{array}\right], \text { and } \\
U & =\left[\begin{array}{l}
U_{1} \\
U_{2}
\end{array}\right],
\end{aligned}
$$

Since the matrix of the endogenous variables is triangular, in the absence of any other problems, ordinary least squares will yield estimates with the desired properties. This is true only if the error terms are uncorrelated across equations. The cost and lead-time equations were reestimated using the technique of seemingly Unrelated Regression (SUR). This econometric technique takes into account the correlation of population errors across equations. Since the results using the SUR method were similar to those obtained using ordinary least squares, the amount of correlation of the population error terms is not substantial.

It is also possible that lead-times could be a function of real overnight costs. If this were the case, the matrix of endogenous variables would no longer be triangular, which would imply that the system would be simultaneous rather than recursive. Thus, if lead-times were a function of the real overnight costs, one would encounter a logical problem of identification and the statistical problem of least squares bias.

As a general rule, one equation in a two-equation system will be identified if one exogenous variable excluded from the equation in question is included in the other. Thus, if lead-times are in fact a function of real overnight costs, as opposed to the reported costs (which are of greater concern to the utilities), then, as currently specified, neither equation is identified. As a result, if both lead-time and costs are determined simultaneously, it would be impossible with the specification used in the text to determine how lead-times affect costs or, conversely, how costs influence lead-times.

It is noted in Chapter 3 that the regional binary variables capture the effects of wage rates on costs and the effects of demand issues on lead-times. An alternative specification of the cost equation is to replace the regional binary variables with 
Appendix D

Statistical and Econometric Issues 


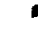


data on the average wage rates in the areas where plants are located. With this alternative specification, it is assumed that the regional binary variables capture only the effects of demand factors. If it is further assumed that wages do not influence lead-times and that load demand factors do not affect costs, then both equations in this alternative specification are in a technical sense identified.

The statistical problem of least squares bias presents a more serious problem. It is well known that ordinary least squares will produce estimates of the coefficients associated with the two endogenous variables (i.e., lead-times in the cost equation and costs in the lead-time equation) that will be both biased and inconsistent. Consistent estimates can be derived using simultaneous equation techniques, such as two-stage least squares. It should be noted, however, that such techniques will yield consistent estimates, which implies that the bias will approach zero as the sample size approaches infinity. Thus, with small samples, such as the ones used in this analysis, it is unclear whether anything would be gained by using a simultaneous equation estimation technique.

Nevertheless, an attempt was made to estimate the alternative specifications of the actual cost and lead-time equations with two- and three-stage least squares. In the lead-time equation, the coefficient associated with the real overnight cost variable was insignificant, and the other coefficients were similar to those reported in the text. With the exception of the lead-time and size coefficients, the same can be said of the estimates in the cost equation. However, the coefficients associated with both the lead-time and size variables were about double those reported in the text. The basic finding that the indirect effect of size, through the effect of lead-time, on costs will offset the engineering economies of scale is obtained when the equations are estimated using three-stage least squares. However, the individual estimates of the effects of size and lead-time on costs are much larger than those derived from the ordinary least squares estimates.

\section{Direct Estimation of the Forecast Error Equation}

As stated in the text, instead of inputting the forecast error equation, it could have been estimated directly. This, in fact, was also done, as shown in Table D6. The relevant measure of experience when the plant was completed and when the report was submitted was used in the actual and estimated cost equations, respectively. When experience was defined as the number of completed reactors, there was very little difference between the values of the experience variables. Since there were fairly large differences between the two values of the experience variables when experience was defined in terms of the number of reactor construction years, two sets of experience variables should be included in the regression; however, this created a serious multicollinearity problem. For this reason, the results reported in Table D6 were obtained using one set of experience variables.

Inclusion of the two lead-time variables also created a serious multicollinearity problem in the 75 percent and 90 percent complete equations. Thus, only the 0 percent, 25 percent, and 50 percent complete equations are reported in Table D6.

As can be seen from a comparison of Table D6 with Table 18 in the text, the two sets of forecast error equations are quite similar. Although the coefficients associated with the first unit variables are about the same, this coefficient was significant when the forecast error equation was directly estimated. 


\section{Table D6. Results of Actual Regression Analysis of Real Overnight Cost Forecast Errors}

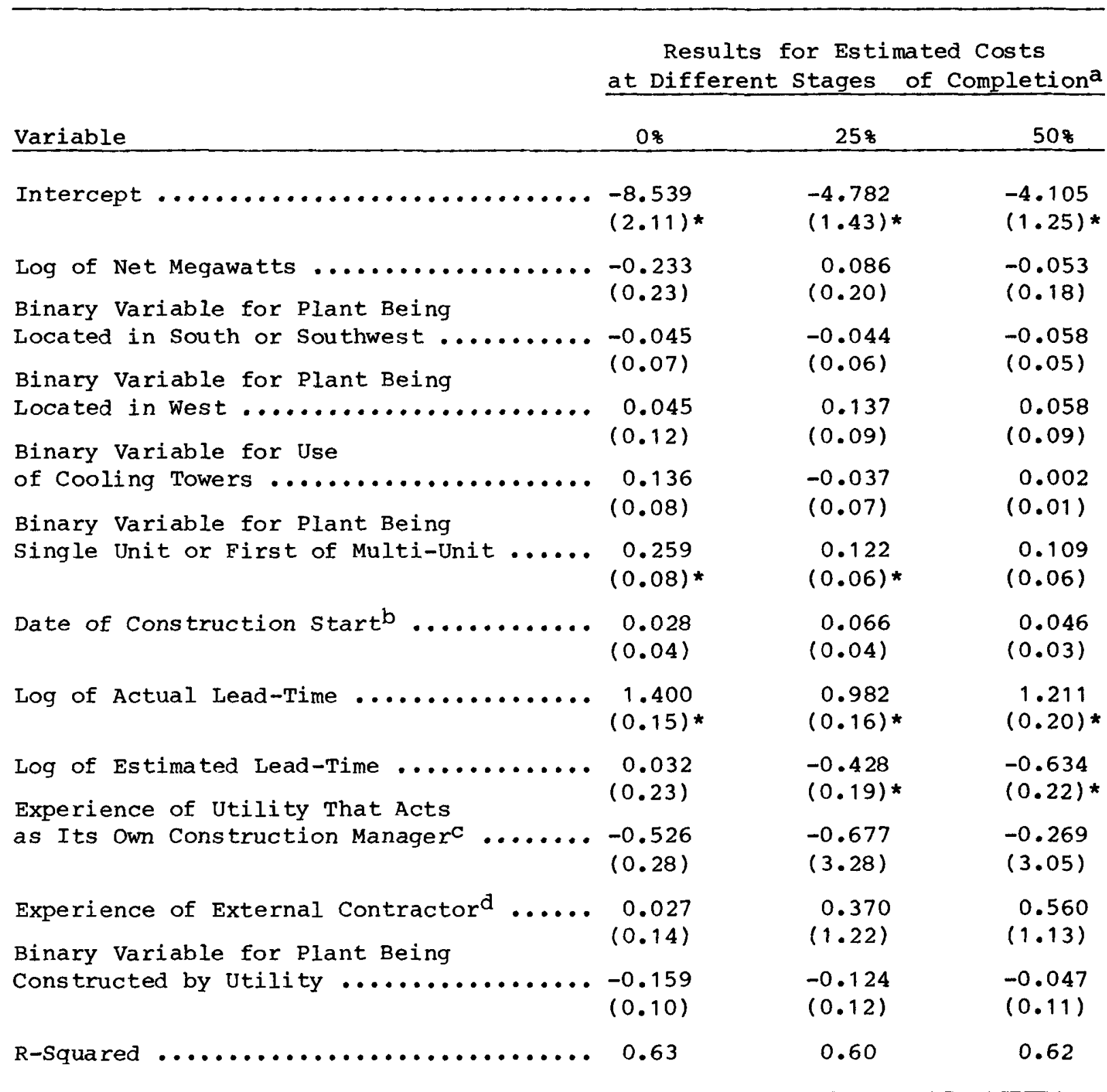

antries are the actual regression coefficients from Equation ( 6 ) in the text. Standard errors are shown in parentheses.

bCoefficient and standard error multiplied by 1,000 .

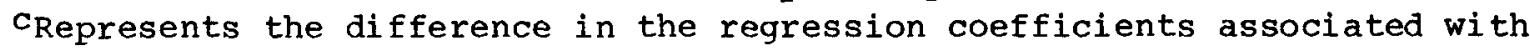
experience for those utilities that act as their own construction managers and those that employ outside contractors (denoted as INTER in the equations presented in the text).

$d_{\text {This }}$ is the coefficient associated with the contractor's experience variable (denoted as CST1 in the equations presented in the text).

Source: Computations based on data from Energy Information Administration, Form EIA-254, "Semiannual Progress Report on Status of Reactor Construction," and predecessor survey forms. 